\title{
DESEGREGATION AND ITS IMPACT ON \\ INSTITUTIONAL CULTURE AT \\ A HISTORICALLY BLACK UNIVERSITY
}

\author{
A Dissertation \\ Presented to \\ The Faculty of the Department of Educational Leadership and Policy Analysis \\ at the University of Missouri - Columbia \\ In Partial Fulfillment \\ of the Requirements for the Degree of \\ Doctor of Education \\ by \\ GABRIELLE MALFATTI-RACHELL \\ Dr. Barbara Townsend, Dissertation Supervisor \\ MAY 2009
}


(C) Copyright by Gabrielle Malfatti-Rachell 2009

All Rights Reserved 
The undersigned, appointed by the dean of the Graduate School, have examined the dissertation entitled

$$
\begin{gathered}
\text { DESEGREGATION AND ITS IMPACT ON } \\
\text { INSTITUTIONAL CULTURE OF A HISTORICALLY BLACK UNIVERSITY }
\end{gathered}
$$

presented by Gabrielle Malfatti-Rachell, a candidate for the degree of doctor of education, and hereby certify that, in their opinion, it is worthy of acceptance.

Professor Barbara Townsend, Chair

Professor Joe Donaldson

Professor Jerry Valentine

Professor Jennifer L. Hart

Professor Von Pittman 


\section{DEDICATION}

I dedicate this dissertation to the Lincoln University men and women who participated in this study and to the generation to which they belong. They are the men and women, who transformed our country forever by transitioning from a segregated past into the promise of a truly integrated future.

I am eternally grateful to each of you. You are amazing! 


\section{ACKNOWLEDGEMENTS}

My heart overflows with gratitude as I complete this project. I am grateful to the Pure Spirit that moves within and around me. I have never felt so on purpose as I did working on this project and I truly believe that this dissertation was mine to write and it was entrusted to me by Divine design.

I am grateful to my husband, David, who always sees me larger than life and with whom being a W.I.F.E (Woman In Full Expression) is made simple. Thank you for your love, your support and your faith in me. Thank you for the gift of time.

I want to acknowledge and give thanks to my children, Carolyn, Nikolas and Alexandria. The love you so freely give me and the love you inspire in me constitute the solid foundation on which I stand and from where I can reach and manifest my Highest Self. You are my greatest source of inspiration. Thank you for your patience and support.

To my other source of inspiration, my students, I love you lavishly. You kept asking about my project, got excited about it with me, and kept reminding me just by being, that I had to set a great example. You have brought great joy to my life.

To the mothers in my life, Lucy Garcia, Susan Gray, Dora Serrano and Carmen Teal, each of you has nurtured and loved me selflessly and for that I will always thank you and love you back. Your support, role 
modeling, generosity and faith in me keep me firmly grounded and reaching beyond all boundaries.

A mis hermanos, Giannino, Juan Angelo y Adriana. ¡Ustedes son mi fortaleza! Y a mi Papi, que está siempre conmigo dónde quiera que yo estoy.

To my dissertation adviser, Dr. Barbara Townsend, who understood the significance of this project, completed countless readings of this document and set the tone for excellence right from the start. Your guidance and professional example were most inspiring and encouraged me every step of the way. Thank you for embarking on this journey with me.

To my dissertation committee: Dr. Joe Donaldson, Dr. Jerry Valentine, Dr. Jeni Hart, and Dr. Von Pittman. Each of you added your own touch of wisdom and expertise to this project. I am forever grateful to you.

Special gratitude to Dr. Karen Cockrell who suggested I enter the ELPA program and to Dr. Flore Zephir who encouraged me to "get out of the box" and find my perfect fit.

To the Lincoln University community who excitedly supported my project. To our president, Dr. Carolyn R. Mahoney, to my colleagues in the English, Foreign Languages and Journalism Department, to my Dean and friend, Dr. Ann Harris, and to my Department Chair, Dr. Jerry Nelson who kept asking for my graduation date, the time has come! 
To Dr. Antonio Holland and Dr. Ablo Bah. You are such incredible men. I have been very blessed by your friendship.

A special thank you to Jamere Brown and Jason Shelvy in the Center for Teaching and Learning, your technical support was paramount to the completion of this project. Also to Gloria Enloe, Dan Yeager and Art Gerhart at the JCTV studio, you were so generous in allowing me to use your studio.

I also want to extend a special thanks to Mary Kabiri, Joe Loethen, Joe Johnson, Dr. Charles Ledbetter, and Gene and Susan Lock. These Lincolnites set many wheels in motion for me to obtain the interviews that informed this dissertation. 


\section{TABLE OF CONTENTS}

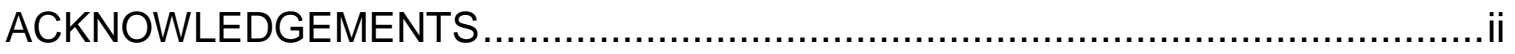

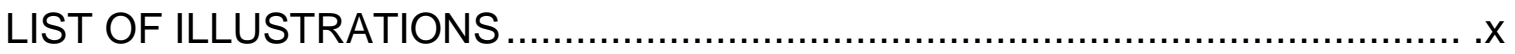

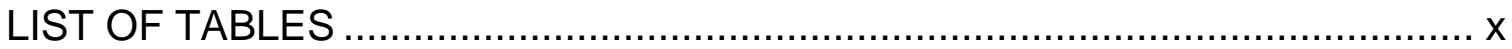

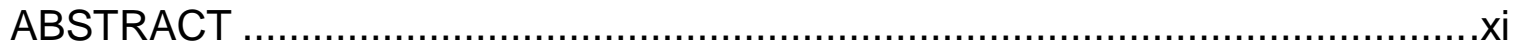

\section{CHAPTER}

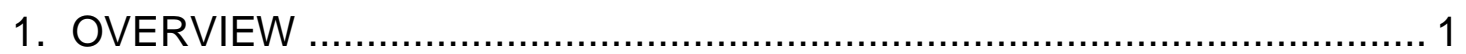

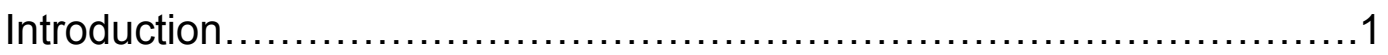

Statement of the problem...................................................

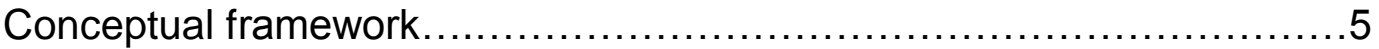

Literature review.......................................................

Organizational culture and intergroup contact............................12

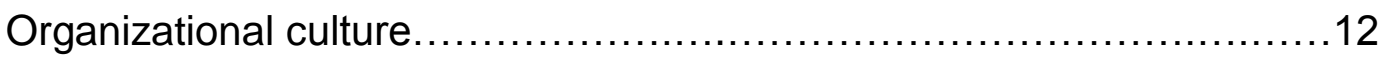

Race relations, intergroup contact and organizational culture.............13

Segregation and racial integration in higher education....................17

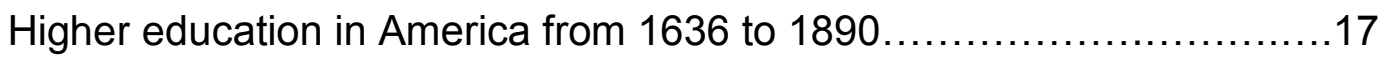

The Negro Colleges: making up for lost time 1890-1960 ..................18

A racially integrated system of higher education 1960 -

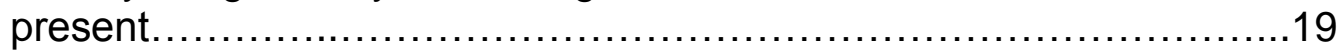

Black students at Historically Black Colleges and Universities..............20

Black students at Historically White Institutions............................21

White students at Historically Black Colleges and Universities............23

Lincoln University of Missouri...........................................25

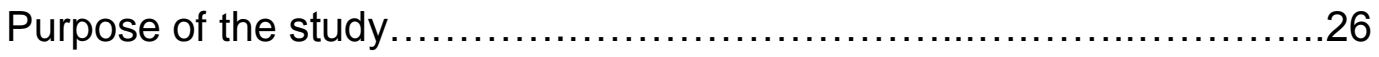




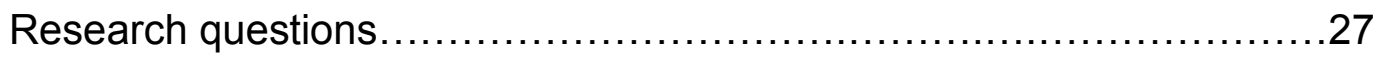

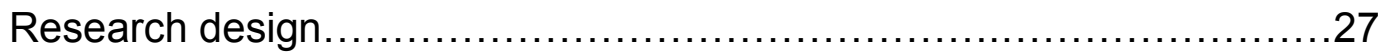

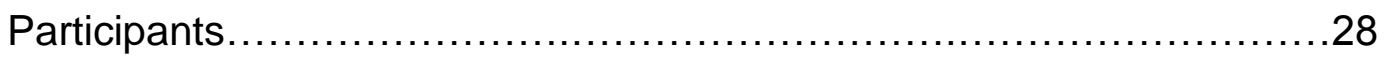

Data collection...........................................................

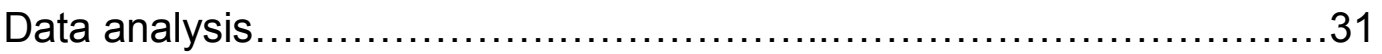

Definition of key terms and constructs.................................

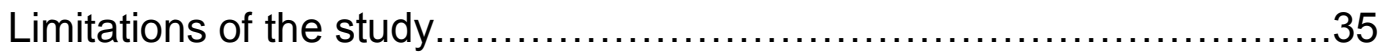

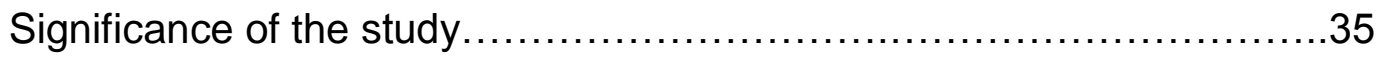

Researcher's perspective................................................

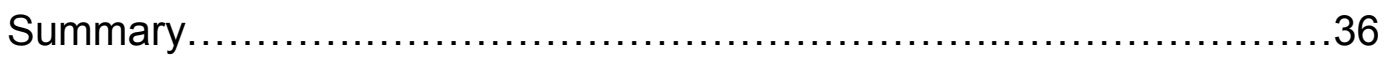

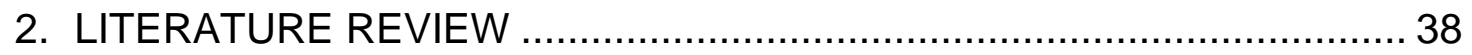

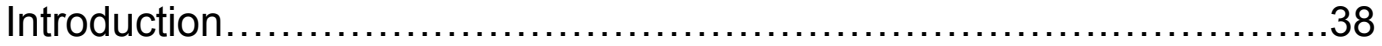

Organizational culture and intergroup contact..........................40

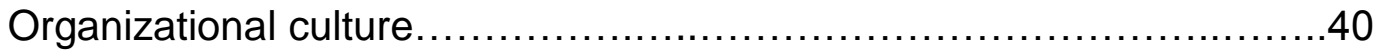

Race relations in organizational culture ................................44

Intergroup contact and the creation of organizational culture $\ldots \ldots \ldots \ldots \ldots . .47$

Organizational culture and racial climate in institutions of higher education.................................................. 50

Segregation and racial integration in higher education.....................57

Higher education in America from 1636 to $1890 \ldots \ldots \ldots \ldots \ldots \ldots \ldots \ldots . . \ldots \ldots \ldots$

The Negro Colleges: making up for lost time 1890-1960_................61

Landmark Higher Education Legal Cases Prior to 1954 ..................66

Increased access to education........................................69

A racially integrated system of higher education $1960-$

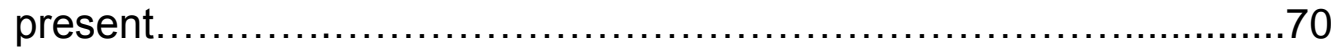


Black students at Historically Black Colleges and Universities.............71

Black students at Historically White Institutions...............................80

White students at Historically Black Colleges and Universities.............90

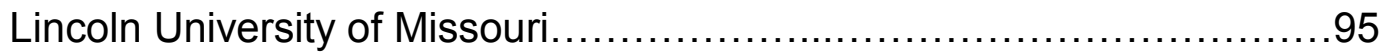

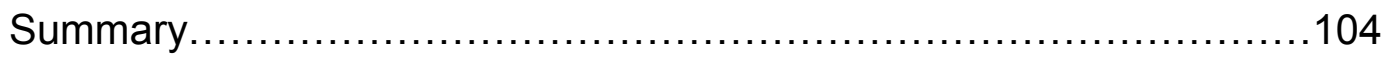

3. RESEARCH DESIGN AND METHODOLOGY..........................107

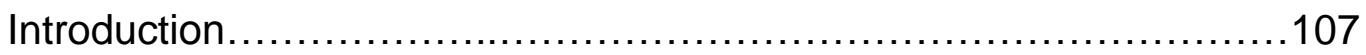

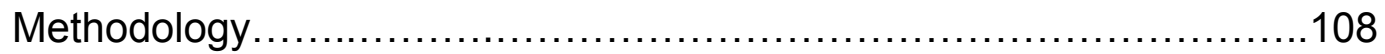

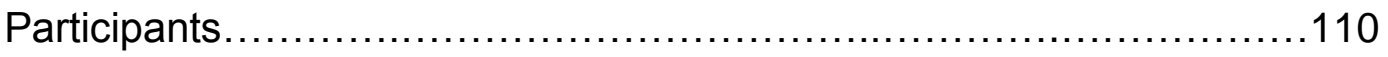

Data collection........................................................ 117

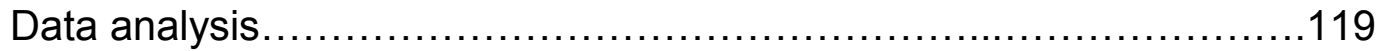

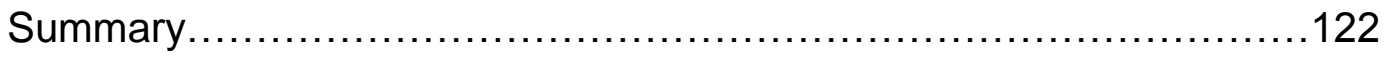

4. DATA ANALYSIS ..................................................... 124

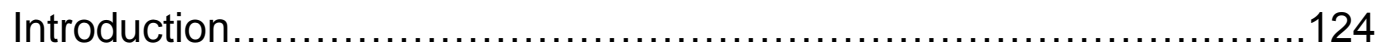

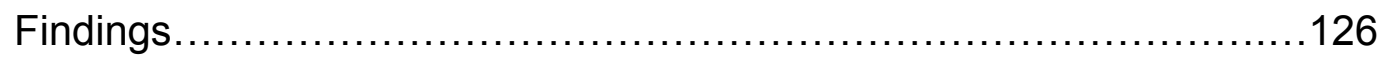

Findings on Research Question One................................126

Lincoln University provided the first truly desegregated educational experience for the great majority of students who attended between 1954 and 1969.

Lincoln was a desegregated university within a segregated Community.....

The expectations and the overall college experience varied widely for Black and White students at Lincoln University.......................139

Lincoln's post-desegregation leadership hindered internal integration due to its accommodationist approach...............................150 
Findings on Research Question Two...................................164

Equal status within the contact situation...............................165

Intergroup cooperation............................................. 169

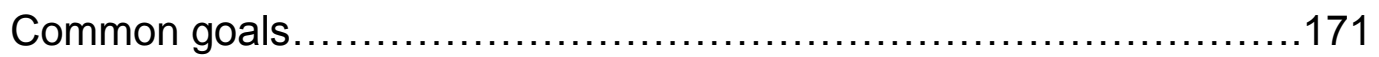

Support of authorities, law, or custom...............................173

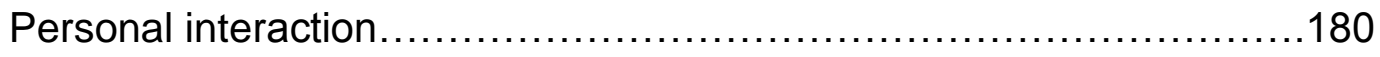

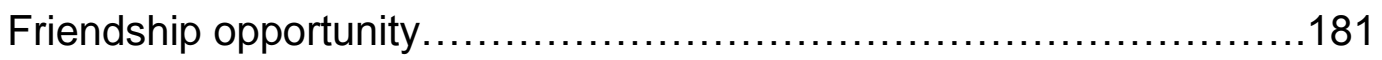

Findings on Research Question Three.................................183

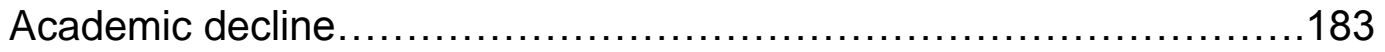

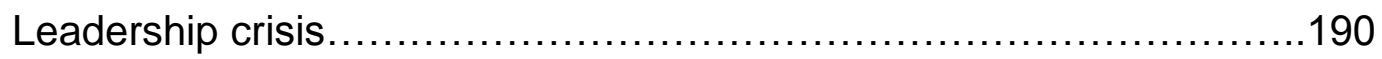

Intergroup disconnection.............................................. 195

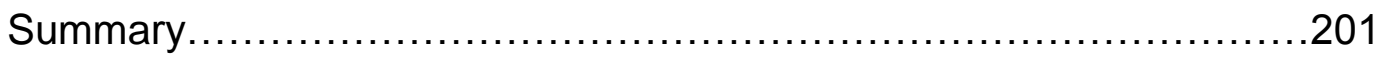

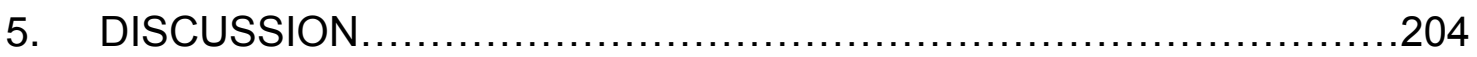

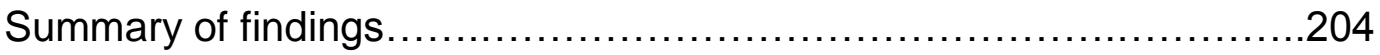

Discussion of findings.................................................. 210

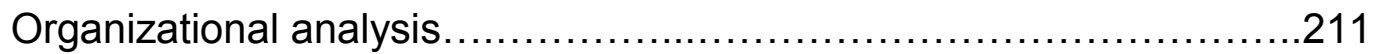

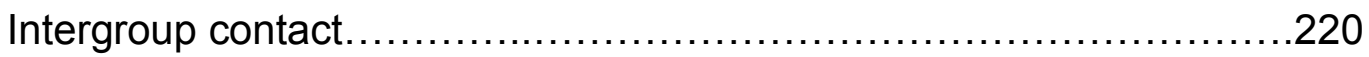

Organizational culture and racial climate .............................228

Experiences of Black and White students at Lincoln between

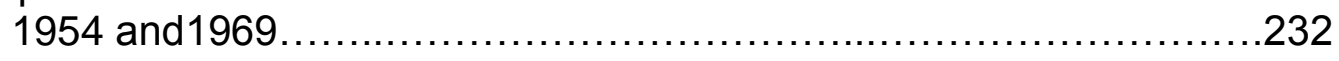

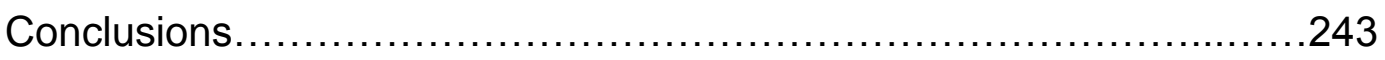

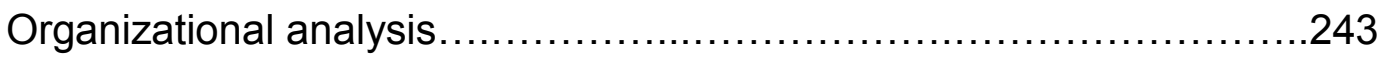

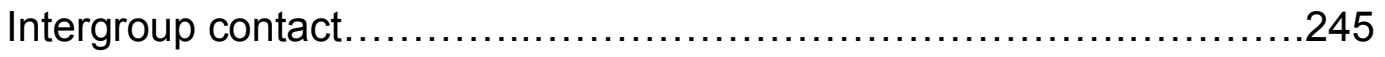

Organizational culture and racial climate ............................247 
Experiences of Black and White students at Lincoln between 1954 and 1969.

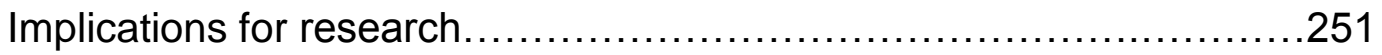

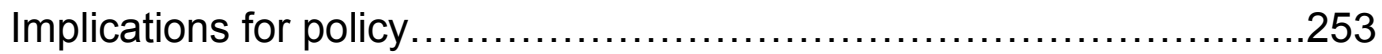

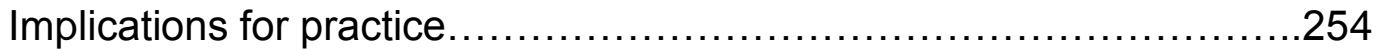

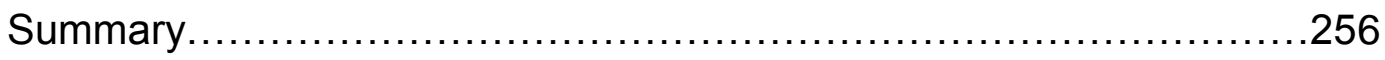

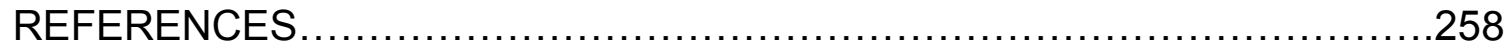

APPENDIX

A. LETTER TO POSSIBLE PARTICIPANTS ..........................277

B. PRELIMINARY QUESTIONNAIRE - STUDENTS ...................278

C. PRELIMINARY QUESTIONNAIRE - EMPLOYEES ...................279

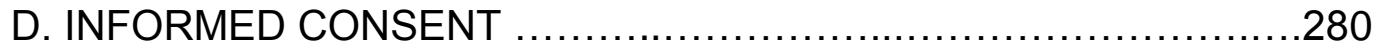

E. PUBLIC SERVICE ANNOUNCEMENT INVITATION ..................281

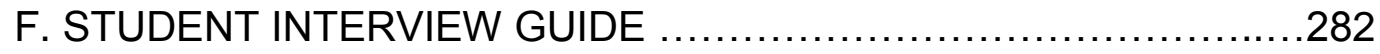

G. FACULTY/STAFF INTERVIEW GUIDE $\ldots \ldots \ldots \ldots \ldots \ldots \ldots \ldots \ldots \ldots . .283$

H. 1954-1969 NATIONALAND INSTITUTIONAL TIMELINE.............284

VITA 


\section{LIST OF ILLUSTRATIONS AND TABLES}

Figure

Page

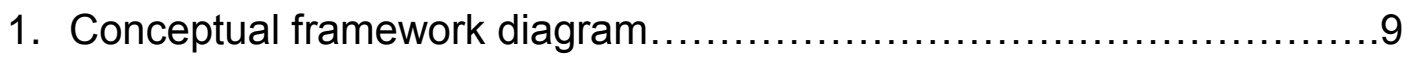

Table

1. Student Participants .....................................................

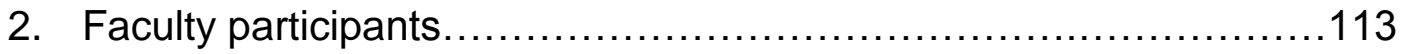

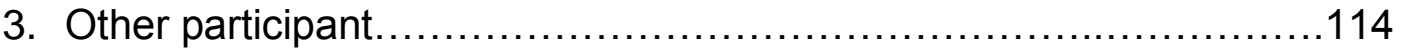




\section{ABSTRACT}

In this case study, 38 Black and White participants shared their recollections of intergroup contact during the first 15 years of desegregation (1954-1969) at a Historically Black University in a predominantly White Midwestern community. Faculty and alumnae/i candidly evoked their experiences in this unusual desegregation setting and their memories collectively provided a vivid portrayal of Lincoln University's transition from a Black university to a fully desegregated institution over the period of the study. Bracketed within the zenith of the Civil Rights Era, this study provides a rich account of the movement as it unfolded and influenced this Historically Black University. Findings of the study revealed a positive process of desegregation marked by the absence of racial hostility. A retrospective organizational analysis showed that desegregation had a profound effect on the institutional culture due mainly to the depletion of Black scholars and highly talented Black Students and a leadership crisis that engendered the rise of a powerful student government. 


\title{
CHAPTER ONE
}

\author{
OVERVIEW
}

Introduction

From the distance of 40 years, it is hard to imagine how hard White Mississippi fought back on October 1, 1962, to keep a Black man [James Meredith] out of school.

To protect him, U.S. Attorney General Robert Kennedy sent 123 deputy federal marshals, 316 U.S. border guards and 97 federal prison guards...

As the violence grew, President John F. Kennedy then sent 16,000 federal troops to the campus. (CNN, August 28, 2007)

This is the picture of racial desegregation in higher education most representative of the process in Southern and Border States. A single Black student or a small group of Black youths escorted by law enforcement officials, pushing their way through angry mobs of White students and other citizens screaming insults and threatening the lives of the Black citizens standing up for their rights. The case of James Meredith illustrates the determination of some White schools and segregated communities to preserve the racial homogeneity of their campuses, as well as the values, mores, and societal privileges reserved to the dominant group. Nonetheless, there is another aspect of racial desegregation in higher education, one that has received very little attention: the enrollment of White students at Historically Black Universities following the school desegregation mandate of Brown v. Board of Education in 1954 (Brown v. Board of Education, 347 U.S. 483, 1954). It was to the acknowledgement and understanding of this desegregation process to which this study sought to contribute. 
From the establishment of the first colonial universities, the system of higher education in the United States was marked by racial segregation of African-Americans (Carney, 1999; Drewery \& Doerman, 2001; Herbst, 1988; Johnson, 1938; United States Equal Rights Commission, 1961). From the period following the Civil War to the mid 1960s, African-Americans received their education, almost exclusively from Black colleges and universities (Allen \& Jewell, 2002; Anderson, 1988a; Brown \& Davis, 2001; Drewery \& Doerman, 2001; Moore, 2003; Pifer, 1973). Johnson (1938) found that of the 31,090 academic degrees conferred to Negro graduates between 1826 and 1936, 25,697 were awarded by Negro institutions and 5,393 were awarded by Northern colleges. This trend was to be maintained until the passage of the Civil Rights Act in 1964.

Long before the 1954 United States Supreme Court decision of Brown v. Board of Education, the concept of segregated education and the illusion of "separate but equal" had been challenged in the higher education arena. Prior to 1954 there were 117 all-Black colleges which were, "by most standards, inferior operations-starved for funds, poor in staff, buildings, and equipment" (Levy, 2004, p. 69). The quest for remedy of this disparity was played out in courts at the state and federal level (Urofsky, 2004). The cases brought forth on behalf of African-American students like Donald Murray (University v. Murray, 169 Md. 478, 1936); Lloyd Gaines (Missouri ex rel. Gaines v. Canada. 305 U.S. 337, 1938); Ada Lois Sipuel Fish(Sipuel v. Board of Regents of University of Oklahoma. 332 U.S. 631, 1948); George W. McLaurin (McLaurin v. Oklahoma 
State Regents. 339 U.S. 637, 1950); and Heman Sweatt (Sweatt v. Painter. 339 U.S. 629, 1950), helped paved the way for the landmark case of Brown v. Board of Education, where the issue of racial segregation, and not just the Fourteenth Amendment's "equal protection" clause, would finally be addressed.

Following the Brown v. Board of Education Supreme Court decision, Historically White Institutions began to desegregate and to admit Black students, thus marking a historical moment for the nation and for academia. Initial interest in Black students enrolling at White-only institutions dealt mostly with issues of compliance with non-discrimination mandates (United States Equal Rights Commission, 1961). Since the 1970s when school demographics changed and three fourths of all Black college students were enrolled at historically White institutions (HWl's) (Allen \& Jewell, 2002), researchers began to study the experiences of Black students at these previously segregated institutions (AllenCastellito \& Maillard, 2001; Chavous, 2005; Guiffrida, 2004; Hatter \& Ottens, 1998; Lee, 1999; Reddick, 2006; Taylor \& Olswang, 1997).

As a result there is an extensive body of research that documents the current condition of African-American students at HWls. According to the literature, current conditions continue to be marked by perceived negative attitudes from White faculty (Allen, Bobo, \& Fleuranges, 1984; D’augelli \& Hershberger, 1993; Davis, Dias-Bowie, Greenberg, Klukken, Pollio, Thomas, \& Thompson, 2004; Fries-Britt \& Turner, 2002; Jay \& D’augelli, 1991; Sedlacek, 1999; Smith, 1991), conflict with White peers (Dinka, Mazzella, \& Pilant, 1980; Feagin \& Sikes, 1995; Fries-Britt \& Turner, 2002; Peterson, Blackburn, Gamson, 
Arce, Davenport, \& Mingle, 1978), cultural and ethnic isolation (Loo \& Rolison, 1986), as well as exposure to racist jokes (Feagin \& Sikes, 1995), racist slurs and graffiti (Davis et al., 2004) and microaggressive language and actions (Solórzano, Ceja, \& Yosso, 2000). Publications with titles that contain phrases like "A fly in the buttermilk" (Davis et al., 2004) and "the 'raisin in milk' syndrome" (Williams, 1994) and "thin ice" (Steele, 1999) aimed to convey a graphic depiction of the fraught experience of Black students at predominantly White universities. Yet, White colleges continue to graduate the vast majority of Black college students and Smith (1991) found that persistence was highest among Black students attending prestigious HWls.

In contrast, research on White students at HBCUs has been quite minimal (Aber, 1959; Conrad \& Brier, 1997; Hall \& Closson, 2005; Hazzard, 1988, 1996; Payne-Brown, 2004; Peterson \& Hamrick, 2009; Taylor \& Oswalg, 1999) perhaps in part because White student enrollment at most HBCUs is also minimal. In 2005, only nine out of the 106 historically Black colleges and universities reported White student enrollments above 10\%. In 2005, the greatest concentrations of White students at HBCUs were found at Bluefield State College in West Virginia, where White students comprised $87 \%$ of the student body and at Lincoln University of Missouri and West Virginia State College where the percentage of White students was $52 \%$ and $58 \%$ respectively (U.S. Department of Education, National Center for Education Statistics, Integrated Postsecondary Education Data System (IPEDS), "Fall Enrollment" surveys 1994 -2005). The literature is nearly void of studies that could provide a comprehensive 
understanding of desegregation taking place at Historically Black Universities. This void is illustrated by the absence of such studies, or any dealing with Whites at HBCUs in Pascarella and Terenzinni's $(1991 ; 2005)$ well regarded literature reviews that examined 40 years of research on the effects of college upon students.

\section{Statement of the Problem}

There is a missing chapter in the history of racial desegregation in American higher education. That chapter would speak of the process and effect of racial desegregation at Historically Black Colleges and Universities. There have been only a few studies that focused on this socio-historic event (e.g., Aber, 1959; Conrad \& Brier, 1997; Hall \& Closson, 2005; Hazzard, 1988, 1996; PayneBrown, 2004; Taylor \& Oswalg, 1999) including a focus on the organizational culture of the newly integrated HBCU.

\section{Conceptual Framework}

This study used the frameworks of intergroup contact theory and various organizational culture theories to examine how the initial Black/White intergroup contact ensued by the mandated racial desegregation of one HBCU, Lincoln University of Missouri, in 1954 influenced the institution's organizational culture. Intergroup contact theory, also known as contact hypothesis, was proposed by Gordon Allport in 1954. In the midst of the Supreme Court's desegregation mandate, Allport realized that the hearts of people would not be changed by judicial order and that active intervention would have to take place in order for Blacks and Whites to achieve optimal contact, the type of contact that 
brings about an elimination of prejudice. Allport defined prejudice as "an antipathy based upon a faulty and inflexible generalization. It may be felt or expressed. It may be directed toward a group as a whole or toward an individual because he is a member of that group" (p. 10).

In the original formulation of the theory, optimal intergroup contact required the following conditions: "it should [1] lead to a sense of equality in social status, [2] should occur in ordinary purposeful pursuits, [3] avoid artificiality, and [4] if possible enjoy the sanction of the community" (Allport, 1954, p. 454). Intergroup contact theory has evolved through the work of many researchers (Cook, 1985; Dovidio, Gaertner, \& Kawakami, 2003; Hewstone \& Brown, 1986; Pettigrew, 1998; Pettigrew \& Tropp 2000; Stephan \& Bingham, 1985; Wittig \& Grant-Thompson, 1998). The contact theory framework utilized in this dissertation deemed the following conditions as necessary for prejudice reduction and internal integration (a) equal status within the contact situation; (b) intergroup cooperation; (c) common goals; (d) support of authorities, law, or custom (Allport, 1954, Pettigrew, 1998); (e) personal interaction; and (f) friendship opportunity (Dovidio et al., 2003) thus this study sought to identify which, if any, of these conditions were present during the initial stage of desegregation (1954 - 1969) at Lincoln University and how the resulting intergroup contact among Black and White students, faculty and staff influenced the organizational culture of the institution.

Issues of ethnic prejudice and Black/White intergroup contact are virtually absent from organizational culture literature (Martin, 1992; Nkomo, 1992; 
Schiele, 1990; Shelton, 2000). The neglect of these issues hinders the understanding of organizations as "social system[s]" (Schein, 1991, p. 65). Organizations may be analyzed from an integrationist point of view which defines organizational culture in terms of shared values and beliefs (Davis, 1984; Schein, 1984; Sergiovanni \& Corbally, 1984; Siehl \& Martin, 1982), shared meanings and understandings (Sathe, 1985), and shared assumptions (Barley, 1991; Schein, 1984). Organizations may also be analyzed with theoretical frameworks of differentiation and fragmentation that hold the vision of organizations as environments filled with subgroups and subcultures (Alderfer \& Smith, 1982; Gagnier, 1990; Riley 1983; Schein, 1996) functioning in conflict and ambiguity. Martin (2002) proposed that a study of culture should encompass simultaneous utilization of the frameworks previously discussed. The author argued that

The three perspectives oppose each other on the three dimensions of comparison: the relationship among cultural manifestations, the orientation of consensus in a culture, and treatment of ambiguity. Because they take different positions on these three dimensions, the three perspectives complement each other in a precise way...[and]... offer a wider range of insights than is available from any single view point (p. 120).

This type of approach complements the objectives of qualitative methodologies that seek to examine the same occurrence from various vantage points. One of those vantage points relates to personal identification within a particular racial group and its consideration enriches the understanding of an organization's culture. There is value in delving into the dynamics of race relations in organizations because race is a strong determinant of personal 
identity and social relations in U.S. society. Race dynamics are especially important in the unique situation of Lincoln University, because studies of prejudice have customarily been conducted on White prejudice and have ignored how the racial attitudes of Blacks influence inter-racial relations. In this scheme, Whites are seen as active participants who inform the research while Blacks are treated as passive experimental confederates (Shelton, 2000).

Looking at the organizational culture of Lincoln University through the lens of intergroup contact can reveal new insights about desegregation. To date, research on higher education, and organizational culture in general, appeared framed in terms of the dominant culture whereby Blacks were most often viewed in contrast to White males, the defining, normative group (Nkomo, 1992). As a result, organizations appeared to be race-neutral (Nkomo, 1992), when in fact, as microcosms of the larger society, organizations are imbued with tensions, conflicts, and multiple interpretations of meaning (Gregory, 1983). In the last 20 years, researchers have shifted from the Black/White racial dichotomy and studied intergroup relations in organizations under the diversity umbrella (Hurtado, Milem, Clayton-Pedersen, \& Allen, 1998, Kezar, 2007, 2008; Milem, Chang, \& Antonio 2005). In this new conglomerate, race appears to be secondary to gender in the body of literature addressing diversity of leadership (Kezar, 2000; Wise \& Tschirhart, 2000).

Since soon after its desegregation, Lincoln University has often been in the ambivalent position of being both a Black institution by heritage and a predominantly White university by enrollment numbers. The percentage of White 
student enrollment since 1995 has oscillated between a high of $73 \%$ in 1996 and a low of 52\% in 2005 (U.S. Department of Education, "Fall Enrollment" surveys 1994 - 2005).

Seeking a greater understanding of desegregation in higher education through the accounts of those who experienced the initial intergroup contact and through analysis of documents that hold information about the process can contribute to the existing scholarship on the subject and provide insight into how the process unfolded, under what conditions, and how that initial Black/White contact influenced one institution's organizational culture.

Conceptual Framework Diagram

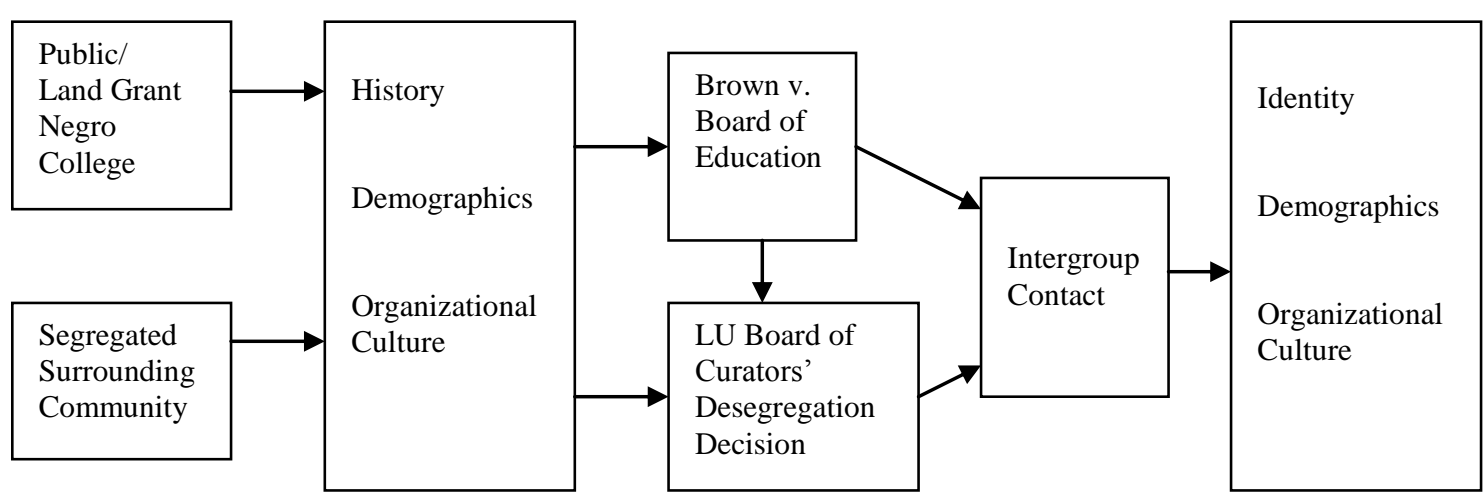

This study examined the effect of intergroup contact generated by the Brown v. Board of Education mandate on the institutional culture of Lincoln University. To understand whether or not, and how, the institution's culture changed due to its desegregation is imperative to take into consideration how it had developed in the context of an exclusively Black college. Lincoln Institute was established in 1866 through the collaborative efforts of the Black soldiers and White officers of the $62^{\text {nd }}$ and $65^{\text {th }}$ Colored Infantries. With the Morrill Act of 
1890, Lincoln became a Land Grant College and was deemed the state's Negro College to insure Missouri's compliance with the Act which stated in part that,

No money shall be paid out under this act to any State or Territory for the support and maintenance of a college where a distinction of race or color is made in the admission of students, but the establishment of such colleges separately for White and colored students shall be held to be a compliance with the provisions of this act [emphasis added] if the funds received in such State or Territory be equitably divided (7 U.S.C. Chapter 841 , Section 1 ).

Though the first statement in this section appeared to put an end to segregation in federally funded/state provided higher education, the allowance for the establishment of separate facilities for "White and colored students" gave the endorsement of congress to segregated higher education. The 1890 Land Grant status of Lincoln was used as the primary point of departure for this conceptual framework because it solidified Lincoln's role exclusively as a Negro college.

The second point of departure was the surrounding community in which Lincoln functioned. Unlike other HBCUs located in predominantly Black communities, Lincoln was located in the predominantly Whitesegregated state capital of a Border State. Jefferson City is a predominantly White community with marked German Catholic and Lutheran traditions. It is surrounded by various small rural communities, most of which share the capital's ancestry. In Jefferson City, the desegregation of local public schools, including Lincoln University, took place immediately following the Brown v. Board of Education decision. 
The desegregation of public facilities did not come easily or swiftly to the community.

The segregated nature of the university and the community around it determined the early demographics of the campus and engendered a distinct history for the university. This history was imbued with financial strife, but also great academic achievement. In the 1920s and 1930s, Lincoln grew in status as its administrators purposefully sought out some of the brightest Black PhDs of the time for its faculty. By the 1950s, Lincoln was regarded in some circles as the "Harvard of the Midwest," offering various undergraduate programs, as well as professional degrees in law and journalism. By 1954, Lincoln's history was well cemented in its role as a public Negro college providing exceptional academic and social preparation to an emerging Black bourgeois.

On May 17, 1954, the U.S. Supreme Court ruled school segregation unconstitutional. That coupled with Missouri Attorney General John Dalton's, declaration that the state's segregation laws were thereby null and void prompted the Lincoln University Board of Curators to allow the admission of White students. By the fall semester that same year White students from Jefferson City and the surrounding community began to enroll and by 1956 they comprised $22 \%$ of the student body (Holland, 1997).

The 15 years immediately following desegregation were marked by changes brought about by external and internal forces. Commuter student 
enrollments grew rapidly and Black students became very vocal about their expectations of the administration. This study sought to gain a greater understanding of the cultural forces converging at Lincoln through new dynamics of intergroup contact and their ultimate impact on the institutional culture.

\section{Literature Review}

The review of the literature for this study provided a point of departure for understanding how the desegregation of Lincoln University influenced its institutional culture. The historical context, organizational environment, and intergroup dynamics inherent in the process of desegregation are all aspects of great significance in understanding this social and historical event. The following section includes a brief analysis of the literature on the overarching themes of organizational culture and intergroup contact; and segregation and racial integration in higher education.

\section{Organizational Culture and Intergroup Contact}

\section{Organizational culture}

Organizations in general and the cultures and subcultures that develop within them have been studied from many different perspectives, most of which can be categorized under the socio-scientific perspectives of integration, differentiation and fragmentation (Martin 1992). Perspectives in these three categories differ from each other in what is considered to be the essence of the organization's culture. Integrationist researchers have theorized that organizational cultures are defined by what is shared, be it values and beliefs 
(Davis, 1984; Schein, 1984; Sergiovanni \& Corbally, 1984; Siehl \& Martin, 1990); meanings (Siehl \& Martin, 1990), and understandings (Sathe, 1985); communication activities (Schall, 1983); or assumptions (Barley 1991; Schein, 1984).

Differentiation theories present a view of organizations as conglomerates of subgroups and/or subcultures (Alderfer \& Smith, 1982; Gregory, 1983; Riley, 1983; Schein, 1996) that interact bringing forth, issues of power, conflict and special interests (Alderfer, 1977; Alderfer \& Smith, 1982; Alderfer \& Tucker, 1996; Kolb \& Putnam, 1992; Martin, 1992).

The postmodern view of organizational culture is that organizations are filled with ambiguities, a myriad of interpretations of meaning, and complex relationships within and without the established boundaries of the entity (Martin, 1992). This state of flux brings about fragmentation.

In looking at the effects of desegregation in an organization, aspects of each approach (integration, differentiation, and fragmentation) can provide insights as to how intergroup relations among distinct racial groups affect the institutional culture. This method allows the three approaches to complement each other and produces a more comprehensive understanding of the organizational culture (Martin, 2002). The following section looks at how race relations have been viewed in the literature on organizational cultures. Race Relations, Intergroup Contact and Organizational Cultures

Race relations have often been neglected as a dimension of organizational analysis (Cox \& Nkomo, 1990; Martin, 1992; Nkomo, 1992) and 
this neglect has led to an assumption that race-neutrality is a characteristic of organizations (Nkomo, 1992). In a comprehensive literature review of articles addressing race in organizations, Cox and Nkomo (1990) found that most studies dealt with the suitability of minorities to fit within the normative White-male norm prevailing in most organizations. The topics most often addressed were affirmative action, staffing, job satisfaction/motivation, and evaluations of employee performance. In the reviewed studies race tended to be presented as merely a demographic value, an issue or a problem (Nkomo, 1992; Omi \& Winant, 1986). In the last 20 years, intergroup relations in organizations have been gathered under the diversity rubric. In that period of time, women and minorities have made considerable gains in the labor force and it is estimated that by 2012 , White men will account for only 43 percent of the U.S labor force (U.S. Department of Labor, Bureau of Labor Statistics). Women and minorities have also made considerable gains in higher education. From 1971 to 2007, the percentage of White women who completed a college degree or higher grew from 15.4 percent to 39.2 percent, for Black males it grew from 6.9 percent to 18.9 percent, for Black women it grew from 6.6 percent in 1971 to 20.0 percent in 2007. Hispanics as a group reached 11.6 percent in 2007 from 5.1 in 1971 ("The Condition of Education," 2008).

Organizational culture is created in the context of human interaction. Increasingly that context has grown in diversity and therefore so has inter-group contact. At the onset of federally mandated desegregation of public spheres, Gordon Allport (1954) recognized that a legal mandate would not be enough to 
erase hundreds of years of segregation and deeply rooted prejudices. He proposed that in order to achieve intergroup contact that reduces prejudice and leads to optimal interaction, four elements were necessary: The contact should lead to "[1] a sense of equality in social status, [2] should occur in ordinary purposeful pursuits, [3] avoid artificiality, and [4] if possible enjoy the sanction of the community" (p. 454). As intergroup contact evolved in American society, other researchers have contributed to Allport's original proposition highlighting the importance of cooperation and interdependence (Sherif, Harvey, White, Hood, \& Sherif, 1961), and facilitation of friendship (Amir, 1976; Brewer \& Miller, 1984; Cook, 1985).

Intergroup contact theory has framed research on interactions and racial attitudes among Blacks and Whites (Sigelman \& Welch, 1993; Wittig \& GrantThompson, 1998); racial climate at predominantly White college campuses (Chavous, 2005); effects of interracial stress in ethnically diverse classrooms (Marcus-Newhall \& Heindl, 1998); the enhancement of campus climate for racial and ethnic diversity (Hurtado, Milem, Clayton-Pedersen, \& Allen, 1998); race and ethnic relations among community college students (Williams \& Shammas, 2007); and status legitimacy for intergroup attitudes among numerical minorities (Bettencourt \& Bartholow, 1998).

Institutions of higher education over the last 50 years have had to learn to deal with issues of racial desegregation and intergroup contact. Overcoming a history of over 3 centuries of segregation has engendered challenges and 
opportunities that shape the institutional culture of each campus whether historically White or historically Black.

Of special interest to this study are the issues of campus diversity and racial climate that relate to organizational analysis factors of external adaptation and internal integration. Hurtado et al. $(1998,1999)$ proposed looking at campus racial climate through the examination of external and internal factors. The external factors included the impact of policy and sociohistorical forces, and the internal factors related to the institution's historical legacy of inclusion or exclusion, numerical distribution of diverse populations, perceptions and attitudes among groups, and the social behaviors among various groups and their members. Other researchers suggested that a comprehensive examination of campus racial climate must also include a study of its organizational/structural dimension, which includes elements such as curriculum, budget allocation and admission practices (Milem, Chang, \& Antonio, 2005). Researchers have concluded that a campus racial climate imbued with prejudice has adverse effects on the persistence of both Black and White students at that campus (Cabrera, Nora, Terenzini, Pascarella, \& Hagedorn, 1999; Eimers \& Pike, 1997; Hurtado et al., 1998, 1999; Milem, Chang, \& Anthony 2005; Zea, Reise, Beil, \& Caplan, 1997), and that the key factor for success of a diversity agenda is leadership (Hurtado et al., 1998, Kezar, 2000, 2007, 2008). 
Segregation and Racial Integration in Higher Education

Higher Education in America from 1636 to 1890

The history of higher education in the United States has reflected the history of American society. In its beginning higher education was the privilege of White men, most of them affluent, who received their professional formation at Harvard (1636), William and Mary (1693), or Yale (1701). These colleges, chartered in the seventeenth and early eighteenth centuries, enjoyed the endorsement of the local church and colonial legislatures.

Minorities and women had no access to formal education until the 1800s at places like Wheaton and Mount Holyoke Female Seminaries, which opened in 1834 and 1837 respectively. American Indians were granted access to formal education in the charters of most universities during the colonial period, including Harvard, William and Mary, and Dartmouth. Nevertheless, from the time of these institutions' charters to the American Revolution, only 47 Indian students appeared on those colleges' combined records of attendance and of those, only four graduated (Carney, 1999). For Blacks, collegiate history dates back to 1826 when John Russwurm was awarded his college degree from Bowdoin College. Since 1826 until the beginning of the Civil War, there were 28 Black college graduates (Johnson, 1938). All of these degrees were conferred by White institutions and there is no record of a Black college conferring a degree until after the Civil War (Drewery \& Doerman, 2001).

Public higher education in the United States was greatly influenced by the passing of two congressional acts. In 1862 the first Morrill Act bequeathed states 
and territories public lands to be utilized or sold for founding colleges to provide agricultural and mechanical training in addition to classical studies and military tactics (Morrill Act, 1862, Ch. 130, Sect. 4).

The second Morrill Act of 1890 expanded funding to benefit Black students with training in agriculture and mechanical arts. At the same time this funding expanded educational opportunities for Blacks, it also perpetuated a segregated system of higher education. Seventeen of the original 70 Land-Grant colleges established under the Morrill Act of 1890 are Historically Black Colleges and Universities (List of Land-Grant Universities, 2009). The Negro Colleges: Making up for Lost Time, 1890-1960

Following the end of the Civil War, Negro colleges were established throughout the South and in Border states. Many were founded through the efforts of the Freedmen's Bureau (Drewery \& Doerman, 2001; Moore, 2003); Northern philanthropists (Pifer, 1973), and missionaries as well as the freedmen themselves (Roebuck \& Murty, 1993).

Though most people agreed that freed Blacks needed to be educated, there was disagreement as to what the purpose of that education should be. Some like Booker T. Washington (1901) felt that Blacks would be best served being educated in the trades of agriculture and industry. Others like W. E. B. DuBois believed that the uplift of the Negro race rested on the shoulders of the "Talented Tenth" who would be educated in the liberal arts and who would in turn lead the way for the uplift of the Negro race. 
African-Americans took advantage of the educational opportunities available to them at vocational and liberal education colleges and between 1914 and 1936 their enrollment rose dramatically by $495.8 \%$ at Northern schools and by $602.4 \%$ at Negro schools (Johnson, 1938). Yet, by 1940 only 2\% of Blacks aged 25-29 had graduated from college (Drewry \& Doermann, 2001). In contrast with the access to baccalaureate education, access to professional education was marked by obstacles and court battles. This struggle is illustrated by the court cases presented on behalf of Donald Murray (University v. Murray, 169 Md. 478 (1936)); Lloyd Gaines in 1938 (Gaines v. Canada); Ada Lois Sipuel Fisher in 1946 (Sipuel v. Board of Regents of Univ. of Okla.); George W. McLaurin (McLaurin v. Oklahoma) in 1950; and Heman Sweatt (Sweatt v. Painter) also in 1950. The cases cited above were all decided on the grounds of equal protection and provided no remedy for segregated practices prevalent in the South and in Border States.

With the 1954 decision of Brown v. Board of Education the U.S. Supreme Court established that the doctrine of "separate but equal" could no longer be applied to public education (Brown v. Board of Education, 347 U.S. 483, 1954). Although decided on the basis of a K-12 case, the publicly stated end of segregation in education marked a new chapter in the educational condition of Blacks in the United States.

A Racially Integrated System of Higher Education, 1960 - Present

Following the 1954 Supreme Court decision in Brown most colleges and universities also desegregated and initiated cross-racial enrollment. Efforts were 
put forth to disassemble dual university systems, institute unitary systems that eliminated the remnants of de jure segregation and functioned without the need of permanent supervision from the federal government (Brown, 1999). Absent the explicit restrictions imposed by segregation students could make choices about where to pursue their higher learning. Although some Blacks continued to enroll at Historically Black Colleges and Universities (HBCUs), others enrolled at Historically White Institutions (HWIs), and some HBCUs opened their doors to White students. This section looks at studies conducted on each of the above mentioned categories.

Black students at HBCUs. The period immediately following desegregation was one of uncertainty for the Negro colleges. In 1964 as part of Civil Rights legislation, these colleges were relabeled Historically Black Colleges and Universities. Since then, many researchers have examined the role of these institutions in the larger context of American higher education and have found them responsible for uplifting the socio-economic condition of Blacks in the United States, and more specifically for the emergence of a "Black middle-class community" (Gurin, 1975, p.27), a Black bourgeoisie leading a break from the status quo for Blacks in the United States.

The unique contributions of Black colleges to American higher education were publicly recognized in the Adams case as these institutions serve a disproportionately disadvantaged sector of the population. African-Americans attending HBCUs immediately prior to the Adams case were found to be ill prepared for collegiate work (Jaffe, Adams, \& Meyers, 1968; Jencks \& Riesman, 
1967; McGrath, 1965), and to come from economically disadvantaged families (Bowles \& DeCosta, 1971; Brimer, 1971; Gurin \& Epps, 1975; Jaffe, Adams \& Meyers, 1968; McGrath, 1965; National Advisory Commission on Black Higher Education and Black Colleges and Universities [NACBHEBCU], 1979; Thompson, 1973).

Against the odds of poor pre-collegiate preparation and financial strain, throughout the last 5 decades researchers have repeatedly found that Black students who attend HBCUs enjoy a greater degree of college persistence (Astin, 1975b; Cross \& Astin, 1981; Fleming, 1981,1984; Nettles, Thoeny, \& Gosman, 1986, 1987; Willie \& Cunnigen, 1981). Attending HBCUs was also linked to greater academic attainment for Black students (Anderson, 1988a; Thomas \& Gordon, 1983). This positive effect held true for Black women also (Pascarella, Smart, \& Stoecker, 1989). Allen and Haniff (1991) found that Black students at HBCUs performed better academically than Black students at HWIs, and that a great majority of Black doctoral candidates had graduated from HBCUs (Brazziel, 1983). Black students at HBCUs also reported higher levels of satisfaction with their college environment and leadership opportunities (Outcal \& Skewes-Cox, 2002). When Black students speak of their historically Black campuses, they often use terms that allude to family and supportive environments (Bennet \& Xie, 2003; Fries-Britt \& Turner, 2002).

Black students at HWIs. The arrival of Black students at HWls marked the advent of intergroup contact in the higher education arena. As outsiders being allowed entrance, Blacks were expected to adhere to the mores and values of 
the receiving institution. Early interest of researchers and federal agencies had to do with the numbers of Blacks enrolled at publicly founded universities in Border and Southern states and these institutions' compliance with mandates against racial discrimination (United States Equal Rights Commission, 1961).

Most African-American college students in the United States attend HWIs (Allen, 1992; Bowles \& DeCosta, 1971) where diversity is the norm (Carnevale \& Fry, 2000; Menand, 1997; Milem, Chang, \& Antonio, 2005). In spite of desegregation and diversity efforts, lack of participation has been deemed "the greatest problem of the Negro community with respect to higher education" (Bowles \& DeCosta, 1971, p. 215) and in later years, researchers have also expressed great concern for the Black losses in degree attainment (Deskins, 1991; Trent, 1991), especially among Black males (Nettles \& Perna, 1997).

After 50 years of desegregation, Black students continue to confront social challenges at HWls. Pascarella and Terenzini's (1991) first review of 20 years of research deducted that "Black students who attend predominantly White colleges and universities experience significantly greater levels of isolation, alienation, personal dissatisfaction, and overt racism than their counterparts at historically Black institutions" (p. 381). Other studies also found that Black students in predominantly White campuses continue to perceive negative attitudes and unfair treatment from White faculty (Allen, Bobo, \& Fleuranges, 1984; D'augelli \& Hershberger, 1993; Davis et al., 2004; Feagin, 1992; Feagin \& Sikes, 1995; Fries-Britt \& Turner, 2002; Jay \& D'augelli, 1991; Sedlacek, 1999; Smith, 1991) and Black students felt their White peers were uneasy around them (Peterson, 
Blackburn, Gamson, Arce, Davenport, \& Mingle, 1978). On many campuses, Black students were exposed to racist jokes (Feagin \& Sikes, 1995); racist slurs and graffiti (Davis et al., 2004); various types of microaggressions (Solórzano, Ceja, \& Yosso, 2000) and since September 2007, nooses have been found at Columbia University in New York, University of Maryland, and at the Coast Guard Academy in Connecticut where there were two separate incidents (Nealy, 2007). As a result of these social challenges, some Black college students tend to selfsegregate (Feagin \& Sikes, 1995; Gosset, Cuyjet, \& Cockriel, 1998) sometimes feeling alienated even from other Blacks (Davis et al., 2004). Other Black students at HWls were found to remain disconnected from the social environment of the campus while present in it. This social construct of intergroup dynamics has been deemed "irrelation" (Sims, 2008).

Studies that have looked at the interactions between White and Black students reported that all of these barriers encountered by Black college students as they seek to develop a sense of belonging at predominantly White institutions have an adverse effect on their satisfaction with the college experience and negatively impact their persistence (Booker, 2007; D’Souza, 1991; Tinto, 1975, 1987).

White students at Historically Black Institutions. The incorporation of White students into historically Black campuses has received relatively little attention by scholars. This lack of attention may be due in part to the fact that desegregation of HBCUs has been slow and sporadic. Lincoln University of Missouri was one of the few Negro colleges to integrate immediately following Brown v. Board of 
Education and by 1959 White students comprised $25 \%$ of the total enrollment. The first White students to desegregate Lincoln were mostly older and had had little contact with Blacks prior to attending the university (Aber, 1959). Thirty years later, Hazzard (1988) found that White students attending HBCUs in the South also tended to be older, had had only casual contact with Black people before enrolling, were seeking to complete a degree in order to advance their job situation and had no intention in participating in college life. Hazzard (1996) found White undergraduates at HBCUs to be non-traditional in that they mostly did not go to college directly after high school, their average age was 24 , they enrolled for the purpose of completing a particular program of study, and their decision to enroll was influenced by cost, reputation of the institution, availability of financial aid, and proximity.

Other researchers have examined the reasons why Whites choose to attend HBCUs (Conrad \& Brier, 1997) and how satisfied they are with their choice (Conrad \& Brier, 1997; Hall \& Closson, 2005; Hazzard, 1988, 1996). Hall and Closson (2005) set out to find whether or not White students at HBCUs experienced some of the same hurdles as reported in the literature for Black students attending HWls.

HBCUs are caught in the crux of continuing to be true to their legacy and embracing diversity. These institutions must learn what it means to be desegregated and diverse, yet remain faithful to their historic mission (Brown, Ricard, Donahoo, 2004; Dwyer, 2006). 
Lincoln University of Missouri. Lincoln University has been trying to balance faithfulness to its historic mission and embracing diversity for over 50 years. Born of the inspiration and commitment of Black soldiers and White officers of the Civil War, Lincoln Institute opened its doors in 1866 and in1879 became a state school with the support of Governor Phelps who felt it should provide to Black students what the University of Missouri was providing to White students (Savage, 1939).

In 1890, the Second Morrill Act was a catalyst in the establishment of an industrial school at Lincoln Institute. The "separate but equal" underpinning still rang true when in 1921 the state legislature approved a name change from Lincoln Institute to Lincoln University and converted it to a four-year college. During the late 1940s Lincoln enjoyed the same surge in the enrollment of G.I. Bill recipients as did other state schools. This enrollment trend was to be reversed during the 1950s as veterans graduated and Black students began to be admitted at desegregated universities.

In the summer of 1954, following the decision of Brown v. Board of Education, the Lincoln University Board of Curators voted to open admission to all qualified applicants and Lincoln admitted its first White students in the fall of that year (Greene, 1959). During the late 1950s and continuing into the 1960s, these students brought Lincoln's enrollment from 1,184 in 1958 to 2,143 by 1969 (Holland, 1991). By the late 1960s, Lincoln University and West Virginia State College were the only two HBCUs in the nation with about an equal proportion of White and Black students. During the 1970s and 1980s Lincoln continued to 
enroll large numbers of local White students. Sawyer (1989b) pointed to Lincoln University as being one of five HBCUs in the nation that had become predominantly White. This change in demographics had social implications for Black legacy students who felt they had to justify the situation to older family members.

Lincoln is now nearing its $150^{\text {th }}$ anniversary and continues to serve a widely diverse student population. In the years between 2001 and 2005, enrollment of Black students rose by $16.7 \%$ and that of White students declined by $19.7 \%$. For the fall of 2006 and 2007 , enrollment of Black students was $37.6 \%$ and $37.9 \%$ respectively, while White enrollments were $54.4 \%$ in fall 2006 and 55.3\% in fall 2007 (Lincoln University Facts and Figures, 2007). Enrollment of Hispanics has increased and the enrollment of international students has remained steady.

As the literature review revealed, organizational analysis has overlooked race relations as a dimension of organizational dynamics. In higher education, most studies have focused on the incorporation of Black students into the HWls mainstream and very few studies have explored desegregation as it unfolded at HBCUs. Lincoln University offered a fertile setting for enhancing the understanding of the process of racial desegregation in higher education.

Purpose of the Study

The purpose of this study was to examine how the initial Black/White intergroup contact generated by the mandated racial desegregation of Lincoln University of Missouri in 1954 influenced the institution's organizational culture. 


\section{Research Questions}

This qualitative study explored the following questions:

1. What were the cultural forces that converged on Lincoln's campus during the first 15 years following its desegregation?

2. What were the dynamics of intergroup contact at Lincoln University during the late 1950 s and during the 1960 s?

3. How were the University's culture and organizational identity influenced by its racial desegregation?

\section{Research Design}

The researcher sought to attain answers and insights to the above stated inquiry through a qualitative case study. A case study affords the researcher the possibility of clearly targeting the focus of the study. Case studies are bound to a program, organization, or period in time (Krathwohl, 1991) and develop when a "researcher figuratively puts brackets around a temporal and spatial domain of the social world" (Van Maanen, 1983, p. 9). In this case, the organization is Lincoln University of Missouri. The figurative brackets encompass the period between September of 1954, when the first White students matriculated at Lincoln, and May of 1969 when White students constituted the majority of the institution's enrollment. This period of time also coincides with the administrative and presidential tenure of Dr. Earl Dawson, who served as interim chief administrative officer from 1954 until 1956 and then as president until his resignation in 1969. Case studies provide the readers with an opportunity to vicariously experience an event or situation through the eyes and interpretations 
of others thus augmenting the readers' own knowledge base (Stake, 1994). The experience of racial desegregation at Lincoln was inherently different from the ways it was experienced by people at historically White universities. The personal stories communicated through this study enhance the knowledge on the subject of racial desegregation in higher education.

The qualitative approach is of special value when one seeks rich descriptions that help "to make sense of, or interpret, phenomena in terms of the meanings people bring to them" (Denzin \& Lincoln, 1994, p. 2). In organizational research, qualitative research can enhance the diversity of points of view and therefore aid in the discovery of insights that may otherwise remain silenced (Van Maanen, 1983).

\section{Participants}

Three subgroups participated in the study: (a) African-American alumnae/i, (b) White alumnae/i, and (c) African-American and White faculty, who experienced the desegregation of Lincoln University of Missouri immediately following the landmark decision of Brown v. Board of Education in 1954. An interview was also conducted with the 1965-1971 Assistant Director/Director to the Missouri Commissioner on Human Rights. This interview was used mainly for triangulation purposes. The final number of participants was determined by the attainment of a point of redundancy or saturation (Lincoln \& Guba, 1985; Patton, 1990). The researcher secured a sample representative of each subgroup to obtain rich qualitative data from which to identify salient dimensions, establish comparisons, and draw conclusions. 
The first group consisted of 16 African-Americans who attended Lincoln between 1954 and 1969: 13 men and 3 women. The second group consisted of 14 White students who attended Lincoln during that same period of time in this group: 7 men and 7 women. These two groups provided first-hand accounts of how the racial desegregation process began at Lincoln University and shared their perceptions about this historical and cultural event. They were identified by purposeful sampling (Frankel \& Wallen, 2003; Miles \& Huberman, 1984) with initial help from the Lincoln University Office of Alumni Relations. To enhance the sense of trust, students were initially reached through a listserv hosted by 1968 graduate Mr. Joseph Johnson. Responses were received from both Black and White alumnae/i from the period and a process of snowballing was set in motion. Two alumnae/i from the Jefferson City community set the process in motion by completing their own interviews and either contacting or providing contact information for other participants. The same was true for an alumnus who now lives in California but maintains strong ties with some of the students who attended Lincoln from the surrounding rural communities. Those potential participants were contacted by the researcher to provide a brief description of the project and to set up either person-to-person or phone interviews. The third group included participants of both races who served as faculty or staff during the same period of time. They too possessed intimate knowledge of how Lincoln University moved from being a Black University to an integrated HBCU. These participants were identified by purposeful sampling (Fraenkel \& Wallen, 2003; Miles \& Huberman, 1984) and "snowballing" approaches (Merriam, 1998, p. 63), 
in which one participant provided the names of others who met the sampling criteria. People currently associated with Lincoln University were asked to provide the names of those they considered "information-rich key informants" (Patton, 1990, p. 46).

\section{Data Collection}

The data for this study were collected through individual interviews, and study of archival sources including yearbooks, institutional records, and local and university newspapers. Although direct observations were not possible given the historic frame for this study, observations of participants were made at the time of the interviews. Two basic types of interviews were utilized: open-ended interviews and conversational interviews (Patton, 1990; Seidman, 1998). Three basic interview protocols were developed. Each contained some questions common to all the participants and some group-specific questions to avoid conducting the research in a framework of "cultural monism" (Azibo, 1990) that fails to acknowledge differences across race (Nkomo, 1992).

With the explicit consent of the participants, all interviews were audio and/or video-taped for future archival use. In addition to the oral accounts, archival documents pertinent to the racial desegregation process at Lincoln University such as local and institutional newspapers, minutes from Board of Curators' meetings, and yearbooks from the period were studied. The study of these documents was completed by identifying the relevant archival sources and carefully reading sections to triangulate information gathered during the interviews. Institutional and local newspapers as well as yearbooks from the 
period provided a record of those aspects of community or college life that were considered important enough to be addressed at the time or save for perpetuity. The pictorial record preserved in yearbooks served as a testament to the change in racial composition of Lincoln, cultural aspects of the institution and its strong Black heritage. Institutional records such as the Minutes of Board of Curators' meetings provided a unique background to issues confronted by the administration and to the actions taken by its governing body. In some instances, participants provided detailed information about particular events on campus and it was interesting to find that they were not recorded in the traditional institutional documents. At times silence in the documented history made the participants' evocations even more powerful.

\section{Data Analysis}

Qualitative data are analyzed by systematically organizing and probing into the information that has been gathered in the transcripts of interviews, field notes, and other documents. From this process, researchers emerge with a deeper understanding of the experience or situation and can share their findings with others (Bogdan \& Biklen, 1998). To analyze the data collected through this study, the researcher completed multiple viewings of the video-recorded interviews, and listened to the available audio recordings. Partial transcripts of each interview were written and read multiple times for an initial "free textual analysis" (Smith \& Osborn, 2003). Margin notes and memos were written to highlight interesting portions, record researcher's reactions and commentaries or to document external situations that may not be apparent in the transcripts. At 
this point, the data were analyzed through a thorough examination of the data on the merits of the data itself. As suggested by Patton (1990) it was important for the researcher to become aware and suspend her own biases, judgments, etc. and to focus on the responses of the participants from which meaningful groupings were created, abstractions of the experience were identified, and the essence of attending or teaching at a desegregated HBCU during the late 1950s or during the 1960s emerged (Patton, 1990). This process was greatly facilitated by the researcher's Latina background which allowed her to remain ethnically removed from the Black/White dichotomy. Furthermore, the researcher is a foreign born American who did not live through the period in question in the United States and was able to allow the participants to create this history for her through their recollections. Data were coded and clustered under emerging themes. Cross-referencing among participant responses and of participant responses to archival documents were used for triangulation purposes.

Definitions of Key Terms and Constructs

This section aimed to clarify the meaning and context in which the following terms were used in this study.

Accommodationist: Is generally defined as "[o]ne who compromises with or adapts to the viewpoint of the opposition" (Soukhanov, The American Heritage Dictionary of the English Language, 2005, p. 11). In African-American history accommodationist or accommodation is defined as the position assumed by Booker T. Washington who believed that "African-Americans should accept segregation while learning a trade" (Clark Hine, Harrold, \& Hine, 2008, p. BG-7). 
Desegregation: The process of reorganizing and running institutions of higher learning in a way that dismantles the segregated system and insures access to all students regardless of restrictions placed upon them by past segregated precedents. (Revised Criteria Specifying the Ingredients of Acceptable Plans to Desegregate State Systems of Public Higher Education, 1978). Historically Black Colleges and Universities (HBCUs): “...any historically Black college or university that was established prior to 1964 , whose principal mission was, and is, the education of Black Americans, and that is accredited by a nationally recognized accrediting agency or association..."( 20 U.S.C. 1061, Sec. 322).

Historically White Institution (HWIs): Term that has been customarily used when speaking of colleges and universities that were established to meet the educational needs of White Americans. The terms historically White, traditionally White and predominantly White are often used interchangeably, but there are now HBCUs which are predominantly White, thus blurring the meaning of that label. For that reason, only the terms historically White and traditionally White were used throughout this study except when quoting from the literature. Industrial Education: Also known as vocational education and championed by Hampton Institute and Tuskegee. It aimed at providing Black students with practical skills that would become the foundation for the uplifting of the Black race.

Intergroup contact theory: Premise that evolved from the tenets for optimal intergroup contact hypothesis proposed by Gordon Allport in 1954. It "proposes 
that simple contact between groups is not automatically sufficient to improve intergroup relations. Rather, for contact between groups to reduce bias successfully, certain prerequisite features must be present" (Dovidio, Gaertner, Kawakami, 2003, p. 5).

Linconites: Term commonly used to denote Lincoln University graduates and others who display a strong affinity and loyalty to the institution. True Linconites are the closing words of the final verse of the Alma Matter (Lincoln University of Missouri, retrieved, 4/09/08 from http://www.lincolnu.edu/pages/213.asp). Morrill Act of 1890: Provided federal funding that insured access to state supported higher education for Blacks engaged in the study of agriculture and mechanics in addition to other educational pursuits. Seventeen Historically Black Colleges and Universities trace their roots to this Act (List of Land-Grant universities, 2009).

Racial Integration: The bringing of people of different racial or ethnic groups into unrestricted and equal association, as in society or an organization; desegregation. (The American Heritage Dictionary of the English Language, 2005, p. 938).

Talented Tenth: The most able ten percent of Blacks who would in turn uplift the race through their leadership. This phrase is attributed to DuBois (1903) who wrote:

The Negro Race, like all races, is going to be saved by its exceptional men. The problem of education, then, among Negroes must first of all deal with the Talented Tenth; it is the problem of developing the Best of this race that they may guide the Mass away from the contamination of the Worst, in their own and other races (p. 385). 


\section{Limitations of the Study}

The limitations of this study were:

1. The participants experienced the desegregation of Lincoln University over 40 years ago and this lapse of time may cause some of the recollections of the participants to be "polluted" by events in their own lives and in American society.

2. Although the researcher originally planned to interview people who were staff members during the 1954-1969 period, this group proved to be elusive as most of its members have already passed away.

3. The researcher is a faculty member at Lincoln University and her position there may have inhibited participants' responses about the institution.

\section{Significance of the Study}

Historically Black Colleges and Universities hold a unique place in American higher education as they were created for the very specific purpose of educating and socializing African-Americans. When Lincoln University deviated from that singularity of purpose by opening its doors to White students, its internal culture had to be redefined. This study, through the lens of intergroup contact theory and multiple organizational culture theories, examined the unique perspectives of students, and faculty who participated in the desegregation process of American higher education at a minority serving institution that opened its doors to the dominant group. 
The actors in the chapter of school desegregation history are an aging, dying group whose stories are at risk of being lost forever. Their perceptions of the role played by conditions of equal status, intergroup cooperation, common goals, the support of established authorities, personal interaction, and friendship opportunities can enrich the way we understand racial climate in higher education and in other organizations. The retrospective aspect of this study allows for an evocative look at the transformation of institutional culture from that of a racially segregated Black university to an integrated one.

Researcher's Perspective

I first came in contact with Lincoln University as an international student in 1984. The fact that Lincoln was a Historically Black University eluded me for at least the first semester and when I learned of this fact, it had very little relevance to me. As a Latin American immigrant, American interracial dynamics did not register with me. After three semesters I transferred to the University of Missouri at Columbia where I completed my Bachelor's and Master's degrees. I returned to Lincoln in 1998 as full-time faculty. This time around I took notice of the intergroup workings on campus and came to realize that Black and White students had very different college experiences while attending Lincoln. I decided to undertake this study to seek an answer to the reason why after more than 50 years of desegregation, Lincoln has not achieved racial integration.

\section{Summary}

This study explored how Lincoln University's organizational culture was influenced by the initial Black/White intergroup contact generated by mandated 
racial desegregation. The introductory chapter began with an overview of desegregation in higher education and stated that lack of information about how desegregation unfolded at HBCUs was a problem worthy of study. The conceptual framework that was utilized for looking at desegregation at Lincoln University is based on Gordon Allport's (1954) contact hypothesis. Contact hypothesis, now known as intergroup contact theory, has evolved through the work of many researchers and is an accepted framework for studying race relations. This chapter also provided a condensed version of the review of pertinent literature, articulated the purpose of the study, presented the research questions and provided an overview of the research design. The first chapter ended with a discussion of the significance of this study, which is its contribution to the scholarship on the desegregation of higher education as experienced at a Historically Black University. Few studies have focused on the process of desegregation at HBCUs and the organizational culture of the newly integrated HBCUs (e.g., Aber, 1959; Conrad \& Brier, 1997; Hall \& Closson, 2005; Hazzard, 1988, 1996; Payne-Brown, 2004; Peterson \& Hamrick, 2009; Taylor \& Oswalg, 1999).

Chapter Two provides a comprehensive review of literature related to the history of segregated and desegregated higher education. The review highlights issues relevant to the education of African-Americans and the historic and current condition of HBCUs. The review also delves into the role of Black/White relations in organizations and evaluated studies that proposed that race should be an aspect of organizational analysis. 


\section{CHAPTER TWO}

\section{REVIEW OF THE LITERATURE}

Introduction

Organizations are societal settings where people interact to achieve a common goal. In institutions of higher education groups of people come in contact in the pursuit of personal and institutional goals. At colleges and universities, as in other types of organizations, assumptions, values and beliefs of interacting groups come into play. The more homogeneous the group the greater the chance of those values and beliefs being commonly held. When different racial or ethnic groups come together in an organizational setting they tend to import the societal conflicts into the organizations. Relations between Whites and African-Americans have been made problematic by three centuries of Black slavery, the Jim Crow Era and institutionalized racial discrimination that left a legacy of social and economic disparity for African-Americans. This legacy continues to affect societal race relations over one hundred and forty years after the Emancipation Declaration in 1865. Through it all, African-Americans have remained steadfast in their pursuit of educational opportunities to better the lot of present and future generations. "[E]ven as America developed history's most elaborate institutional barriers to deny African-Americans equal access to learning and knowledge—Black people continued to pursue education" (Allen \& Jewell, 2002, p. 242).

In higher education, this pursuit first found fulfillment at Negro colleges known today as Historically Black Colleges and Universities (HBCUs), institutions 
established to impart classical knowledge and/or labor training to Black students not allowed to enroll at the colleges where White students were being educated. In the 1950 s as schools desegregated, the number of Black students at Historically White Institutions (HWls) began to rise and by the 1970s most Black college students were attending these institutions (Allen, 1992; Bowles \& DeCosta, 1971). Some HBCUs also began to enroll White students in the 1950s; nevertheless their desegregation has been more gradual. In 2005 , only nine out of the 106 historically Black colleges and universities reported White student enrollments above 10\% (U.S. Department of Education, National Center for Education Statistics, Integrated Postsecondary Education Data System "Fall Enrollment" surveys 1994 - 2005).

This qualitative study sought to examine how the initial Black/White intergroup contact generated by the mandated racial desegregation of Lincoln University of Missouri in 1954 influenced the institution's organizational culture. This chapter provides an overview of the literature on two overarching themes: (a) organizational culture and intergroup contact, and (b) segregation and racial integration in higher education. The review of the literature on organizational culture and intergroup contact provides a comprehensive analysis of relevant scholarly works on the topics of (a) organizational culture; (b) race relations in organizational culture; (c) intergroup contact and the creation of organizational culture; and (d) Organizational Culture and Racial Climate in Institutions of Higher Education. The review of the literature on segregation and racial integration of higher education provides a chronological overview of the 
education of African-Americans and the role of HBCUs in American higher education. This section is divided into three categories: (a) higher education in America from 1636 to 1890; (b) Negro colleges: making up for lost time 18901960; and (c) a racially integrated system of higher education 1960 - present. This last category is organized into subcategories to provide a comprehensive and detailed analysis of the literature: (a) Black students at HBCUs; (b) Black students at HWIs; (c) White students at HBCUs; and (d) Lincoln University of Missouri. The race-related labels employed throughout this section of the review of the literature reflect those used by scholars at the time the various studies were conducted.

\section{Organizational Culture and Intergroup Contact Organizational Culture}

Organizations of higher education bring together groups of people who value knowledge. There are those in higher education who impart it and those who receive it. In their interactions, knowledge is also created and these knowledge-seeking, knowledge-sharing, knowledge-creating interactions form the basis for organizational culture within higher education.

The way researchers approach the study of the culture of an organization is highly dependent on their own understanding and views of what culture in organizations should reflect. According to Joanne Martin (1992), culture research is embedded in one of three social scientific perspectives: integration, differentiation, and fragmentation. Integration-based studies focus on consensus and absence of ambiguity reached through common interpretations of all cultural 
manifestations. Research guided by the differentiation perspective looks at the presence of ambiguity and how it is channeled to avoid its intrusion into the clarity present within subcultural boundaries. Studies conducted from a fragmentation perspective see ambiguity as the essence of culture in an organization. In this view, consensus and dissent are ever present facts of organizational life.

Models of integration consider what is shared by the members of the organization as the essence of the organization's culture. Shared values and beliefs (Davis, 1984; Schein, 1984; Sergiovanni \& Corbally, 1984; Siehl \& Martin, 1990); shared meanings (Siehl \& Martin, 1990) and understandings (Sathe, 1985); shared communication activities (Schall, 1983); and shared assumptions (Barley 1991; Schein, 1984) have each been theorized as being the mortar that holds an organization together and defines its culture. According to Schein (1991) that which is shared defines the culture of an organization to the point that what is not shared prevents the organization from having a culture as it pertains to those things. Schein (1991) then defined culture as:

[A] pattern of basic assumptions - invented, discovered, or developed by a given group as it learns to cope with its problems of external adaptation and internal integration- that has worked well enough to be consider valid and, therefore, to be taught to new members as the correct way to perceive, think, and feel in relation to those problems (p. 9).

External adaptation deals with the coping mechanisms employed by an organization in order to navigate changes in its environment. The mechanisms employed are closely tied to the organization's mission or its understanding of its reason for being (Schein, 1991). According to Schein (1991) internal integration 
is the manner in which the organization builds and maintains itself. External adaptation and internal integration processes influence the creation of a shared culture without which there is only an "aggregate of people, not a 'group"' (p. 50).

Differentiation and fragmentation theories stress the role of subgroups and individuals upon the cultural development of the whole organization. One definition of a group within an organization is provided by Alderfer (1977):

A human group is a collection of individuals (1) who have significantly interdependent relations with each other, (2) who perceive themselves as a group by reliably distinguishing members from nonmembers, (3) whose group identity is recognized by nonmembers,(4) who, as group members acting alone or in concert, have significantly interdependent relations with other groups, and (5) whose roles in the group are therefore a function of expectations from themselves, from other group members, and nongroup members (p. 230).

Proponents of differentiation theories of organizational culture depart from the seemingly seamless portrayal of organizations provided by integration theories. Differentiation theories see organizations as conglomerates of subgroups and/or subcultures (Alderfer \& Smith, 1982; Gregory, 1983; Riley, 1983; Schein, 1996) and pay close attention to how in the interactions of these subgroups, issues of power, conflict and special interests are played out (Alderfer, 1977; Alderfer \& Smith, 1982; Alderfer \& Tucker, 1996; Kolb \& Putnam, 1992; Martin, 1992).

Differentiation theories recognize that subgroup interactions may lead to divergent interpretations of meaning (Louis, 1985); conflict (Kolb \& Putnam, 1992; Mills, 1988; Van Maanen \& Barley, 1985), said to exist "when there are real or perceived differences that arise in specific organizational circumstances 
and that engender emotion as a consequence" (Kolb \& Putnam, 1992, p.312); and disconnections between how an organization defines itself and how it actually performs. Burnsson (1989) deemed this disconnected approach "organizational hypocrisy...to talk in a way that satisfies one demand, to decide in a way that satisfies another, and to supply products in a way that satisfies a third" (p. 27).

Fragmentation theories of organizational culture are rooted in postmodern thought and view the organization as ridden with ambiguities, a myriad of interpretations of meaning, and complex relationships within and without the established boundaries of the organization (Martin, 1992). Fragmentation analyses look both at what is said and what is kept silent. These analyses do not look for consensus but explore multiple fragmented interpretations. Sub-group membership and coalitions are considered fluid as members engage in temporary connections around a particular issue (Gagnier, 1990). "At the organizational level of analysis, then, the Fragmentation perspective reveals a constantly fluctuating morass of allegiance. All is heterogeneous and in flux. No static, totalizing, organization-wide interpretation is possible" (Martin, 1992, p. 157).

More recently, organizational analysis scholars have proposed that a thorough study of organizational culture would show interplay of the various perspectives previously discussed. In such analysis, the researcher would be open to the possibility that:

Some things will seem to be consistent, clear, and indicative of collectivity-wide consensus. Simultaneously, other aspects of the 
culture will seem to coalesce into subcultures, enabling these subcultures to reinforce, be independent, or conflict with each other. At the same time, still other elements of the culture will seem fragmented, in a state of constant flux, and infused with confusion, doubt, and paradox (Martin, 2002, p. 158).

This last proposition seemed most applicable to this study when one considers the inherent hierarchical divisions of academia where subgroups interrelate to produce a kaleidoscopic organizational culture.

\section{Race Relations in Organizational Culture}

Organizations have provided a fertile ground for researchers from various theoretical perspectives. Their research has yielded volumes of studies on many aspects of organizational life. Yet, one aspect that has received little attention is race-relations in organizations (Cox \& Nkomo, 1990; Martin, 1992; Nkomo, 1992). The neglect of race relations as an aspect of organizational dynamics can lead to the belief that race-neutrality is a characteristic of organizations (Nkomo, 1992). As a matter of fact, most organizational research is notably void of mentions of Blacks and other minorities. When mentioned, they are most often viewed in contrast to the defining group, White males. This may be due in part, to the prevailing thought of integration and assimilation of minorities into the cultural norm (Nkomo, 1992). After a review of articles addressing issues of race in organizations, published between 1964 and 1989, Cox and Nkomo (1990) concluded that 201 race-related articles out of 11,804 articles published in over 16 different organizational behavior and human resources management journals did not constitute "a significant research base for understanding race in organizations" (p. 422). Most of the 201 race-related articles dealt with affirmative 
action, staffing, job satisfaction/motivation and evaluations of employee performance. Many of the studies questioned the adaptability of Black workers to White organizations, or whether or not Blacks and women had what it took to perform as White males did. Race was often viewed as merely a demographic value (Cox \& Nkomo, 1990), an issue, or a problem (Nkomo, 1992; Omi \& Winant, 1986).

Treating women and minorities as the other, prevents researchers from recognizing the uniqueness of these groups' contributions to the organization and the acknowledgment or recognition of their socio-historical experiences. The alternative is to recognize that race-neutrality in organizations is an illusion. Nkomo (1992) suggests applying power-conflict theories to the study of organizations to gain insight into how those organizations develop their racial constructions, the relations of power that preserve racial divisions and domination and the role of capitalist mode of production upon those divisions. Researchers that see organizations as conflict ridden, remind us that diversitybased conflicts in the larger society are imported into organizations and must be recognized (Kolb \& Putnam, 1992).

Schiele (1990) offered another organizational perspective based on an Afrocentric view of the world that could provide an alternative to the prevailing theories which, in his view, "are circumscribable and biased and omit different conceptualizations of human beings and society found in other cultures" (p.145). According to Schiele, Afrocentric values of organization provide for

A unified, collective membership maintaining survival; a close identification between the community and the organization; a de- 
emphasis on the rate of production and efficiency; low internal differentiation; an emphasis on consensus decision-making; a positive, not negative outlook on worker behavior; a strong emphasis on enhancing members spirituality; a balanced (i.e., qualitative and quantitative) means of evaluating worker performance; and an interpersonal human-centered axiology. (p.159)

Schiele suggested that this approach would be more in accord with human needs, but acknowledges that it would be problematic to maintain accountability in an organizational culture that focuses on relationships instead of production. He insisted, though, that this model lends a better reflection of the human experience.

One possible approach to overcome the tendency toward uniformity when seeking to understand organizations may be

to separate cultural integration from organizational integration, and to describe organizations, rather than cultures, as either "strong" or "weak" in terms of integration. Organizations that lack integration may be comprised of members acting from numerous internally consistent but externally conflicting cultures. Ethnocentrism exacerbates the intensity of conflicts, since each coalition takes its position for granted or may even assume meanings and priorities are shared. The cultures may conflict only in a few situations, or in many (Gregory, 1983, p.365).

At the dawn of a new century, the study of race relations in organizational cultures has been embedded in the area of diversity in organizations. Diversity has become an overarching rubric over differences that compartmentalize individuals into categories. These categories can be "surface-level social category differences" (Mannix \& Neale, 2005), such as those of race, ethnicity, gender, disabilities, and age; as well as "underlying differences" (Mannix \& Neale, 2005) such as 
educational level, functional background, and work experience. The ways in which organizations deal with the intergroup dynamics among individuals in these categories comprise that organization's diversity management. It includes the administration of social environments and systems, climate and procedures. It requires the recognition of, openness to, and utilization of human differences to create a positive organizational environment (VonBergen, Soper, \& Foster, 2002). Whether purposefully managed by the organizational leadership or not, intergroup contact plays a catalytic role in the creation or evolution of organizational culture. The following two sections explore this catalytic role, first in general terms as it relates to organizations and secondly as it is manifested in the racial climate of colleges and universities.

\section{Intergroup Contact and the Creation of Organizational Culture}

Organizational culture is in effect a byproduct of the interaction among its members: individuals who bring to the mix their own sets of values, beliefs, and ways of thinking, some of which can push the individual to self-identification with a particular subgroup in society. In the 1950 s the United States experienced an unprecedented shift in how subgroups within the national society came in contact with one another. This shift was most evident between Black and White people and especially so in Southern and Border States. In the early 1950s, as the nation was dealing with issues of segregation in public places and most directly in its public schools, Gordon Allport (1954) recognized that it would not be enough for people from different groups to get together and assume that this 
alone would erase preexisting prejudices. He proposed that in order to achieve optimal intergroup contact (contact that reduces prejudice), four elements must be present, "[1] a sense of equality in social status, [2] should occur in ordinary purposeful pursuits, [3] avoid artificiality, and [4] if possible enjoy the sanction of the community" (p. 454).

Allport's framework was in part informed by the 1947 publication of C.R. Williams Jr.'s The Reduction of Intergroup Tensions and a series of studies conducted on racially mixed neighborhoods in 1951 and 1952 (Pettigrew \& Tropp, 2006). The aforementioned set of conditions became known as intergroup contact theory (also known as contact hypotheis) and, with some modifications, has been utilized in multiple studies seeking to better understand relations among diverse groups.

Intergroup contact theory has evolved through the work of many researchers. Sherif, Harvey, White, Hood, and Sherif (1961) highlighted the importance of cooperation and interdependence. Cook (1985) introduced the notion that Allport's seminal conditions would be enhanced by a fifth condition of facilitation of friendship. Amir (1976) and subsequently Brewer and Miller (1984) concurred with Cook's suggestion of opportunities for friendship and highlighted the need for personal acquaintance with members of the other group to dispel stereotypic expectations. Stephan and Stephan (1996) cautioned that intergroup contact was affected by "societal antecedents [or] the prior relationships between the groups influence the contact situation and the people participating in them" (p. 88). 
Intergroup contact theory has provided the conceptual framework for research seeking to understand Black-White interactions and racial attitudes (Sigelman \& Welch, 1993; Wittig \& Grant-Thompson, 1998) and status legitimacy for intergroup attitudes among numerical minorities (Bettencourt \& Bartholow, 1998). Other studies have utilized intergroup contact theory to explore various aspects of interaction among groups of diverse racial backgrounds in educational settings. The topics of study included: the racial climate at predominantly White college campuses (Chavous, 2005), the effects of interracial stress in ethnically diverse classrooms (Marcus-Newhall \& Heindl, 1998), the enhancement of campus climate for racial and ethnic diversity (Hurtado, Milem, ClaytonPedersen, \& Allen, 1998) and race and ethnic relations among community college students (Williams \& Shammas, 2007).

The historic development and utilization of Intergroup Contact Theory has also received attention by various researchers. Dovidio, Gaertner and Kawakami (2003) explored the past, present and future of the theory and provided a historic timeline of its development, as well as considerations of conditions and psychological processes required for successful intergroup contact. They also looked at conditions required for generalization and proposed directions for future research. Pettigrew \& Tropp (2006) conducted an extensive meta-analytic test of intergroup contact theory and found that indeed, intergroup contact reduces prejudice, that the results typically generalize to the entire outgroup and that although originally tested with racial and ethnic groups, the theory can be applied to other groups. The authors cautioned that Allport's conditions appear to be best 
conceptualized as a grouping of interrelated factors. Other studies found that the reduction of prejudice can be obtained in absence of the conditions and invited researchers to explore negative factors that impede the reduction of prejudice.

The theoretical framework adopted for this dissertation was used to explore which of the conditions for optimal intergroup contact [(a) equal status within the contact situation; (b) intergroup cooperation; (c) common goals; (d) support of authorities, law, or custom (Pettigrew, 1998); (e) personal interaction; and (f) friendship opportunity (Cook, 1975; Dovidio et al., 2003)] were manifested during the initial stage of desegregation at Lincoln University and how the resulting intergroup contact among Black and White students, faculty and staff impacted the organizational culture of the institution.

Organizational Culture and Racial Climate in Institutions of Higher Education

Racial and ethnic diversity are growing trends in the composition of college student populations. Census records showed that in October of 2007, $31.5 \%$ of all college students identified themselves as part of one of the three largest minority groups: 13\% African-American, 11.5\% Hispanic, and 7\% Asian (U.S. Census Bureau. School enrollment - social and economic characteristics of students: October 2007). Granted some of these students were enrolled in minority serving institutions, the overall picture is that the growing trend on college campuses is a diverse student body. It is projected that by 2015 , minority students will comprise $80 \%$ of 2.6 million new students and constitute about $37.2 \%$ of the overall college enrollment at the same time, the White student population is expected to fall by $7.8 \%$ (Carnevale \& Fry, 2000). 
As diversity and with it intergroup contact increase on college campuses, there is more interest in studying how members of the various subcultures interact and contribute to the overall culture of the institution. A result of those interactions is the campus racial climate.

Very few studies that looked at racial climate in higher education have defined the concept. Chavous (2005) proposed that racial climate in an institution of higher education consists of "the beliefs, attitudes, values, and expectations shared by students at the institution that are sustained over time" (p. 240). Two aspects of this definition warrant a closer look. The first is the close similarity between this definition and integrationist definitions of organizational culture which hinge on ideas of values, beliefs, assumptions, and understandings that are shared and communicated over time (Barley, 1991; Davis, 1984; Schein, 1984; Schein, 1990; Sergiovanni \& Corbally, 1984; Siehl \& Martin, 1990). This similarity could be interpreted as racial climate and organizational culture being one and the same, or being so inextricably intertwined that one cannot be examined without examining the other. The second aspect of Chavous' definition that warrants attention is the narrowing of racial climate to the student population at a college or university. Although studies have shown that student interactions are indeed a component of students' perceptions of racial climate on campus (Davis et al., 2004; Dinka, Mazzella, \& Pilant, 1980; Feagin, 1992; Feagin \& Sikes, 1995; Peterson, Blackburn, Gamson, Arce, Davenport \& Mingle, 1978; Solórzano, Ceja, \& Yosso, 2000), limiting racial climate to student interactions is problematic because it neglects other contributing factors that have been found 
to influence students' perceptions, mainly student/faculty relations. Studies that have examined the satisfaction of minority students at predominantly White institutions often point to perceptions of prejudice communicated by faculty members as one of the main issues contributing to African-American students' negative perceptions of the campus racial climate (Allen, Bobo, \& Fleuranges, 1984; D’augelli \& Hershberger, 1993; Davis et al., 2004; Jay \& D’augelli, 1991; Sedlacek, 1999; Singer, 2005; Smith, 1991; Suárez-Balcazar et al., 2003). Other studies have also looked at institutional practices such as the academic advising of Black student-athletes (Singer, 2005) and the design of cultural events for African-Americans on HWIs (Fries-Britt \& Turner, 2002) and found that those practices also contributed to African-American students' perception of the racial climate of an institution.

A more comprehensive approach to the study of racial climate was offered by Hurtado et al. (1998) in which external and internal aspects are considered when examining the racial climate of a college or university. Among the external factors, these authors proposed

(a) the impact of governmental policy, programs and initiatives [such as court mandates, affirmative action, federal financial aid] and (b) the impact of sociohistorical forces [such as external events that affect how people view racial relations, for example the events of September 11 or the Jena Six trials]" (p. 282).

Among the internal forces that shape racial climate, the authors proposed the following:

[a] an institution's historical legacy of inclusion or exclusion of various racial/ethnic groups, [b] its structural diversity in terms of numerical representation of various racial/ethnic groups, [c] the psychological climate of perceptions and attitudes between and 
among groups, and $[\mathrm{d}]$ the behavioral climate dimension

characterized by intergroup relations on campus (p. 282).

The legacy of inclusion or exclusion relates to the campus' enrollment practices that have either embraced students from various groups or purposefully kept them from matriculating. Most colleges and universities in the nation have to contend with a history of exclusion that is much longer than their history of diversity. The resistance that an institution exerted against desegregation efforts plays a role in this category. The numerical representation aspect looks at the positive and negative facets of increased numbers of nonminority students. Psychological climate refers to the attitudes toward people of different racial/ethnic backgrounds, perceptions of racial hostility or prejudice - both individual and institutional. The behavioral climate looks at social interactions in terms of actual involvement and contact with people of other races/ethnicities, both from the point of view of the participants and the observers. Hence this aspect deals with issues of perceived student engagement and self-segregation.

Other researchers (Milem, Dey, \& White, 2004; Milem, Chang, \& Antonio, 2005) advocate the inclusion of a fifth dimension in the study of campus racial climate.

The organizational/ structural dimension of climate [which] is reflected in the curriculum; in campus decision-making practices related to budget allocations, reward structures, hiring practices, admission practices, and tenure decisions; and in other important structures and processes that guide the day-to-day "business" (Milem, Chang, \& Antonio, 2005, p.18).

Studies have shown that racial climate is interpreted differently by diverse groups with the most divergent opinions being held by African-American and 
White students. Ancis, Sedlacek, \& Mohr (2000) found that even when a sample includes other minority groups such as Hispanic and Asian students, AfricanAmericans consistently report "greater racial-ethnic hostility; greater pressure to conform to stereotypes; less equitable treatment by faculty, staff, and teaching assistants; and more faculty racism than did other groups" (183). Cabrera, Nora, Terenzini, Pascarella, and Hagedorn (1999), found a strong correlation between students' perceptions of campus climate and their level of commitment to the institution. An interesting finding of this study was that while the experience of prejudice in the campus climate is the most dominant factor for determining African-American students' commitment to an institution, it was also found to have the second largest direct effect (after parental encouragement) on White students' commitment to the institution. The finding of the Cabrera and colleagues' study is consistent with those of Zea, Reise, Beil, and Caplan (1997) as well as Eimers and Pike (1997) who found that White students' persistence at a particular campus was influenced by their perception of racial hostility toward minorities. Both of these studies had samples that compared White students to various racial minorities. This finding is significant because it points to the overall benefit of an inclusive and respectful campus climate where all members of the institutional community feel valued and appreciated and where positive modeling of intergroup relations is found throughout the institution.

Milem, Chang and Antonio (2005) in a study commissioned by the Association of American Colleges and Universities suggested that efforts for improvement must go beyond the increase in diversity of the student body at an 
institution. They proposed that the first step in improving racial campus climate is for institutions to acknowledge their legacies of inclusion and exclusion. This may be achieved through special programs and/or telling their story in terms that highlight inclusion milestones. The authors further suggest that commitment to diversity be expressed through mission statements and initiatives and policies that enhance faculty/staff diversity. Other efforts to be undertaken in the pursuit of a positive campus racial climate include addressing racial/ethnic Balkanization; creating cultural spaces where minority students can assert and explore their heritage; engaging in curricular transformation that incorporates and validates diverse perspectives; promoting active learning pedagogies that allow for exposure to multiple points of view; facilitating intergroup dialogues; encouraging and fostering interracial contact to facilitate friendships; and requiring commuter students to live on campus during their first year at the school to increase proximity among diverse populations.

Researchers have proposed that transformation of racial climates through the institutionalization of a diversity agenda must include campus wide involvement (Hurtado et al., 1998, 1999; Milem, Chang, \& Anthony 2005). Nonetheless, the single most important factor for success of a diversity agenda is leadership (Hurtado et al., 1998, Kezar, 2007, 2008). Kezar (2008) redefined the advancement of a diversity agenda as a political endeavor because invariably, "[e]xisting groups defend the resources and power that they have, and new groups emerge trying to obtain resources and power, creating conflict" (p. 410). The author further suggested that conflict may also be embedded in values that 
the underrepresented group may hold and that the traditionally dominant groups do not share or understand.

The literature on racial climate and diversity on campus is dominated by studies conducted almost exclusively at historically/predominantly White institutions that have incorporated African-Americans and other minority groups into their campuses. Just as with the literature on organizational diversity, the norm is the incorporation of minorities into majority organizations. In a study of how HBCUs may look at diversity on their campuses, Dwyer (2006) proposed that at these institutions, diversity is most evident in their structure as many of these institutions employ faculty and staff from many ethnic groups other than African-American, and have seen an increase in the number of non-Black students they enroll. The author also proposed that diversity is evidenced in the multiculturalism imbedded in the curriculum and the use of "equity pedagogy... one which takes into consideration the cultural or ethnic background of the students in order to better assist their learning" (Drewry, \ 39). The author then linked the statement to what she deemed a common practice toward classroom multiculturalism at HBCUs: "the employment of education that utilized an AfricanAmerican perspective that takes into account the cultural background of the majority [emphasis added] of students in the classroom" (\$ 40). This is a problematic statement because it appears to create a double standard whereby HBCUs accomplish diversity in the classroom by maintaining a majority African-American perspective; while HWls are expected to achieve diversity by being inclusive of minority perspectives. There is in effect a void in the literature 
pertaining to racial climate and diversity at desegregated HBCUs, tribal colleges and other minority serving institutions. Furthermore, there is a need to define what diversity means at minority serving institutions.

Segregation and Racial Integration in Higher Education

Higher Education in America from 1636 to 1890

Throughout its history, higher education in the United States has adjusted to shifts in the society, excluding or including members as dictated by social norms and mores. During the colonial period, higher education in the United States was provided by Harvard, William and Mary, and Yale. These colleges enjoyed the endorsement of the local church and colonial legislatures and prepared White, affluent men for political and professional pursuits. As other colleges were established and religious diversity increased, these colonial colleges and those that emerged later responded by enacting policies of "toleration...[and]... preferment" (Herbst, 1988, p. 54), which allowed for the inclusion of students from other Protestant faiths and favoritism for those who shared the religious denomination of the college founders.

As time passed, there began to develop an affinity for secular education and in 1754, William Livingston of New York introduced a bill for the creation of a public college overseen directly by the Assembly. His bill did not pass, but his ideas found manifestation later in the eighteenth century with the transformation of the College of Philadelphia into the University of Pennsylvania, and King's College into the University of New York (Herbst, 1988). 
The value system guiding education during the nineteenth century was characterized by the post-revolutionary vision that viewed formal instruction as a tool for socialization. By the 1830's there was a strong movement toward replacing the pay and charity schools with a uniform system of schools. As these systems evolved, more people participated in higher education, but the enrollment of women and minorities remained limited. Women, for the most part, attended schools specifically designed for them, including Wheaton and Mount Holyoke Female Seminaries which opened in 1834 and 1837 respectively. The education of American Indians was embedded in the charters of most universities during the colonial period, including Harvard, William and Mary, and Dartmouth. Nevertheless, from the time of these institutions' charters to the American Revolution, only 47 Indian students appeared on those colleges' combined records of attendance and of those, only four graduated (Carney, 1999). Blacks were rarely admitted on an equal basis, even in Northern states. Bowdoin College awarded the first college degree to a Black man, John Russwurm, in 1826. From that time until the beginning of the Civil War, the number of Black college graduates was 28 (Johnson, 1938). All of these degrees were conferred by White institutions and there is no record of a Black college conferring a degree until after the Civil War (Drewery \& Doerman, 2001).

The enslaved and marginalized existence of Blacks during the colonial and post-revolutionary period afforded them very few educational opportunities. As noted above, toward the second half of the nineteenth century, Blacks began to make some strides by enrolling in White colleges in the North and later at 
institutions created for the purpose of their education. Delany (1968) provided an inventory of colored students enrolled in colleges in 1852 , who at that time were pursuing professional preparation in law, theology, medicine and homeopathic medicine. All of these pursuits were taking place at Northern colleges. The first institutions of higher education designed to serve Blacks sprouted in the North: Avery College in Allegheny, PA (1850), Ashmun Collegiate Institute (1856) which became Lincoln University in Pennsylvania in 1865 - and Wilberforce University in Xenia, OH (1856) (United States Commission on Civil Rights, 1960).

In 1862, states received the first form of federal aid to promote higher education by means of the first Morrill Act, which awarded states and territories public lands to be utilized or sold for

the endowment, support, and maintenance of at least one college where the leading object shall be, without excluding other scientific and classical studies, and including military tactics, to teach such branches of learning as are related to agriculture and the mechanics. (Morrill Act, 1862, Ch. 130, Sect. 4)

The Morrill Act of 1862 is credited with the establishment of many state universities currently known as land-grant institutions.

Also in 1862, President Abraham Lincoln issued the Emancipation Proclamation and in 1865, the XIII Amendment ended and prohibited slavery. The educational needs of millions of ex-slaves were to be served by segregated public elementary and secondary school systems established in the South and Border states. The need for Black school teachers became evident and state supported Normal schools opened in Missouri (1870), Alabama and Arkansas 
(1873), North Carolina (1877), Texas and Louisiana (1879), Virginia and Florida (1887) (United States Commission on Civil Rights, 1960).

Higher education for Blacks was also a concern of the federal government and the second Morrill Act of 1890 expanded funding to benefit Black students with training in agriculture and mechanical arts. The Act stated that no monies should be spent

for the support and maintenance of a college where a distinction of race or color is made in the admission of students, but the establishment of such colleges separately for White and colored students shall be held to be a compliance with the provisions of this act if the funds received in such State or Territory be equitably divided. (7 U.S.C. Chapter 841, Section 1)

With this wording, the Second Morrill Act opened doors of educational opportunity for Blacks and at the same time aided in the perpetuation of a segregated system of higher education. Today there are 106 colleges and universities designated as 1890 Land Grant Colleges; 18 of those are Historically Black Colleges and Universities that owe their existence to the funding provided by this act (APLU, 2009).

The integration into society of freed Blacks following the Civil War was not an easy process for the states or the nation. Differing ideologies on an integrated society emanated from the minds of thinkers and politicians, both Black and White. This conundrum of how two peoples were to become one was labeled "the Negro Problem," and it became an umbrella concept under which many authors couched their writings on race relations in the United States during the period of Reconstruction. In 1903, a collection of essays by Black thinkers of the day, including Booker T. Washington, W. E. B. DuBois, Paul Laurence Dumbar 
and Wilford Smith, among others, was published under this rubric. The Negro Problem contains essays on education, legal status, political disfranchisement, and a compilation of the names and accomplishments of noteworthy American Blacks at the turn of the century. Education became a pivotal aspect of the solution to the "Negro problem" and to that end, many philanthropic and religious organizations from the North contributed to the establishment of private colleges in the South (United States Commission on Civil Rights, 1960).

The Negro Colleges: Making up for Lost Time, 1890-1960

Some authors credited the Freedmen's Bureau with having great influence over the educational situation of Blacks in the South (Drewery \& Doerman, 2001; Moore, 2003); others credited Northern enterprises (Pifer, 1973). Roebuck and Murty (1993) characterized the establishment of educational facilities for Blacks as the result of a multi-party effort: "the Freedmen's Bureau (which functioned until 1870), Northern missionary societies, and the freedmen themselves laid the foundation for the major colleges and universities" (p. 25).

As the number of Negro colleges increased, so did the arguments over what type of education they should dispense. The dichotomy was established early on between those who felt freed African-Americans would be best served by vocational education and those who saw liberal arts education as the only road for uplifting the race. In the telling and retelling of the history of education of Blacks in the United States, these two divergent points of view have been personified by the industrialist, Booker T. Washington, and the liberal educationalist, W. E. B. DuBois. 
For Washington (1901), the uplifting of the Negro race was to be a slow and gradual process that would require the sacrifice of the present generation for the benefit of future ones.

[M]y theory of education for the Negro would not, for example, confine him for all time to farm life - to the production of the best and the most sweet potatoes- but that, if he succeeded in this line of industry, he could lay the foundations upon which his children and grandchildren could grow to higher and more important things in life. (p. 203)

Washington's life as an educator was inextricably intertwined with Tuskegee Institute where he served as Principal from 1881 until his death in 1915. During his tenure, Tuskegee became a model for industrial education. Students at Tuskegee grew their own produce, cared for chickens and cows, built their own buildings, made brick, and had to keep their place and their bodies immaculate. Washington (1901) felt that the future of his students and Blacks in general was gravely dependent on their perceived contribution to society.

I think that the whole future of my race hinges on the question of whether or not it can make itself of such indispensable value that the people in the town or the state where we reside will feel that our presence is necessary to the happiness and well-being of the community. (p. 282)

Washington received most of the funding for Tuskegee from Northern philanthropists and rose in social and political notoriety in Black and White circles. At the beginning of his Northern incursions he was happily surprised by the absence of segregated practices (Washington, 1901) but felt it necessary to maintain them at Tuskegee (Moore, 2003). The philosophy of race relations prevalent at Tuskegee and other Negro colleges that favored industrial education echoed the ideas of Thomas Jesse Jones, a Welsh immigrant, who "contributed 
to the 'solution of the Negro question' by promoting continued subservience, accommodationism, gradualism, and the promise for a better tomorrow" (Watkins, 2001, p. 107).

W. E. B. DuBois, on the other hand, espoused a belief that within the Black community, a select group of educated leaders would rise and uplift the rest through their guidance. This group he deemed the "Talented Tenth." In a tone of manifesto, DuBois (1903) stated his perceived solution to the "Negro question:"

Men of America, the problem is plain before you. Here is a race transplanted through the criminal foolishness of your fathers. Whether you like it or not the millions are here, and here they will remain. If you do not lift them up, they will pull you down. Education and work are the levers to uplift a people... The Talented Tenth of the Negro race must be made leaders of thought and missionaries of culture among their people. No others can do this work and Negro colleges must train men for it. The Negro race, like all other races, is going to be saved by its exceptional men. (p. 403)

The sentiments of DuBois were shared by other Black leaders of his time. Writers of the Cleveland Gazette and the Washington Bee encouraged their readers to relegate the industrial training to a secondary role and focus on the education of doctors, lawyers, and other professionals (Anderson, 1988a).

Throughout his career, DuBois saw the place of the public Negro university as a unique and indispensable catalyst in American race relations. Speaking at Lincoln University of Missouri in 1941, DuBois warned its administrators against trying to become another University of Missouri and against falling into small thinking and nepotism. Thus spoke DuBois at Lincoln University on the occasion of its $75^{\text {th }}$ anniversary: 
You have an extraordinary opportunity, not so much for social imitation and social conflict, but rather for social invention, for planning and carrying through methods by which, without hatred, agitation or upheaval you can show how a minority cannot simply repeat the accomplishments of the majority, but can show the majority the way of life...

But for this, Lincoln will need freedom and funds. It will need to be administered by men [sic] of large vision who think of this school not as a temporary make-shift or as a place where their relatives get positions or their firms sell goods, but rather as a center where the cultural outlook of this country is to be changed and lifted and helped in the reconstruction of the world. (DuBois, 1941, p. 136)

The dichotomy between vocational and liberal education is one of the topics in the conversation about education in general and specifically as it pertains to the mission and purpose of HBCUs. Other aspects include access and attainment, persistence and socialization of Blacks through higher education.

DuBois manifested concern for the type of education Blacks were receiving at so called Negro colleges and in his study, The College-Bred Negro (1900) sought to determine which Negro institutions could really be considered colleges when their entrance requirements were measured against the Carnegie units. The study also sought to determine the social condition of Negro college graduates. A follow up study (DuBois \& Dill, 1910) continued this exploration and produced a three-tiered ranking based on the number of students who, at admission, had completed 14 or more Carnegie units of entrance requirements. Surveys of Negro college graduates were used to collect demographic data and information about their social economic and political status and philosophical views on the condition of the Negro race in America. Following the study, recommendations were made for increasing the number of Negro college 
students; increasing funding; establishing public Negro high schools in the South; increasing the time allocated to the study of natural science, English, history and sociology; decreasing time spent on Greek and Latin; and using vocational education as a supplement to cultural training.

In 1917, the industrialists had their voice heard in Thomas Jesse Jones' publication Negro Education. The study provided enrollment and graduation figures and advocated for Northern philanthropy, industrial education and collaboration of Negro schools and the South by means of adaptation to the needs of the community. This study received mixed reviews among Negro educators. DuBois (1918) characterized it "as a dangerous and in many ways unfortunate publication" (p.161), and an editorial by T. E. McKinney (1948) in the Quarterly Review of Higher Education Among Negroes credited the Jones report with awakening the officials of Negro colleges and setting a standard of performance that had been absent until that time.

In 1925 the Association of Colleges for Negro Youth set out to plan a rating system for Negro colleges and with the help of the Phelps-Stokes fund the Survey of Negro Colleges and Universities (1928) was published by the Bureau of Education. It contained information compiled through cooperation with 79 colleges and the State Departments of Education of 19 states (McKinney, 1948). Johnson (1938) conducted a study to better understand the educational condition of Negro students during the period following the Civil War and into the first thirty-six years of the twentieth century. According to his findings, there were 31,090 academic degrees conferred to Negro graduates between 1826 and 
1936. Of those, 25,697 were awarded by Negro institutions and 5,393 were awarded by Northern colleges; 26,283 were awarded between 1914 and 1936 . By 1936, Northern colleges had awarded the majority of masters' degrees and all the doctoral degrees. Negro institutions had conferred most bachelors' degrees and a large portion of all professional degrees. Johnson's (1938) examination of the number of Negro graduates showed that in comparing the number of graduates in 1914 to those in 1936 , the numbers had risen by $495.8 \%$ at Northern schools and by $602.4 \%$ at Negro schools; yet, in 1940, only 2 per cent of Blacks aged 25-29 had graduated from college (Drewry \& Doermann, 2001). Landmark Higher Education Legal Cases Prior to 1954

Although access to college increased exponentially for Blacks during the first half of the twentieth century, their access to professional education was marked by obstacles and court battles. According to the 1939 study Graduate Instruction for Negroes in the United States, conducted by Fred Mc Cuistion, "only seven Black colleges in America offered any graduate work whatsoever; nine Southern states had no provision whatsoever for Black graduate education" (In Levy, 2004, p. 69). The fight to open doors of professional education for Blacks is illustrated by the following four landmark Supreme Court Cases and one Maryland case that paved the way for desegregation in higher education. In 1935, Donald Murray, a graduate of Amherst College of Massachusetts, was denied entrance to Maryland Law School since the state had no law school for Blacks. The National Association for the Advancement of Colored People (NAACP) took on his case and the Baltimore City Court ordered that Murray be 
admitted to the law school. The state appealed but the decision was upheld and Murray was admitted to the law school because the scholarship system that Maryland had created to send Black students to attend college in other states had never been funded by the legislature and Maryland was unable to provide for the costs of travel and living far from home (Levy, 2004 ).

The first Supreme Court case challenging a state's refusal to admit a Black student to professional school was that of Lloyd Gaines (Gaines v. Canada), a Lincoln University graduate, who filed suit to attend law school at the University of Missouri. The trial court and the court of appeals sided with the state's segregated system. In 1938 Gaines' case went to the Supreme Court. The lower court's decision was reversed and the state was mandated to admit Mr. Gaines to the law school at the University of Missouri (Levy, 2004). This case set the precedent for the states being required to offer uniform education within their borders to all their citizens, even if on a separate basis. The Gaines decision effectively moved Black colleges into the mainstream of American higher education as they began to be compared against the measure of the traditionally White universities (Trent, 1959).

In the spring of 1946, Ada Lois Sipuel Fisher presented herself for admission to the University of Oklahoma Law School. Her admission was denied on the basis of her color.

In 1941, Oklahoma [had] passed statutes that made it a misdemeanor to admit Blacks into White schools, a misdemeanor to teach in a classroom that contained both Whites and Blacks, and a misdemeanor to be a student in such a mixed-race classroom...On November 7, 1945, the University of Oklahoma's Board of Regents directed President George Lynn Cross 'to refuse 
to admit anyone of Negro blood as a student in the University' (Levy, 2004, p. 74).

President Cross, at the request of Sipuel's legal counsel, crafted a letter stating that he had reviewed all of her credentials and was denying her admittance solely on the grounds of her race. With this document, the case went in front of county and state courts where her request was rejected. With Thurgood Marshall as her lawyer, the case was taken to the United States Supreme Court, which ruled unanimously that the Equal Protection Clause of the Fourteen Amendment required Oklahoma to make law instruction available to Blacks and do it as readily as it did for other groups (Sipuel v. Board of Regents, 1948). Because this Supreme Court decision failed to address the issue of segregation, Oklahoma responded by establishing, in less than a week, the Langston University School of Law. Sipuel, unimpressed by the state's efforts, returned to county court which sided with the schools, and then again to the U.S. Supreme Court where the outcome of two other cases would bring remedy to Ms. Sipuel's plea.

Mr. George W. McLaurin' (McLaurin v. Oklahoma) sought to pursue a doctorate in education at the University of Oklahoma. Because of the ruling in Sipuel, the University's Board of Regents would have been forced to offer the program for Blacks or discontinue it for its White students. In an effort to comply with the ruling and still maintain racial segregation, the university administration was told to hold all of McLaurin's classes in the same room, where he would seat in an anteroom where he could see and hear what was going on in the classroom, but remain separated from Whites. A desk was placed in the library 
with his name on it, only to be utilized by him; he was to eat by himself and was assigned his own toilet (Levy, 2004).

A very similar case was unfolding in Texas where Heman Sweatt had been denied admission to the state law school and provided with a poor substitute. Both cases were heard by the U.S. Supreme court on April 4, 1950. The NAACP attorneys decided to challenge, for the first time, the constitutionality of racial segregation and stated that the "separate but equal" doctrine that emerged from Plessy v. Ferguson was wrong. Although the cases were decided in their favor, the court refused to take into consideration the racial segregation issue and in delivering the opinion of the court, Chief Justice Vinson stated:

Broader issues have been argued for our consideration, but we adhere to the principle of deciding constitutional questions only in the context of the particular case before the Court. We have frequently reiterated that this Court will decide constitutional questions only when necessary to the disposition of the case at hand, and that such decisions will be drawn as narrowly as possible...Because of this traditional reluctance to extend constitutional interpretations to situations or facts which are not before the Court, much of the excellent research and detailed argument presented in these cases is unnecessary to their disposition. (Sweatt v. Painter, 1950)

The issue of segregation would not be addressed by the Supreme Court until 1954 when it deliberated on Brown v. Board of Education. Increased Access to Education

While some Blacks were seeking remedy to their marginalization through the courts, others were gaining access to higher education through the GI Bill following World War II. It is an accepted fact that the Gl Bill contributed immensely to the professional development and financial attainment of returning 
soldiers. The bill was written to provide benefits for all veterans regardless of race, but the reality encountered by Blacks upon their return was that segregation was still the law of the land in most of the United States. Schools, housing and hospitals remained segregated after World War II. The bill has been credited with erasing the historical elitism of higher education, but it was not enough to combat deep-rooted racial segregationist practices (Herbold, 1994). These practices prevented Black students from enrolling in many White universities and made it difficult for Black colleges to absorb the increased numbers which grew by over $55 \%$ from 1940 to 1950 . Black colleges were forced to turn away prospective students or place them on waiting lists (Olson, 1982).

In 1954, Brown v. Board of Education changed the way in which the United States spoke about desegregation and integration in its public schools as the doctrine of "separate but equal" could no longer be applied to public education (Brown v. Board of Education, 347 U.S. 483, 1954). Although decided on the basis of a K-12 case, the publicly stated end of segregation in education marked a new chapter in the educational condition of Blacks in the United States.

\section{A Racially Integrated System of Higher Education 1960 - Present}

Following the 1954 Supreme Court decision in Brown, the scholarship on the education of Blacks in the United States had to take into account that regardless of desegregation efforts in higher education, some Blacks would continue to enroll at Historically Black Colleges and Universities (HBCUs), while others would enroll at Historically White Institutions (HWIs), and that some 
HBCUs would open their doors to White students. This section looks at studies conducted on each of the above mentioned categories.

Black Students at Historically Black Colleges and Universities

A Historically Black College or University (HBCU) is defined by the Higher Education Act of 1965 as "... any historically Black college or university that was established prior to 1964, whose principal mission was, and is, the education of Black Americans, and that is accredited by a nationally recognized accrediting agency or association..."( 20 U.S.C. 1061, Sec. 322). Black colleges have been credited with uplifting the socio-economic condition of Blacks in the United States, and more specifically with the emergence of a "Black middle-class community" (Gurin, 1975, p.27), a Black bourgeoisie leading a break from the status quo for Blacks in the United States. Brown and Davis (2001) saw the gains made by Black graduates from Black colleges in terms of the economic ties that aid them in their post-college years. Gurin (1975) and Foster (2001) argued that not all Black colleges produced this desirable result of socio-economic uplift. Both authors continued the discussion on vocational versus liberal education, as it was the latter that produced the above mentioned Black bourgeoisie. According to Gurin (1975), the most prestigious and selective liberal schools, founded mostly by religious missions, "catered to the 'better classes' within the Black population...the children of Free Negroes or the more advantaged of the slave community, the house slaves" (p. 27). Foster (2001) acknowledged the contributions of most selective HBCUs and denounced the survival of minimally selective and open admission HBCU's as part of a 
conspiracy that began 135 years ago [and] continues today. Funding ineffective Black colleges keeps the industrialist mentality of the $19^{\text {th }}$ century alive; it continues to allow the Black accommodationists to receive money, to reward friends, punish enemies and tenaciously hold on to missions which support the victimization mantra 'you can't expect descendants of slaves to excel because 135 years later the effects of slavery still linger'(p.24).

The ill sentiment toward accommodationists and industrial educators in the South was also harbored by Dennis (2001) who saw Southern Black universities as a protective shield of White supremacy:

Progressive educators wanted to transform the social order from one mired in poverty and racial conflict to one built on industrial productivity and racial harmony. Central to their scheme for a New South, however was an insidious program of social engineering and racial control. Cloaking their ideas in the language of objectivity and evangelical uplift, they clouded the elements of coercion and racism inherent in progressive education. Southern higher education became entangled in the cross-sectional crusade to educate Blacks in subservience. Its history was inseparable from the chronicle of the Jim Crow South.

On the other hand, Roebuck and Murty (1993) saw a commonality among HBCUs regardless of their original industrial or liberal arts leanings. In their view, "HBCU's, unlike other colleges, are united in a mission to meet the educational and emotional needs of Black students" (p. 10). The authors go on to list the six specific goals for HBCU's as citing Walters (1991),

(1) to maintain the Black historical and cultural tradition (and cultural influences emanating from the Black community) by preserving and acting as a repository of material records and by encouraging scholarly accomplishments of Black professors in teaching about and researching the Black condition; (2) to provide key leadership in the Black communities because college administrators, scholars, and students have an important social role to play in community affairs (the HBCU functions as a model of social organization and contributes to the resources needed for the expansion of Black community activities); (3) to provide an 
economic function in the Black community (HBCUs often have the largest institutional budget within the Black community which involves the acquisition of funds, the distribution of these funds to workers and their families and to small businesses, and the investment of these funds in economic institutions); (4) to provide Black role models in the Black community who can interpret the way in which social, political, or economic dynamics at the general society level impact on Black people; (5) to produce graduates with special competence to deal with the problems within the minority and majority population groups; and (6) to produce Black agents for specialized research, training and information dissemination in dealing with the life environment and other minority communities. (p. 10)

The above mentioned goals for HBCUs seem to take the academic aspect of a college education as a given, but may be the reason why Pasacrella and Terenzini's (2005) meta-analysis of research conducted during the 1990's on how students are affected by their college experience indicated that the modestly superior persistence of African-American students at HBCUs had more to do with the HBCUs social support mechanisms than with differences in the academic standards of HBCUs and HWls. Their analysis also found that HBCUs enhanced African-American students' professional aspirations and their desire to enroll in graduate studies.

These findings are consistent with those of Brown and Davis (2001) who categorized HBCUs as the embodiment of America's social contract with the freed slaves following the Civil War and saw their place in American education today as "purveyors of social capital" (p. 4). These authors argued that in the predominant society, families and their networks decode and transmit social capital, but in the Black community, that role is expected to be fulfilled by the HBCUs. In addition, these schools have in place a network of agents that 
"identify, negotiate and transmit resources...that purchase opportunities for the accomplishment of HBCU's collective agenda-the educational development and attainment of African-Americans" (Brown \& Davis, 2001, p. 5).

Most research on Blacks in higher education prior to the Civil Rights Movement of the mid 1960s was conducted by the government and philanthropic foundations. Most of this research was also conducted at Black colleges given that most Black students at the time attended those colleges. In 1960, the United States Commission on Civil Rights produced a report entitled, Equal Protection Under the Law in Higher Education. Its main purpose was to look at the state of discrimination against Blacks in admission to colleges and universities, with special attention to institutions located in Southern and Border States. The commission also took a historical look at federal laws and policies and declared that "this study of Federal laws reveals that the Federal Government has been deeply involved not only in the initial establishment but in the growth and development of the system of racial segregation in higher education in the South" (p. xv). The report provided information on voluntary and non-voluntary compliance of desegregation mandates, the arrival of Black students at White campuses, desegregation of Negro colleges, discriminatory admission practices throughout the nation, the state of Black students at White and Black institutions, financial aid, a summary of problems, and recommendations. Among the recommendations, the Commission proposed the denial of federal aid to any institution that discriminated on grounds of race, color, religion or national origin. The Commission's report further recommended that states create a system of 
remedial education for students who are "handicapped professionally or scholastically as a result of inferior educational opportunity and training" (United States Commission on Civil Rights, 1960, p. 271).

Another seminal study on the condition of Black students during the 1960s was completed by McGrath (1965) under the auspices of the Carnegie Corporation of New York. For this study, McGrath focused on the existing 123 Negro colleges and examined their curriculum, facilities, faculty and administration, libraries, costs and admission policies and orientation and improvement programs. McGrath concluded that the Negro colleges that constituted $3 \%$ of the nation's colleges, educated over half of the Black students. These students were found to be "less well prepared for college work than those in the other colleges" (p. 157), and their families were less financially prepared to meet the costs of higher education (McGrath, 1965). The institutions themselves were poorly funded, required to offer remedial education, lacked in the research efforts of their faculty, and had outdated and inadequate physical structures and poor libraries (McGrath, 1965). Research on Black colleges by other scholars yielded similar findings with regard to the disadvantaged economic condition of Black students (Jaffe, Adams, \& Meyers, 1968) and the students' lack of preparation for collegiate level work (Jencks \& Riesman, 1967; Jaffe, Adams, \& Meyers, 1968).

Another government study (Fichter, 1967) published by the National Institutes of Health and was titled Graduates of Predominantly Negro Colleges Class of 1964. This retrospective study focused on "how the Negro graduate 
view[ed] his academic training, his hopes for graduate study and employment, and his career aspirations" (p. III). The study also provided background information on family, place of origin, economic status, views on societal issues, the place of Black women in education and society, and pre-college preparation. This study affords the reader a glance at the graduates of Negro colleges in 1964 and the opportunity to draw comparisons with today's students at HBCUs.

During the 1970s studies on Black students at HBCUs continued to look at the socio-economic condition, pre-college preparation and political views of Black students attending Black colleges and universities. Many researchers confirmed that Black students attending HBCUs came from families with lower financial status (Bowles \& DeCosta, 1971; Brimer, 1971; Gurin \& Epps, 1975; National Advisory Commission on Black Higher Education and Black Colleges and Universities [NACBHEBCU], 1979; Thompson, 1973). The studies looking at Blacks' preparation for college level work in the 1970s took for a fact that HBCUs had always dealt with the poor preparation of their students and began to look at programs developed to meet that challenge. Researchers looked at the curricular innovations taking place at $\mathrm{HBCU}$ and found that most colleges were involved in novel ways to meet students' needs including off campus study, remedial programs, freshman seminars and such. (Calbert \& Epps, 1975; McBay, 1978; Roundtree, 1978; Smith 1978; Thompson, 1978). A comprehensive study of the educational conditions for Blacks was also completed by the Institute for the Study of Educational Policy at Howard University in 1976. This study examined the existing data on Blacks in college and found that they were not accurate or 
soundly utilized. The study also looked at issues of access, distribution, persistence, the impact of a college education on income for Blacks, barriers to attaining a college education and the federal legal landscape as it pertained to equal access to education. The values and political ideologies of Black students were of interest to other researchers (Taylor, 1976, 1977; Yankelovich, 1972) as the nation dealt with issues of racial integration, shared power and the uplifting of the race by individual achievement (Gurin \& Epps, 1975).

By the mid 1970s the majority of Black college students attended predominantly White institutions. The 1980's were marked by a resurgence of the discrimination debate in higher education as the Adams v. Richardson case was filed against the Office of Civil Rights and the Department of Health, Education and Welfare for failing to enforce Title VI against the state of North Carolina (Brazziel \& Brazziel, 1987; Malaney, 1987; Pruitt, 1987). The Adams case was noteworthy because for the first time, the courts publicly recognized the unique contributions of Black colleges to American higher education (Ware, 1994). Other studies on the social condition of Black students reinforced the notion that overall, Blacks had limited access to higher education (Thomas \& Braddock, 1987) and Black students faced greater attrition rates, lower progression and performance rates (Nettles, Thoeny \& Gosman, 1986, 1987), but that attending HBCUs afforded Black students a more supportive environment that improved their adjustment to academic demands (Fleming, 1981, 1984; Nettles, Thoeny \& Gosman, 1986; Willie \& Cunnigen, 1981). Other studies found that Black students displayed greater persistence when enrolled at HBCUs (Astin, 1975b; 
Cross \& Astin, 1981) and Brazziel's (1983) inquiry into the college of origin of most Black doctoral candidates in the latter part of the 1970 s yielded that a great majority of them had graduated from HBCUs. Other researchers concluded that attending an $\mathrm{HBCU}$ had a positive effect on the academic attainment of Black students (Anderson, 1988a; Thomas \& Gordon, 1983). This positive effect held true for Black women also (Pascarella, Smart, \& Stoecker, 1989).

With most Black students attending HWls, some researchers began to examine why Black students would continue to self-segregate and attend an HBCU. Some students chose these colleges because of lower tuition costs (Gray, 1993) and others because they wanted to avoid the social challenges present at predominantly White institutions (Feagin, Vera, \& Imani, 1996). Allen and Haniff (1991) found that Black students at HBCUs performed better academically than Black students at HWIs, and Jackson and Swan (1991) found that Black students at HBCUs were more self-reliant as they tended to solve their own problems instead of relying on family or institutional resources. A study conducted by Constantine (1995) found a positive effect of attending an HBCU on the future wages of Blacks who had graduated from these colleges in the early 1970 s.

Baker and Velez (1996) examined the access and opportunity afforded to Black students in American higher education through a compilation of research comparing educational achievement at HWls and HBCUs and surmised that although racial integration at HWIs had significantly expanded academic opportunities for Blacks, HBCUs continued to fulfill a unique and important 
mission in serving the educational needs of Black Americans. When compared to African-Americans attending HWls, Black students at HBCUs reported higher levels of satisfaction with their involvement in the campus community, student-tostudent interaction, and opportunities to develop leadership skills (Outcalt \& Skewes-Cox, 2002). Other researchers found that students at HBCUs often referred to their campus with allusions to family and supportive environments (Bennett \& Xie, 2003; Fries-Britt \& Turner, 2002).

HBCUs have faced many challenges throughout their history and in the last decades they have dealt with legal challenges to their racial composition (Jones, 1993). The push for racial integration of HBCUs is more of an issue for publicly funded colleges and universities whose missions must embrace all the students of the state (Taylor \& Olswang, 1997) even if all the students of the state are not ready to be embraced. This is illustrated by the case of Alcorn University in Mississippi which has reached well beyond the boundaries of the state to comply with the mandate of $10 \%$ non-African-American enrollment postulated by Mississippi's desegregation settlement. Alcorn state now enrolls a significant number of international students and plans to tap into the expanding Hispanic-student market. According to then president Clinton Bristow Jr., these students "are not entrenched in the kind of racial issues and history that has plagued the citizens of the state" (in Hebel, 2005, p. A33).

At the dawn of the $21^{\text {st }}$ century, the conversation on Black students at HBCUs deals more and more with the institutions themselves. Questions are raised about their current purpose and researchers examine the past and 
possible future for these institutions. The percentage of Black students served by HBCUs amounted to $12 \%$ in 2002 , yet Blacks were more than twice as likely as Hispanics to attend an institution where they made up at least $80 \%$ of the total enrollment (12\% vs. 5\%) (The Condition of Education, 2005).

Studies on HBCUs and their service to Black students touched upon some recurring themes. Allen and Jewell (2002) provided a historic view of where these institutions came from and offered commentary on their present and future condition. Price (2000) revived the call for liberal education for Blacks as he found that "the apparent uniformity of a vocational academic curriculum among virtually all HBCUs is detrimental to the progress of the traditional constituency served by HBCUs- Black Americans" (p. 100). Mykerezi and Mills (2004) studied the role of HBCUs in rural communities and found that in those communities in particular, HBCUs continue to be the only means of educational and thus economic advancement for Blacks.

Black Students at Historically White Institutions

The arrival of Black students at HWls marked the advent of intergroup contact in the higher education arena. As outsiders being allowed entrance, Blacks were expected to adhere to the mores and values of the receiving institution. The contact has not always been smooth.

During the early 1960s reports on Black students at predominantly White institutions focused on the numbers enrolled at publicly founded universities in border and Southern states and these institutions' compliance with mandates against racial discrimination (United States Commission on Civil Rights, 1960). 
Missouri exemplifies the unfolding of desegregation in border and southern states. Two private institutions, St. Louis University and Washington University, admitted Black students during the late 1940's but the state university did not admit Black students until 1950 when it was ordered to admit scholastically qualified Blacks to its graduate schools if the subjects they wanted to study were not immediately available at Lincoln University, the Negro state school (Greene, 1959). Desegregation of higher education in Missouri truly began to unfold after 1954. By 1959, all HWIs in the state were enrolling Black students, but only Harris Teachers College had Black faculty members (Greene, 1959).

Today, most African-American college students in the United States attend predominantly White institutions (Allen, 1992; Bowles \& DeCosta, 1971) and a diverse student body is a given at most historically White institutions (Menand, 1997). Nonetheless, Black students' access and attainment in higher education are issues that continue to capture the attention of researchers and many of the studies on these topics are being conducted at HWls. Lack of participation was deemed "the greatest problem of the Negro community with respect to higher education" (Bowles \& DeCosta, 1971, p. 215). This lack of participation was exacerbated by the fact that the trend toward racial integration in higher education during the 1970s began to decline in the mid 1980's (Deskins, 1991; Dickerson \& Jacobs, 2006). Bowen and Bok (1998) found that Blacks lagged behind in numbers at selective institutions and Karen (1991) found that the number of Blacks at Ivy League schools had dramatically declined from that of the 1960s and 1970s when programs were set in place to promote 
opportunities for Blacks and other minorities. Deskins (1991) characterized as "catastrophic" (p. 37) the Black losses in degree attainment during the decade of 1974 to 1984 . His concern was echoed by Trent (1991) who, looking at the tabulations of degrees conferred during 1975 -1976 and 1980-1981, found a trend toward "the feminization of education among Blacks" (p.59). The numbers of Black males in college continued to slip and in 1994, the matriculation of Black males in postsecondary institutions had dropped from $4.6 \%$ in 1976 to $4.1 \%$ in 1994 (Nettles \& Perna, 1997).

One of the most studied issues related to Black students attending predominantly White institutions is persistence. Persistence was found to be less for Black students attending HWls than for those attending HBCUs (Astin, 1975a, 1975b; Cross \& Astin, 1981; Pascarella, Smart, Ethington, \& Nettles, 1987). Social adaptation of Black students attending predominantly White institutions has been found to be a determining factor on the persistence of those students (Fleming, 1981, 1984; Gruber, 1980; Loo \& Rolison, 1986; Pfeifer \& Sedlacek, 1974). Smith and Allen (1984) developed a predictive model for academic and social outcomes for Blacks attending HWls by identifying institutional and student related factors particular to this population. Their model responded in part to classical models that provided little specific predictors for the educational attainment of Blacks and studies that suggested some traditional aspects of classical models had no applicability to understanding the condition of Blacks in higher education (Epps, 1981; Gurin \& Epps, 1975; Tinto, 1975). A recently proposed model of social adaptation is "irrelation" (Sims, 2008). The author 
studied the social constructs of Black women at a predominantly White college and found that they neither felt to be in a state of isolation or marginalization, but rather in a state of "irrelation" which the author describes as being "analogous to the relationship two strangers may have as they sit together on a city bus" (Sims, 2008, ๆ 5). The author further suggested that this state of disconnection did not prevent the students from remaining at the college and graduating.

A typology of Black students attending a predominantly White campus was proposed by Jackson and Swan (1991) who examined a sample of 1,580 Black college students distributed among HBCUs and HWIs. Jackson and Swan found that both male and female Blacks attending HWIs came from families where both parents had higher levels of education and occupation; had higher high-school GPAs; and were more reluctant to participate in campus activities. They also found that Black students at HWIs relied more on family for financial support, while Blacks at HBCUs tended to rely more on institutional resources. Fischer (2007), in her study, found a different type of African-American student enrolled at HWls: first-generation to pursue higher education and also more likely to be from a lower socio-economic background than their White peers.

The social situation of Blacks at predominantly White institutions has received the attention of agencies and researchers alike and most of those studies focused on the social challenges that Black students confronted at HWls. The U.S. Commission on Civil Rights reported in 1967 that Black students who attended HWls enjoyed participation in predominantly White groups and societies and students attendance at athletic events. The report further stated that most 
HWIs enrolling Blacks in the late 1960s found it a challenge to find them housing and facilitate acceptance of them in the neighboring business communities. Willie \& McCord (1972) found that Black students spent significant time and energy discussing the issue of racial discrimination, while for White students this was a non-issue. Pascarella and Terenzini's (1991) first review of twenty years of research revealed that "Black students who attend predominantly White colleges and universities experience significantly greater levels of isolation, alienation, personal dissatisfaction, and overt racism than their counterparts at historically Black institutions" (p. 381).

More recently, a comparison of how campus racial climate affects Black and White students revealed that perceptions of racial tension in the forms of prejudice and discrimination had a negative effect on persistence into the second year for both White and non-White freshmen (Cabrera, Nora, Terenzini, Pascarella, \& Hagedorn, 1999; Eimers \& Pike, 1997; Zea, Reise, Beil, \& Caplan, 1997). Yet various studies confirm that White students, for the most part, remain unaware of the challenges faced by Black students (Davis, Dias-Bowie, Greenberg, Klukken, Pollio, Thomas, \& Thompson, 2004; Phillips, 2005; Sedlacek, 1999) and that race prejudice and race-relations issues are far more salient for Blacks than they were for Whites (Dinka, Mazzella, \& Pilant, 1980). Judd, Park, Ryan, Brauer, \& Kraus (1995) attributed this difference to the way White children are socialized to ignore racial differences and refrain from stereotyping Blacks, while the socialization of Black students highlights their belonging to a particular group and the differences between that group and 
others. Even when compared to other minority groups such as Hispanics and Asians, African-American students report experiencing more differential treatment than do members of the other minority groups (Suárez-Balcazar, Orellana-Damacella, Portillo, Rowan \& Andrews-Guillen, 2003). Black students tend to perceive campus activities as designed for Whites. Fries-Britt \& Turner (2002) found that African-American students perceived the efforts of HWls to provide ethnically-appropriate social events as patronizing or as an effort to impress potential Black students "during critical recruitment periods" (p. 322). In the same study, though, some students expressed that the lack of social activity for Blacks translated into greater commitment to their studies and fewer distractions. Fischer (2007) found that, in general more significant involvement in formal activities on campus translated into greater satisfaction with the college experience and greater academic success for African-American college students.

Black students at predominantly White campuses continue to perceive negative attitudes and unfair treatment from White faculty (Allen, Bobo, \& Fleuranges, 1984; D’augelli \& Hershberger, 1993; Davis et al., 2004; Jay \& D’augelli, 1991; Sedlacek, 1999; Singer, 2005; Smith, 1980; Suárez-Balcazar et al., 2003). African-American students feel disenfranchised and misunderstood when they realize that on White campuses their beliefs are not consistent with majority opinions (Fries-Britt \& Turner, 2002). Some students were made to feel inferior when their English patterns were characterized as Black English because in doing so the instructor assumed the position that White English is the standard and therefore superior (Feagin, 1992). Feagin and Sikes (1995) reported that the 
Black students who participated in their study felt that White professors failed to see them as individuals instead of representatives of their racial group, that White professors did not understand and hence did not value work that projected a Black viewpoint or related to Black experiences. When Black students were asked how they would expect to be treated by faculty, they expressed a desire to be treated with respect and be seen as valued members of the university community (Dinka, Mazzella, \& Pilant, 1980; Feagin, 1992; Fries-Britt \& Turner, 2002). That value would be communicated by professors providing feedback and reinforcement (Feagin, 1992, Daniel, 2007).

Other studies have looked at the interactions between White and Black students and reported that Black students felt their White peers were uneasy around them (Peterson, Blackburn, Gamson, Arce, Davenport, \& Mingle, 1978), others found that White students held deeply rooted negative stereotypes about Blacks (Dinka, Mazzella, \& Pilant, 1980; Feagin \& Sikes, 1995). On many campuses, Black students were exposed to racist jokes (Feagin, 1992; Feagin \& Sikes, 1995); racist slurs and graffiti (Feagin, 1992; Davis et al., 2004); and witnessed fraternity parties and parades with racist themes (Feagin, 1992). Racism on campus is evident to Black students at HWls in the form of microaggressions or unconscious utterances that convey a feeling of White superiority (Solórzano, Ceja, \& Yosso, 2000) the authors found that Black students perceived microaggressions both in the academic and social realms of the campus. Sometimes hostility toward African-Americans takes on a more graphic form. Since September 2007, nooses have been found at Columbia 
University in New York, University of Maryland, and at the Coast Guard Academy in Connecticut where there were two separate incidents (Nealy, 2007). The latent feeling of overt and subtle discrimination often causes Black college students to self-segregate (Feagin \& Sikes, 1995; Gosset, Cuyjet, \& Cockriel, 1998) and this exacerbates cultural alienation resulting from "cultural domination of White, middle class values...[and] ...ethnic isolation resulting from being a small proportion of the student body" (Loo \& Rolison, 1986, p. 64). As a result, AfricanAmerican students at HWls often develop a negative perception of campus climate as "racist, hostile, and disrespectful" (Rankin \& Reason, 2005).In some instances, Black college students at HWls feel alienated even from other Blacks (Davis et al., 2004). Through the study of a group of African-American women on a predominantly White campus, Sims (2008) derived a new social construct for intergroup relations. He deemed it

irrelation [which] is characterized by having neither positive nor negative relationship with others in daily social interactions or by having relationships that are defined by the environment (a classroom setting) or by gender or racial groupings (the 'Black' table in the student union). [With the end result being] lack of social communication and interactions between groups ( $\$$ 5)

The barriers encountered by Black college students as they seek to develop a sense of belonging at predominantly White institutions have an adverse effect on their satisfaction with the college experience and may affect their persistence (Booker, 2007; D'Souza, 1991; Tinto, 1975, 1987). Even for students who persist through graduation, college-alumna/e relations may be jeopardized. Studies that look at how African-American alumnae/i relate to their historically White Alma Maters are very rare. One such study compared levels of 
satisfaction of White and African-American physicians who had attended the same predominantly White medical school and found that although both groups expressed similar levels of satisfaction with their medical education and the career they presently had. The African-American group expressed being less satisfied various aspects of their medical school years, mainly interactions with faculty and staff and with the social environment. The "dissatisfaction with the social environment of medical school lingers long after leaving medical school and is reflected in fewer African-American graduates contributing to Jefferson's Annual Alumni Giving Campaign and in recommending the medical school to African-American applicants" (Gartland, Hojat, Christian, Callahan, \& Nasca, 2003). This finding carries with it grave implications as colleges and universities grow to depend more and more on their endowments.

As African-American students continue to enroll at HWls, researchers are looking at issues that touch them in particular and offering recommendations. Benton (2001), studied the challenges faced by African-American students at predominantly White campuses and suggested that in order for these students to succeed at PWIs, they need to feel valued in the campus environment, that special attention should be placed in the teacher-student relationship so that it promotes a better climate and increased retention, and that PWIs must recognize their role beyond academic preparation.

Singer (2005) examined how African-American male athletes experienced racism at HWIs and found that in their perception they were denied leadership roles and decision- making opportunities, were placed in classes merely to 
maintain eligibility and not to make progress toward graduation, and were disciplined more harshly and with more dire consequences than their White counterparts. In his conclusions, Singer (2005) warned of a practice of academic exploitation of Black male athletes at HWIs with high profile athletic programs. This is a significant warning because at elite universities, underrepresented minority status has been trumped by athletic ability status in admission decisions (Espenshade, Chang, Walling, 2004).

Rankin and Reason (2005) suggested that challenges faced by AfricanAmericans and other students of color at HWls can only be appropriately addressed through "a shift of basic assumptions, premises, and beliefs in all areas of the institution" (p. 59) in order to dismantle the majority/privileged assumptions that interfere with minority students' sense of belonging. On that same vein, Daniel (2007) suggested that the retention and professionalization of minority students including African-Americans, in graduate programs, would benefit from increased quantities of minority faculty and students, a revised curriculum that is more culturally relevant, and the inclusion of cross-cultural content. She further acknowledges that some of the difficulties experienced by minority graduate students may hinge on the concerns they bring with them which are then magnified by the marginal treatment they feel they receive from the White faculty. Other researchers (Mendoza-Denton, Downey, Davis, Purdie, \& Pietrzak, 2002) have recognized that the sensitivity toward rejection that African-American students may bring into the HWI influences their overall experience. These researchers found that students who had a high expectation 
of race-based rejection, as measured by a validated questionnaire on race rejection sensitivity, developed a deeper sense of alienation, a decline in academic performance, and sense of mistrust toward the institution.

White students at Historically Black Colleges and Universities

Following the desegregation mandate of Brown v. Board of Education and Brown II, some White students began to enroll at the then called Negro colleges and their presence there was cause for inquiry. Intergroup contact at an institution where the social minority was the majority unfolded very differently than it did at HWls. One of the earliest studies on intergroup contact at an HBCU was conducted in 1959, Elaine Aber, one of the first White students to attend Lincoln. She published a study that examined how attending Lincoln University influenced the racial attitudes of White students. She stated that at Lincoln, the onus of adjusting to a new environment was on the White students because Black students were "in the established position" (p. 284), meaning it was their campus. Aber (1959) sampled 62 White students of the couple hundred attending Lincoln at the time. Her respondents were mostly older (25 years and up); $79 \%$ of the students surveyed reported having "an improved conception of Negroes" (p. 286); and 76\% of the respondents expressed being more aware of racial misunderstandings than before they attended Lincoln. 37 of the 62 respondents had had some contact with Blacks before enrolling at Lincoln, mostly through business dealings, domestic servant relationships or military service (Aber, 1959). The author proposed that the enhancement of racial attitudes was due in part to "the equal status, common purpose, nature of 
contacts, plus the reversal of the majority-minority roles...the latter forces the White student to face squarely any prejudice he might have" (p. 289)

Terry Hazzard conducted two studies that examined attitudes of White students at HBCUs. The first study (1988) surveyed 38 White students at two HBCUs, one in Alabama and one in Florida. $94.7 \%$ of those surveyed reported not attending college straight after high school; over half of them had transferred from predominantly White institutions. The major factors cited for attending were: academic programs, cost and proximity. $86.8 \%$ of those surveyed said they would recommend the institution to other students. Although over half of the respondents reported having had contact with Blacks prior to attending an $\mathrm{HBCU}$, the nature of the contact was limited to attending the same school, being employed at the same place, or through military service. Most of the respondents expressed feeling at ease in the classroom environment with Black peers and with White or Black faculty. $69.4 \%$ indicated that the institution's leadership played an active role in breaking down racial barriers. Most of the students manifested they had no intention of participating in campus activities and cited lack of time as the main reason for their choice. 52.8 of the students reported that they had encountered racist attitudes.

The second Hazzard study (1996) surveyed 370 White students and 377 Black students enrolled at $23 \mathrm{HBCU}$ in the South using the ACT Entering Student Survey. The purpose of the study was to determine the factors influencing White student's decision to enroll at HBCUs. Reminiscent of Aber's findings in 1959 and mirroring the findings of his own earlier study, Hazzard 
(1996) found that White students attending HBCUs in the South also tended to be older (24 years and up), had had only casual contact with Black people before enrolling and were seeking to complete a degree in order to advance their job situation. In addition, this group of students was comprised mostly of females and had a solid academic footing having an average of $B$ to $A$ minus. In making their choice, they relied on information found on catalogs, campus visits, brochures, and conversations with recruiters. In contrast to the Black students, White students reported that the advice of family and friends did not play a role in their decision. Some of the determining factors for White students to enroll at HBCUs were cost, availability of financial aid, proximity, and particular programs- in the case of this study, health sciences.

Some authors have explored the reasons why White students choose to attend an HBCU. Conrad and Brier (1997) identified fourteen major factors that influenced White students' decision to enroll at a historically or predominantly Black college or university. Among those factors were the reputation of the $\mathrm{HBCU}$, alternative modes of curriculum offerings, access to scholarships, and the institutions' image as a multiracial institution with an inclusive and supportive campus environment. Various studies have found that White students attending HBCUs were satisfied with their choice (Conrad \& Brier, 1997; Hall \& Closson, 2005; Hazzard, 1988, 1996). The Hall and Closson (2005) study focused on the experiences of White and Black graduate students attending an HBCU. The researchers sought to find out if White students as "temporary minorities" (p.31) at HBCUs experienced some of the same hurdles as reported in the literature for 
Black students attending HWls. Their study revealed that White students had trouble integrating socially but did not perceive this difficulty as a racial issue, but as a social one. White students at HBCUs did not perceive any obstacles in reaching out to faculty. For the White students, time in graduate school provided an opportunity to grow individually; the Black students saw their academic attainment as a means to help their community. White students also expressed concern that Black students received high grades they did not deserve and for the most part refused the notion that any of their Black peers might possess greater academic skills than theirs (Hall \& Closson, 2005).

As societal relations evolve, different dimensions of intergroup contact become salient and warrant the interest of researchers. Peterson and Hamrick (2008) examined issues of race, privilege and power under the umbrella of racial consciousness among White male full time students attending HBCUs. Their participants reported situations of hypervisibility in classes. In response, they engaged in self-censoring behaviors during class discussions in fear of generating negative reactions to their opinions. Participants also reported being socially disconnected from the campus. These three findings are similar to research findings of studies conducted with Black students at PWIs. Beyond the temporary majority/minority issues discussed above, Peterson and Hamrick (2009) also explored the topic of White privilege and their findings were very personalized as the seven respondents reported having different levels of understanding of the privileges afforded to them as White males. The authors found that attending an $\mathrm{HBCU}$ caused these White males to put negative racial 
stereotypes to the test, dispelling some and reinforcing others. Participants reported gaining empathy for minority status and experiences, but none of them felt they had a role in changing that system. Nonetheless, the authors propose that there is value in the influence that attending an $\mathrm{HBCU}$ can have on White students' racial beliefs and understandings.

Although the desegregation of some HBCUs began prior to the Brown $v$. Board of Education case, it is just beginning to take hold at most of these institutions. In 2005, only nine out of the 106 Historically Black Colleges and Universities reported White student enrollments above 10\%. And 18 of them had less than five White students in their total enrollment. (U.S. Department of Education, National Center for Education Statistics, Integrated Postsecondary Education Data System (IPEDS), "Fall Enrollment" surveys 1994 - 2005). During the school year 2006-2007, White enrollments at Lincoln University were 57.3\% of undergraduates and $70.4 \%$ of graduate students (Lincoln University facts and figures 2006-2007). White enrollments also constitute the majority at West Virginia College and Bluefield State College (Payne-Brown, 2004). Yet overall, HBCUs serve a minimal sector of White college students, a fact that may account for the scarcity of studies on this population. The lack of this sort of studies is made evident by their absence in well respected literature reviews such as those conducted by Pascarella and Terenzini $(1991,2005)$ who have reviewed over forty years of research on college students.

Because their role in ending segregation is imbued in ambiguity, HBCUs must learn what it means to be desegregated and diverse, while remaining 
faithful to their historic mission (Brown, Ricard, \& Donahoo, 2004; Dwyer, 2006). Payne-Brown (2004) found that even at a college that had completely transformed from historically Black to predominantly White, the alumnae/i -or its connection to its historic past- remained the only predominantly Black aspect of the institution.

\section{Lincoln University of Missouri}

Since the desegregation of higher education took hold in the 1960s, few HBCUs have achieved a level of diversity comparable to that of Lincoln University. Today it is a historically Black, predominantly White university with a unique history in American higher education. The following section offers an overview of this history.

At the time the Civil War began in 1861, Missouri had a slave population of 114,931 and a free-Blacks population of 3,752 , many of them eager to serve in the Union Army. Their wish came true with the 1863 passage of General Order 143 authorizing the enlisting of Black troops (Holland, 1991). Richard Baxter Foster, a White officer, was the First Lieutenant of the $62^{\text {nd }}$ U.S. Colored Infantry during the Civil War. Born to a distinguished family in Hanover, New Hampshire, he had relocated to Illinois and lowa where he taught, and upon learning that Black troops would be used, volunteered for the $62^{\text {nd }}$. Troubled by the absence of a school in Missouri where soldiers could continue their education after the war, Foster and the men of the $62^{\text {nd }}$ regiment set out to create such a school. Men of the $62^{\text {nd }}$ raised five thousand dollars and the $65^{\text {th }}$ United States Colored Regiment contributed $\$ 1,379.50$. A committee was formed and with over 
$\$ 6,000.00$, Foster attempted to establish a school in St. Louis (Savage, 1939). When met by opposition and lack of enthusiasm for his cause, Foster moved to Jefferson City.

In Jefferson City Lieutenant Foster sought assistance from White and Black churches, but both of them turned him down because of the Black students or the White teachers. Eventually, he was granted use of an abandoned school building and on September 17, 1866, Lincoln Institute opened its doors with two pupils and two departments: preparatory and normal. In 1868, Foster requested to be hired by the Jefferson City Board of Education to provide education to the Black children of the community and the Board agreed.

Lincoln did not share the auspicious beginnings of the Black colleges started with philanthropic endowments and in 1870 when W.H Payne was asked to come to lead Lincoln Institute he was presented with the condition that he would have to provide his own salary. He accepted and began to secure outside funds to move the institution forward (Savage, 1939).

Lincoln Institute became a state school in 1879 with the support of Governor Phelps who felt the state should provide to Black students at Lincoln what the University of Missouri was providing to White students (Savage, 1939). In 1890, the Second Morrill Act was a catalyst in the establishment of an industrial school at Lincoln Institute. Under pressure from the federal government, the state legislature had no choice but to fund the project if it were not to lose its federal funding for the state university (Savage, 1939). The "separate but equal" underpinning still rang true when in 1921 the state 
legislature approved a name change from Lincoln Institute to Lincoln University and converted it to a four-year college. At that time, the newly established Board was authorized and required to reorganize Lincoln University so it would provide the same opportunities available to White youth at the University of Missouri at Columbia even if that meant supporting the educational efforts of Black students beyond the borders of the state:

The 1921 Law also stipulated that until Lincoln University was fully developed, the Board of Curators was authorized to arrange for the instruction of Black students of the State at any university, in any adjacent states, where Blacks could enroll in courses that they were not permitted to enroll at the University of Missouri. (Holland, 1991, p. 13)

The years that followed were marked by growth and political turmoil. Under the leadership of President Nathan Young (1923-1927), Lincoln University's high school and the two-year teacher training program received accreditation by the State Department of Education and the North Central Association respectively. Young's administration was characterized by high objectives, a priority of hiring quality faculty and long-range plans, "but the political system under which Board members served at the pleasure of the governor proved troublesome and an insurmountable obstacle to the completion of his program" (Holland, 1991, p.17).

During the 1930's, Lincoln University continued to grow and so did the educational ambitions of Black Missourians. In 1938, the U.S. Supreme Court heard the case of Lloyd L. Gaines, a Lincoln University graduate who in 1935 had been denied admission to the University of Missouri Law School. The court ruled that Gaines would have to be admitted to the University of Missouri or the 
state would have to establish a law school at Lincoln University (Holland, 1991). In 1939, Lincoln University Law School opened in St. Louis with an enrollment of 30. Gaines was not one of them as he had mysteriously disappeared.

Another Supreme Court ruling led to the 1942 establishment of the Journalism School at Lincoln University. Miss Lucille Bluford had sought admittance to the University of Missouri Journalism School, which had accepted her transcripts, but upon her arrival to the university, she was denied admission because of her race. In an effort to preserve the segregated character of the University of Missouri and to avoid future litigation, the Missouri General Assembly ordered the creation of graduate programs at Lincoln University (Holland, 1991). Prior to the decision in Brown, the state-mandated segregation was also enforced at Lincoln,

the only state-supported institution of higher learning for Negroes in Missouri, [where] White students were as rigidly excluded as Negro students from other colleges. Efforts of White persons to gain admittance to Lincoln were discouraged for several years before 1954. On one occasion a Catholic priest threatened to sue for admission to the University on the grounds that he was being denied equal protection of the laws. (Greene, 1959, p. 151)

During the late 1940's enrollments soared as many soldiers returning home from World War II took advantage of the G.I. Bill to attend college. In the 1950s, enrollment figures returned to their pre-war numbers as veterans graduated and Black students began to be admitted at desegregated universities. In Missouri, three Lincoln University graduates sought admission to the Graduate School at Columbia and the School of Mines and Metallurgy at Rolla only to be declined because of their race. In the case of Curators of the University of 
Missouri v. Elmer Bell, George Everett Horne and Gus Ridgel, Circuit Court judge, Sam Blair ruled that the segregation required by Missouri's state constitution was superseded by the equal protection clause of the Fourteenth Amendment to the United States Constitution. Following this ruling the three students, along with other Black applicants, were admitted in September of 1950 (Greene, 1959).

In 1954 the United States Supreme Court declared school segregation to be unconstitutional in the ruling of Brown v. Board of Education. Within a month, The Midwest Society for Welfare facilitated a panel discussion that included college professors; newspaper reporters; religious leaders; businessmen; Black and White mothers; and Black and White high school students as well as the State Commissioner of Education, Hubert Wheeler; Sam C. Blair, Judge of the $14^{\text {th }}$ Circuit District of Missouri who had ruled for the opening of the University of Missouri to Black students. Over 200 people attended the meeting.

The meeting was held at the Missouri Hotel in Jefferson City. It was attended by persons of both races. It was probably the first such discussion of the Supreme Court's decision to be held in the country. (The Supreme Court decision...,1954)

The meeting discussed the future of desegregation in the elementary and secondary schools, but there was no mention of what would happen at Lincoln or in higher education in the state. On June 30, 1954, Missouri Attorney General John Dalton, declared all Missouri laws and regulations mandating segregation to be null and void (Greene, 1959).

That summer, Lincoln University had to decide how it would deal with the new mandate. 
The Dean [Earl Dawson] presented the matter of what is to be done about applications of all qualified persons (and not of the Negroid race) who may seek admission to Lincoln University. The matter was discussed at length and it was finally agreed that all qualified applicants who are not of the Negroid race would be admitted on a probationary status pending the final decision of the Board of Curators (Minutes of the meeting of the Executive Board of the Board of Curators of Lincoln University, dated July 9, 1954, Lincoln University Archives).

A final decision was reached within weeks:

After a careful study of the text and implications of the Decision of the Supreme Court in reference to the abolition of racial segregation in the public schools of the nation, and after a well considered judgment by the Board of Curators of the Lincoln University has been reached in reference to the admission of any qualified citizen of the State to be served at the Lincoln University as a result of that decision, it is resolved by the Board of Curators of the Lincoln University that the Board of Curators of the Lincoln University shall, with the consent and the cooperation of the Attorney General, the Governor of the State, the General Assembly, and other State Educational Agencies and Organizations of Higher Education, provide and make available the offerings of the Lincoln University to any qualified resident of the State who may apply for admission to be served at the Lincoln University ; and it is further resolved that the offerings of the Lincoln University shall be provided and made available to such qualified citizens as soon as the opinion and consent of the above mentioned Officers and Agencies can be ascertained as to the feasibility and readiness of the state to implement the intentions implied in the Decision of the Supreme Court.

The recommendation of the above statement of Resolution was given thorough consideration, discussed at length, and finally approved for adoption (Minutes of the meeting of the Board of Curators of Lincoln University, dated July 31, 1954, Lincoln University Archives).

During the late 1950s and continuing into the 1960s, students from the surrounding communities brought Lincoln's enrollment from 1,184 in 1958 to 2,143 by 1969 (Holland, 1991). The desegregation of the campus has been credited with being one of the factors that led to the closing of the Jefferson City 
Junior College in 1958 (Holliway, 2004). In that same year, Lincoln's White enrollment was estimated to be one third of its 1,184 students. White students were participating in sports, attending school functions and influencing the racial integration of the local community.

The quick changes that are taking place at the college on the hill are being duplicated in the city that surrounds it. Local schools have integrated, along with a downtown hotel and two movie houses. A new spirit of cooperation now exists in Jefferson City (School, 1958).

Nonetheless, the desegregation of the community did not unfold without some resistance. When Lincoln desegregated, a golf team was established. Its members were both Black and White. All the players learned the basics of the game on campus, but when time came to practice, the Black students were not allowed on the part-public, part-private golf course. Because of the disadvantage and inequality created by this lack of access, the coach discontinued the program (Greene, 1959). The desegregation of off campus facilities came very slowly with movie theaters being among the first establishments to serve Blacks without restrictions, but as of 1959 restaurants remained fully segregated and at soda fountains, ice cream parlors and pharmacies, Blacks could purchase products but could not consume them in the buildings. Taverns, bars and bowling alleys were also segregated (Greene, 1959).

By the late 1960s, Lincoln University and West Virginia State College were the only two HBCUs in the nation with about an equal proportion of White and Black students. At Lincoln, the White students came from the neighboring community and restricted their time on campus to time spent in classes. At that 
time, they felt scrutinized by both Blacks and Whites and professors noted that social interactions were kept to a minimum and Black and White students sat separately in the classrooms (Integration, 1966). Young (1966) questioned the future role of Lincoln as it enrolled large numbers of White students. The author expressed concern as the lack of interaction among students surmounted the boundaries of the campus:

Just as there is no dialogue between White and Negro students, so there is none between Lincoln University and the surrounding White community. Lincoln University is silent, too. None of the civil rights organizations are accredited on the campus, although the Jefferson City chapters are made up largely of University personnel. (p. 9)

Just as it was the case in colleges and universities throughout the nation, students at Lincoln found themselves advocating for student rights and protesting lingering segregation in the community. In 1969, there were violent protests and arson fires burned on the campus. Some of the protests were engendered by students' dissatisfaction with administrative practices and were not racially motivated. Others had to do with the local newspapers' negative characterization of Dr. Martin Luther King a few days prior to his assassination. The state responded by sending "Jefferson City Police, Missouri Highway Patrolmen and 150 Missouri National Guard troops" (Holland, 1991, p. 60) to restore order.

During the 1970s and 1980's Lincoln continued to enroll large numbers of local White students and faced many challenges, including the possibility of being absorbed by the University of Missouri system. Alumnae/i rallied to support university administrators against what they considered "public attacks on their alma mater by White legislators (Whitaker, 1986). Sawyer (1989b) pointed to 
Lincoln University as being one of five HBCUs in the nation that had become predominantly White and the social implications this brought for Black legacy students who felt they had to justify the situation to older family members. The continued division between commuters and campus students was also made evident in her article. In spite of that division, White students attending Lincoln commented on the absence of racial tension on campus (Integration, 1966; Sawyer, 1989a, b).

The 21st century found Lincoln facing new challenges and internal turmoil. Time magazine featured Lincoln in an article titled "Black colleges go White" (Drummond, 2000). The article talked about the increasing White enrollment, near $70 \%$ at the time, and quoted the sitting president with saying that "despite changing demographics, 'the university's culture is still driven for the most part by African-American standards"'( $(5)$. This dichotomy of non-reconciled interests created a sense of fragmentation. A professor quoted on the article stated: "Lincoln is schizophrenic at this point. There's always the real concern about how we're going to maintain our heritage" (\$ 4). Dissatisfaction with administrative practices, low faculty morale due to inequality in salaries and disenfranchisement prompted the Faculty Senate to take a vote of no confidence against the sitting president in April of 2002. The Board of Curators dismissed the vote and the university moved forward as if nothing had happened. Following President Henson's resignation due to health issues a new president was named. In 2005, Dr. Carolyn R. Mahoney became the $18^{\text {th }}$ and first female president of the university. Her arrival ushered a new age for the institution. Currently, the 
university is enjoying the rewards of competitive salaries, extra-mural funding from grants and sponsored research, expanded residential facilities with the building of a new apartment style residence hall and renovation of some of its historic buildings and reinvigorated relations with the surrounding community. Shared governance has also been a trademark of this new administration. In June 2007, President Mahoney was awarded the Ralph S. Brown award by the American Association of University Professors (AAUP). This award is given to an American college or university administrator in recognition of an outstanding contribution to shared governance (AAUP, 2007).

Lincoln is now nearing its $150^{\text {th }}$ anniversary and continues to serve a widely diverse student population. In the years between 2001 and 2005, enrollment of Black students rose by $16.7 \%$ and that of White students declined by $19.7 \%$. For the fall of 2006 and 2007 , enrollment of Black students was $37.6 \%$ and $37.9 \%$ respectively, while White enrollments were $54.4 \%$ in fall 2006 and 55.3\% in fall 2007 (Lincoln University Facts and Figures, 2007). Enrollment of Hispanics has increased and the enrollment of international students has remained steady.

\section{Summary}

The goal of this chapter was to provide an overview of the literature on two overarching themes: (a) Organizational culture and intergroup contact and (b) segregation and racial integration in higher education.

The review of the literature on these two themes makes it evident that although racial segregation and racial integration constitute a defining chapter in 
the history of the U.S., the intergroup contact ensued by racial integration has not been the subject of much scholarly inquiry in organizational analysis. The desegregation of colleges and universities has received a lot of attention by scholars and public agencies. In most cases, studies have focused on the process of desegregation as it relates to Black students crossing the color line into historically White institutions (e.g., Astin, 1975b; Bowen \& Bok, 1998; Bowles \& DeCosta, 1971; Cross \& Astin, 1981; Daniel, 2007; Davis et al., 2004; Deskins, 1991; Dickerson \& Jacobs, 2006; Feagin, 1992; Feagin \& Sikes, 1995; Fisher, 2007; Fleming, 1984; Fries-Britt \& Turner, 2002; Gartland et al., 2003; MendozaDenton et al., 2003; Pascarella \& Terenzini, 1991; Phillips, 2005; Rankin \& Reason, 2005; Sims, 2008; Singer, 2005; Solórzano, Ceja, \& Yosso, 2000; Suárez-Balcazar et al., 2003). This focus, characteristic of the research on higher education and organizations in general contributes to maintaining Whites and White institutions as the normative model against which minorities are compared and defined (Cox \& Nkomo, 1990; Martin, 1992; Nkomo, 1992; Van Maanen, 1983).

By comparison, research on the presence of White students at HBCUs is quite limited. Aber (1959) and Hazzard (1988) provided a picture of White students as older, having had little previous contact with Blacks and unattached from campus life. These White students are often attracted to HBCUs by the school's reputation, geographical proximity, access to scholarships, programs of study (Hazzard, 1988 1996) and ideals of diversity, inclusive and supportive environments (Conrad \& Brier, 1997). 
As HBCUs become more and more diverse, they are reshaped by the frictions between impetus for change and efforts to retain traditional values. One such HBCU is Lincoln University of Missouri.

At Lincoln University of Missouri, the legacy of educational dreams for underprivileged students still guides its open admissions practices. Risen from humble beginnings to prominence among the Negro colleges of the twenties and thirties, Lincoln University was deeply affected by desegregation as White local students flocked to the campus and Black students sought educational opportunities at HWls. Those demographic changes brought a certain degree of flux to the institution and a new organizational culture developed from the Black/White intergroup contact ensued by desegregation.

Chapter three will provide a detailed description of the research design and methodology of this case study. The following chapter presents information about the site, the participants, the methods of data collection and analysis and triangulation processes. 


\section{CHAPTER THREE \\ RESEARCH DESIGN AND METHODOLOGY \\ Introduction}

The review of the literature compiled in Chapter Two makes evident that the process of desegregation of HBCUs and the Black/White intergroup relations that ensued have not been the subjects of much research to date. Furthermore, transcending the boundaries of higher education, organizational analysis in general has, for the most part, been conducted from the point of view of the majority, mainly White males. The result is a slanted view of the process of racerelations in higher education and organizations in general a view that neglects the perceptions and experiences of minority groups.

The purpose of this study was to examine how the initial Black/White intergroup contact generated by the mandated racial desegregation of Lincoln University of Missouri in 1954 influenced the institution's organizational culture. This quest for understanding was guided by the following research questions:

1. What were the cultural forces that converged on Lincoln's campus during the first fifteen years following its desegregation?

2. What were the dynamics of intergroup contact at Lincoln University during the late 1950 s and during the 1960 s?

3. How were the University's culture and organizational identity influenced by its racial desegregation?

To contribute to the scholarship on race relations in higher education, this study relied on the perceptions and experiences of: (a) African-American 
alumnae/i, (b) White alumnae/i and (c) African-American and White faculty, who experienced the desegregation of Lincoln University of Missouri in the fifteen years immediately following the landmark decision of Brown v. Board of Education in 1954. As a research site, Lincoln University provides one of the few examples of a Black university integrating White students in the late 1950s and during the 1960s. This chapter specifically details: (a) research design and methodology, (b) participants, (c) data collection and (d) data analysis.

\section{Research Design and Methodology}

A qualitative case study approach was chosen because of its precise focus on a particular case, the information it contains and what can be learned from it (Stake, 1994; Yin, 1984). It also serves to increase the knowledge and understanding of a phenomenon in relation to the individuals, organization or society that experienced it (Yin, 1984). A case study showcases not a method, but a choice of what is to be studies (Stake, 1994). Case studies are bound to a program, organization, or period of time (Krathwohl, 1991) and develop when a "researcher figuratively puts brackets around a temporal and spatial domain of the social world"(Van Maanen, 1983, p. 9). Case studies provide the reader with the opportunity to vicariously experience a phenomenon through the eyes and interpretations of others thus augmenting the readers' own knowledge base (Stake, 1994).

A qualitative study is of special value in organizational research as it can enhance the diversity of points of view and therefore aid in the discovery of insights that may otherwise remain silenced (Van Maanen, 1983). According to 
Denzin and Lincoln (1994), "All knowledge is always local, situated in a local culture and embedded in organizational sites. This local culture embodies cultural stereotypes and ideologies, including understanding about race, class and gender" (p. 204).

Qualitative research is the most appropriate type of inquiry in seeking understanding of the effects of desegregation on the organizational culture of Lincoln University because the descriptive data gathered through personal accounts, both oral and written, of an experience provide well-grounded and rich descriptions that explain the unfolding of an event in a particular context (Miles \& Huberman, 1984). The inductive nature of qualitative research allows for a picture to emerge as the collected data are analyzed. Thus the researcher does not set out to prove or disprove a given hypothesis (Bogdan \& Biklen, 1998). The qualitative researcher guided by the contributions of each participant, moves from the general picture to the specific details. In this study the retrospective stories of participants addressed the very specific context of desegregation at a $\mathrm{HBCU}$ and their perspectives expand the understanding of the meaning (Bogdan \& Biklen, 1998) of desegregation in higher education in the United States.

The case study approach was also chosen because understanding the impact of racial desegregation on the organizational culture of Lincoln University required the gathering of information from a select group of individuals who experienced it first hand at a particular moment in time. Hence the researcher "puts brackets around a temporal and spatial domain of the social world" (Van Maanen, 1983, p. 9): the 15-year period following Brown v. Board of Education at 
a HBCU in a predominantly White community in a border state. The uniqueness of demographic and social conditions coupled with the significance of the temporal frame that internally corresponds to the tenure of one Lincoln University president and externally coincides with the years of the Civil Rights Movement warranted the utilization of a case study.

\section{Participants}

The selection of participants within the qualitative case study is commonly purposeful as the event is proprietary to those who have first-hand experience of it (Miles \& Huberman, 1984). The participants were selected because of their attachment, knowledge and perceptions of the situation, their readiness to tell about it and their ability to gain and facilitate access to others (Krathwohl, 1991). Three subgroups participated in the study: (a) African-American alumnae/i, (b) White alumnae/i and (c) African-American and White faculty, who experienced the desegregation of Lincoln University of Missouri during the 15 years immediately following the landmark decision of Brown v. Board of Education in 1954.

The question of how many participants should take part in a qualitative study has been answered by some researchers with a recommendation of sampling until a point of saturation or redundancy becomes evident (Lincoln \& Guba, 1985; Patton, 1990). The researcher sought to achieve saturation and to secure a participant sample equally representative of each racial group to provide rich qualitative data from which to identify salient dimensions, establish comparisons and draw conclusions. Descriptive statistics of each participant 
were recorded including the person's race, gender, time of enrollment or employment at Lincoln University and level of involvement with the institution after their period of enrollment or employment. This last category was deemed important because the degree of involvement with the organization beyond the period selected for the study could potentially influence the perceptions of the participant. Involvement beyond the selected time period did not disqualify a participant, but it was noted.

Tables 1, 2 and 3 provide a list of the participants who shared their recollections of the time they spent at Lincoln University during the period bracketed for this study. All participants received an invitation to participate (Appendix A) and completed a preliminary questionnaire (Appendices B \& C) to compile demographic data and to establish relationship with the university and willingness to participate in the study. An Informed Consent Form (Appendix D) was prepared in accordance with University of Missouri's IRB specifications. All participants signed this form, which provided the background of the project and the purpose of the study. The form also contained information about voluntary participation, benefits, risks and confidentiality. All participants consented to the use of their own name in association with the study.

Table 1

Student Participants $(\mathrm{n}=30)$

Name

Mr. Alex Cooper

Mr. Robert Mitchell
Time spent at Lincoln

$1951-1955$

$1952-1956$
Race or ethnicity

African-American

African-American 
Name

Mr. Lloyd Mallory

Ms. Frances Regina Robinson

Ms. Teresa Brown Sullivan

Ms. Mary Balkenhol Kabiri

Mr. A. Visanio Johnson

Dr. Charles Ledbetter

Ms. Verna Luebbert

Mr. Bill Luebbert

Mr. Joseph Loethen

Mr. Winston Rutledge

Mr. James E. Miller

Mr. Eugene Lock

Ms. Susan Heinen Lock

Mr. David Vanderfelz

Ms. Victoria Patterson

Mr. David Patterson

Mr. Harry Howard

Mr. Donald Bates

Mr. Joseph Johnson

Ms. Dorothy Balkenhol Harriman
Time spent at Lincoln

$1955-1959$

$1947-1949$

$1958-1960$

$1958-1961$

$1959-1962$

1958 - 1962

$1959-1963$

$1959-1963$

$1961-1963$

$1961-1965$

$1961-1965$

$1969-1971$

$1961-1965$

$1961-1965$

$1962-1966$

$1961-1965$

$1962-1966$

$1963-1967$

$1963-1967$

$1964-1968$

$1964-1968$

$1964-1968$
Race or ethnicity

African-American

African-American

White

White

African-American

African-American

White

White

White

White

African-American

White

White

White

White

White

African-American

African-American

African-American

White 
Dr. Thomas J. Cooper

$1965-1970$

African-American

$1972-1974$

Ms. Sandra Diggs

$1966-1970$

African-American

Mr. Wayne Kitchen

$1966-1970$

African-American

Ms. Sharon Sestak Strickland

$1966-1970$

White

Mr. James F. Harriman

$1966-1972$

White

Mr. Joseph Scoggin

$1963-1970$

African-American

Ms. Barbara Kitchen Mitchell

$1967-1971$

African-American

Dr. Richard Presberry

$1967-1972$

African-American

Table 2

Faculty Participants ( $n=7$ - * faculty members listed in the student section) Name Time employed at Lincoln Race or ethnicity

Dr. Thomas

D. Pawley

$1940-2000$

African-American

Mr. Robert Mitchell*

$1958-2000$

African-American

Mrs. Teresa Brown-Sullivan*

$1963-1968$

White

Dr. Pete Kellogg

$1964-1966$

White

Dr. Peter Filene

$1965-1967$

White

Dr. Wayne Linhardt

1965 - present

White

Dr. Herman Miller

1966 - present

African-American

Dr. David Finley

$1967-2000$

White

Ms. Mary Kabiri*

1968 - present

White

Ms. Celia Smith

$1968-1995$

Hispanic 
Table 3

Other Participant

Mr. Richard Risk

Executive Director Human Rights Comission-1965-1970

The participants listed above were selected because each of them had intimate knowledge of some portion of Lincoln University's first fifteen years as a desegregated Black university in a predominantly White community. Potential participants were informed of the study through direct mail, direct contact, alumni listserv and through public service announcements (Appendix E) that ran on the Lincoln University radio station -KJLU- and the community TV station -JCTV. All participants volunteered to share their recollections.

The first group of participants consisted of 16 African-Americans (13 males and 3 females) who were students at Lincoln University between 1954 and 1969. The second group consisted of 14 White alumnae/i $(7$ males and 7 females) who attended Lincoln during the same period stated above. These two groups of Linconites provided first-hand accounts of how the racial desegregation process began at Lincoln University and the surrounding White community and shared their perceptions about this historical and cultural event. Any participants who were students and later became faculty or taught as adjunct faculty at Lincoln were listed among the faculty, but only counted in the student participant section. The third group included seven participants of both races who served as faculty during the fifteen years following the Brown v. Board of Education decision: two Black males, four White males and one Hispanic female who chose to be categorized by ethnicity instead of race. They too possessed intimate 
knowledge of how Lincoln University moved from being a Black University to a desegregated $\mathrm{HBCU}$ and were able to provide a perspective of how things were perceived from the point of view of instructors.

Participants were identified by purposeful sampling (Fraenkel \& Wallen, 2003; Miles \& Huberman, 1984) and "snowballing" approaches (Merriam, 1998, p.63), whereupon one participant provided the names of others who met the sampling criteria. For the initial purposeful sampling and to confirm enrollment, names and contact information of students who attended the university between the fall of 1954 and the spring of 1969 were obtained from the Lincoln University Office of Alumni Relations. To enhance the sense of trust between the researcher and participants, common points of contact were utilized. This means that the researcher reached out to known potential participants, invited them to participate and relied on them to set things in motion to reach out to other participants. There were four common points of contact. The first one was Mr. Joseph Johnson who administers a listserv that reaches hundreds of alumnae/i. Mr. Johnson was a participant and forwarded the invitation to participate (Appendix A) to his readers. This allowed the researcher to reach alumnae/i throughout the U.S. One of those alumni was Mr. Gene Lock who lives in California, but maintains ties with commuter students and faculty members from the era. Locally, Ms. Mary Kabiri and Mr. Joe Loethen were early participants and provided lists of potential participants. As interviews were conducted either in person or by phone, participants were asked to provide the names of other potential participants and many of them did. 
All identified students received a written description of the study and an invitation to participate in it. Those who responded affirmatively then received a questionnaire (Appendices B \& C) aimed at identifying "information-rich key informants" (Patton, 1990, p.46). The questionnaire also included an inquiry about people's willingness to participate on a one-on-one interview with the researcher and/or in a focus group. The idea of holding focus groups was later abandoned for fear that only local participants would be able to take part in them. The researcher felt this may result in other participants feeling they had not had equal opportunities to share their stories. Together with the questionnaire, participants received a participant informed consent form (Appendix D). The consent form recorded participants' willingness to participate in the study and their willingness to have their interviews audio and/or video-recorded. All participants agreed to have their interviews recorded. All face-to-face interviews were both digitally audio and video-recorded. All phone interviews were digitally audio-recorded. Upon receipt of the questionnaire and signed consent form, the researcher contacted the participants to schedule an interview.

To identify the participants who worked at Lincoln University during the selected time period, the names of possible participants were gathered from current faculty and staff, participants, yearbooks, school newspapers and other documents. The contact process mirrored the one previously described for the other two groups.

To comply with University of Missouri rules and regulations concerning research involving human subjects, permission to conduct the research was 
obtained from the Institutional Review Board (IRB) following the stated guidelines for the procedure. As a preliminary step in this process, the researcher completed, on August 24, 2007, the Educational Training Quiz required of all university researchers. Permission to conduct the research was also obtained from the Lincoln University Biohazard and Environmental Safety and Protection of Human and Animal Subjects Committee.

Interviews were conducted in person with those participants who were geographically accessible to the researcher and by phone with participants who were not geographically accessible. The participants and the researcher scheduled the interviews during times that were mutually convenient. Most of the person-to-person interviews were conducted in the studios of the local access television station, JCTV; others were conducted in the homes or offices of the participants according to their preference. All face-to-face interviews were digitally audio and visually recorded. Phone interviews were digitally recorded. All interview files were saved on the researcher's password protected computer's hard drive and an external hard drive. All movie files were also converted to DVDs and the audio-only files were converted to CDs. All files and data containing devises were kept locked in the researcher's office and will continue to be so for the three years required by University of Missouri campus IRB.

\section{Data Collection}

The data for this study were collected through interviews and archival searches. Interviews are considered to be essential sources of data in case studies (Yin, 1984). They provided access to first-hand accounts and insights into 
the perceptions and opinions of each informant. Two basic types of interviews were utilized: open-ended interview and conversational interview (Patton, 1990; Seidman, 1998). The first contained a pre-established set of questions to be asked of each informant seeking to establish a common body of knowledge (Appendices F \& G). The conversational interview questions allowed the researcher the freedom to pursue emerging facts. These types of questions also as serve triangulation when used to confirm facts uncovered with other participants. Two basic interview protocols were developed, each containing some questions common to the whole sample and some group-specific questions. This was done in part to avoid conducting the research in a framework of "cultural monism" (Azibo, 1990) that fails to acknowledge differences across race (Nkomo, 1992).

With the explicit consent of the participants, whenever possible, interviews were audio and video recorded. Phone interviews were digitally recorded. The researcher felt that the historical significance of these interviews made it imperative that they be digitally recorded and properly archived. All participants agreed to have their interviews recorded and archived at Lincoln University's Page Library. They also consented to having their names linked to the findings.

In addition to the oral accounts, archival documents pertinent to the racial desegregation process at Lincoln University were studied. These documents included institutional yearbooks for the years 1954 to 1969, newspapers, Board of Curators actions, archived interviews and photographic records. The researcher also examined local newspaper articles and city and state legislative 
actions related to the desegregation of Lincoln University. These documents provided triangulation to the data collected through the interviews as well as a historic record that revealed insightful information about the institutional culture of the university. Pictorial records allowed the researcher to get a glimpse into the past as the photographs provided the researcher with a visual of what participants had looked like at the time they attended, the campus organizations to which they belonged and the events they might have attended. The pictures also revealed changes in the demographic composition of Lincoln, the transformation of the fashion codes, the campus' buildings and grounds and the social events of the time. A timeline of national and institutional events related to race relations and the Civil Rights Movement between 1954 and 1969 was created to aid in the reader (Appendix $\mathrm{H}$ ).

\section{Data Analysis}

The three research questions that guided this study provided a roadmap to explore the unfolding of racial desegregation at a historically Black university in a predominantly White community during the 15 years immediately following the mandate of Brown v. Board of Education. The participants' accounts of their experiences during those early years enhance the understanding of racial desegregation in American higher education and the way it impacted the institutional culture of Lincoln University.

To analyze the data collected through this study, the researcher completed multiple viewings of the video-recorded interviews and listened to the available audio recordings. Partial transcripts of each interview were written and 
read multiple times for an initial "free textual analysis" (Smith \& Osborn, 2003). Margin notes and memos were written to highlight interesting portions, record researcher's reactions and commentaries or to document external situations that may not be apparent in the transcripts. At this point, the data were analyzed by systematically organizing and probing into the information that has been gathered in the transcripts of interviews, field notes and other documents. From this process, the researcher emerges with a deeper understanding of the phenomena and can share his/her discoveries with others (Bogdan \& Biklen, 1998). The fact that desegregation of HBCUs has received very little scholarly attention facilitated taking the participants' narratives as the primal source for understanding this phenomenon.

It is important to point out that the researcher of this case study considers herself socially removed from the experience being studied as she is neither Black nor White and came to the United States decades after desegregation was decided. This cultural detachment aided in taking the participants' stories at face value and making them the primary sources of information.

The researcher conducted multiple viewings of the video-recorded material and listened to the interviews immediately following the meeting with the participants. The researcher then transcribed the relevant portions of the interview noting the specific times of the chosen portions for later review. Given the evocative nature of this study, external historic events, for example the assassination of Dr. Martin Luther King, were a part of the recollections of the participants. The analysis of such key events focused on the context of 
experience of the event as students or faculty at Lincoln and not on the event per se. This was a valuable step in that it allowed the researcher to give equal weigh to all the personal recollections that contributed to the collection of data.

The next step was to organize the data into "meaningful clusters" (Patton, 1990, p. 408) that held significant information about the desegregation of Lincoln and allowed for the pruning of irrelevant data. The transcriptions were read multiple times to identify salient themes. As themes emerged, quotes that spoke to each particular theme were lifted through a process of copy and paste and gathered into new pages labeled with the theme's descriptor. This type of clustering allowed the researcher to look at the same phenomenon from various vantage points provided by the various participants' accounts.

The final step was the "structural synthesis" where the researcher identified a deeper level of meaning in the narratives of the participants. During this part of the analytic process, the researcher searched for connections among the various themes looking mainly at themes that facilitated an understanding of cause and effect.

In addition, the researcher sought to insure the validity of the study through a variety of processes of triangulation which are known to enhance the worth of the data and the correctness of the researcher's interpretations (Fraenkel \& Wallen, 2003). All interviews were digitally audio and/or video recorded to allow for reviewing of the data thus collected. During the interviewing process, the researcher often checked one informant's recollections against the recollections that other informant had of the same key event. Key events were 
noted and checked through document analysis of archival records. Eight participants provided member-checking. They were asked to review the findings chapter for accuracy and to make suggestions that might expand the researcher's and ultimately the reader's understanding of the phenomenon of desegregation at a Historically Black University.

\section{Summary}

There is a void in the scholarship referent to the desegregation of higher education in the United States. Very few researchers have looked at the desegregation of Black institutions or at the effects of Black/White racial relations within organizations.

This chapter provided a detailed description of the research design and methodology that were utilized in the development of this qualitative case study to examine the desegregation of Lincoln University of Missouri and the effects of that process upon the organizational culture of the institution. The examination was conducted through the lens of intergroup contact theory.

The core participants were Black and White students who attended Lincoln University after August of 1954, when it was officially desegregated and May of 1969. Participants were identified through the records and directories of the Lincoln University Office of Alumni Relations as well as by personal referrals and were contacted either by phone, mail or e-mail to be invited to participate. Other participants were Black and White faculty, who were employed at Lincoln during that same period of time. These participants were identified by current university personnel, students, alumnae/i and were also invited to participate. 
All data collection was conducted in compliance with University of Missouri IRB regulations and Lincoln University's Human Subjects Protocol. Data were collected through personal interviews and document analysis.

The data were analyzed by conducting multiple viewings or listening to the interviews, reading through the transcripts coding and categorizing data. Salient ideas were recorded and supportive data were gathered under various emergent themes that were then carefully studied to get to the core essentials of the desegregation of Lincoln University and the impact this event had on the university's organizational culture. Processes of triangulation were conducted to insure the accuracy of the data and researcher's interpretations.

Chapter four will provide the findings of this study through the recollections of participants who had personal experience of the process of desegregation of Lincoln University. The presentation of the findings will be structured in terms of themes as they relate to the research questions that guided the current inquiry. 
CHAPTER FOUR

\section{DATA ANALYSIS}

Introduction

Prior to the Brown v. Board of Education decision in 1954, most Blacks received their primary, secondary and baccalaureate education in segregated schools known at that time as Negro schools. When desegregation of education became the law of the land, many Black students began to enroll at traditionally White colleges and universities. At the same time, Black colleges opened their doors to White enrollment.

The focus of this study was to look at one of those Black institutions, Lincoln University of Missouri, for the purpose of examining how the initial Black/White intergroup contact generated by the mandated desegregation of Lincoln University of Missouri in 1954 influenced the institution's organizational culture. The study utilized open-ended, conversational (Patton, 1990) and retrospective (Frankel \& Wallen, 2003) interviews to explore the perceptions of Black and White students and faculty who were at Lincoln University between 1954 and 1969 regarding the impact of the university's desegregation on its institutional culture. The selected period was chosen because of its historical significance within the Civil Rights Movement following the desegregation mandate of Brown v. Board of Education. The period is also bracketed by the administrative tenure of Dr. Earl Dawson who served as chief administrative officer from 1954 to 1956 and as president from 1956 to 1969 . By the time of his departure, Lincoln had transformed into a historically Black/predominantly White 
institution. Interview protocols were adjusted according to the race and category (i.e., student or faculty) of the participant to avoid conducting the research in a framework of "cultural monism" (Azibo, 1990) that fails to acknowledge differences across race (Nkomo, 1992).

Data for this study were collected through various methods. A preliminary questionnaire was used to identify potential participants, determine their race, time of attendance/ employment and continued involvement with the university. To explore the recollections of initial desegregation of alumna/e and faculty, open-ended, conversational and retrospective interviews were conducted. Interviews with 38 participants (30 students, seven faculty members and one Executive Director of the Commission for Human Rights) were designed to gather the perspectives of the participants in regard to their personal experience of the process of desegregation at a historically Black university located in a predominantly White segregated community. The level of connection with the university following participants' departures was varied. Some reported that they have remained actively engaged with Lincoln (10 Black students, 6 White students, 1 Black faculty member and 1 White faculty member); others indicated they maintained some involvement, most commonly by attending cultural events on campus or through communications with alumni chapters (4 Black students, 2 White students, 1 White and 1 Hispanic faculty members); and there were also some participants who had had minimal to no contact with the university since their departure (2 Black students, 6 White students and 2 White faculty members). 
The study sought to ascertain answers to the following research questions:

1. What were the cultural forces that converged on Lincoln's campus during the first fifteen years following its desegregation?

2. What were the dynamics of intergroup contact at Lincoln University during the late 1950 s and during the 1960s?

3. How were the University's culture and organizational identity influenced by its racial desegregation?

\section{Findings}

Given the historic and evocative nature of this study, findings related to the three research questions are presented with illustrative quotations, thus allowing the voices of the participants to construct the scene of desegregation at a historically Black university. This sequence permits the communication of the individual perceptions gathered through question one, links the theoretical tenets of intergroup contact in question two and, in question three, conveys the shared meaning that led to a transformed institutional culture and organizational identity as the study site evolved from a Negro college to a Historically Black University with a significant White enrollment.

Research question 1. What were the cultural forces that converged on Lincoln's campus during the first fifteen years following its desegregation?

Responses to this question provided insights into the various components of Lincoln's institutional culture and the internal and external forces that acted upon that culture. Since the desegregation of Lincoln brought together groups of 
people who had been kept apart by legal and social norms, it was important to gather information about the participants' past experiences with members of the other racial group. The 38 participants provided background information about the school systems they had attended prior to coming to Lincoln, the knowledge they had of the institution before enrolling in it, first impressions of the campus and its surrounding community and feelings about the desegregation of Lincoln at the time of their attendance. From the analysis of this section of the inquiry, four major themes were identified. These major themes were: (a) Lincoln University provided the first truly desegregated educational experience for the great majority of students who attended between 1954 and 1969; (b) Lincoln was a desegregated university within a segregated community; (c) the expectations and the overall college experience varied widely for Black and White students at Lincoln University; and (d) Lincoln's post-desegregation leadership hindered internal integration due to its accommodationist approach.

Lincoln University provided the first truly desegregated educational experience for the great majority of students who attended between 1954 and 1969. All of the Black participants who attended or taught at Lincoln prior to 1969 had received all or part of their elementary and secondary education at segregated schools. One of the African-American participants mentioned having Black classmates who had been educated in integrated schools and for whom Lincoln provided the first opportunity to be taught by a Black instructor, but this was not the norm. The White students had attended schools that were completely segregated or had very small Black enrollment. For the Black 
students interviewed for this study, segregated schools provided a rich and nurturing environment where education was seen as indispensable to social mobility and teachers took special interest in the academic success of those students who might seek a college education. A student from Southeast Missouri described it in the following manner:

In the Black high school the teachers knew that there would be a very small number of kids that would be able to go to college. So they began giving those kids more work, more responsibility so that when they got to college it wouldn't be just a step off in space. They did not discriminate, they told all [pause] but they just [pause] there were 33 in my high school class and maybe four of us went to college and and since you had that small number, by the time you were in your junior year, they began to ask more of you, to give more, check your responsibility, see how you talked and they would start the dialogue, "Now if you go to college, these things you'll be required to do.

The following account from a student who arrived at Lincoln in 1959 exemplifies the level of involvement of high school teachers in Black students' futures:

Toward the end of my senior year, my band director called me into her office and told me that she had applied to Langston University, Howard University and Lincoln University for me and that l'd been accepted to all of them. Then she informed me that she had applied for scholarships to all of those schools...so she gave me that information and told me to take the information home and decide which university I was going to attend and to let her know. She said that if she hadn't heard from me by the date that the first of the universities were scheduled to start, then she would be by my house to take me to that university. She said to me, "You are going to college. You don't have a choice." Well I looked them over and chose Lincoln.

Most of the White students who desegregated Lincoln had also emerged from educational settings characterized by racial homogeneity. A White student who enrolled in 1961 and was born in of one of the rural communities surrounding Lincoln recalled, "During my elementary and high school years I 
never had an Afro-American as a fellow student." This absolute absence of racial diversity was the norm for most of the White participants' educational experiences prior to attending Lincoln. A few spoke of having very few Black students in their elementary or secondary schools. A student who enrolled at Lincoln in 1959 stated, "I went to school here in Jefferson City and there were [pause] my school had one student, one Black student. The Black students attended the elementary and public schools, I went to the Catholic high school." Another White student who matriculated in 1958 spoke of childhood interactions with a Black classmate:

When I went into first grade, in 1946 at St. Peters, there was a Black girl in my grade, so integration had already taken place in 1946 in the private school; and she was a friend of mine. In fact I think it was her mother that was part of some housing riots in Maryland...Baltimore, Maryland, and I recognized the name that it had to be the same mother, and the girl and I were good friends, she came to my house, I went to hers, completely acceptable.

Overall, for both Black and White students attending Lincoln between 1954 and 1969, Lincoln provided the first opportunity to share classes with peers of a different race and for all of the White participants, the first experience of being taught by a Black professor.

Growing up in segregated communities and attending segregated schools had created a paradigm that influenced intergroup relations. For the Black participants who grew up in the 1940s and 50s, intergroup relations with Whites were very limited and the mindset was one of staying out of their way, literally and figuratively. A Black participant who came to Lincoln in 1967 recalled being taught by his mother and grandmother about how to behave around White 
people. The lesson was triggered by the brutal killing of Emmitt Till, a Chicago youth who was visiting family in Mississippi and aroused the fury of three White young men for having whistled at a White young woman:

My grandmother would take every opportunity to teach me and my brother. At that time, my brother and I were the oldest. During the time from about four or five years old until we were about 12 or 13 she would really talk to us about how to act around White people so that we wouldn't put ourselves in a situation to receive that wrath that we knew could happen regardless of how young. The situation I'm pointing out, we lived in the Mississippi Delta from the time I was three, four years old til I was six or seven. And it was only a hundred miles from Money, Mississippi where Emmitt Till was killed. It was 1955 and she used that as a teaching moment to drive home the fact that there were certain ways that we should act so that we didn't end up like Emmitt Till.... if we were walking on a sidewalk toward a group of Whites we were supposed to lower our heads and get off the sidewalk. Those were the kinds of things that she taught us so that we wouldn't put ourselves in danger. 'Cause during that time, those kinds of things could make the difference between life and death for folks - for Black folks- and nothing would be done about it.

Another Black participant from Haity, Missouri, illustrated the degree of segregation in which he had lived with the following recollection, "Where I am from, I had to get on the back of the bus to ride to school, to Lincoln, in 1965." Once at Lincoln, he kept to the immediate vicinity of the campus because "I knew my place." In fact, the notion of "knowing one's place" was repeated among several Black students from the earlier years of desegregation. Black students saw the segregation of the Jefferson City community as an extension of their previous experiences:

For most of us who came from Oklahoma and Missouri - and most of the Black students then were from Missouri - segregation had been a way of life for us. So again, it wasn't necessarily something that we weren't used to during that time. 
The White students expressed some confusion at becoming aware of it:

I think maybe we didn't look into it [segregation] very carefully because we knew it was happening. We were ashamed of it, but didn't know what to do about it. But the other part was that the Black students didn't tell us either. I don't know if they thought we wouldn't be receptive or wasn't any reason to tell us, 'cause it had to be shameful to them as well - "I don't go into that place "cause they won't serve me or they don't treat me well."

A Black student who arrived in 1964 offered the following comparative reflection between the desegregation he experienced in his home town and the one he encountered at Lincoln:

I went from a segregated school from the first grade to the tenth grade in Poplar Bluff and then, in my eleventh and twelfth grade years, I was bused to the White school. So I knew that integration was going one way but not the other. They didn't bus any White kids to the Black school. Integration was: "You gotta come to our school." So the first experience with busing was not White kids being bused, it was us being bused. We drove right past our Black school on the way to the White school. That was how they met their integration requirement. When I came here [to Lincoln] I wasn't surprised there were Whites. There were a number of White teachers here. What I experienced here [at Lincoln] was something more heart-warming in the sense that when I went to the White school there weren't any Black teachers there. So they didn't bring the Black teachers and instruction was not integrated. I knew we were different. I knew that there were more White professors here than Black professors at the University of Missouri.

When Lincoln University opened its doors to White community students in 1954, it brought together groups of young people who, for the most part, had not had prior contact with members of the other race and made manifest a unique version of desegregation in higher education: a minority led institution welcoming the White offspring of a segregated community. 
Lincoln was a desegregated university within a segregated community.

When Lincoln University began to admit a significant number of White students from its surrounding community, the institution became one of two significantly desegregated Negro colleges in the nation. The other one was West Virginia State College. A Lincoln graduate who is intimately familiar with both universities offered this statement:

Because of its dwindling Black enrollment, on October 23, 1956, the West Virginia State Board of Education voted to surrender the land-grant status of West Virginia State College (effective July 1 , 1957) and transfer all personnel and expense funds to West Virginia University, the state's 1862 Land-Grand Institution. To save the institution, West Virginia State College purposefully began to recruit White students.

Lincoln and West Virginia State College were widely acclaimed as the only Negro colleges to effectively desegregate immediately following the 1954 Brown v. Board of Education decision. Even today, less than $10 \%$ of all HBCUs have non-Black enrollments greater than $10 \%$ as compared to Lincoln which has maintained an almost even 50/50 enrollment since the late 1960s. A Black faculty member who had been teaching at Lincoln for 14 years by the time it integrated offered the following explanation for the quick desegregation of Lincoln:

The moment this school opened up, the local people applied. Within 2 to 3 years they were pouring into this school. That did not happen at my alma mater in Petersburg, Virginia which to this day is overwhelmingly Black. The attitude of this people -and I think it has to do with the ethnic background, the German ethnic background- You see, the Germans were anti-slavery in this area to begin with. They were practical minded: "Why would I send my son over to University of Missouri when I know there is a perfectly good school right here." They knew it was a good school and the moment it was open they sent people in, and people moved in and within a few years it was 50/50. There was no problem, you didn't have to go out and advertise. They, the White people of the community, 
began to go to school here because they wanted to further out [sic] themselves. They knew they could get business here, they could get an education here.

The desegregation of Lincoln was not mirrored in the public accommodations of the surrounding community. Black and White students who attended during the 1960s spoke of the segregated nature of the town as exemplified by this 1971 Black graduate's evocation:

If you went to a store, people looked over your shoulder. I do remember going to the movie theater and having to sit upstairs, up in the balcony. I don't know what would've happened if you'd gone downstairs, but I know that the African-Americans, especially Lincoln students, had to sit in the balcony. There were situations where [Black] students had tried to go to the night spots in town and were rejected. Even though I don't know that there was an ordinance or anything formal to prevent them from going into the establishment, I know that some students were unable to go certain places. And of course there was some harassment of students by police.

All the White students interviewed for this study acknowledged being aware of disadvantageous treatment of Blacks in the community and contrasted it with the way Whites were treated on campus:

I think being a White student I probably had privileges even though I came from a financially very poor family. I wasn't denied things because of being a White individual and I assumed it was going to be like that when I came here [to Lincoln]. And it was. We weren't denied anything. Now, my fellow students, Black students, probably had a different experience.

Attending a welcoming desegregated Black university while living and working in a prejudiced community generated some discomfort for a White student who said:

The interactions were friendly and peaceful on campus, I didn't have any problems on campus [but] there were a number of places [in town] that really didn't seem like they wanted any Black patrons 
at their stores at that time. That was in 1966 and there was a feeling in town, it seemed like to me, that the Black students should stay on campus. They shouldn't go out in the community. It was uncomfortable to work in the community. I worked at a department store and feeling toward the students and the impact of it was not friendly...you know the [Black] faculty wasn't really appreciated as a patron at the department store either, it was strictly a racial line that was drawn.

Some members of the community harbored negative feelings toward Lincoln and shared them with some of the local students who were attending. One of them recalled what was said to him about his choice of college, "there were comments made about going to Lincoln, that it wasn't a real school, that it was a Negro school, that I wouldn't get any jobs going to Lincoln."

Some of the White students joined their Black peers in challenging the community's status quo. One of them remembered:

I was in the first sit-in strike in Jefferson City, in fact the only sit-in strike I'm aware of. It was a pizza place on East High, across from Grace Episcopal Church, the building isn't there anymore. It was a local pizza place and eight of us decided one night to see what we could do about integrating, and two White couples and two Black couples, eight of us just showed up there one night to be served and of course, they didn't serve us. We sat there for almost two hours and they didn't serve us and they talked to some of the men in the group and the owner said, "We'd like to do this, but we would not be looked favorably by other business if we did this." So after two hours we went home and it was kept very quiet.

In pursuing such courses of activism, the student quoted above recalled being concerned about the reactions of her White home community as well as her Black student community. As far as her family went she said:

I didn't want to rock the boat with my whole family. I knew my family was very happy for me to be here, but socially I didn't know exactly how they would feel about things like the sit in strike, so I did it without them knowing anything about it until two or three months later. My father mentioned that he had heard there was a group of 
students wanting to get served at the pizza house and I said, "Oh, yeah, Keith and I were there." He might of [sic] kind of suspected that [pause]

I think there was a lot of hesitancy on the part of a lot of the White students about "how is my family going to react to me making friends here, maybe this is going to lead to interracial dating" and concerns like that.

When it came to her student community, she was concerned because:

There were a few on campus that were very radical in their feelings, a few Blacks, and we were a little bit afraid that if they found out, they would be down there with us that night and we didn't want them there.

The discriminatory practices were not limited to the student population. A Black participant who graduated in 1963 remembered, "Even the adults of the African-American community tended to socialize on campus and among themselves instead of in the larger community in Jefferson City. It was pretty much a segregated community."

A White student who attended in the early years of desegregation reminisced with a mixture of pride and regret about the lack of interaction between the community and Lincoln's Black faculty:

The faculty that was at Lincoln University at the time is probably, or was, a faculty you'll never see again at any university. We were taught by PhDs, generally Eastern educated, eastern schools, Harvard, but they taught undergraduate classes and really cared about us. That was a tremendous resource that could have done a lot in the community [pause] if the community would have embraced them at the time.

But the situation in the community was one of exclusion toward Blacks regardless of academic attainment. Black faculty members lived within the immediate perimeter of the campus because housing was segregated well into the 1970s: 
LU faculty were probably the best paid people in town as a group, yet they could not buy real estate outside of three or four blocks of Lincoln University. It's almost as they were fenced in. And what's strange about it, some of the young guys who had taken real estate classes at Lincoln turned right around and wouldn't sell to them.

A participant, who worked as deputy director and director of the Commission on

Human Rights in Jefferson City between 1965 and 1970 confirmed:

The Black community was all around Lincoln University. The west end particularly, which had some of the nicest homes, was an allWhite area. This is in 1965 to 70 . So a professor who taught here who was Black couldn't buy a nice home, I mean the nice homes, a lot of them were in the west end [pause] Regardless of ability to pay. So they started a group that worked on that. I had a woman that worked for me. She was not a full-time employee. She and her husband lived in town for years and years, raised their children in Jefferson City...She had a house on the west end and she and her husband wanted to sell it and she knew that the professor Lorenzo Greene, that his wife, Thomasina, taught piano lessons, I think that her kids had taken piano lessons from Thomasina Greene. So they arranged for a direct sale, they sold their house to them and that integrated the west end, I think. To my knowledge he was the first Black to live on the west end...But that's what it took, efforts by individual people.

A White faculty participant recalled being surprised at the housing situation faced

by some of his Black peers:

One of the deans did buy a house in a White neighborhood and at a meeting he said that he was sitting up all night to protect the home and somebody asked him if he had a gun and he said, "Oh, no! I wouldn't want to hurt anybody" - He's having to sit up all night to protect his home and he wouldn't want to hurt anybody or make any threats- I was so impressed with his heroism and decency. That was really, really emotional.

The animosity toward Lincoln was so entrenched that it also affected White faculty. A White professor who was victimized by the community's discriminatory housing mores recalled: 
Back during the time when I came, we were kind of ostracized. Ahh, I recall one time when I applied for a loan at one of the local banks and they wouldn't give it to me 'cause I worked at Lincoln [and] there was one realtor here in town, she wouldn't even show us a place 'cause I worked at Lincoln. [Researcher: Even though you were White?] Even though I was White... of course she didn't know that, we were on the phone and she asked where I worked and I told her and she said, "I don't have anything for you." I thought at that time about filing a complaint, but it probably wouldn't have gone anywhere. I had better things to do with my time.

In spite of the recollections of community segregation, all of the White participants, students and professors, perceived their homes as being free of prejudice against Black people. Many shared statements to this effect and credited those family values with their lack of reservation when enrolling at a Black institution. A White female student commented: "We three kids were from a family that did not have any prejudice at all, especially my father. He did not have an ounce of it." Other White students had grown up in families that had active dealings with the Black community. One of them remembered:

My father grew up a just a block away from Lincoln and interacted with the Black community in a way that few people interacted with them. He sold used cars. We had a farm, he sold produce. And we didn't set up shop, it was that the families knew him and would say you know where I can get such and such. So l'd probably been around a different Black community than most of the youngsters who came here had, and had more interaction with Black families than a lot would've had.

A White faculty member also mentioned how his family had contributed to breaking down barriers for Black workers:

My father was in construction and his was the first company to hire a Black laborer. There were some consequences to that, but it didn't hurt that he was a union company and that he was very strong and a high ranking officer in the Carpenters Union...So personally this racial issue was not an issue. Even when I was working as a kid for dad's company there was this Black laborer, 
not a carpenter, because that would've really started something, if it was a skilled crafter; that just wasn't done in the community.

A Black professor recalled being concerned about how racial prejudice would affect Lincoln's desegregation:

It was a little edgy at first, but it calmed down...It went off well. I was a little skeptical about how it was going to proceed, at first, because of the way in which the legislature and others had fought to keep us [Blacks] out of the University of Missouri. It was Judge Blair who opened the University of Missouri and Gus Ridgel [a Lincoln graduate] went over there who proceeded to enroll in the department of Economics for his Master's degree.

As it turned out, participants' recollections were that the arrival of White students served to change the way in which legislators dealt with Lincoln:

If we had integrated faster, we would've had more money for equipment, and supplies, because the legislature knows what is going on here. If it's only $10 \%$ White kids, is one thing, if it gets to $30 \%$, then they start voting different.

Another Black participant concurred:

When the enrollment started going up, when White students started coming up here the whole attitude changed, not overnight, but it began to change 'cause now the representative from Jefferson City knows his constituencies, these are his neighbors, and the senator from the district... it began to change.

The effect of local enrollment was seen as a life line by one of the Black faculty participants:

They [the White students] saved Lincoln. Lincoln's student body was way down. You see we'd lost, after the veterans, after WWII, we had a huge increase in enrollment with returning veterans, but after the veterans finished their work there was not an increase in enrollment, the state legislature was not ever munificent in its awarding of funds to Lincoln University and there were needs that were not being met. 
Reservations held by Blacks at Lincoln during the initial years of desegregation were also addressed by some participants. A White commuter student offered this speculation of what Black faculty members might have been thinking at the time:

The Black faculty who was in place treated us very well, I mean, I think, around their coffee tables they knew what was going to happen to Lincoln, in terms of integration. Surely it'd become less Black. Hopefully it'd become better funded from our wonderful state legislators who weren't all that fond of funding this little Black microcosm in the middle of their state - I'm putting words in their mouth but the funding was not good for Lincoln.

A Black faculty participant expressed the following:

...some of them [Black faculty members and administrators] wouldn't admit it, but they would've liked for Lincoln to be an African-American university with no White kids.

The desegregation of a minority-led institution surrounded by a segregated White community created a unique set of conditions that transformed both the institution and the surrounding community and touched the lives of all involved.

The expectations and the overall college experience varied widely for Black and White students at Lincoln University. The perceptions of college life at Lincoln varied widely between White and Black students who attended between 1954 and 1969. For the White students from the local community, Lincoln was first and foremost an affordable, local university where they could complete their higher education. For the Black students, the Lincoln campus was a multifaceted enclave addressing aspects of the students' academic and social lives. The following section illustrates this dichotomy. 
With the exception of one study participant, all of the White participants lived off campus and commuted to school. Most of the White participants, who were first- generation college students, liked the idea of living at home and being able to hold a job while going to school:

I chose Lincoln primarily because it was close to home and it gave me a chance to work and commute. The other reason was that it gave me a chance to be a first generation to attend college and I had looked forward to doing that. It was a smaller school and that was probably good for me.

One of the local students spoke of how for first-generation students, working while going to college was the norm:

I was a first-generation student. The oldest of six kids and we didn't know about loans and stuff like that. We didn't borrow money. If you were going to go to college you were going to have to pay for it, so we had to work. I think that put it in a different perspective for most of us.

Another, who by being an athlete was entitled to room and board on the campus, explained that his family farm chores prevented him from living in the dorms:

I was the baby of seven kids and my dad needed me in the farm to milk. I had no other reason 'cause I was treated like a king on campus. But it was just my dad, my uncle and I. I really had no choice.

For a young White woman in the community, Lincoln allowed her to reach beyond her father's expectations:

The reason that I came to Lincoln was that my father didn't believe that women needed higher education and he thought, he felt, that he would put me through some secretarial course, but that was it. But I got a Curators' scholarship to Lincoln.

The local White students who enrolled during that period spoke of seeing the campus as just the place where they took classes and they did not, for the 
most part, participate in campus activities or utilize services such as the cafeteria. Two students spoke of it this way:

We did not eat there -that's a big thing-groups of White students did not go to the cafeteria. We either ate a sandwich we brought from home, in the car. Or we went to local places to eat. It never dawned on us that we should or shouldn't do that nor did anyone ask us or encourage us to do that.

The second student said:

We were not immersed in the campus and it was easy not to be immersed because we commuted, we didn't go to the social functions and as a basic White kid I don't dance very well and I knew I wouldn't look very good in that respect, so it was easy not to do it. Maybe I'd been better off if I had.

Black student participants recalled noticing the absence of White student's participation in collegiate activities beyond the classroom:

I saw White students here as well, and I felt they were not taking advantage of the opportunities outside the classroom, because you and I both know that learning takes place, in fact much more outside the classroom than inside. I didn't see them at the dances. When I came here there weren't that many in fraternities or sororities, and none were living in the residential halls so they were just commuter students, they came to get what they wanted and they left. I am sure some others have said it, it was like in the day time you thought you were at MU because the White students were everywhere, but after 5:00, you were in a Black campus, because everyone lived on campus, we ate here, and so forth.

Another Black student recalled:

The interaction between Blacks and Whites on campus was rather marginal in terms of interaction socially. There was some participation of Whites in student government, but those were your more progressive Whites. Generally speaking the Whites were not really progressive, they reflected the community from whence they came and what happened there at Lincoln was that during the daytime was primarily White students in many of the classes and of course at night it took a different complexion because Blacks lived on campus and the Whites were commuters. 
A White faculty member also spoke of the commuter/resident division, which at Lincoln occurred along color lines:

There were two sets of students. There were the commuter students and the campus students and the two never met. The on campus students were Black and the commuter students were White. Most of them commuted, oh, from about a 25 -mile radius. The Black students were from all over the country. There was a large contingency from St. Louis, Kansas City as you'd expect; from Gary, Indiana and from Detroit. A few were from Los Angeles, from the west coast but most from Kansas City, St. Louis. The students were, well, they kept their separate agendas. The White students didn't participate - I shouldn't say that - most of the White students didn't participate in any campus activities at that time, whereas the Black students did.

Yet, some White students did fully embrace campus activities and their level of involvement influenced their college experience and understanding of the world around them. For some of these students, the deeper involvement meant a total immersion in the racial divide of the era. A White student who participated in the theater group recalled a trip into the South and the uneasiness her presence caused her Black director:

I was among the first [White students] who was active in the theater and we were going to take a trip, to the South. We were putting on a play, oh isn't that terrible I cannot think of the name of it...I was a waitress - anyway, Dr. Pawley had been invited to bring the play into [pause] some place in Tennessee, Memphis, I think and I was going to go down with them and he didn't know how to handle it, because we were going into the South and here was this obviously White person going into the South and I remember the night before we left I couldn't sleep. And he worked it out so I would stay at the home of the students who were from Tennessee and I was brought to their home to spend the night and I don't think he ever - either Dr. Pawley himself - or another faculty member left being where I was. It was just that uncomfortable for him having a White student and I guess I didn't realize the possible danger , I was very nervous about going, but I think I would've been nervous had it been a White group and I am traveling with a theater group. But I know Dr. Pawley was extremely concerned about that particular trip. 
A White male student who from 1963 to 1965 was the only White player

in the football team shared his memories of games and travel in the South:

Lincoln had $30 \%$ White when I was here so the desegregation had already began here, but when I traveled to other campuses, there was no desegregation and in most campuses that we went to, I was the only White on campus. We played Kentucky, Arkansas, Tennessee, Florida, and when I went on campus [there], I had to be accompanied, you know, with other football players 'cause the coaches were afraid that if I walked by myself there might be a problem...During the game there was always a fight and usually the fight was over myself. But the only major problem I had was when we were in Pine Bluff, Arkansas. We were playing Arkansas A \& M and back then, you know Governor Wallace, George Wallace, was a predominant person down in Alabama and when I went into the locker room, you know to dress, they had my picture in the locker room, I don't know how many were there, but there were several of them and Governor Wallace was written across each of those pictures. Coach Reed had said, "Don't let him go anywhere with at least two with him," and that was the only campus that I was leery of walking on...

... It taught me a lot about the Black culture, going to Lincoln University, because when you travelled south you saw the poverty that Blacks were living in. That stayed with me and I would've never known that if I hadn't played for Lincoln.

A deeper appreciation of the social issues of the era was also attained by a White female student who lived in the dorms between 1966 and 1968. She went to Lincoln from an all-White community west of Jefferson City. According to this White female student, her deeper understanding of issues that touched Black people at the time was acquired by:

Having people in my dorm room and visiting other girls in their rooms. It was a lot of fun, had I just been a day student, an awful lot of the important experiences I had would not have occurred.

Because, you know, you get a lot from the classes and interacting with students there, but it is not social interaction... That stuff is not going to come up in the classroom, it comes out in social interactions, and not just with the Black students, we had students 
from Iran and Nigeria...You just became a little more aware, you expanded your view of things.

Other White students participated in college activities such as student government elections, the newspaper and the literary magazine. One of those students said,

I ran for student government president which was crazy, but again, I was treated with respect - they probably thought I was crazy. I don't know why we did that, I think we were trying to become more integrated with the school, it wasn't a rebellion....and it was the advice of some teachers who wanted desegregation to happen.

For the White male students, ROTC provided another opportunity for inter group contact out of the classroom and a place to check their pre-existing prejudices:

Back then under Land Grant College, ROTC was required for two years. I think that was a real eye opener, the fact that we were put in a more integrated area carrying guns if you will- even though they were dummies, no bullets- but we were brought together through ROTC and here we saw - if there were any stereotypes that were handed down previously - here we saw Black students in leadership positions as battalion or cadet officers, or sergeants that were telling the White students you are going to do this or you are going to do that. But there wasn't any effort to counteract that. We saw it as part of growing up.

White participants in general expressed that they knew attending Lincoln during the era bracketed for this study afforded them a unique opportunity to develop skills for intergroup relations based on respect and equality. For most of the White students, arrival at Lincoln marked their first contact with Blacks. The results were overwhelmingly positive. Many students referred to the respect they had for their Black professors:

I really respected some of the professors I had. I remember talking to them and they are now down in history as some of the top Black American professors, Black in the world. Like Dr. Lorenzo Greene, Dr. Stamper, Dr. Miller, the historian, Dr. Fuller who I believe was 
the first Negro to get a PhD in music, he was here. He developed the up pace march in the football field. I remember seeing those people perform it was just unbelievable. At that time it was tops, it was state of the art. It was the best...you didn't realize it at the time, but when you look back you realize, man that was the best!

One White student spoke of his experience having Black peers for the first time in his life:

Most of the Black students were second and third generation college students. Their parents, and many of them, their grandparents had gone to college. Of the White students, they were almost all first-generation college students. Neither their parents nor grandparents had ever gone to college, which presented a very unique academic situation because probably, I'm sure no other college had a make-up that had any sort of parallel to that situation where the Black students, academically, were more attuned to being collegiate than the White students.

Many White students spoke about how being educated at a minority serving institution had shaped their values and attitudes toward people of diverse backgrounds:

I became so aware of how to interface with people who are different than me because I came from this little place where everyone is German-American and Catholic. You aren't an insider or neighbor until the third generation... it was great in that if forced me to be a social person which I turned out to be and I don't think I particularly learned that in my little town.

Another student spoke of overcoming some of the prejudice that had been around him during his childhood.

My parents were accepting, my grandparents were not. One of their concerns was, you know you can't trust, all the old stereotypes, you have to be careful around them, you can't get close to Black people and I think a little bit of that, a lot of that was probably present in all of us. But I think meeting the youngsters our age did a lot to alleviate that. Because whether you realize it, whether you have this light bulb that pops up and says "Oh, my, we all want the same thing," you unconsciously see that we are all moving in the same direction, that we all want the same thing. 
A White faculty member had this recollection of what he learned at Lincoln:

I've told everybody ever since I was at Lincoln that's where I really learned about race, race relations, and learning how to teach it was an invaluable experience. I was glad this was a place that was working it [integration] out.

In summary, for the White student participants Lincoln mainly provided an affordable way to attain a college degree. In most instances, as first-generation college students, it allowed the students to fund their own education by holding jobs off campus and kept them near their homes and communities. At the time they attended, they saw the university as a good educational investment. "That was the primary goal to get an education and not spend too much money," said one of the commuter students. In retrospect, they recognized it as a place that influenced their understanding of others and enhanced the way they related to different people.

For Black students, Lincoln was not only the center of academic pursuits, but it constituted their whole social environment:

The campus was a hub of social activity for [Blacks in] Jefferson City. Sports, culture, everything from what was in those days [pause] the old memorial hall they used to show movies on Friday and Saturday evening for 25,30 cents so the campus community and the [Black] community at large used to come see movies right at Lincoln. At the same time, when you went to the movie theaters in downtown, they were segregated. There were two movie theaters: one you had to sit in the balcony and the other there was a velvet rope and the more popular the movie, the further they moved the rope to the back, and if you were African-American you had to sit behind the rope. So hence the university offered movies.

A White student spoke of how he perceived the social needs of Black students were different than his own: 
We weren't leaving our hometown culture and the Black students living on campus were, and they were making the best of a completely new environment to them. To us it was just one part of our environment.

This sense of a Black campus community influenced the expectations that Black students had of the university's administration.

Although the Black students who attended Lincoln after 1954 could have enrolled at historically White institutions that were desegregating, some chose Lincoln as a safe haven from the turmoil of what was unfolding at those institutions or from the experiences they had endured at their desegregated high schools. One participant from Southeast Missouri said:

I really had no desire to continue that struggle, in terms of going to an institution that didn't want me there. The high school that I graduated from had not integrated. We had a Black school system and a White school system under one board. The last four years in high school the White school had extended the opportunity for some African-Americans to attend the White high school if they wanted, but they still maintained the dual school system. It wasn't until the fall after I graduated that the federal government put pressure on the Caruthersville school system to integrate. I graduated in 1967[from high school]. I came to Lincoln because I did feel I wouldn't have to continue that struggle, and undergo the insults on the campus that I had undergone for as long I could remember growing up in the South for the most part. So yeah, I had no desire to go to one of those predominantly White institutions and continue that overt struggle. We continued the covert struggle regardless, because those were the times, but I chose Lincoln intentionally to not have to deal with those kinds of things.

His sentiments were echoed by another Black student who travelled to Lincoln from the Deep South:

When I graduated from high school I didn't have a chance to go to Georgia Tech or University of Georgia because they really weren't too keen on recruiting Blacks at that time - this was 1964- it started about two years later, but in 64 I decided not to even worry about going to a White school although I had the grades and I was good 
enough to start in sports so I started looking at the Black schools and Lincoln popped up and what intrigued me about Lincoln, it was an integrated school...

...I wanted to have the experience of integration without all the hostility, 'cause I'd had enough hostility growing up in Georgia I wanted to experience it without all the hostility and I was able to do that at Lincoln. There was no hostility there between Blacks and Whites.

Another Black student who had been one of the first Blacks to integrate his local

White school recalled:

I was part of an integration process in my high school years. I was tested, because I was a bright kid, I was tested and I was selected to go to the all-White high school in my city of Sedalia and going from an all Black nurturing environment community and neighborhood where the church and the school was a focal part of social as well as political involvement. Having to walk from my community into an all White community and going into a school that nothing was Black other than the Blackboard and myself [sic] at the high school. A bright, talented young man fell through the cracks. I would raise my hand and no one would see it. Going to my locker and finding peanut butter on my locker and of course when you're walking toward it you think it is something else, but peanut butter was on my locker and you sit down in the classroom and kids start moving their chairs as if you had body odor. I lost my drive of wanting to learn, I became a very poor student I lost interest in learning because no one had interest in me learning...When I got to Lincoln I was happy seeing so many Black students and I sensed a sense of family and camaraderie and a sense of I can do anything because you know the editors of the newspaper were Black, the archivists of the yearbook were Black, the campus queens were Black, the SGA presidents were Black, I saw all this happening and it gave me a sense of empowerment.

Lincoln also provided to some Black students the first opportunity to

compete on a level playing field with White peers:

l'd grown [up] in the period when we were told that Whites didn't go to school with Black kids. I never went to a school with a White kid til I got to Lincoln and we'd been told that we weren't good enough - by some people- it was a chance for me to see just how good I was in the academics and in athletics. 
Many of the Black students interviewed received scholarships to attend

Lincoln and saw that opportunity as the means to escape the life they were living.

A Black student from the Missouri Bootheel said:

If you wanted to do better in life, have more, be able to offer your children more, live in certain parts of town, then you needed to go to college. That was my motivation right from the start...I didn't want to pick cotton.

Black students perceived the confines of the campus and the adjoining Black neighborhood as the geographic area in which all their educational and social needs were to be met. One student remembered it this way:

Our existence at Lincoln was in a more circumscribed community around Lincoln and we had what was then called "The Foot,"[a commercial district immediately adjacent to the Lincoln campus were all the Black businesses were housed] and there were a number of places there and they tended to satisfy our needs. There was pool hall, a grocery store, there was Ms. Leona's, there was a tavern, there was a crab game at the back of the tavern, there was a dance...Ms. Leona's you could dance there...so we were able to stay within our own niche. We would go downtown to the movies or what have you. Might go to different places...but it was more contained that it is now...

This sense of confinement created issues that were unique to the residential students:

We wanted our dorms to be upgraded or replaced and we didn't want to wait for the next eight years for that to happen because the school was growing... There were a lot of Black kids who wouldn't have stayed on campus if we were not from out of town.

Summing up, Black students who attended Lincoln during the period studied relied on the university to provide them with the education they sought and a positive and attentive social environment given that the community immediately surrounding the campus was still highly segregated. 
Lincoln's post-desegregation leadership hindered internal integration due to its accommodationist approach. Prior to desegregation, Lincoln University was an exclusively Black institution where power was distributed in a traditional hierarchical manner. The greatest power was assumed to be held by the administration, followed by the faculty and lastly by students. At the same time that Lincoln began to desegregate, a new leader assumed the helm of the institution. During the first semester of its desegregated history, Lincoln lost the leadership of Dr. Sherman Scruggs after he suffered a stroke. Dr. Scruggs had been president since 1938. The administration of the university was placed in the hands of Dr. Earl Dawson, who served as interim chief administrative officer for two years and was named president in September of 1956. Dr. Dawson remained in that position until 1969.

Both students and faculty participants characterized Dr. Dawson as a man who compromised and sided with outside constituencies as his way of protecting the interests of the university. The term "Uncle Tom" was used by various participants to describe the actions taken by Dr. Dawson. His administration was perceived as conforming to the status quo of Blacks "knowing their place." A Black faculty member who worked under his administration stated:

Dr. Dawson was not...how should I express this, because I respect the man....his technique was different, his technique was that of the older generation of administrators who sought to accommodate themselves to the situation that existed, it was a Booker T.

Washington approach rather than a W.E.B DuBois. Scruggs [the previous president] was more like W.E.B DuBois than Booker T. Washington. He [Dr. Dawson] was fighting for Lincoln in his way, but he gave the impression that he was an "Uncle Tom". I don't think he was, came from Kansas, just like Dr. Scruggs [pause] He 
was accommodationist with things in the city. He didn't want demonstrations and that sort of things.

An African-American student who interacted with Dr. Dawson while serving as vice-president of student government in the early sixties had this recollection of a meeting with the president:

I will never forget sitting in his office with some of the other students as he gave his speech to us about why we shouldn't be doing, making that effort to integrate the bowling facility and I think the thing that still stands out in my mind after all of these years is the fact that he could never look us in the face as he was attempting to do that. I can visualize him to this day sitting there at that conference table with his head down and his eyes looking down at the table as he talked to us. He never once looked us in the face and I thought "What a sad man." I couldn't sympathize with him at that point. As a student, I really didn't think about what he might be going through and the politics, and all that might be taking place at his level. Of course I was aware of the fact that the legislature was, to my knowledge, bringing pressure. He never said this to us, but I knew the legislature was bringing pressure on him to do something to stop us and I was told that they had even threatened to cut Lincoln's budget if he didn't do something about stopping the demonstrations. But he never said any of that to us at those meetings and I just remember how sad I thought he was in terms of his efforts to get us to stop and the fact that he couldn't even look us in the face when he was attempting to talk us into stopping the demonstrations. Of course as students, we ignored his efforts at getting us to stop and continued. And as I've mentioned, we even hanged him, President Dawson, in effigy there on the campus during one of our rallies as we prepared for one of our demonstrations at the bowling facility. We were so upset with him in terms of his lack of support for what we were attempting to do.

A White female student who participated in a different meeting during the same period remembered:

The president at that time had a reputation of being somewhat weak, unable to take a stand and I assume that was somewhat justified. One night we did have a march from Lincoln to the capitol, to downtown, and I participated in that march. This was after our attempt to have the sit in and the president got very worried about that [the march]. He didn't realize that we were having that and 
about two days later several of us got called in to the president's office. But even there, he was very careful about how he worded. He just had some questions about why we had decided to do that, but he just didn't want to stir up, even with that...I think he was worried that we would make some problems for the school by doing that.

The president's apparent passivity was not a good complement to the rapidly changing social environment of the 1960s. A Black student who attended between 1966 and 1970 recalled how those times were characterized by the emergence and evolution of social movements:

That was during the time of Malcom X, Stockley Carmichael, Martin Luther King and the Black Panther Movement in California, and the movement was changing from the Martin Luther King philosophy of turn the other cheek kind of thing, to the new philosophy of by whatever means necessary - and you had various factions, political factions on our campus which is a beautiful thing - when you have people with different mind sets as to how change is to be dealt with and at that particular time it was "burn baby burn" and out of anger and out of rage, you burned. Of course we were dealing with students from all over the U.S. We're not talking about kids from Jefferson City, Sedalia, and Columbia. We had kids from New York City, Chicago, Saint Louis, LA, East LA, San Francisco we are talking about kids from all over the U.S, we cannot leave out Alabama and Mississippi, they were all here on this campus at the same time with their own personal experiences from where they came, they were here and so you had all these political ideals. That was part of the students' philosophy and we wanted to be heard.

That social turmoil reached Lincoln as students and faculty who identified with the goals of the Civil Rights Movement began to arrive on campus. One of the participants characterized the students of the period as displaying a case of "classic youthful impatience with the slowness of change." Many of the Black students who attended throughout the 1960s expressed having been left to feel that shattering the status quo of race relations and seeking equality was up to them. This feeling was exacerbated by the way in which the administration 
reacted to students' efforts to accelerate the desegregation of the surrounding

community. A faculty member offered this assessment of Dr. Dawson's position at the time:

Dr. Dawson gave the appearance of being against the movement, let's put it this way, I don't think he was deep down his heart, I think just been brought up in a way that was not the way that the younger generation felt things should be approached. The way he dealt with the majority was not the way the younger generation that was coming on felt that you should deal with them.

Although students were aware of the outside political pressure exerted upon Dr.

Dawson and of his belonging to a different generation, they were baffled by some of his retaliatory actions against student leaders. One of the African-American students who were at Lincoln during that period offered this reflection:

I guess, as a result of all the pressure he [Dr. Dawson] was facing, he had to, in his view, do something to demonstrate that he tried to stop all of this and his method for doing that was to suspend these seniors who were in leadership positions in the demonstrations...They were all suspended and forced to leave before they got their degrees. It was in the spring of their senior year which I just, to this day could never understand.

The pressure that students referred to was embodied by the conservative community surrounding Lincoln and the Missouri Legislature. In the community, business owners resorted to creative ways of delaying the end of discriminatory practices. This stirred strong emotions for students:

We, as a student body had anger, we were not content with the status quo...for example, there was a drugstore at the corner of East High and Lafayette, Eastend Drugstore was owned by the mayor of Jefferson City, Waley. Waley had in his drugstore a fountain and there were some tables. If I as a Black youngster went in and wanted a fountain drink, it was given to me in a paper cup. Well, in the early part of the sixties some students decided, they were just going to sit there and force this drugstore to let them sit. 
So the drugstore's answer? They removed all the seats. And this was the mayor...

Black students were not the only ones to notice the difficulties that the administration had in dealing with external agents. A White commuter student observed:

It was a struggle for them [administrators] to relate positively with the community. It was a struggle for them to relate positively with the legislators. It was a struggle to get for the university what the university needed to do what it needed to do.

Youthful impatience evolved into activism and it was met with fury by the administration under Dr. Dawson's leadership. A student who in 1958 had chartered the first student chapter of the NAACP at Lincoln and had become its president during his senior year in 1962 recalled being an active negotiator for desegregation in the community throughout his years at Lincoln. Most efforts received the support of the local chamber of commerce and went smoothly, but in the spring of 1962 the owners of one of the local bowling alleys still refused to desegregate their facility. They were willing to rent the facility during the off hours for Lincoln students to take bowling classes, but would not allow Blacks in the premises during regular business hours. A White student who worked as a cook at the bowling alley confirmed the segregated practices it adhered to:

It [the bowling alley] wasn't the place where Black students showed up on a regular basis, that wasn't allowed. There was a league especially for Black bowlers and not a lot of them bowled with White bowlers. It was all pretty well segregated in the community.

The student chapter of the NAACP began to pressure the university and the owners of the bowling alley for rapid change. This is one student's recollection of what happened: 
At one point I was contacted by the administration that a meeting had been set up where I would attend the meeting with the dean and we would meet with the local Chamber of Commerce and of course, I was insistent in taking our officers with me, but they said, "No you have to come by yourself." Well, I was opposed to that. So, at any rate, the dean picked me up, we went down there and we talk to them [the owners of the bowling alley]. And at the meeting, I am trying to explain our position and they had their own position and the problem came up that they wanted to begin the movement the following fall. I mean begin the integration the following fall. I wanted to initiate the integration now. So I had no support. The dean, I was allowing him to offer something, he wouldn't offer anything. So I ended up agreeing, "OK, well, we'll wait til fall." So I went back to the campus and had called a meeting. There were about 300 students there and I explained to them what had happened; that I had felt intimidated and isolated and made a decision that I shouldn't have made because I didn't have the authority to ban the chapter, the NAACP chapter. So I put it to a vote. The student body voted, "No, we want it integrated now." So in essence they interpreted it as me going back on my word. So, at any rate, we had the marches, demonstrations, torches and that kind of stuff around the campus. Some of the students, they would run wild down the halls and stop students, all the typical things people do. Falsify fire alarms and get the disturbance without never really tearing up anything. And we had scheduled the big demonstration on my birthday - I did that - which was March $10^{\text {th }}$, and I got a notice when I went to work that Monday morning - I worked at the cafeteria- and I had had that job for three years, my employer told me that he had to let me go because the president had ordered my expulsion from the school. So that took care of that. So I went and told the other people [NAACP members] and they had gotten notices too, but Walter Jackson didn't get a notice, Cole Farris didn't get a notice but [name] and I got notices that we were out of school... All of us were told in the expulsion - and I call it expulsion because they [pause] I couldn't come back to Lincoln for four years and I was ten weeks from graduation- and I got, got expelled...

Throughout the decade the administration held its accommodationist

approach and students, especially Black students, kept rising in political awareness and seeking equality. A professor recounted the following exchange he had with a student in the mid 1960s: 
I had one student come back incredibly excited because he had been involved in Civil Rights demonstrations and had chained himself to the pillars of a bank, protesting the bank, probably been arrested, and he was just exonerated and his attitude was: "White people are sick and we are going to heal them." It wasn't angry, hostile, it was just exonerated.

Students who were witnesses and participants in the social movements of the 1960s saw Dr. Dawson as subservient to forces external to the campus. A Black student from Missouri who attended during the late 1960s recalled:

We had a president when I got here who wanted to be in the good graces of the forces that be, not make waves and as a result many times, the big thing that he was accused of was of turning back funds, unused funds that the university could have used, but to be in the good graces of the powers that be, he would not use funds to build up the university, to assist students, or whatever. So [for] the three demonstrations that happened while I was on campus, that was one of the big demands, they were asking that he be ousted as president, and eventually he did resign, but, yeah that was an attitude that he had. It was referred to back then as him being an "Uncle Tom". An attitude that did not push for the equality that we felt as the CEO or the primary administrator of the university he had the responsibility to further equality of this campus, making sure that the university had the resources that other universities had.

Following officially mandated desegregation, the character of intergroup relations in the country began to transform. The participants of this study belong to a generation that took the United States out of its segregated/Jim Crow past and set it on the path toward racial integration. Black and White participants alike expressed knowing that things were never going to be the same. A White student stated:

There were so many things going on. It's a situation where you know that you are living at a pivotal moment and that things are not going to come out to be the same as when you went into that era, and you didn't know how far it's going to go, you didn't know when the smoke cleared what things were going to look like, literally in some cases when the smoke cleared. 
A Black student spoke of his peers' awareness and desire to be part of that imminent change,

In 64,65 , the march from Selma to Montgomery, yeah, we were aware, in 48 hours we raised enough money to take two busloads of kids and joined Dr. King and marched into Montgomery...there was a consciousness of what was going on.

Even students who did not actively participate did what they could to support the efforts of those who did. A White female student mentioned: "I was too afraid to go [to Selma]. I wasn't a very outgoing person. I think we gave money to finance the trip, so that other kids could go...It wouldn't have been a lot ...just a donation."

A Black student spoke of support that was found in a group of young White scholars who, funded by post-graduate fellowships, were teaching at Lincoln at the time:

The ones who initially came in were more progressive, some at least like Kellogg and Filene, they sincerely interacted with Black students and they, in fact, wanted to take Black students to another level - politically. They were of an integrationist mentality.

Part of the support also came in the form of university students from other campus joining the Lincoln students who traveled to Selma:

There were a number of interested students, the [Lincoln University] student government those students on campus that were rather politically sophisticated. We chartered a bus and we joined others, here in Saint Louis - at Washington University- who also journeyed to Montgomery with us. We went to Selma/Montgomery and we joined the march in St. Jude, and that was an experience.

One of the teaching fellows who accompanied the students had this recollection of how the trip came about: 
[A student] started walking with a hand written sign on cardboard hanging around his neck: "I am in sympathy with the Reverend [James] Reeb and the events in Selma, Alabama." Just that simple thing and he got enough interest among students that for the final day of the Selma demonstrations, Selma - Montgomery March, he organized students, raised money and went to the Greyhound bus. I was on it, and I think other three or four faculty, some of them White. And we rode that bus all night. As I recall we slept on the floor of Jackson State University gym. We were at the SelmaMontgomery march and heard Martin Luther King speaking with all the confederate flags flying on the state capitol and all the state troopers and the cameras and binoculars, the most incredible hatred l've ever seen in my life, from the soldiers and the White people. And then when we were leaving, getting lost and boy! Did we all cheer when that bus found its way from the White community to the Black community where we felt safe - Incredible - That was the night Viola Liuzzo was murdered.

Activism grew at Lincoln following the trip to Selma, "We later came back on campus and we did a number of things in terms of organizing, politicizing students on campus," said a Black student who participated in the march. Lincoln's students remained involved in the evolving Civil Rights activities of the era. The same White faculty member cited above recalled:

The next year students organized a bus -and this is the Meredith March against Fear in Mississippi - this is after he'd been shot and injured and Martin Luther King took it over. So they'd rented a bus and we went to that and that was very different because that is when Stockley Carmichael started shouting "Black Power" - I still got a button with a Black Panther, "move on over, oh! Move on over you!"- but, I felt a little bit less[pause] I didn't know if I was welcome there. But it was a bus load of Lincoln students.

During the late 1960s, students staged demonstrations that went from outbreaks in the cafeteria to the burning of the student union. Although the disturbances were not racially motivated by inter group contact on campus, Black students, as the participant quoted below, felt the administration should secure 
for Lincoln's campus the same freedoms, privileges and standards of living

afforded to college students at the state's predominantly White campuses:

I think Lincoln could have been much further along if they had not been so strict relative to basic rights. It would not have been too difficult to give some basic rights to students. You can't imagine how rigid that structure was. [some basic rights such as] dress, curfew, things that kids at White institutions took for granted Lincoln was more In Local Parentis than the White institutions.

The quality of campus dining was one of the issues that ignited students' demands and in 1967 it contributed to two separate "riots." A Black student broke into laughter at the mention of "riots" and offered this clarification:

[Laughter] Well, let me tell you about the riot. I know the person who started that riot and he didn't start it with the intent of a riot. We were on spring training, the football team. We came up to the cafeteria to eat and the food they had for us was not fit to eat so this one player from Alabama took his tray and said "I'm not eating this junk!" and threw it [laughter] That started the riot. I think the newspaper folks were in town for some kind of program that was going on that night and we also found out that that's where all the good food went to their dinner and that was what pissed us off. We knew some people that worked in the cafeteria and they told us that all the good food was going to that banquet that night which is why we didn't get anything worth eating for our meal that evening so the guy threw down his tray and other people threw down their trays and they locked down the thing and got out of there. We had one individual who was talking about burning down and we said, "No you're not burning down." But we threw those trays and they locked us out of there. When they finished throwing trays they called the cops and the cops came up and the state patrol and locked us out and told us we couldn't go in the cafeteria or the student union the cafeteria wasn't in the student union. They locked down the whole building. So everyone carpooled and went to McDonald's.

A White female student who lived on campus at the time also laughed at the mention of the riot and stated:

Students always complained about the dorm food. I remember there was going to be a big dinner with all these people from out of town and so forth, so they were preparing all this food in the 
cafeteria [for the event] and there was a riot, basically over the food...some football players came through and they decided they didn't have enough substance that was edible.

External events also had an effect on the campus atmosphere. One of

those events was the assassination of Dr. Martin Luther King:

I guess part of it was the fact that Martin Luther King had been assassinated earlier that year, April, I believe it was April, and it was shortly after. That coupled with the student unrest across the country. I guess our students felt that they had to do something to show they were around. But there were no repercussions. You know. And like I said, there was no violence against the people, just the buildings [pause], "Burn baby burn," that's what it was.

The assassination of Dr. King also incited the concern of Black students for the welfare of their White peers. A White student recalled being warned:

I was on campus, in Bennet Hall when Martin Luther King was assassinated and I remember how charged the campus was about that happening. I remember some of the Black students saying to me, "Be careful, because a lot of people know you here, but other people don't and you may be targeted"...There was some concern about the White students who were living on campus, at least voiced by some of the other students. But I never experienced anything hostile at all.

In contrast, a White student recalled the concern he felt for his campus peers

when law enforcement descended on the campus:

I remember vividly when Senator Danforth was the Attorney General. He had a bus load of troopers in riot gear sitting in a bus. There was some unrest with some Black students. At that time the attorney general wanted to make a statement asking everyone for calm and for understanding and I saw the troopers barging out of that bus to make sure everything was $\mathrm{OK}$, and I kept praying. The fact that they'd been in that bus for two or three hours, it was hot. l'd just hoped nobody made any stupid moves. Fortunately, calm prevailed and everything was all right.

The Black students continued to grow impatient with the administration's disregard of their requests and their demonstrations became more aggressive. In 
the spring of 1969, a group of Black students took over the student union. A White faculty member recalled how even though the students' demands and methods had intensified, their target continued to be the administrators whom they perceived to be unresponsive:

There was never violence against the faculty or students. It was all against the administration. The administration at that time was- I hate to say this- but they weren't really honest with the students and that's my recollection of it.

Although the 1969 student-led disturbances at Lincoln were few and mild when compared to unrest at other campuses throughout the nation, they were deemed as riots by the administration and public safety units of the local police and the state patrol swarmed into campus as a result of them. As the demonstrations became more heated, President Dawson refused to meet the whole group of student leaders' who called themselves the "Committee of Thirteen." The president formed a committee of faculty and staff to intervene. One of the faculty members who served on the intervention committee spoke of how events unfolded:

Then they had the riots, the so called student riots, this was in '68 we had just moved into Founders Hall -students had taken over the student union - they had the state police out there loaded with gear, full gear I should say. They were all in riot gear. Of course that didn't help matters any, so what happened was they set up a committee of students, faculty, and administrators over at the student union. I don't know if I had the fortune or misfortune of being put in it. Being new here, I didn't know any better and so we met and Oscar Chapman was the leader of the administration at that time and the dean of students was Pugh, Ben Pugh I think. And Chapman kept making statements that he knew he couldn't deliver, you know, making promises, and Pugh made a statement to the students that if their demands were not met, he would resign. Well, students found out that he had already accepted another position and it didn't set very well with them. And they refused to 
leave the student union and they were ordered, there was a court order, I believe that they were to be out of the student union by 9:00, unless the committee was meeting. Well, several of us -the students wouldn't leave- and rather than them going to jail, several of us, stayed the night, sleeping on the hard floor and [pause] actually it didn't go anywhere and the culmination of the protest was the fires on the campus...The only building where there was any damage was their own building, the student union building, the bookstore burned, the cafeteria burned, there was considerable damage. And there were some reports of shooting going on, but those were never verified. At least, not to my knowledge.

The disturbances of 1967 through 1969 had a common thread: they were centered on the Black students' perception that the leadership of President Dawson was not providing them with the same campus atmosphere available to White students at predominantly White campuses. Students' demands were not explicitly racial as it pertained to White students on Lincoln's campus. Their issues were related to living conditions and what they considered antiquated practices, Black students felt that they were fighting for racial equality, not necessarily on their own campus, but when compared to what their White peers enjoyed at the public predominantly White institutions in the state:

The administration being what it was could not afford or did not afford the accommodations to students as did the White institutions: food, living accommodations so they were not as pleasant as you might expect at a White campus. So consequently our movement took on a different pitch. A lot of times we were actually talking about basic rights, freedom of speech, the food we were being served in the cafeteria. A lot of things White students took for granted at their institutions we were struggling here and we were confronting the administration that was recalcitrant in its delivery of those things. So that led to us really marching on campus us, actually meeting with our state representatives, we marched on the Capitol in '67. 
While motivations were very clear to the students involved in the demonstrations, others had trouble understanding their actions. A Black professor stated:

I've wanted to see some of those guys to this day and ask: "Why in the hell did you do that, why did you do it?" It wasn't necessary to do it. They were here talking about Black studies and we had all the courses you asked for already, we had all the courses you asked for, we were teaching those courses. What are you doing? Why did you burn down the union? I've never understood that to this day.

One participant's response may provide a partial answer:

We had to change so the movement thought that by burning it'd bring attention and they got heard because today there is no mandatory ROTC, there are no curfews. We knew things were changing and we wanted to be part of that change. We were knocking down all the status quo.

The general sentiment among the Black students of the period was that

their White peers didn't quite get what was going on:

Now, I can think of three of four White students -who I rememberwho got involved in the demonstrations, who did understand what was going on, but as a general rule, I don't know that the White students had an understanding of what the Black students were trying to accomplish in terms of equality and putting down racism.

A White student who lived on campus compared her own views to those of White commuter students:

Some of the older White students who were coming in [pause] just [pause] it was, they didn't have the same view of things as the students who lived on campus. It was like they didn't get it. They didn't understand very much what was happening with that [the Civil Rights Movement] and I remember being concerned about things then, you know, concerned about the safety of everybody, really. When you see things about Kent State, which really hit me very hard when that happen, about the shootings at Kent State, you just don't know how bad it's going to get somewhere, and you don't know what divisions between police and students and communities 
and students and campus, you don't know where that's going to go, about safety and what's going to happen.

This student's recollection fits the description of what a professor remembered hearing from other White students and the impact the campus unrest had on the White student population:

They [White students] talked to me about it. They couldn't understand what was going on. Some were sympathetic with what they were doing, some were not. The next year the enrollment fell off, the White enrollment.

At the end of the 1968-1969 academic year President Earl Dawson submitted his resignation and left Lincoln. A Black professor recalls his feelings surrounding that event:

I think that part of the problem toward the end was that Dr. Dawson was not well, 'cause subsequently he was put in a nursing home and I don't know where it was...some place like Hermann, at a distance. It was not in this immediate area, I was told. I never saw him again after that. Dr. Dawson was sick, he was not well, I found out later on and Dr. Dawson had dementia. To me that explains many of his reactions during that last year.

Research Question 2. What were the dynamics of intergroup contact at Lincoln University during the late 1950s and during the 1960s?

The answer to question two was sought through a portion of the interview that looked for examples of conditions for optimal intergroup contact among Blacks and Whites during the first fifteen years of desegregation at Lincoln University. Optimal intergroup contact, according to Allport (1954) leads to elimination of prejudice against the other group. Intergroup contact theory first proposed by Gordon Allport in 1954 has evolved into the theoretical framework adopted for this dissertation. This framework proposes the following conditions 
as necessary for optimal intergroup contact: (a) equal status within the contact situation; (b) intergroup cooperation; (c) common goals; (d) support of authorities, law, or custom (Allport, 1954,Pettigrew, 1998); (e) personal interaction; and (f) friendship opportunity (Cook, 1975; Dovidio et al., 2003).

Equal status within the contact situation. As the findings linked to question one revealed, prior to the Brown v. Board of Education decision, Black and White people in mid-Missouri had not had significant contact with one another. Given the nature of segregation when inter group contact took place, it was never under an assumption of equal status. Within the confines of the campus, White students who desegregated Lincoln found that although they were the minority, they did have equal status with their Black peers.

In the college environment of Lincoln University between 1954 and 1969 there were two major spatial dimensions for the students. One was the academic one, classrooms, labs, co-curricular activities. The other one was the residential dimension, dorms, the student union, extra-curricular activities and university sanctioned social events.

All participants, Black and White students and faculty, reported that within the academic realm all students, regardless of race, were treated equally and held to the same standards. A White student who attended during the early 1960s offered this recollection which is representative of what many said. He reported:

[In class] we were treated equally, I can't remember being singled out for any reason other than not doing what I was supposed to be doing, I can't remember anyone else being singled out for any kind of discipline or derogatory remarks because of race. I think the 
expectation for the Black students was pretty high. That the faculty often times expected them and encouraged them to do better than they were doing if they could. And I experienced that same thing. Mrs. Savage was the English teacher, I came from a small high school and I coasted through it, but I didn't learn how to study. I didn't learned to do my readings before I completed my papers and of course, Mrs. Savage picked up on that pretty quickly and as she did with several others in the classroom, but there wasn't a sense of you being picked on for who you were, just what you were doing.

This sentiment was echoed by the perceptions of Black students. One of them put it in the following manner:

The expectations that Dr. Greene or Dr. Miller had were the same for all students, regardless of anything. I remember one time I was in Dr. Miller's history class, the first day, he told us if you have more than 12 hours and you are taking my class, you either need to drop a class, or drop my class. There was no difference in the expectations of students in the academic environment here at Lincoln.

For some White students at Lincoln's predominantly Black campus, the sense of equal status was derived from drawing comparisons with how desegregation was unfolding at some traditionally White institutions:

I had a pretty good overview of how Black students were treated and ostracized and tormented in White schools - for which I am very ashamed of the White race- but I would really want to stress that the way we were received, the way we were taught and the relationships that we had with our teachers were wonderful.

This sense of equal status and expectations in the classroom rang clear and true to all participants. In the social environments such as dorms, the student union and social events, the sense of equal status was more elusive because most White students did not fully partake of these opportunities. Nonetheless, those who did found that they were held in the same regard as their peers. For a White football player, equal status was made manifest in his being awarded a 
scholarship and his knowledge that his coach would only give them to those who truly deserved them:

I am proud because I made the team and I'd tell my friends, I don't know if I made the team because I was good or because I was White. But I got a scholarship and I know Coach Reed wouldn't give a scholarship just to give it. I am very confident about that.

The comments of a Black athlete confirm that both in the classroom and in the football team there were no displays of favoritism:

We all had to do the same in the field or in the classroom because they didn't care what you were. If you failed your courses, you failed your courses and if you couldn't play ball you didn't keep your scholarship.

However, for most White student participants, there was never a sense of equal status - experienced by many as belonging- in the social realm of the university. A White faculty member remembered the following:

I didn't go to the cafeteria very often, but once in a while I would and once I got a White student to go in there with me and he was petrified [when he saw] all those Black people there. There was nothing hostile. There was no threat or intimidation. Just being the only one or one of two people in that room.

A White female student recalled avoiding the cafeteria, and echoed the sentiment that it had nothing to do with having been told whether or not she should go there:

Although I was in speaking and friendly terms with a lot of those in my class, we did not eat there... Groups of White students did not go to the cafeteria. We either ate a sandwich we brought from home, in the car. Or we went to local places to eat. It never dawned on us that we should or shouldn't do that nor did anyone asked us or encouraged us to do that.

This student was not alone in her practice of eating in her car. Another White student confirmed the practice: 
I remember if I had classes most of the day l'd probably eat my lunch in my car rather than go into the student union. So there was that apprehension, it wasn't apprehension it was maybe a feeling of not really belonging at that time [pause] other than we [Blacks and Whites] are in classes together [pause] you go your way, I go my way after that.

Later in the interview, the student added:

The four years I attended here I never once was in a dormitory. I don't know what the living conditions were like. Only in a few occasions did I eat in the student union. Which is really, not a nice thing to say having been here, but I didn't. At that time Young Hall had a long bench and I think it was referred as the White student union, the long hallway bench, that's where we'd congregate. We went to the library but we didn't partake in the student union, shame on me, but I didn't.

White faculty participants who began working at Lincoln during the mid sixties felt they integrated easily into the existing environment. "We would have dinners or whatever at each other house. There were a lot more Lincoln sponsored events; luncheons and such. The faculty was a lot smaller and very close knit." A Black professor also recalled this being the case. "When I first arrived we had a number of really young White professors, and I think they got along really well with the [Black] university professors, it was good, cordial, give and take." But those "university professors" also kept a watchful eye on the incoming faculty. A visiting teaching fellow who became closely involved with the students' movement recalled:

I remember Dr. Miller kind of warning me "be careful here," that I was being arrogant [in challenging the administration], and he was right, I was. And he reminded me that I could leave, but most of these faculty could not because they couldn't find a job probably as easily as I could. So he was, in a supportive way, reminding me to be careful but in saying you go ahead and say what you need to, but I can't and I won't support the students the way you are but he 
was smart and he tried to help me, I was young and arrogant and kind of naïve at the same time and to me this was exciting.

Intergroup cooperation. Intergroup cooperation implies that people belonging to different groups come together in order to succeed. It was the general perception of Black students that "opportunity at Lincoln for collaborative work with students and student organizations was always open to White students." Yet, when asked for examples of collaborative efforts undertaken by Blacks and Whites together, students only had sketchy remembrances such as "working together on a float with the French club;" or "working on the Clarion and the literary magazine." For a White football player, there was a more specific recollection as cooperation translated into an issue of personal safety:

There wasn't a game that we played that we didn't have a fight because I was on the team. I remember the first couple games I played, I didn't wear rib pads, and I would get kicked a lot so I got some cracked ribs. So I started wearing rib pads 'cause when you're at the bottom of the pile, you know, I wasn't loved and my teammates protected me... loved playing for who I was playing for, those guys protected me.

Beyond the traditional classroom/campus interactions, another aspect of college life characteristic of the 1960s provided opportunities for intergroup cooperation. Civil Rights efforts were led by Black student leaders and supported by some of the White students on campus. A Black student recalled:

We started having demonstrations on campus and our group got larger and larger and larger, we had torch demonstrations, we were speaking all over the campus, and had a real [pause] I guess about 500 kids got involved, basically Black kids. Oh, I'm sorry. There was a White couple that got involved, a guy by the name of Joe and his wife Marilyn. 
A White faculty member who intervened during the 1969 student-led takeover of the student union recalled a particular moment of cooperation with Black students during campus unrest:

There was a court order, I believe, that they were to be out of the student union by 9:00, unless the committee was meeting. Well, several of us, the students wouldn't leave, and rather than them going to jail, several of us, stayed the night, sleeping on the hard floor... I think the only concern for doing that was keeping students out of jail because they had a court order to get the students out of there if there were no faculty there. I don't remember who all stayed, but I know I did, I know Rosemary Hearn did, maybe we were the only ones who did.

At that same time, a White student opened her apartment to offer refuge to students during the campus unrest:

I was here during the time when our student union was burned, I didn't live on campus then, I had an apartment on Clark [Avenue] and that night some students came to our apartment and slept there.

A true sense of cooperation among students interviewed was only present for White students who took part in Lincoln initiated extracurricular activities such as ROTC, theater, the newspaper or in athletic teams. Other Black and White students mentioned that inter group cooperation was achieved by students who jointly pursued desegregation efforts in the community.

Among the faculty interviewed, intergroup cooperation was accomplished through committee work, service in task forces and the faculty senate. White faculty members recalled enjoying a strong sense of collegiality. "We [White faculty members] were very collegial and the Black faculty were very collegial with us...Basically Lincoln faculty has been very collegial." In some instances, though, cooperative efforts seemed senseless because they were disregarded by 
the administration. "When I came here we had a faculty senate, but we might have as well called it a faculty tea because the administration paid no attention to the sentiments of that body." By and large, the faculty members interviewed for this study expressed having had a sense of collaboration among themselves as well as with students and the administration, but there were no solid recollections of particular projects or initiatives in which intergroup collaboration was achieved.

Common goals. Common goals refer to explicit ends pursued by both groups through their inter group contact. Getting an education was unanimously cited as the common goal of all student participants in this study. The White student participants explicitly cited getting an education or a college degree as their singular goal for attending Lincoln. As an example, one of the White students said, "I was more focused on completing my college education and other things didn't get my attention." Another White female student proposed, "Everybody had a purpose to get the best education, because it was your only opportunity, your only chance." A Black student's comment confirms that this singularity of purpose on the part of White students was evident to their Black peers: "At that time the White students who attended commuted. Their primary focus was to get a good education. They could get a good education here." For Black students the purpose of completing their college degree came in competition with specific social and political pursuits engendered by residing on a Black campus in a predominantly White segregated community during the zenith of the Civil Rights Movement. Besides completing their education, they also felt a need "to cause equality to happen that had not happened because even though 
we were kind of isolated on the hill, we dealt with racism when we were out in the city."

Socially and politically, the agenda and goals of Black students revolved around assertion of their rights on campus and in the community. A Black student who attended Lincoln between 1959 and 1963 remembers, "I was very much a participant with my classmates, the students who lived on campus -the Black students who lived on campus- there was pretty much total support for what was going on." What was "going on" was a student-led movement for equality that included efforts to desegregate the surrounding community and secure funding from the legislature that was comparable to that granted to predominantly White institutions. These efforts continued throughout the end of the 1960s and resident students' demands focused on parity with other universities in the state:

We wanted to move from the small integrated college that had minimal resources to have a growing integrated college that had excellent resources. We wanted to be comparable to the University of Missouri which was only 30 minutes away. We felt that they [UM] got more funding than we did and we didn't like that. We felt our academics weren't as good as theirs and we didn't like that [even though] there were some of the [Lincoln] professors that were well known, we wanted Lincoln to get the recognition it should get and the money it should get, not what the [Lincoln Board of]Curators or the legislators felt we should get. We wanted more of our fair share of the funds that were coming out of the legislature each year. When we found out we weren't getting our fair share, that's when we started talking.

Throughout the 1960s, residential students' demands evolved from the individual level of securing service at local businesses, to the institutional level of seeking parity with the historically White universities in the state, namely the University of Missouri at Columbia. White commuter students for the most part 
continued to enroll in increasing numbers but remained on the fringe of the social and political environment of the campus.

Support of authorities, law, or custom. The support of authorities, law or custom refers to an explicit statement of approval of the intergroup contact. In the central Missouri area where Lincoln University is located, Black and White people, for the most part, had remained apart from each other until 1954 when Brown v. Board of Education ended segregation in public K-12 schools and other institutions followed suit. When it came to authorities and the law supporting intergroup contact, it was provided by the Supreme Court ruling followed by Missouri's attorney general heralding desegregation as the law of the land and the Lincoln University Board of Curators opening enrollment to White applicants. As a related note of support, as soon as Lincoln proclaimed that it would accept White students on campus, the legislature closed down the local community college that had been serving the White community for many years prior. One of the participants characterized the move as an effort to save money, but regardless of why it was done, the end result was that it had a direct impact on the White enrollment at the university in the early years:

The state legislators were afraid to take steps before they had to, [they were] reluctant to allow integration to take place, but once they made up their minds, it moved. They closed down the junior college here in Jefferson City, "We are not wasting that money anymore" - I'm using my own language now- "There is no point in having a junior college when you can go to Lincoln University, we can save that money."

As it pertained to social custom, it is not clear whether or not things moved based on some predetermined design of Lincoln's administration. It is a fact that 
Lincoln opened its doors to White students, but in the mind of most Black and White participants it remained a Black school. This perception appeared to be weakest among White students who attended immediately following desegregation, and strongest among Black and White students who attended Lincoln in the late 1960s. Through the participants' statements a thread was revealed that attributed the high and low points of intergroup relations on campus to an initial sense of hope and excitement about race relations following the Brown v. Board of Education decision and tension following the rise of Black Power toward the mid and late sixties. A White female participant who enrolled as a student in 1959 said about her time of arrival:

The racial climate was quite promising. I think there was kind of an excitement that this was an opportunity to have cooperation between Black and White students.

A Black student who attended between 1955 and 1959 felt that during his time at Lincoln "any White person who wanted to be a friend, or an associate, or wanted to be around the other people was welcome." In those early days, students even ventured out into interracial dating. The same student recalled:

there was a young [White] lady that I dated and we would meet in the library and staff like that and if there was a night program, she would drive in and she lived about 30 miles [away] and we might see a play or something together and we'd go out this drive-in and she would drive and I would drive... there were other people dating. It wasn't just me. There was quite a bit of [interracial] dating going on like that.

Nonetheless, interracial dating did not enjoy the sanction of community or university authorities. This Black student and his White girlfriend had a taste of that: 
One night we parked and she was sitting in my car and her car was behind and here come the cops - a cop - so he went down and then he came back, asked for my license, registration all that and asked her for her name and stuff, and then he said, "Well, you know it's dangerous sitting out here, you probably shouldn't be doing that." And then he left. Scared the hell out of her! and I didn't feel too good either. Her family didn't know that's why she was scared. So I came back to campus and she went home, he stopped her again on her way home. The next day in the library we met and she was still shaken, he'd threatened to tell her family, just scared the poor girl half to death and so [pause] we still saw each other. About three weeks later, they stopped Westbrook [whose car I had been driving the night of the incident] and first thing the cop asked him was, "Where is M...?" so they had to be talking to each other and then one of the professors said, "Mr. M..., can I see you a minute? I can't tell you what to do, but I'll tell you, you should be as careful as you can be, you know what I mean?" He was trying to say we don't want an incident or anything like that. So I just thanked him. So the friendships were dampened by things like that... you never could do anything openly or free so that put a damper on relationships too, and then you had to deal with the police, and then it was already bad enough you couldn't go to a damn movie, you know what I mean, you really didn't have a lot of options.

A White female student who enrolled in 1958 spoke of how social norms against interracial dating affected her:

I did not date any of the Black students and that was something that I didn't feel that society was ready for and I was not ready for that. I could not handle that kind of a social ostracism... Which doesn't mean that I didn't find some of the young men very interesting and very fascinating people.

Another White female who attended in the early 1960s also felt those norms even if they weren't articulated:

When I started school there, there was no interracial dating. There were barriers in terms of - you know - it wasn't [pause] if you went out with someone Black, as a White woman there wasn't any place that you could go because it was a small town and the era, the businesses in the town were not open. It was almost a southern town. So [pause] and there was no encouragement for that on campus, because the school didn't want the problems [pause]There 
was no discouragement, just an understanding that this was not going to happen, it wasn't going to be.

As the 1960s went on, interracial dating became even less of a likelihood and as a Black student who attended in the mid sixties recalled, the only aspect of intergroup contact that generated ill feelings, "the only time there was hostility was if a Black guy dated a White woman or if a Black woman dated a White guy, then there was hostility."

The flourishing of inter group relations, even outside of dating, was hindered by the segregated practices of the surrounding community because it prevented Black and White students from engaging together in social activities at restaurants, ice cream parlors, soda fountains, etc. Yet, at least one female White student participant recalled being socially active on campus in the late 1950s and early 1960s:

My [White] boyfriend and I attended fine art series events and the summer theater programs. He was the student ROTC commander in his senior year and we attended ROTC social events. With other math majors, Black and White, we had our own daytime social group. We studied together, ate lunch, and in general enjoyed conversing with each other. One time, I remember Dr. Talbot laughing because we were dancing the Limbo in the hallway.

The students who enrolled during the early days of desegregation appeared eager to fully embrace inter group contact. But neither the community, nor the university manifested endorsement for such relations. A White faculty member who arrived at Lincoln in 1964 had the following reflection about the lack of support from the school:

In terms of [Lincoln's leadership] doing anything to promote integration or positive interracial relations, I hadn't thought about 
that before, but it would seem to me unlikely - because it could've been taken as political activism. That would've been troublesome.

Some of the White students who enrolled in the early 1960 s were surprised to see Lincoln clinging to its Black heritage:

I think that as a White student here I had a naïve attitude, even at 21 , as though we would all appreciate each other and they would probably want to take on the White culture - because I was naïve, about that - I began to realize later that there was no reason to think that. They were proud of their Black culture too. And it would have been nice if we could have gained from both cultures and that's happened somewhat.

By the mid 1960s, Lincoln had a significant White student enrollment and had added many White faculty members to its teaching staff. Some of those professors were credited by student participants with helping to challenge the status quo on campus and the community:

With integration there also came in a large number of young Caucasian teachers and they began to infuse a different type of energy into the university and it was more a highly integrated kind of energy. I don't characterize it as a Black energy, and a White energy, but it was a very different energy. These young people came and they challenged people like my father [Dr. Errol Miller] and others who'd been there 32 plus years to question their assumptions in the ways in which they handled things.... which I think was real good, but it put the university in transition.

These professors encouraged White students to participate in campus elections and to get involved in other ways that pushed local students beyond their comfort zone. When a male White student ran for student body president, a female White student found herself visiting the dorms for the first and only time. "I was in the dorms once - the boys' dorm - campaigning for Eugene Lock." Another female student recalled running for homecoming queen. One of the efforts undertaken by one of these professors was the creation of a commuter student association: 
He started the off campus students association and started getting projects together that involved them in the campus, it was an avenue for a lot of people to actually start them doing social things on the campus without having to break into another social group.

Black students also related well with the newly arrived White faculty. They felt that these younger professors understood what they were going through. One of the faculty members recalled:

They [resident students] had a rally on the grass outside the building and I went out there to talk to them and just saying "hi" as my first statement they all applauded, took me [pause] I still don't know what was going on. They were, I think, simply saying thank you for supporting us by talking to us and being here at our rally. So that tells you where I was and where people thought I was and I was very outspoken after that.

At the same time that these integrationist faculty members arrived, the tone of the Civil Rights Movement was changing at the national level and some participants credited the rise of the Black Power Movement with a derailment of the strides that had been made in the arena of inter group contact. This sentiment was thus articulated by a Black faculty member who had taught at Lincoln since the time it was exclusively a Black school:

It [integration] was going beautifully... It was a model. Then, when the Black Power Movement took over and the Black activists got in charge of things, oh boy! did things changed, they changed so radically... This whole Black Power thing made it appear that Whites were no longer wanted, which was not true. As far as the faculty was concerned it wasn't true.

A newly arrived faculty member also noticed the change:

In the second year [1966] Black Power crept in and that changed the tone quite a bit. Black students started really becoming much more assertive. There was a really interesting kind of tension...I don't know where it came from. I started noticing some Black students, males, started being a little sarcastic about Whites, more willing to talk about "crackers," not me, not at Lincoln, but outside. 
Black student participants who were at Lincoln during the late 1960s had a common perception of their White peers. They saw them as taking advantage of the opportunity afforded to them by Lincoln without giving anything in return. "Most of the White students were either farmers or descendents of business people and used the university primarily to get their higher education degree."

Another Black student who attended at the end of the 60 s had this perception:

They [White students] needed an education and they realized that they could get it at Lincoln. I guess that they had to have some courage to come to Lincoln, but didn't do nothing [sic]. When it was dark they were off campus. That's an indication that they were scared to be on campus after dark, maybe, maybe not. It was an all Black school after dark.

Participants who were at Lincoln in the mid and late 1960s held the view that inter group contact was not explicitly sanctioned by local or institutional customs and that this had resulted in all constituents perceiving Lincoln as a Black campus. A Black student who attended from 1967 till 1971 held that view:

I always saw Lincoln as a Black institution, an African-American institution. I really didn't think of it that way [as a desegregated institution] I just saw Lincoln as an African-American institution. While on campus, even though there were White students around, and I attended classes with White students, I never thought of it as being integrated.

A White faculty member who joined Lincoln in 1967 recalled how the "Black campus" mentality became clear to him:

The elections that were held for student offices were held primarily for Black students. If the White students should have to run, they wouldn't get anywhere with it. As a matter of fact, there was one time that there was a White student running for student council and the election was supposed to take place in Young Hall at a certain time. Well, what they did, the student government moved the 
election to the student union and didn't tell anybody, except the Black students. So the White students didn't have a chance.

Faculty members stated that for them, the institution did not explicitly encourage intergroup contact among faculty, but it was achieved through participation in committees and in social gatherings initiated by various departments. A professor who arrived in 1968 stated:

There was always opportunity or the necessity to talk to your colleagues about this matter [curriculum of commonly taught courses]. We all had our offices in MLK and we all kept our doors opened and we would drop into each other's offices. Once in a while one of them would entertain in their home and invited the rest, or there would be celebrations on campus - there were many opportunities to cement friendships that way.

Personal interaction. Personal interaction refers to social interactions that allow for personal disclosure and interpersonal exchanges about one's life, values, goals, fears, etc. Student participants reported having very little personal interaction with members of the other race. A Black student stated:

There was not too much (cross-racial) socialization. Those intricacies of sharing meals together in the student union or the normal act of chatting about your life or your home or taking trips together during the holidays. I don't recall being taken to any student's home there.

One of the Black student participants who arrived at Lincoln in 1965 felt he had had the opportunity for personal interaction with White peers. However, it was not provided by Lincoln, but through his participation in a baseball league in a nearby community:

The socializing of Blacks and Whites was something I had never done in my life. When I came there, there were some guys that were in my class and, I started to play baseball with a little club that was in Linn, Missouri and I was the only Black down there, you 
know, but even in the little town of Linn, I wasn't perceived as

Black, I was perceived as a guy that played pretty good baseball.

On campus, a White female student who got involved with the theater group circa 1958 shared the following about her experience:

I thought they were very accepting of me. When you are spending that many nights, sometimes until two in the morning, you are just simply exhausted, any barriers that you may have are going to be broken down. There was a lot of humor that we had to use to just kind of keeping yourself going. There were a lot of people that I was fond off...

For incoming faculty, personal interactions were facilitated by an overall welcoming atmosphere. One of these participants said, "People welcomed me, faculty and students, Black and White. I felt very welcomed." Those new faculty members expanded the circle of interaction with students beyond the classroom:

There was a group of them [Black students] that invited me to their room to hear what I guess was John Coltrane music, telling me this was music that I would not understand but I really needed to hear it.

Friendship opportunity. Friendship opportunity refers to the development of relationships that go beyond the context that first generated the intergroup contact. All of the participants expressed having been aware of the opportunities for intergroup friendship available to them during their time at Lincoln. Many White students reported becoming friends with Black faculty members. "We had friends [in the faculty], we had easy relationships with them. I invited Mrs. Savage to our wedding," said a White female student. Another White student also reported having a long lasting relationship with a faculty member and his whole family. "Ted and Clara were the godparents of one of my children. Still when I go 
back to town, my first stop is to visit Ithaca and Clara who are the children of Ted and Clara."

A White female student reported developing strong bonds with Black male students, free of the concern of the friendship evolving into a dating situation:

As a woman at Lincoln I had a lot of Black male friends, just because we could be social and funny and talk to each other about class work and things like that, without any of the sexual issues being at play.

Yet, another White female student expressed not having developed very meaningful friendships with her Black peers, "I did not have any deep friendship with anyone [Black]. We were friendly, but it just didn't happen. For no real reason, you just stick to your own I guess." Her sentiment was echoed by a Black student from the late 1960s who characterized the intergroup relations he developed more as cordial exchanges than true friendships:

I remember some friends that I had in my PE class that I see even now. Some in my math classes that I developed fairly good rapport with. But it wasn't the kind of relationships where I would go to their houses or spend time with them outside of class... and I'm not saying that that didn't happen to other folks, but I never felt those relationships to be more than cordial relationships. I still now run into folks that I had classes with and we still have cordial relations, but I don't see that being different than the general society. Very few of us have friendships with members of other ethnic groups.

Yet another Black student who attended during the mid sixties felt there were opportunities for meaningful cross-racial friendships:

Opportunities for Blacks and Whites to have life-long friendships were present. The long term relationships of college students overlook one's color and we at Lincoln had a good opportunity to cross those barriers with friendships. 
For other students, the intergroup friendships that began in the early 1960 s have strengthened through the years. A White student offered the following reflection:

I think that bringing us together in classes and business league and things like that we really developed friendships. In fact, racially, you didn't know it existed and to these days some of my closest friends are Afro-Americans that I met then. In fact, it is closer now, it's like when you are doing it you don't realize you are doing it and when you go back you realize there was a strong tie there.

Research question 3. How were the University's culture and organizational identity influenced by its racial desegregation?

Findings on the spheres of influence upon the institutional culture at Lincoln at the time bracketed for this study presented three distinct themes: (a) academic decline, (b) leadership crisis and (c) intergroup disconnection. To understand how the university's culture and identity were influenced by desegregation, the researcher probed the recollections of students and faculty who were at Lincoln prior to, during and after desegregation in 1954.

Academic decline. In 1954, Lincoln University was a small Black university that prepared undergraduate students for careers in teaching, liberal arts, business and agriculture. It also managed a law school and a journalism school. Nineteen of the 26 full professors and associate professors held doctoral degrees conferred by some of the most renowned universities in the nation. These professors also had a substantial body of publications and were well respected in their fields. Since the 1920s, university administrators had risen above the conditions of a separate and highly unequal system of higher of education to bring together a faculty who in academic preparation, commitment and 
scholarship students perceived could rival that of any prominent university in the

nation. A student who attended between 1955 and 1959 stated:

Lincoln had one hell of a faculty. When I tell him [grandson] that in freshman biology I had a PhD teaching me, I had a PhD in chemistry teaching me because I was premed, I had a PhD in a couple of other classes and I was a freshman. They were from Cornell, they were from Harvard, they were from Yale, from University of Chicago they were from all the big universities because they sort of represented the elite, the cream of the Black Schools that were able to get them into these great institutions. The thing about it was that when they got out they had no place to go so they wound up here for three or four thousand dollars a year which I didn't know at the time, but came to know.

Participant after participant, especially those who attended in the early

years of desegregation, echoed his sentiment and exalted the merits of this

illustrious group. A Black student who attended Lincoln between 1951 and 1955

spoke of the faculty at the time of desegregation:

The faculty at Lincoln was of such a status that the integrations of Whites into the school were no challenge to them at all. Because at that time, most of those faculty, had gone to White school to get it [a doctorate], and they had to be at the top, or near the top of their effort, to make it, so they didn't have any problem at all. Some of the students found that the teaching crew here, at Lincoln, initially, could hold its place with any, in certain fields [pause] Dr. Greene had written 14 books.

The fact that faculty members teaching at Lincoln at the time of its desegregation had received their PhDs from White schools was perceived to be a reflection on their ability. One of those faculty members offered this thought:

Lincoln had a faculty that, well although it was not as large as that at the University of Missouri, were educated at the same institutions: Columbia, Harvard, Michigan, Yale, they had the same people- Illinois, lowa, Kansas, Scruggs himself was a PhD from Kansas, they knew those people were here and they knew that people didn't give us those degrees, they knew they'd made us work for those degrees. 
A White student who attended in the early sixties proposed that these faculty members were not just well known for their degrees and accomplishments, but also for the standards they conveyed in all they did:

Professionalism was set first. The professors came in with suits on, bow ties - I remember that very vividly - they came walking in and they wanted the students, Black and White, to act professionally. They were very concerned that you come to class on time...otherwise you went to the dean's office. You didn't want to go the dean's office.

Another commuter student recalled a long lasting lesson in integrity:

Mr. Blue, he had such a high sense of integrity. He would talk to us about that. He had a sense of academic integrity, and academic integrity didn't just mean not copying from your neighbor on a test. It encompassed much more than that. If you really didn't know something, you didn't go out and pretend you did. It encompassed so much more than cheating on a test and that has stood with me forever. Not only the academic, but what integrity meant. If I had to pick one [professor] who influenced my life the most, it would be Mr. Blue and this issue of integrity... He didn't have a PhD. He was from Harvard, and he had all but his dissertation, and I remember a few times students called him Dr. Blue and he'd stopped them right there and told them, "No, I'm Mr. Blue." It was important to him that we were honest about ourselves. And here I am 67 and I was 18 and that still influences me.

The academic culture at Lincoln at the time it was desegregated was one of scholarly rigor and character education. Students, Black and White, expressed that for the most part they knew they were being imparted a great education. A Black student who went on to graduate school recalled how the academic rigor overflowed into the social sphere of the campus and prepared him to succeed:

The fraternities would sort of compete with who'd have the most people on the honor roll. Of course, my fraternity always had the most, probably because they had a reputation from years back of being studious and others had a reputation of having good parties and they were happy with that...As a post doc in California, I was 
doing experiments in the lab and people stood and watched and asked, "Where did you learn that?" and l'd say, "As undergraduate." They couldn't believe that I had that much experience from what I learned as an undergraduate. And I did not get it while working on my masters, or my doctorate, I already knew all of that stuff.

A White faculty member who arrived in the mid sixties felt privileged to be exposed to a body of scholarship that even his Harvard education had not provided:

The faculty- the Black faculty- most of them were very impressive people and opened up to me a whole world that I had been pretty much unaware of. This Black higher education and scholarship things that had gone on beyond my horizon and now I was able to see what they'd been doing in the segregated academic world and I was quite awed by many of my colleagues there [at Lincoln].

The desegregation of Lincoln had very little immediate effect on the academic culture of the school. A White student recalled recognizing very early on that those teachers were the essence of the high quality education he was receiving at Lincoln:

At the moment [of desegregation], the faculty stayed the same - in the culture - and the culture of the school remained the same. Not so much changed in Lincoln...but as soon as those professors left - because as you probably know, Nathan Young back in the 1930s went out and upgraded Lincoln substantially and received a bunch of young instructors, PhDs and those teachers came in the 30 s and 40 s and were with the school until approximately the 1970s, give or take - and that was engrained at Lincoln when I came, but I knew that as soon as those professors left there would be a great transition.

The professors who were teaching at Lincoln at the time of desegregation had enviable knowledge of their subject matter and of Black culture:

We had things here that the other schools had not achieved, we had Dr. Cox here teaching courses in sociology you couldn't get at the University of Missouri, Mr. Blue was teaching Black literature, Greene and Savage were teaching Black history. 
Local students who were at Lincoln during the transition years when White faculty members were incorporated into the teaching staff felt that they had been exposed to the best of both worlds:

When I was at Lincoln, the professors were amazing! There were lots of really, really, really good [Black] teachers. And those were supplemented my junior and senior year by some very intense young White teachers that came to have the experience - Pete Kellogg was one, there was an incredible literature professor Bob Claus, Peter Filene, and then one of our journalism professors, Dr. Martin and they all came to this school because of what was happening there.

As the student's recollection implies Lincoln's desegregation experiment was attracting White scholars to the campus. Nonetheless, desegregation also had a disastrous side effect: the Black brain drain. As White campuses throughout the nation began to diversify their student and faculty populations, Black colleges like Lincoln lost some of their brightest:

Integration of course opened the avenues of employment for African-American faculty all over the country and just as there was a called brain drain all over the country, it happened here. So we lost my neighbor down the street, A.P Marshall who became the librarian at eastern Michigan University; we lost Dr. Miller, in government who went to the University of Indiana as Head of Forensics. I was offered - I almost went, as I told you- I almost went. I had three offers.... I would've doubled what I was making.

A White student who attended Lincoln in the early 60 s was aware of the faculty departures after his graduation:

Some of LU's stellar faculty, who benefitted me so greatly [left after I graduated]. Dr. Talbot of the Math Department went to Michigan I think, where I hope he got a great salary, commensurate with his ability. Dr. Miller left eventually as well. Mrs. Savage of the English Department, she was priceless. 
These academics were not only teachers, but repositories of Black culture. Their departure due to better opportunities or retirement left a void in the cultural aspect of Lincoln as a Black institution. One of their colleagues who stayed reflected:

[Black] traditions were lost, lots of people tried to preserve them, but they didn't know them to preserve them. You can't preserve what you don't know. The alumni tried to preserve them [pause] It didn't mean the faculty weren't sympathetic to them, they just didn't know them to preserve them...

As these talented professors left, it became almost impossible to replace them:

It became very difficult to get highly trained African-American faculty. If you earned a doctorate, had earned a doctorate, you got an offer from the big ten schools, the big 8 -All over the country. Lincoln couldn't compete. It became very difficult. So what happened was large number of Asian, African and Caucasians had to be brought on to fill the vacancies in the faculty. We scuffled, because we said, that's fine, but we still think there ought to still be one or two Black faculty members. I can remember, in the Department of English how we were scrambling to find a Black PhD and we couldn't and when we found them, we couldn't bid with'em.

Prior to Lincoln's desegregation the caliber of its Black students had been that of "quality kids." One of the Black students who was a senior at the time of desegregation recalled:

Before it was integrated you were selective in the people that could come to Lincoln, that is, the competition was so great for persons to go to college. You know there was no [pause] coming to Lincoln, I wasn't getting no Pell grant to come to Lincoln...You really had those people that really had a commitment to learn, you know, and were willing to sacrifice what it took to learn, in order to get there...When it became integrated, you lost that...and one other thing, that pride of being a college student in the fifties. College was not an opportunity for everybody.

The tradition of high achievement continued during the early years of desegregation. A White student who attended during the early years after 
desegregation spoke of how Lincoln's reputation attracted some of the higher achieving White students also:

The role of being a very elite school like the Harvard of the Midwest. That was brought about because you received the best students. The White students at the time- and again, knowing this area, several high schools south of here and east of here and west of here- I know our class had several individuals who graduated at the top of the class: valedictorians, salutatorians, honor society and those were the White students who were attending in that first batch. You could see it and I think it brought up the standards even higher 'cause you brought in the best: the best of the Blacks and the best of the Whites.

Class rankings for incoming freshmen during those early years confirmed this student's recollection:

In 1963, sixty-eight of the 329 first-time incoming freshmen ranked first, second, or third in their high school graduating class. Another thirty-nine freshmen ranked in the upper third of their high school class. In 1964, 112 members of the new freshman class of 499 ranked first, second, or third in their high school classes with an additional sixty one ranking in the upper third of their high school classes (Holland, 1991, p. 47).

But by the mid sixties however, a less prepared student population also began to matriculate. A White female student who later taught classes as adjunct faculty made comparisons between the students with whom she had studied and the ones she was taught:

When I came back as a teacher, that would've been back in $63 \ldots$ I was teaching the English 101, 102 which all the students had to take and at that time some of the inner city - St. Louis and Kansas City kids - were coming in and I was really struck by the difference between those people and the students that I had associated with as a student myself. That they were not as qualified, that they did not have the background that the other students had.

A White faculty member who taught at Lincoln in the mid sixties expressed being surprised by the lack of aspirations of Black students. He noted: 
One thing that came across over time was the limited aspirations of [Black] students. Most of them were going to be teachers, undertakers a few, maybe lawyers but the only professions they considered were professions that would serve the Black community. This is before the civil rights laws. So no one was studying engineering. You'd assume you would have to work for a White company.

That trend continued even after the passing of the Civil Rights Act of 1964 and another White faculty member who arrived at Lincoln in 1965 stated:

I was astonished that so many Black men were looking forward to going into the army, or the military, and it took me a while to figure out that, oh! That was one career line that was relatively more open to Blacks that others were.

One of the White student participants had the rare opportunity of going through his major courses twice. His experience illustrated what many other participants suggested:

In 1967 we [my wife, also a Lincoln graduate, and I] left and went to Saint Louis and in 1969 we came back...I took my accounting courses over [to prepare for the CPA exam] and I could tell a difference in teachers compared to what I had had from 63 to 67 . Some would just almost give you a grade, whatever you'd want. I was just so surprised. I was more interested in studying the second time around.

Leadership crisis. The administrative period preceding desegregation was marked by leadership focused on Lincoln thriving as a segregated university. In contrast, desegregation and all its implications posed many challenges to Lincoln's leadership. Following desegregation, Lincoln's administration, for the first time in its history, had to serve the social and educational needs of a Black resident population, incorporate a White commuter population, respond to the void left by the Black brain drain caused by retirements and the desegregation of historically White universities, redefine its place in a semi-segregated community 
and maintain a working relationship with the state legislature. These often competing interests created an ambiguous agenda that led to much internal turmoil.

As illustrated extensively in the responses to question one, Dr. Dawson's leadership of Lincoln between 1954 and 1969 was perceived by Black and White participants alike as, "kowtowing to the White legislators," and had a tremendous impact on the culture of the institution during his tenure and beyond. The period bracketed for this study was marked by the rise of a powerful student government, comprised mostly of Black students, and the demise of a top administration perceived to be out of touch with the socio-political context of the institution. This perception led many to characterize the leadership of President Dawson as compliant. A Black participant stated:

Dawson was an extreme - we would characterize him as extreme Tom- and he reflect that, and those he hired reflected that kind of mentality. So we had people in administration like James Errol Miller who was reactionary and Dean Hoard who was quasi reactionary. He recognized the necessity for change, but he also recognized the need to keep his job and those people he recruited, Pugh, and Betty Adams were also of the same cloth.

A White faculty participant recognized that Dr. Dawson's acquiescent administrative style might have been essential to the survival of Lincoln as a desegregated institution:

I think it would've been impossible for him personally [to change his administrative style]. He had developed a political role that had worked as well as it had, not great, but there was Lincoln University doing a remarkably good job under the circumstances. So for him to change at the age of 67 , or whatever he was, that was impossible. And politically speaking too, if he had stood up, he would've been pushed out I suppose. He was outdated, suddenly 
by events [pause] he was still operating under rules from before the Civil Rights Movement.

The political forces of the Civil Rights Movement were running strong among students on campus and when confronted by the demands of this movement, the administration repeatedly came on the side of the status quo and against the student leaders. A Black student leader recalled how this played out for him in 1967:

The day of the demonstration Dean Chapman, who was the dean of instruction, had sent people around to get me out of class.

Eventually he came and got me out of class himself and took me to his office and he wanted me to call off this possible demonstration that was going to occur in the cafeteria. And, he asked me what my intention was upon graduating and I said, "Well, I'm thinking of going to graduate school" and at that time he indicated that I could literally get into any graduate school, that he'd write the letter of recommendation for me to call things off - "Are you trying to buy me off?" [I said], [and he responded] "No, no, no." Then the demonstration occurred and I was arrested. They went through a kangaroo court in kicking me out and it was on those grounds that I took the school to court [because] I wasn't offered due process and my case became a classic case regarding student rights [pause] the school was forced to let me back in.

Looking at the situation in retrospect, a White faculty participant reflected on the political landscape of the time:

I talked to President Dawson at least once or twice [pause] and he was [pause] I really admire his willingness to talk to me because I was being kind of obnoxious, acting as if I could argue with him, where here I was, a young White person totally newcomer to this scene. He knew what was going on, which was that he was running a state-supported school and the state was not happy with these Black people causing disorder. This was at the same time that Stockley Carmichael was running around screaming "Black Power" and terrifying White people. President Dawson needed funds and needed support from people who wanted a good compliant Negro president. I knew that was the case, but somehow I thought he should've stood up and defy the people that controlled this 
university but he was stocked in the middle and I was pushing him from the outside.

For another White faculty member, Dr. Dawson's dealings with external constituencies were reminiscent of those of a fictional character:

It [Lincoln] was in the state capital a very conservative town in a very conservative state. While I was there, I read Ralph Ellison's Invisible Man, which has this college president, Bledsoe. It sent chills down my spine because Bledsoe reminded me so much of Lincoln's president. And he was a Black man who since before integration had had to work with those White legislators to get money for his school. So one of the things he had to do was keep the lid on and that's what he had to do to protect the school and survive. I don't think this man [Dawson] was as cynical as Bledsoe, or as capable, but I think he was dedicated to the school and that's what he had to do.

But, while the adults could, in retrospect, see the conundrum in which Dr.

Dawson was placed, those who were students at the time could only see him as failing them and the university. A Black student stated:

[There was] a rather conservative, Booker T. Washington, type of mentality that the administration under the leadership of President Dawson was fostering at the time, and of course that went back to the administration feeling it had to stay in place in order to get the few crumbs they were receiving from the legislature at that time.

Desegregation affected the administrative component of the institutional culture of Lincoln by making it inexcusable for its president to remain an accommodationist. The students who attended Lincoln following the Brown $v$. Board of Education decision expected their president to claim for their university all that, as a state institution, it was entitled to receive. The disparities of the "separate but equal" era were to be remedied and when students felt that Lincoln wasn't getting its fair share, they took matters into their own hands. By the late 
1960s the power grip exerted by Dr. Dawson in the earlier years of his administration yielded to a strong student government:

Our president at that time was -I think Dr. Dawson- he was not very forceful with the legislators or the curators so we kind of moved him out of the way - and said "Hey, you had your chance, now give us a shot because what you've done so far, what you've done hasn't been too good." He moved out of the way and let the Student Government Association and most of the students do the talking with the curators and the legislators because we really felt like he wasn't taking proper measures.

Student leaders began forging alliances with local students, new faculty, curators and Black legislators:

We had quite a few of those [White] individuals who were at those meetings and in most cases quite vocal - they were as vocal as the Black folk - we had a good mix of people that said "hey! it's time for this place to change" and one thing we looked at was, if Lincoln doesn't change - we are talking about 65, 66 - there is no chance that is going to grow because we are going to talk to everyone we know and tell them don't come here [pause] and we had some people in the [Board of] Curators that were sympathetic, but they were not the whatever the chief person was at the curators, but in time they got in a position to help and we also got some of the graduates from Lincoln on the Board of Curators and that also helped.

This shift in power turned the hierarchical leadership of the institution on its head and created an organizational environment in which the students and the newly arriving faculty felt they were best suited to define the institutional agenda and pursue what was in its best interest. Given the traditionally patriarchal and authoritarian nature of administration at Historically Black Colleges and Universities, this shift created a leadership crisis in the organization and confusion about its organizational identity. A White faculty member who arrived in the mid sixties offered this diagnosis of the situation: 
The institution has a kind of schizophrenic personality, kind of split personalities. We have a difficult time reconciling our mission statement in terms of "we are open to all students" and the point that we are a historically Black school. The institution has never resolved that, those two sets of goals.

Intergroup disconnection. Prior to desegregation Lincoln had functioned

solely as a residential college partly because the surrounding community practiced segregated housing. The administration exerted control over the academic and social aspects of students' lives. A participant who grew up on Lincoln's campus offered this recollection of life on campus prior to desegregation:

I think prior to 54 you had second and third generation students coming to Lincoln from the same family. Their parents went there, their cousin went there, the person around the corner went there. So therefore there was a logical progression and feeder system in place by virtue of the fact that the HBC offered, as we used to say, more than an education in the classroom, it was a cultural education. For example, prior to 54 there was a certain rigidity. Young women had to be in Anthony Hall by nine fifteen at night, young women had to have a permit to ride in a car, gentlemen were only allowed in the front door of the dormitory; a whole host of other things. So parents when they sent their daughters to Lincoln expected Lincoln to be a family. Sure you will learn political science and mathematics and biological science, but at the same time you were monitored carefully, behaviorally you had things in place that provided exposure to African-American culture.

Another Black student who arrived in the late 1960s confirmed:

Many of the Black colleges were like being at home with your mom and dad. They had rules and regulations and if you violated those rules and regulations there were consequences and all those kinds of things. You left your parents' home and went to a larger home with those same kinds of rules and regulations. 
Some of the first White students to attend Lincoln mentioned noticing that social aspect in the culture of the school. "The students I associated with were upper socio-economic students from the South and they had been looked after."

The early years of Lincoln's desegregation were characterized by positive feelings on the part of Blacks and Whites alike. A Black faculty member reminisced, "It was going beautifully. The story that is in that Ebony [Magazine] is true: "The school that was too good to die." It was going beautifully. It was a model." White students commented, "We were happy as larks...I had these wonderful teachers...for the most part...and so did the other community students."

Desegregation exerted a major shift in the constituencies that converged in the institutional culture of Lincoln University. When Black students integrated into predominantly White colleges and universities, they were assumed to adopt the cultural values and social mores of the majority group. When majority students integrated this Black university, their social circle remained their community and the soon established $50 / 50$ racial composition of the classrooms was never reflected in the residence halls or other social spaces of the campus. The following quotes illustrate that social situation. A White faculty member who began working at Lincoln in 1967 said:

I don't remember much interaction between Black and White, and the dormitories were entirely Black. The school was 50 percent White and the dormitories were all Black. White students lived in town or around there and came because it was cheaper.

His perception was not very different from that of a Black student who enrolled at Lincoln in 1959: 
I would say that Black students, in my view, benefited a lot more from the college experience while I was at Lincoln. I think that all students got a good academic education and the institution did a good job at fitting all students into that academic environment, but only Black students got a social education. For the most part, Black students were the ones that were fitted into the social environment of the school. They would be the ones you'd see at and participating in the theater productions, the concerts, and lecture series. They would be the ones you would see in the debate club. If there was any group that I think missed out in that time frame from what l'd consider a whole college education it was the White students.

But White students did not see Lincoln as being responsible for the social aspect of their lives. Even though they were attending Lincoln, they were still inextricably connected to their community. Even when on campus, they sought the familiarity of places that could be easily identified with their upbringing. For many of the Catholic local students, the Newman Center became the de-facto commuter student union, "In between classes I went to the Newman Center, that's where we all hung out," said a White female student.

Desegregation at Lincoln meant that the university, which until then had been a cohesive academic, social and cultural center for the Black community had to redefine itself in terms of its mission and institutional identity. The incorporation of White students was very rapid. According to institutional figures, Lincoln's White enrollment had reached $22 \%$ by 1956 and $32.5 \%$ by the fall of 1958. With the arrival of the White students, cohesion eluded Lincoln's institutional culture:

There were two Lincolns. There was a day time one that was highly integrated, where there were large numbers of White citizens from the surrounding farm areas of Jefferson City and Jefferson City, who during the school day participated at the university. And then, after dark, it became an African-American institution or HBC in 
which there were minimal numbers of White students. So you really had two universities and it wasn't segregated per se, but in fact it was.

But it wasn't just the arrival of a new group that influenced Lincoln's culture and identity during the 1960s. The process of its redefinition was also greatly impacted by the cultural currents running through the African-American community at the time. For Blacks in the United States, the 1960s were characterized as a period of deconstruction of old archetypes and the search for a new identity. It was a time of assertion of those rights that were granted on paper, but often denied in practice. It was a time of flux in the nation and at Lincoln, even among Blacks there wasn't a shared monolithic view. A Black faculty member spoke of his surprise the first time he saw two African-American female students walk into the cafeteria sporting Afros. Participants who had a pre and post experience of the Civil Rights Movement perceived that some of its facets hindered a true integration of Lincoln.

A Black faculty member felt that the movement created a negative atmosphere for White students. "Black students were saying to White students, 'There is no way we can survive together until the whole system is changed."'

A White female participant who was a student in the early sixties and returned as faculty in the late sixties shared the opinion stated above:

I came back to Lincoln in 68 as faculty. When the Union was burned, that's when I became more aware that there was some radical Black thinking that was different from the White thinking. I had thought that we were all appreciative of being at Lincoln, that everything was the way that all Blacks and Whites would like it. Like we all agreed that we were going the right direction until this happened and then I thought, "There are some issues here that maybe I wasn't too aware of." 
As far as the Black students were concerned, there were indeed many issues to address and they tried to identify faculty allies who would support the new paradigm they were trying to establish:

There were White faculty too who were supportive, Filene and Carter who were Woodrow Wilson Fellows and they were supportive and other people too, like Cecil Blue as well as Lorenzo, Lorenzo Greene, who was one of our mentors. Cox was kind of in the back. Cox was more of an intellectual and was not involved with those "cause" sorts of things. Cox would intellectualize about revolution [laughter] but he saw the mission of a professor as a right to talk about those sorts of things.

During the 1954 to 1969 period, Lincoln University's institutional culture was affected by multiple internal and external variants. These variants, brought upon the campus largely by desegregation, influenced its academic, administrative and social aspects. Participants offered the following reflections about the final outcome. A Black student said:

I think it [desegregation] changed the character of a Black institution which was revered by many, respected by many, and was the jumping off point for a whole three or four generations of Black educators, primarily. I don't necessarily think that the change was good, but the world at that time demanded the change.

The feeling that Lincoln lost more than it gained by desegregating was shared by a White female student who attended the university in the early 1960s. For her, the realization that Lincoln was giving up aspects that made it unique became clear as she had an opportunity to explore some of the institution's history:

Unfortunately, I don't think it [desegregation] was good for Lincoln. I think Lincoln has become more of a community college. [While I was there] I went through a bunch of all newspapers that were stored in the basement of the journalism school and found all these things on these people that came back as World War II Veterans and were very intense about the school and wanted to get a degree 
and wanted to change the school and desegregation and all that, reading all that, I felt - We are making these huge changes here that are good for us, but not good for the school.

A White male student who attended during the same period commented on the impact of desegregation upon the previously cohesive student body:

The student body, the Blacks, as I look back, in the 1950s -and I have a lot of friends who were here in the 50 s -they are very, very close knit group...When they were diluted [pause] I mean, at that time it was Black students and diluting it particularly with commuter students [pause] I think eventually led to bringing in not as many good Black students. Black students had other places to go. When this occurred many went to other universities, not historically Black universities, they wanted another experience a diverse experience which was brought to them by freedom of choice.

A White female student who was a residential student in the late 1960s offered this assessment of how Lincoln's culture changed during the 4 years she attended:

I can say a lot of change took place on this campus, a lot of administrative changes, a lot of rule changes and I think it was reflective of what was going on all over the country, it was putting a lot of opposing forces together and people had to sort that out and it didn't always come comfortably or easy, but very eye opening for people who attended this campus at that time.

Summing up, the desegregation of Lincoln immediately following the Supreme Court's decision of Brown v. Board of Education took hold in the classrooms in a much more successful manner than it did in the social sphere of the campus. This lack of social interaction among resident and commuter students resulted in Lincoln developing a fragmented identity. On the one hand its administration and pre-desegregation alumni tried desperately to cling to its glory days as the Black Harvard of the Midwest and the center of Black culture and society in the community. On the other hand, it had to go into survival mode 
serving a White constituency that was foreign to it, making up for the loss inflicted upon it by the Black-brain-drain of faculty and students and negotiating the demands of incoming Black students who abhorred the status quo represented by Lincoln's administration under president Dawson's leadership.

\section{Summary}

The findings from this study were presented in this chapter linked to the research questions that guided the inquiry. The first research question was: What were the cultural forces that converged on Lincoln's campus during the first fifteen years following its desegregation? Findings that helped answer this question were clustered into the following themes: (a) Lincoln University provided the first truly desegregated educational experience for the great majority of students who attended between 1954 and 1969; (b) Lincoln was a desegregated university within a segregated community; (c) the expectations and the overall college experience varied widely for Black and White students at Lincoln University; and (d) Lincoln's post-desegregation leadership hindered internal integration due to its accommodationist approach.

The findings clustered in these themes provide an overview of the cultural forces that converged at Lincoln during the period bracketed for this study. Those forces were linked to the culture of the school at the time of its desegregation, the culture of the surrounding community as the immediate external environment, the social contexts from where the students and faculty emerged and the sociopolitical movements that came together on campus between 1954 and 1969. 
The second question was: What were the dynamics of intergroup contact at Lincoln University during the late 1950s and during the 1960s? Findings used to answer this question were gathered under the themes provided by intergroup contact theory which includes (a) equal status within the contact situation; (b) intergroup cooperation; (c) common goals; (d) support of authorities, law, or custom (e) personal interaction; and (f) friendship opportunity.

Findings linked to this question provide evidence that intergroup contact during the years bracketed for this study gave participants the perception that there was equal status in the academic realm of the university, but in the social aspects of college life, Lincoln was perceived by both Black and White participants to be a "Black campus." Intergroup cooperation was very limited and most likely to occur in the context of extracurricular activities. The only common goal cited was that of earning a degree. This was a common goal that was individually pursued. Participants felt that initial intergroup contact between Blacks and Whites was not guided by support from authorities in campus or the community. It was reported that opportunities for interpersonal interaction and friendship existed, but were not fully utilized.

The third question looked at the impact of desegregation on Lincoln's institutional culture. At Lincoln the arrival of White students and faculty created a unique situation whereby the incoming White group sort of carved out its own college experience within the framework of the existing Black institution. When Black students integrated predominantly White institutions they were expected to adhere to the values and mores of the majority. Lincoln, as a minority serving 
institution opening its doors to the majority, did not hold those expectations. In fact, some local student participants felt surprised that Lincoln had not adopted White values upon their arrival. The end result was that during the period bracketed for this study, the campus hosted what a participant deemed, "two Lincolns.”

Chapter five will discuss the findings of this study in connection to the existing literature in the themes of organizational culture and intergroup contact when applied to desegregation in higher education. Chapter five will also provide conclusions and recommendations for practice and future research. 


\section{CHAPTER FIVE}

\section{DISCUSSION}

The purpose of this study was to examine how the initial Black/White intergroup contact generated by the mandated racial desegregation of Lincoln University of Missouri in 1954 influenced the institution's organizational culture. This chapter presents: (a) a summary of the findings structured around the research questions; (b) a discussion of the findings as they relate to the literature on organizational culture and intergroup contact in the context of desegregated higher education; and (c) conclusions and implications for research, policy and practice.

\section{Summary of Findings}

This section presents a summary of the findings derived from interviews with the participants and textual analysis of pertinent documents. The study was framed by the following three research questions:

1. What were the cultural forces that converged on Lincoln's campus during the first fifteen years following its desegregation?

2. What were the dynamics of intergroup contact at Lincoln University during the late 1950s and during the 1960s?

3. How were the University's culture and organizational identity influenced by its racial desegregation?

In the answers to the first research question about the cultural forces that converged on Lincoln's campus during the first 15 years following its desegregation, I identified four themes: (a) Lincoln University provided the first 
truly desegregated educational experience for the great majority of students who attended between 1954 and 1969; (b) Lincoln was a desegregated university within a segregated community; (c) the expectations and the overall college experience varied widely for Black and White students at Lincoln University; and (d) Lincoln's post-desegregation leadership hindered internal integration due to its accommodationist approach.

The first theme to emerge was that for most of the participants, Lincoln University provided the first truly desegregated educational experience. This was illustrated with information about the educational background of students prior to their arrival at Lincoln as well as their first impressions in attending a desegregated school. All of the Black student participants had completed all or part of their elementary and secondary education in segregated schools. The participants themselves clarified that this was not the experience of all Lincoln students at the time, but it was true for the majority and indeed for all the Black participants. The White students for the most part had emerged from either totally segregated schools, or in a couple of instances, schools where there had been one or two Black students. None of the White students had ever had a Black teacher until they attended Lincoln.

The second theme to be identified was the dichotomy between Lincoln, a desegregated university and the surrounding segregated community. In a rare case among HBCUs, Lincoln desegregated immediately following the Brown $v$. Board of Education decision and began enrolling a large proportion of students from the surrounding community. In contrast, most public accommodations in the 
White community around the campus remained segregated into the 1960s and in the case of housing into the early 1970 s. This situation created some unique dynamics in the town/gown interactions.

The third theme revealed great disparity between the expectations and the overall college experience for Black and White students at Lincoln University. As it is true at many universities that have a resident and a commuter population, during the period bracketed for this study, Lincoln catered to two student populations with different needs and expectations. The division was made more noticeable at Lincoln because the resident students were Black and the commuter students were White. For the residential population of the campus, Lincoln was not just an academic center, but also the axis of social activity. The White students who commuted from their homes saw Lincoln as a place to get a degree while remaining at home and, in most cases, holding a job in the community. They arrived during the day and disappeared from campus as soon as classes were over. Black students for the most part saw this lack of engagement in campus life as a sign that the local students were not seeking a comprehensive college experience at Lincoln. Both Black and White participants continued to perceive Lincoln as a Black college. Although these local students were attending a historically Black institution at the zenith of the Civil Rights Movement, only a few of those who attended toward the second half of the 1960s realized the significance of the period they were living in; hence they could not relate to the socio-political expectations that Black students had of their institution and its leadership. 
The fourth theme that emerged provided information referent to Lincoln's presidential leadership following desegregation. The first fifteen years of its desegregated history proved to be a turbulent time at Lincoln. The period was marked by a frequent challenge to the status quo fueled by the Civil Rights Movement, the Vietnam War, the Feminist Movement and the Black Power Movement. As waves of these movements converged on the campus, arriving students, mostly the resident students, grew impatient with what they perceived to be an extremely compliant administration and conflicts arose. Some of these conflicts resulted in marches of protest, the burning of the student union, the dismissal of Black student organizers and the presence of law enforcement on campus.

The second research question examined the dynamics of intergroup contact at Lincoln University during the late 1950 s and during the 1960 s. It was informed by participants' recollections of the early intergroup contact on campus in relation to the tenets of contact hypothesis: (a) equal status within the contact situation; (b) intergroup cooperation; (c) common goals; (d) support of authorities, law, or custom (e) personal interaction; and (f) friendship opportunity.

All participants reported having felt that in the academic realm of the university all were held to the same standards and had a sense of having equal status. In the social realm however, the sense of equality was compromised by Black and White students' perceptions that even after desegregation, Lincoln was a Black university and by the difficulties Black students encountered when trying to socially engage in the community surrounding the university. 
Participants could think of very few examples of intergroup cooperation. Among students there was cooperation in particular projects related to classes, or through extracurricular activities such as sports, the campus newspaper, or the theater troupe. Some White students recalled cooperating with their Black peers in efforts to desegregate public facilities in the community. Some faculty members also collaborated with students in these efforts. Among faculty members, cooperation was driven by curriculum development or other committee activities.

When asked about examples of common goals, participants invariably cited seeking a college education as a goal they had in common, even if it was pursued individually. Otherwise, there was not a sense of common goals. In fact, some participants stated that there was a Black agenda and a White agenda on campus at that time.

Since the catalyst for desegregation at Lincoln was the Board of Curators' decision to enroll Whites following the Supreme Court mandate in Brown, it may be extrapolated that support of authorities or law was present within the situation. Yet, the third element of custom was not necessarily there. Black and White students converged on campus without any directive for new rules of engagement. Their interactions were guided mostly by the mores and values they had acquired from their previous experiences.

All participants felt that attending Lincoln provided them with ample opportunities for personal interaction with people of the other racial group. In most cases the interactions were categorized as cordial and superficial. Only the 
White students who were truly immersed in the campus culture, either by living in the dorms or being part of a group or team, felt they had gotten to know their Black peers. Most Black participants felt they had not had significant personal interactions with their White peers. There were, though, strong personal interactions between faculty and students of different races.

Not all personal interactions provided opportunities for friendship. Here again, only students who were immersed in campus activities developed friendships with members of the other group. For some, friendships developed in later years as they were brought back together by a common goal. Faculty members recalled developing friendships with peers almost immediately upon arriving on campus and many students shared having had life-long friendships with faculty or staff.

The third research question sought to understand how were the University's culture and organizational identity influenced by its racial integration? Desegregation transformed Lincoln University from a Negro college into a Historically Black University with a predominantly White enrollment. This transformation translated into an incremental (a) academic decline, (b) leadership crisis and (c) intergroup disconnection within the organization.

Under the theme of academic decline, respondents provided information about Lincoln's professors, practices and reputation in the years prior to desegregation and the years bracketed for this study. Participants felt that about 10 years into desegregation, academic standards became compromised by the brain-drain of Black scholars and high achieving Black students, coupled with the 
exodus of high achieving local White students who took advantage of the advent of financial aid to pursue their education away from home.

The leadership crisis theme was characterized by participants' recollections of how the president of the university at that time tried to juggle the demands of a politically demanding Black student population and the city and state power brokers. Some characterized his efforts as inadequate and ineffective, while others proposed that the president did all that was possible within the socio-political frame in which he functioned. Toward the end of this president's tenure, student government became a powerful force that turned the administrative structure upside down with lasting repercussions for the institution.

Discussion of Findings

I undertook this study due to a gap in the scholarship on the desegregation of Historically Black Colleges and Universities. An extensive review of the literature revealed that the gap indeed existed and that very little attention had been devoted to the examination of this socio-historic event. Furthermore, the review of the literature also exposed a void in the study of interracial relations in organizations; this was especially true in the case of minority organizations that integrate members of the dominant group. The present study thus contributes to the knowledge base on the topics of desegregation in higher education and the impact of desegregation on a historically Black institution. Moreover, it contributes to the scholarship on organizational analysis through the examination of intergroup dynamics at a minority institution during its initial desegregation. 


\section{Organizational Analysis}

Lincoln University was established in 1866 as an institute to meet the educational needs of freed-African-Americans. It was later designated Missouri's Negro College in compliance with the terms of the Second Morrill Act of 1890. From that time until its desegregation in 1954, Lincoln University exclusively served the educational and social needs of Blacks. During that period Lincoln rose from an institute with two pupils to gain university status in 1921. Through the next 3 decades, Lincoln became home to illustrious Black faculty who had received their doctorates at prominent White universities. A Black student who was attending Lincoln when it desegregated said:

Lincoln had one hell of a faculty. When I tell him [my grandson] that in freshman biology I had a PhD teaching me, I had a PhD in chemistry teaching me because I was premed, I had a $\mathrm{PhD}$ in a couple of other classes and I was a freshman. They were from Cornell, they were from Harvard, they were from Yale, from University of Chicago they were from all the big universities because they sort of represented the elite, the cream of the Black Schools that were able to get them into these great institutions (African-American student, class of 1958).

Prior to its desegregation, Lincoln's organizational culture was integrated in terms of singularity of purpose - the education of African-Americans within a segregated educational system - and the methods utilized for achieving that purpose. The institution had developed a pattern of basic assumptions (Schein, 1991), inherent in being exclusively a Negro college. Within that context there were shared values and beliefs (Davis, 1984; Schein, 1984; Siehl \& Martin, 1990) heavily influenced by the tenets of the Talented Tenth, the philosophy espoused by W. E. B. Dubois, who placed the hope for the uplift of the Negro race upon the 
shoulders of "leaders of thought and missionaries of culture among their people" (DuBois, 1903, p. 403). Due to the segregation of the community surrounding the campus, Lincoln's faculty, students and administrators shared a social sphere that catered to the cultural needs of the Black community. The campus held musical recitals, theater productions, movie showings and sports events. This confined existence and the singularity of its mission to educate AfricanAmericans promoted internal integration among the various constituencies in the organization. External adaptation required Lincoln's population, and especially its leadership, to effectively navigate a "White man's world," as funding was controlled by the predominantly White male legislature of the State. In that world Lincoln's leadership had to strike a balance between being complacent and promoting its agenda by fostering coalitions with Blacks and Whites alike.

Both internal integration and external adaption are considered necessary for the creation of a shared culture (Schein, 1991). Faculty and administrators at Lincoln during the years prior to its desegregation had a shared understanding of their reason for being: the education of African-Americans. They also had learned ways to relate to the surrounding community including state government. The means by which these were accomplished "worked well enough to be considered valid and, therefore, to be taught to new members as the correct way to perceive, think and feel" (Schein, 1991) within the context of a dual system of state supported higher education. The teaching of the rules of internal and external engagement to new members took place in the academic and social spheres. "Sure you [would] learn political science and mathematics and biological 
science, but at the same time you were monitored carefully, behaviorally you had things in place that provided exposure to African-American culture" (AfricanAmerican student / Son of faculty member, class of 1965).

Following the decision of Brown v. Board of Education, the Board of Curators considered a proposal to accept "applications of all qualified persons (and not of the Negroid race) who may seek admission to Lincoln University" (Minutes of the meeting of the Executive Board of the Board of Curators of Lincoln University, dated July 9, 1954, Lincoln University Archives) and on July 31, 1954, decided that:

...With the consent and the cooperation of the Attorney General, the Governor of the State, the General Assembly, and other State Educational Agencies and Organizations of Higher Education, provide and make available the offerings of the Lincoln University to any qualified resident of the State who may apply for admission to be served at the Lincoln University (Minutes of the meeting of the Board of Curators of Lincoln University, dated July 31, 1954, Lincoln University Archives).

With this decision, Lincoln left behind its days of being an exclusively Black school and opened its doors to White students from the surrounding community. A Black faculty member who taught at Lincoln before and after desegregation said:

The moment this school opened up, the local people applied. Within two to three years they were pouring into this school... and within a few years it was 50/50. There was no problem, you didn't have to go out and advertise.

One could say that in and of itself, desegregation would demand that the organizational culture of Lincoln be examined through the lens of differentiation as previously segregated subgroups or subcultures began to interact in the 
context of the organization (Alderfer \& Smith, 1982; Gregory, 1983; Riley, 1983;

Schein, 1996). Because race is one of the most salient identifiers, the introduction of a new racial group turned Lincoln into an organization with two easily identifiable subgroups. The early days of desegregation were marked by an overall feeling of hope and good will as Blacks and Whites began to interact on the Lincoln campus. "It was going beautifully. The story that is in that Ebony [Magazine] is true: 'The school that was too good to die.' It was going beautifully. It was a model" (African-American Professor). The students noticed it too: "The racial climate was quite promising. I think there was kind of an excitement that this was an opportunity to have cooperation between Black and White students" (White student, class of 1962).

A deeper examination revealed the presence of another subgroup, Black students who arrived following desegregation informed by the Civil Rights Movement and seeking the equality promised to Blacks in the post-segregation era. Beginning in 1960 and growing steadily until 1969, issues of power and special interests (Alderfer 1977, Alderfer \& Smith, 1982; Kolb \& Putnam, 1992; Martin 1992) led to internal conflict: "real or perceived differences that [arose] in specific organizational circumstances and that engender[ed] emotion as a consequence" (Kolb \& Putnam, 1992, p.312).

Differences arose in regard to a segregated bowling alley in 1962, with the specific circumstance that Lincoln rented this venue for bowling classes, but Blacks were not allowed on the premises during regular business hours. Emotions ran high among students and the administration: 
We even hanged him, President Dawson, in effigy there on the campus during one of our rallies as we prepared for one of our demonstrations at the bowling facility. We were so upset with him in terms of his lack of support for what we were attempting to do (African-American Student, class of 1963).

In response, the administration suspended nine seniors who had been organizing the demonstrations. "All of us were told in the expulsion - and I call it expulsion because they [pause] I couldn't come back to Lincoln for 4 years and I was 10 weeks from graduation- and I got, got expelled..." (African-American student who was expelled in 1962. He never received his degree from Lincoln).

The rapid increase of White enrollment and White faculty hires, the braindrain of Black faculty due to retirement or better opportunities elsewhere, the exodus of the better-prepared Black students and high performing Black studentathletes combined with the conflict between the administration and Black students during the 1960s imbued the institution with ambiguities, a myriad of interpretations of meaning and complex relationships within and without the established boundaries of the organization (Martin, 1992). This fragmentation made for "a kind of schizophrenic personality, kind of split personalities. We [had] a difficult time reconciling our mission statement in terms of 'we are open to all students' and the point that we are a historically Black school" (White faculty member since 1965).

As suggested by Martin (2002), I looked at the organizational culture of Lincoln between 1954 and 1969 through the lenses of integration, differentiation and fragmentation. It is easy to identify aspects of the culture that were "consistent, clear, and indicative of collectivity-wide consensus" (p. 158). All the 
participants made reference to the fact that getting an education was the first priority and that Lincoln at the time of its desegregation, and definitely during the first decade following it, provided a high quality education delivered by established Black faculty and newly-arrived White faculty. The atmosphere of the classroom was one of rigor and professionalism.

As also suggested by Martin (2002), other aspects of the culture were indicative of differentiation and seemed "to coalesce into subcultures, enabling these subcultures to reinforce, be independent, or conflict with each other" ( $p$. 158). Most evident of differentiation among subcultures, was the White commuter/ Black resident distinction among members of the student body. The different needs of these two populations created unique agendas for each subgroup. For the commuter students it was the maintenance of a reasonably priced quality education. For the resident students, it included living conditions and rules of social engagement within and without the boundaries of the campus.

Another set of subcultures developed. On one side was an accommodationist administration led by President Dawson and on the other a rebellious group comprised mostly of Black students, but also some White students and faculty members of both races. These two subgroups were at odds on issues of internal governance and external relations. The administration was perceived to kowtow to the White surrounding community and state government, neglecting the needs of the university. "It was referred to back then as him being an "Uncle Tom." An attitude that did not push for the equality that we felt as the CEO or the primary administrator of the university he had the responsibility to 
further equality of this campus, making sure that the university had the resources that other universities had" (African-American student, class of 1970).

The result was ongoing conflict between the administration and this antistatus-quo coalition. The conflict engendered many demonstrations and harsh disciplinary actions that culminated with the arson of the student union in 1969. The internal turmoil at Lincoln had a fragmenting effect on its institutional culture (Gagnier, 1990). Some elements of the characteristics of fragmented cultures were present at Lincoln during the period bracketed for this study. The institution appeared to be "fragmented...infused with confusion, doubt and paradox" (Martin, 2002, p. 158). Fragmentation was evident in the commuter/resident division among campus students. That division was made more visible by the fact that each group could be easily identified by race: "There were two Lincolns. There was a day time one that was highly integrated....and then, after dark, it became an African-American institution or HBC." (African-American student, class of 1965).

Beyond looking at the various subgroups and coalitions, fragmentation theorists look at what is said and kept silent within organizations (Martin, 1992). A glaring example of this fragmentation among various coalitions within the Black community at Lincoln is the absence of the names of the students who were suspended/ expelled in 1962 on the permanent record of the Board of Curator's meeting in which Dr. Dawson discussed the potential discontent of the NAACP about the suspensions: "The President of the University related the sequence of events leading to the suspension of nine students on charges of insubordination 
and deliberate defiance of authority" (Minutes of the meeting of the Board of Curators of Lincoln University, dated March 24, 1962, Lincoln University Archives).

Based on the findings of this study, I would not characterize Lincoln's culture during the period between 1954 and 1969 as one of constant flux (Martin, 2002). Nonetheless, confusion, doubt and paradox were certainly present in various degrees of intensity throughout the period. Confusion and doubt were brought about by fear of Lincoln being eliminated or absorbed into the predominantly White University of Missouri system. With the desegregation of those campuses well on their way, the need for a Historically Black College only 30 miles away from the University of Missouri - Columbia was placed in doubt. Even after a legislative investigation between 1955 and 1957 declared that Lincoln was indeed needed to serve the growing educational needs of the state, the fear lingered for almost three decades (Holland, 1991). Local and national events added to the confusion within the campus. Locally, desegregation failed to deliver on its promises of equal access and opportunity as most of the surrounding community remained segregated well into the late 1960s. Nationally, the resistance to integration throughout the South and Border States, the Civil Rights Movement and the rise of the Black Power Movement contributed to the rise of a politicized student government at Lincoln. Their leadership bypassed Lincoln's administration in dealings with the legislature and other constituencies. "He [President Dawson] moved out of the way and let the Student Government Association and most of the students do the talking with the curators and the 
legislators because we really felt like he wasn't taking proper measures" (AfricanAmerican student, class of 1968).

This power shift turned the administrative structure of the university on its head. A paradoxical leadership structure emerged whereby students who were expected to be governed by the institution's rules, regulations, mores and practices, assumed a role previously reserved for the administration. These students felt that they knew best what Lincoln needed, and were best suited to create the coalitions to secure it (Gagnier, 1990). This continues to have implications for the institution as this group of students became alumnae/i and retained a highly influential position in its dealings with future administrators.

Various researchers have highlighted the importance of observing the dynamics of race within organizations (Cox \& Nkomo, 1990; Kolb \& Putnam, 1992; Nkomo, 1992). Nkomo suggested this aspect was often neglected due to the prevailing thought of integration and assimilation of minorities into the cultural norm. Imbedded in this suggestion is the biased trend of defining organizations as majority-held entities incorporating minorities into their established cultures. This view overlooks minority organizations that incorporate members of the majority and is evident in the semantic treatment of such inclusions. Terms like reverse desegregation fossilize the myth that integration and assimilation are intrinsic features of majority organizations.

As an alternative to seeing organizations in a frame of race neutrality, Nkomo (1992) advocated dispelling the illusion by applying power-conflict theories to the study of organizations to gain insight into how those organizations 
develop their racial constructions, the relations of power that preserve racial divisions and domination and the role of capitalist mode of production upon those divisions. While the author made this suggestion thinking of majority - White organizations, the present study would suggest that in applying power-conflict theories to the study of organizations, researchers must be careful not to perpetuate the traditional racial scheme of White power over. In expanding the scope of organizational analysis to include minority institutions, new insights can be gained about which aspects are truly racially derived and which are effects of the locus of power.

\section{Intergroup Contact}

Contact hypothesis was first proposed by Gordon Allport (1954). It has evolved through the work of many researchers and it proposes the following conditions as necessary to dispel prejudices that get in the way of meaningful intergroup relations: (a) equal status within the contact situation; (b) intergroup

cooperation; (c) common goals; (d) support of authorities, law, or custom (Allport, 1954, Pettigrew, 1998); (e) personal interaction; and (f) friendship opportunity (Dovidio et al., 2003).

Of the six conditions listed above, one was found to be present for all participants: personal interaction. Four were found to be present under some circumstances: equal status, intergroup cooperation, common goals and friendship opportunity. The condition of support of authorities, law, or custom was found to be absent as perceived by participants in this study. 
Brewer and Miller (1994) highlighted the need for acquaintance among members of the involved groups obtained through personal interaction. All participants felt that attending Lincoln provided them with an opportunity for personal interaction with people of the other race. Interestingly, personal interaction was not necessarily defined as getting to know one another. In some cases it took the form of silent competition as in the case of Black students who felt that attending a desegregated $\mathrm{HBCU}$ at that time in history provided them with a sort of dress rehearsal for the world they would be entering upon graduation. Some of them saw the opportunity of attending a desegregated $\mathrm{HBCU}$ as having the best of both worlds because it provided greater opportunities for socio-political leadership within the Black community and at the same time allowed them to compete with Whites. For some White participants, observation of Blacks within their first contact situation dispelled prejudices that they themselves did not necessarily held, but which they had "inherited" from their elders. One White participant spoke about the admiration he developed for his Black peers and felt privileged for having had the unique opportunity afforded to him by attending a desegregated HBCU: "I'm sure no other college had a make-up that had any sort of parallel to that situation where the Black students, academically, were more attuned to being collegiate than the White students" (White student, class of 1972).

Indirect personal interactions were also thought to occur in the context of classrooms, where students learned from each other and about each other by the inquiries and responses elicited in the class. Personal interactions were 
mostly confined to the campus given the segregated character of the surrounding community. Some White participants had true immersion experiences in the Black community of Lincoln University and they emerged with a greater understanding of what it meant to be Black in America at that time. These immersions were achieved by a student who was the only White player in the football team, a White young woman who chose to live in the dorms, another White female student who got involved in Civil Rights activities, and yet another White female student who joined the theater troupe.

Allport (1954) and Pettigrew \& Tropp (2006) emphasized the importance of equal status within the contact situation. This particular condition is more easily achieved in controlled studies were the groups are removed from their own social contexts. To speak of racial equality in the historical context of the Civil Rights Movement may seem like an oxymoron, yet participants in this study felt that equal status among Blacks and Whites on the academic realm of the campus was present. Faculty and students alike recalled that within the classroom, all students were treated equally. Expectations were rigorous and applied to everyone. There was no evident display of preferential treatment or hostility toward the incoming group.

In the social environment of the college however, there was no sense of equal status. Black students felt that administrative conduct rules were applied to them with greater frequency and magnitude. A Black student also suggested that in dealing with administrative offices, White students were often served first. White participants could not confirm this claim. Yet, Black students also 
dominated many areas of campus life, the residence halls, the student union, the cafeteria, Greek organizations and student government. White students appeared to have a sense of not belonging in the social gathering places of the campus.

Sherif, Harvey, White, Hood and Sherif (1961) added the dimensions of cooperation and interdependence to the contact hypothesis model and suggested they were important factors toward the dispelling of prejudices among groups. In this study, Intergroup cooperation was not a condition that most participants recalled being present at Lincoln at that time. Some participants who participated in extracurricular activities like theater, the football team and the newspaper, spoke of those instances as moments when Black and White students would come together. For a few White participants, faculty and students, intergroup cooperation was centered on the activities of the Civil Rights Movement and that provided an opportunity for members of both groups to strategize and seek change together.

With the condition of common goals, there was an interesting interpretative twist. Repeatedly when asked about common goals, participants mentioned "getting an education." This was a common goal in the sense that it was everyone's personal goal, but it did not depend on peers of the other group for its fulfillment, thus not meeting the condition as stipulated by Sherif et al. (1961).

Many participants acknowledged that had they wanted to make friends with members of the other group, the opportunity was always there. In fact, some 
of the participants mentioned making friends with members of the other racial group. In the case of the White participants, initial friendships were established with faculty members or within the context of an extracurricular activity like a sports team or ROTC. Other White participants spoke of how intergroup friendships did not develop while they were studying at Lincoln, but years after graduation when they served together in committees or in other efforts at the request of the University. As adults, these students were free to make decisions that were not framed by societal antecedents (Stephan \& Stephan, 1996). Most Black student participants felt the intergroup relationships they had during their college days were "shallow" and categorized them as "cordial relationships." Several of them, also mentioned developing deeper friendships with White peers, years after graduation. The reported deepening of relationships over the years is consistent with other researchers' findings of desegregation failing to produce positive effects in the short term, but having generally encouraging effects over time (Marcus-Newhall \& Heindl, 1998; Stephan \& Stephan, 1996).

The condition of support of authorities, law, or custom was perceived to be absent by most participants. This was interesting in that the desegregation of Lincoln University was brought about by the Supreme Court Decision of Brown v. Board of Education, the public acceptance of its mandate by the Attorney General of the State of Missouri and the university's Board of Curators' decision to open the institution's doors to all qualified applicants. Nevertheless, Black and White participants alike felt that the institution had not done anything to sanction or encourage intergroup contact within the campus. Pettigrew \& Tropp (2006) 
considered institutional support to be an essential condition for the facilitation of positive contact effects and Kezar (2000) placed that responsibility most precisely within the scope of presidential involvement in diversity efforts at colleges and universities. One participant suggested that promoting intergroup contact during the period bracketed for this study might have been seen as an act of defiance by the Black president of the university, Dr. Earl Dawson: "In terms of doing anything to promote integration or positive inter racial relation...it would seem to me unlikely - because it could've been taken as political activism. That would've been troublesome" (White teaching fellow, 1964-1966). This statement supports Kezar's (2008) suggestion that all diversity efforts are in effect political in nature, hence the reason many leaders in higher education refrain from undertaking such initiatives.

The overall goal of intergroup contact as proposed by Allport and expanded by other researchers (Amir, 1976; Brewer \& Miller, 1984; Cook, 1985; Dovidio, Gaertner, \& Kawakami, 2003; Sherif et al., 1961) is the elimination of prejudice defined as "an antipathy based upon a faulty and inflexible generalization. It may be felt or expressed. It may be directed toward a group as a whole or toward an individual because he is a member of that group" (Allport, 1954, p. 10).

Research on prejudice suffers from the same condition found in the organizational literature, namely the treatment of Whites as active participants who have information to provide the researchers and of Blacks as passive targets (Shelton, 2000). Shelton suggested that social researchers must 
recognize that "Blacks are not passive targets because all individuals in an interaction influence the dynamics of the interaction" (p. 375). Black and White racial attitudes are hence recognized as playing a role in the outcomes of intergroup contact.

White participants in this study repeatedly stated that they were free of any type of antipathy toward Blacks when they enrolled at Lincoln. In retrospect, most of them acknowledged the positive effect of intergroup contact at Lincoln in their future relations with people of other groups and specifically noted other races, ethnicities and gender (Pettigrew \& Tropp, 2006). For the White students, this was manifested as reduced feelings of anxiety (Blair, Park, \& Bachelor, 2003; Pettigrew \& Tropp, 2006) and enhanced comfort in the increasingly diverse world they encountered after graduation. Given the fact that within the campus their behaviors seemed to indicate they were uneasy in a diverse environment where they were the minority, it would warrant further study to determine the benefits of intergroup contact for situational minorities.

Similarly, African-American participants evoked inclusiveness as an inherent African-American trait and stated not having any problem with Lincoln incorporating White students and faculty. There was, though, a hint of antipathy as African-American students spoke of White students' lack of involvement in the campus and their not giving back to the institution. The lack of involvement was interpreted by some students as Whites being afraid of their Black peers. Nonetheless, African-American participants felt that having the opportunity for intergroup contact with a significant number of Whites while attending an HBCU 
translated into greater confidence to function in what they perceived still to be a "White man's world" beyond graduation.

Pettigrew and Tropp's (2006) meta-analytic test of intergroup contact theory led the authors to deduce that the conditions for optimal contact proposed in Allport's theory should not be considered as necessary for the production of positive outcomes, but rather as facilitating conditions that augmented the propensity for positive outcomes to emerge. The study of intergroup contact at Lincoln University through the recollections of Black and White students and faculty who were there between 1954 and 1969 showed that some gains in positive attitudes were made by members of both groups within the contact situation. White participants more readily noted their positive attitudes toward Blacks and other outgroups (Pettigrew \& Tropp, 2006). Black participants did not explicitly convey positive or negative attitudes toward Whites. This lack of expressed opinion may be explained by an internalization of the dominant paradigm of intergroup contact in which White prejudice aims to be dispelled and Whites who consider themselves unprejudiced want to make sure their position is known (Peterson \& Hamrick, 2009). To Blacks, this means that the passivity ascribed to them "is a reflection that the Black perspective in the study of racial prejudice has been forgiven automatically and [is] thus ignored" (Shelton, 2000, p. 385). In other words, Blacks who are unprejudiced do not feel the need to articulate that position. This is the flip side of prejudice suppression, which suggests "that although Blacks might not be encouraged to express negative 
racial attitudes, it certainly is not of great concern if they do" (Shelton, 2000, p. 384).

\section{Organizational Culture and Racial Climate}

Just as discussion of the organizational culture of Lincoln included internal and external components, the following discussion of racial climate as it pertains to Lincoln University between 1954 and 1969 is structured following the Hurtado et al. (1998) framework, which is stated in terms of external and internal factors.

External factors included (a) the impact of governmental policy, programs and initiatives and (b) the impact of sociohistorical forces [that affect how people view racial relations]"( Hurtado et al., 1998, p. 282). At Lincoln, the mandate to desegregate constituted the original governmental policy to influence the racial climate as it propelled the inclusion of White students and faculty members into a campus with a long tradition of being exclusively a Black college. Another governmental factor was the dependency on the favor of a predominantly White legislature. Many participants, Blacks and Whites, mentioned how the arrival of White students impacted relations with this body.

Sociohistorical forces of interracial relations were a dominant aspect of the period bracketed for this study: The Brown v. Board of Education decision; the resistance to integration in universities throughout the South; the Civil Rights Act of 1964; the Voter Registration Act of 1965; the rise of the Black Power Movement; and the assassinations of Civil Rights leaders including President John F. Kennedy, Robert Kennedy, Malcolm X and Dr. Martin Luther King Jr. The 
forces imbedded in these events were complemented by the Women's Liberation Movement and the anti-war movement in response to the Vietnam War.

Among the internal forces that shape racial climate, Hurtado and colleagues (1998) proposed the following:

[a] an institution's historical legacy of inclusion or exclusion of various racial/ethnic groups, [b] its structural diversity in terms of numerical representation of various racial/ethnic groups, [c] the psychological climate of perceptions and attitudes between and among groups, and [d] the behavioral climate dimension characterized by intergroup relations on campus (p. 282).

The issue of inclusion or exclusion at a Negro college in 1954 did not play a dominant role for newly enrolled White community students. They recognized that segregation had been imposed on Blacks and the prior exclusion of Whites from Lincoln was based on its designation as a Negro college and not on the desire of Blacks to be kept apart from Whites.

The structural diversity in terms of numerical representation of Blacks and Whites had two dimensions. Looking at the academic spaces of the campus, the racial distribution increasingly tipped toward the White population. Beginning with 18 White students in 1954, by 1969 Whites constituted over half of the total enrollment. In contrast, the White presence in the dormitories remained in the single digits. Social spaces such as the student union also remained predominantly Black as did most extracurricular activities such as sports teams, sororities and fraternities.

The psychological climate of perceptions and attitudes between and among groups was heavily influenced by external communities to which the students belonged. White participants spoke about how some of their actions 
were limited by the possible reaction such actions would elicit from their parents and other community representatives. This fear resulted in self-limiting behaviors especially around interracial dating and political involvement as illustrated by the comments such as this: "I did not date any of the Black students and that was something that I didn't feel that society was ready for and I was not ready for that" (White female student, class of 1961).

For Black students who arrived prior to or immediately following desegregation there was an evident programming of "knowing one's place." By the late 1950s, the consciousness of Black students had begun to shift as they were more informed of the expanded rights inherent in the desegregation mandate. In the following decade, race relations were negatively affected by White resistance to desegregation and equal rights efforts and the change in the Black movement from Dr. King's pacifism to Carmichael's and Malcom X's "by whatever means necessary" (Malcom X, 1965).

This distinction between Whites at Lincoln and Whites outside was made by various participants. Most of the turmoil experienced at Lincoln during the 1960s was based on the students' perception that the administration had sided with Whites outside the campus; Whites who controlled resources and failed to give Lincoln its fair share.

The behavioral climate dimension was characterized by the cordial yet detached intergroup relations on campus that led many participants to say Lincoln was in effect "two campuses" in one. Although participants said there 
were no hostilities, both groups reported a lack of interpersonal relationships consistent with Sims's (2008) idea of "irrelation" († 5).

The racial climate of Lincoln during the first 15 years of its desegregated history was influenced by the sociohistorical moment in which it unfolded. It was a time for the U.S. to deconstruct the patterns of race relations of the last century and come up with different patterns. With the exception of a couple of Black and White integrationist faculty, the student participants in this study had very little adult guidance in the matter of race relations. Even today, efforts to bring diverse groups together are too political for some leaders to take on. Kezar (2008) proposed that the advancement of a diversity agenda is a political endeavor that pushes "[existing groups [to] defend the resources and power that they have, and new groups emerge trying to obtain resources and power creating conflict" ( $p$. 410). At Lincoln this was most evident not within the racial diversity, but as a factor of age diversity within the Black group. The "old guard," embodied by the administration, kept holding on to whatever resources and power it had amassed and the "new guard" was embodied by politicized students seeking to obtain greater power and an increased share of resources. This conflict was created by the self-imposed limitations of a leadership unable or unwilling to demand more from the state legislature. Because most of the neglected aspects of the university were tied to housing and boarding, White students remained unaffected by the struggle, yet some of them were involved in demonstrations toward achieving equity with PWIs in the areas of student services at Lincoln. 
Experiences of Black and White Students at Lincoln between 1954 and 1969

The experiences of Black and White students at Lincoln during the period bracketed for this study reflect the findings of some of the literature referent to these two groups of students at HBCUs.

Black students reported being highly satisfied with their level of involvement on campus and the leadership opportunities they encountered (Outcalt \& Skewes-Cox, 2002). Their allusions to the campus environment often included terminology associated with family and home (Bennett \& Xie, 2003;

Fries-Britt \& Turner, 2002) as illustrated in the following recollection:

When I got to Lincoln I was happy seeing so many Black students and I sensed a sense of family and camaraderie and a sense of I can do anything because you know the editors of the newspaper were Black, the archivists of the yearbook were Black, the campus queens were Black, the SGA presidents were Black, I saw all this happening and it gave me a sense of empowerment (AfricanAmerican student, class of 1970).

Even though Lincoln was a desegregated HBCU, Black students still felt they could be protected from the challenges experienced by Blacks as found by previous research (Feagin, Vera, \& Imani, 1996):

I wanted to have the experience of integration without all the hostility, 'cause I'd had enough hostility growing up in Georgia I wanted to experience it without all the hostility and I was able to do that at Lincoln. There was no hostility there between Blacks and Whites.

Researchers have found a positive correlation between the persistence of Black students and their selection of attending an HBCU (Allen \& Haniff, 1991; Fleming, 1984; Nettles, Thoeny \& Gosman, 1986, 1987; Pascarella, Smart \& 
Stoecker, 1989). All of the participants completed their degrees at Lincoln, most of them in 4 years and about half of them now hold advanced degrees. Because only alumnae/i were sought for this study, it is hard to determine the impact of Lincoln being an $\mathrm{HBCU}$ on the persistence and graduate school aspirations of all Black students at the time. But, it was certainly present for the participants in this study.

In an interesting twist, the sense of isolation reported by Black students at PWIs (Pascarella and Terenzini, 1991) was felt by some of the Black participants in this study. It was framed as a function of being in some of the upper division classes in majors such as math, where Blacks have been traditionally underrepresented.

White students' collegiate experience at Lincoln is also reflective of what other researchers have found when looking at White students enrolled at HBCUs. One of the first such studies was actually conducted at Lincoln (Aber, 1959). Most of her participants were non-traditional female students who were among the first to enroll at Lincoln. The White participants in my study were all traditional students who came to college straight after high school. The Aber study sought to learn whether or not attending a Black school positively influenced the White students' attitudes toward Blacks. She determined that it did. Even though she did not articulate using Allport's (1954) contact hypothesis, she used its tenets. Echoing Aber's finding, most of the participants in the present study had had very little contact with Blacks before attending Lincoln and felt that they had an enhanced awareness of racial issues than before they 
enrolled at Lincoln. This was especially true for those participants who lived in the dorm or travelled through the South with Lincoln's football team or theater troupe. Some of the participants in Aber's study mentioned that experiencing a reversal of the majority-minority status forced them to become aware of deep rooted prejudices either held by them or by other Whites. This finding is consistent with what was revealed by participants in my study and also supported by Peterson and Hamrick (2009) who found that the participants in their study felt their experience at an HBCU had enhanced their cultural sensitivity.

Consistent with the findings of Hazzard $(1988,1996)$ cost and proximity were some of the determinant factors for participants to enroll at Lincoln and White students in both studies expressed feeling at ease in the classroom setting. In the Hazzard (1996) study, participants expressed having no intention of participating in campus activities. The same was true for participants in the Peterson and Hamrick (2009) study. In this study, most of the students recalled having had had that same attitude, yet others were fully engaged and had very fond memories of that involvement. Different from the findings of Hazzard (1988), students in my study felt the leadership had played no role in breaking down racial barriers, and unlike Hazzard's participants, none of the participants in my study reported encountering racist attitudes.

White student participants reported high levels of satisfaction with their choice of attending Lincoln (Conrad \& Brier, 1997; Hall \& Closson, 2005). Unlike White students in studies dealing with more recent times (Hall \& Closson, 2005), participants in my study did not feel that Blacks received gratuitous grades and 
felt that their Black peers were just as academically capable and sometimes even more so than they were.

The present study focused on the organizational culture of the desegregated $\mathrm{HBCU}$ and looked at issues of race relations only in the context of how they informed the transformation of Lincoln from a Negro college to a fully desegregated HBCU. Yet, conversations with White participants revealed patterns of White privilege as those found by Peterson and Hamrick (2009) in their study of the racial consciousness of White males attending an HBCU. Maybe because the participants in my study were now mature adults thinking back, their evocations had a reflective tone:

I think being a White student I probably had privileges even though I came from a financially very poor family. I wasn't denied things because of being a White individual and I assumed it was going to be like that when I came here [to Lincoln]. And it was. We weren't denied anything. Now, my fellow students, Black students, probably had a different experience (White male student, class of 1965).

I think that as a White student here I had a naïve attitude, even at 21 , as though we would all appreciate each other and they would probably want to take on the White culture, because I was naïve, about that. I began to realize later that there was no reason to think that. They were proud of their Black culture too (White female student, class of 1962).

Overall, the participants in my study were very appreciative of the way they were embraced by Lincoln. Many said that had they not gone to Lincoln they probably would not have gone to college at all. Some of them spoke proudly of the school activities whether they were participants or observers. All of them praised their professors and many of them described their time at Lincoln as the best time of their lives. Several of the White students have remained connected 
to Lincoln by serving on the Foundation, supporting a scholarship, or attending cultural events on campus. Another group reported having had little to no interaction with the university after their graduation. For seven of the participants in this group, partaking in this study was the first meaningful interaction they had had with anyone at Lincoln since their graduation.

As presented above, the findings of my study are for the most part consistent with the findings of studies that looked separately at the experiences of Black and White students at HBCUs. I also undertook a comparison between the experiences of minority students at predominantly White institutions and White students - a situational minority - at a Historically Black University immediately following desegregation. This analysis is of value given that most HBCUs are just now expanding their non-Black enrollments and can benefit from the Lincoln experience.

White students who participated in this study shared some of the experiences reported by Black students at predominantly White schools. As reported by Black students at predominantly White institutions (Fries-Britt \& Turner, 2002) White students at Lincoln perceived campus activities to be designed for Black students and some reported that the lack of social involvement was a positive in that it allowed them to focus on their studies (FriesBritt \& Turner, 2002; Sims, 2008). As reported by Fischer (2007) for Black students at PWIs, White students at Lincoln who engaged in formal activities on campus reported great satisfaction with their experience. The experience of White students at Lincoln also paralleled that of Black students at a 
predominantly White medical school (Gartland, Hojat, Christian, Callahan, \& Nasca, 2003) in that both sets of students reported high degrees of satisfaction with the teaching and the program of study, dissatisfaction with the social environment, and after graduation were less likely to recommend the school to their family or friends and for the most part did not contribute monetarily to the school.

White students at Lincoln engaged in what has been labeled selfsegregation in the literature (Feagin \& Sikes, 1995; Davis et al., 2004; Gosset, Cuyjet, \& Cockriel, 1998; Sims, 2008). It is significant to note that the literature reports self-segregation as something minorities do and Whites notice (Feagin \& Sikes, 1995; Gosset, et al., 1998). At Lincoln, it was something that White students did and that Black students noticed. This distinction made it more a function of majority-minority, or whose campus it was perceived to be, than a Black-White issue. The majority-minority vs. Black-White distinction may also be applied to another common experience reported by Black students at HWls: the exposure to microaggressions, defined as unconscious utterances that convey a feeling of White superiority (Solórzano, Ceja, \& Yosso, 2000), and leave minorities feeling that they are not wanted or just don't belong. The White superiority component strains a direct comparison. Nonetheless, if one were to apply the notion that, as an example, a HWl's promotional literature that presents only depictions of White students on campus is considered a microaggression, then one could extrapolate that a school which has historically served Blacks exclusively would be engaging in the same microaggressive behavior if all of 
their public documents continue to represent only the Black aspects of the campus, especially if such representations engender feelings and elicit behaviors of not belonging among non-Blacks. For example, White participants reported feeling that the communications sent to them about alumnae/i events made it appear as if White students had never attended Lincoln. Some did acknowledge that they had noticed more depictions of Whites in those communications in recent years.

Also, even though there was only one White athlete participant in my study, his recollection reflected the findings of Singer (2005) about minority students at HWls. This athlete recalled being advised to change his major from accounting to physical education, because the accounting classes were interfering with practice times. The student refused and the coach accepted his refusal.

In contrast to shared perceptions, there were many experiences reported by Black students at HWls that did not reflect the experiences of White students at Lincoln. For instance, Black students consistently reported experiencing differential treatment at PWIs (Suárez-Balcazar, Orellana-Damacella, Portillo, Rowan \& Andrews-Guillen, 2003), all of the White participants in this study reported being treated in the same manner that they saw their Black peers being treated, especially by faculty. This extended to those White students who joined organizations, played in a team, or lived in the dorms, as well as to the male students who were required to participate in ROTC. 
Studies of Black students at PWIs reported Black students perceiving negative attitudes from the White faculty (Allen, Bobo, \& Fleuranges, 1984; D’augelli \& Hershberger, 1993; Davis, Dias-Bowie, Greenberg, Klukken, Pollio, Thomas, \& Thompson, 2004; Fries-Britt \& Turner, 2002; Jay \& D’augelli, 1991; Sedlacek, 1999; Smith, 1980). In contrast, White student participants in this study reported feeling very welcome and nurtured by their Black faculty. Some participants reported having life-long friendships with those faculty members, including them in their weddings. One participant told me about a Black faculty member and his wife, who was a secretary at Lincoln, being the Godparents of one of his children. A White football player had tears in his eyes as he reminisced about the life-long friendship he maintained with the woman who was the house mother in the athletes' dormitory.

Opposite to the lack of respect experienced by Black students at HWIs (Dinka, Mazzella, \& Pilant, 1980; Feagin, 1992; Fries-Britt \& Turner, 2002), the White student participants in this study felt they were always respected by faculty, staff and peers alike and were made to feel they were valued by their professors. Black students have suggested that professors would help them feel as valued members of the college community by providing feedback and reinforcement (Feagin, 1992, Daniel, 2007). White participants in the Lincoln study had copious examples to share of feedback and reinforcement they received from their professors.

Various studies reported that Black students on PWIs are often exposed to racist jokes (Feagin, 1992; Feagin \& Sikes, 1995); racist slurs and graffiti 
(Feagin, 1992; Davis et al., 2004); and, in some cases, more graphic displays of hatred such as nooses (Nealy, 2007). At Lincoln, none of the White participants reported ever having been exposed to any signs of hatred from Blacks on campus, whether students, faculty, or staff. Beyond the campus, though, a White football player was at the epicenter of a racist episode while playing with the Lincoln University team at a Black school in the South:

George Wallace was a predominant person down in Alabama and when I went into the locker room, you know to dress, they had my picture in the locker room, I don't know how many were there, but there were several of them and Governor Wallace was written across each of those pictures. Coach Reed had said, "Don't let him go anywhere with at least two with him," and that was the only campus that I was leery of walking on (White student, class of 1966).

In his case, Black teammates became a protective shield during encounters with players at non-desegregated HBCUs. This action speaks of the empathy that those minority students felt for their White teammate when he was placed in a position of disadvantage as what Hall and Closson (2005) and Peterson and Hamrick (2009) have referred to as a "temporary minority." I choose to refer to it as a situational minority, because as illustrated by this student's story, the discomfort associated with being targeted by a majority was not temporal, but situational. Even though he was always a numerical minority within the team, he did not experience uneasiness around his teammates. In that situation being a team member transcended race and the effects of being a minority were ameliorated or eliminated. It took a change in conditions and a new situation for him to have an uncomfortable minority experience. 
Another point of comparison was the way in which Blacks being the majority at a desegregated HBCU perceived the White students around them, and the way that perception unfolded at PWIs. Some researchers have proposed that Black students at PWIs felt their White peers were uneasy around them (Peterson, Blackburn, Gamson, Arce, Davenport \& Mingle, 1978). The same sentiment was expressed by Black participants in the present study who perceived the lack of campus involvement by White students as a sign of uneasiness around Blacks:

I guess that they [White students] had to have some courage to come to Lincoln, but didn't do nothing [sic]. When it was dark they were off campus. That's the indication that they were scared to be on campus after dark, maybe, maybe not. It was an all Black school after dark (Black student, class of 1971).

When White students were asked about their lack of involvement, all cited practical reasons such as work, commuting with parents or others from out of town, or just not having time. A White integrationist faculty member had this reflection about a moment he shared with a White student at the cafeteria:

I didn't go to the cafeteria very often, but once in a while I would and once I got a White student to go in there with me, and he was petrified [when he saw] all those Black people there. There was nothing hostile. There was no threat or intimidation. Just being the only one or one of two people in that room.

It is noteworthy that whether in the majority or minority, Blacks perceived Whites to feel uneasy around them. In the cases recalled above it appeared to be an issue of members of the white majority feeling threatened in situations in which they would be the minority. In those cases, self segregation by any group 
can be seen as an effort to find strength in numbers, whereby one individual cannot be singled out.

The literature also revealed that White students, for the most part, remained unaware of the challenges faced by Black students (Davis et al., 2004; Phillips, 2005; Sedlacek, 1999). In this study, the level of awareness of the challenges faced by Black students depended on the level of engagement with the campus community that a particular White student or faculty member had. Many of the challenges at that time had to do with issues of equality, discrimination in the surrounding community, housing conditions on campus and conflict with the administration. White students who arrived in the earlier years of the period bracketed for this study were less aware, those who enrolled later were also more aware. Of course, this level of awareness might also had something to do with the media coverage of Civil Rights demonstrations and resistance to desegregation efforts. A student from the early group spoke about being aware of some of the challenges faced by his Black peers, but feeling completely impotent to bring about change. A White student who lived in the dormitories felt she was very aware thanks to the intimate conversations she had with her peers.

Although Lincoln's desegregation was somewhat unique, it produced certain circumstances that made the studied group comparable to other HBCUs and to diverse HWls. The experience of desegregation at a minority-dominated institution provides insights from an untapped perspective for the organizational analysis of an institution of higher education. 


\section{Conclusions}

This study sought to gain a deeper understanding of desegregation in higher education by examining the way it unfolded at Lincoln University of Missouri, a Historically Black University that desegregated immediately following the Brown v. Board of Education decision, and by the late 1960s enrolled a large number of White students. Desegregation, for the most part, translated into the gradual disappearance of Black institutions. In the implementation of

desegregation, the elimination of all vestiges of America's segregated past meant the abandonment of Black cultural institutions (think of the Negro K-12 schools and the Negro Baseball League, for example), for the sake of incorporating Blacks into the mainstream of American society. Today, only the Black churches and Historically Black Universities remain. Within these bastions of ethnic identity, Black Americans strive to preserve a rich legacy. Of the two institutions, HBCUs have experienced increasing desegregation and thus provide a unique research setting for the study of interracial dynamics.

\section{Organizational Analysis}

The analysis of the data collected through interviews and document analysis moved from the broad view of Lincoln as an organization, to the narrow view of Lincoln as a desegregated HBCU. From the organizational analysis I concluded that desegregation had a fragmenting effect (Gagnier, 1990; Martin 1992, 2002) on the organizational culture of the institution. This fragmentation was not only a factor of the incoming White presence, but mainly of the shift in consciousness that American Blacks experienced during the years of the Civil 
Rights Movement. Internal conflict ensued between an administration whose leader continued to function in accordance with the accommodationist status quo and an increasingly informed, assertive and demanding student body.

Desegregation also affected the culture of the school due to the Black brain-drain engendered by active recruitment of faculty and students by HWls seeking to meet federally imposed mandates for dismantling all vestiges of segregation. As Black faculty became scarce due to retirements and seeking new opportunities, the university's role as a repository of African-American cultural tradition was compromised:

[Black] traditions were lost, lots of people tried to preserve them, but they didn't know them to preserve them. You can't preserve what you don't know. The alumni tried to preserve them [pause] It didn't mean the faculty weren't sympathetic to them, they just didn't know them to preserve them (African-American professor, 1940 2000).

The ideological differentiation between the Black leaders of student government and the Black institutional administration created a climate of internal rift that made it difficult for internal integration (Schein, 1991) to take hold. The incoming group of White students had, for the most part, limited contact with Blacks prior to enrolling at Lincoln. Recognition of a Black cultural tradition became impossible when the administration represented an accommodationist paradigm and utilized extreme disciplinary action to maintain the status quo; and the student body and integrationist faculty were challenging that status quo and also going to extremes to demolish old patterns of interracial power relations.

Even under those confusing conditions, all participants felt that attending a desegregated Lincoln had prepared them well for the increasingly diverse world 
they encountered after graduation (Marcus-Newhall \& Heindl, 1998; Stephan \& Stephan, 1996). White students stated that attending Lincoln gave them a view of Blacks as scholars and academics that was not available to them in previous school settings, the media, or their social interactions. Black students felt that attending a desegregated Lincoln allowed them to experience desegregation without hostility and afforded them an opportunity to compete with Whites in a more even plane by being in their "home campus."

\section{Intergroup Contact}

The application of contact hypothesis to an evocative study is different from the way in which this theoretical frame has traditionally been used. Previous studies examined intergroup contact in real time, often in simulated situations. In addition, most studies have looked at Whites as the ingroup and Blacks as the outgroup (Pettigrew \& Tropp, 2006). In this study the situation was reversed. The evocative nature of this study provided benefits and drawbacks.

Among the benefits, participants had over 40 years of background to assess whether their intergroup contact at Lincoln had had a positive impact on their attitudes toward the other group. Interestingly, although most White students remained disconnected from the Black social circle while attending Lincoln, they expressed having great success in relating to people different from them upon joining the workforce. Those who were more engaged during their college years developed life-long friendships with Black peers, faculty or staff and felt that their experience influenced the rest of their lives:

I became so aware of how to interface with people who are different than me because I came from this little place where 
everyone is German-American and Catholic. You aren't an insider or neighbor until the third generation... it was great in that if forced me to be a social person which I turned out to be and I don't think I particularly learned that in my little town (White student, class of 1965).

Among the drawbacks, the passage of time made some details hard to remember specifically when asked about particular instances when some of the conditions of the theoretical framework were present. Some of the Black participants engaged in self-censorship. For example one participant who had recollections of prejudiced practices by members of the community surrounding Lincoln, did not want to reveal information that would embarrass people who he now considered friends. This was the only articulated form of self-censorship and it did not relate to the campus intergroup contact, but it made me wonder how many other participants might have concealed details they felt would hurt someone they now considered a friend.

Of the six conditions proposed by contact hypothesis, personal interaction was the only one consistently present for all participants. Equal status was evident in the academic setting, but absent from the social setting. Intergroup cooperation was only manifested in extracurricular activities. Participants felt they had a common goal of getting an education, but this goal was held individually. Participants felt that opportunities for friendship were there, but for a lot of them, intergroup friendships developed after graduation. The sanction of the intergroup contact by authorities, law or custom revealed that the legal mandate for desegregation of Brown v. Board of Education, the Board of Curators decision to enroll Whites, and the support given to both of these measures by the State only 
managed to bring Blacks and Whites together on Lincoln's campus. Their intergroup relations were gravely affected by custom manifested in the segregated practices of the community, the appeasing nature of Dr. Dawson's leadership in relation to the external community, the racial boundaries that remained from the Jim Crow Era and the rise of new customs brought about by the rise of the Black Power Movement.

\section{Organizational Culture and Racial Climate}

The discussion of racial climate with the participants in this study was somewhat perplexing in that both Black and White participants agreed there were few close relationships among members of the two groups, yet all the participants regarded the racial climate within the campus as positive. Any time there was talk of racial conflict, it was framed in terms of it relating to experiences off campus. White students spoke of feeling welcome, respected and knowing that had they wanted to get involved in any campus activity they could have done so. Black students told me about not having any issue with the White students being on campus, appreciating those who chose to become more informed of issues inherent to the Black community and realizing that White students were close to home and did not need Lincoln to provide for their socialization. These reports are consistent with Sims's (2008) social construct of "irrelation:"

[which] is characterized by having neither positive nor negative relationship with others in daily social interactions or by having relationships that are defined by the environment (a classroom setting) or by gender or racial groupings (the 'Black' table in the student union). [Resulting in] lack of social communication and interactions between groups ( $(5)$. 
The White experience of intergroup relations at Lincoln was not monolithic and it was heavily dependent on personal decisions to fully integrate or irrelate. As members of the outgroup, White students had a decision to make as to the level of involvement they would seek. Those who sought to develop deeper involvement did so by participating in activities that afforded them those opportunities. The ingroup, represented by Black administrators, faculty and students dealt with the intergroup contact and the inclusion of Whites into the institutional culture in very different ways. The administration limited itself to allowing for the enrollment of Whites, the faculty members continued to do what they had done prior to desegregation - imparting the best education they could regardless of who was seated in front of them - and the students went about their academic and social life on campus and in some cases beyond. If the White students joined them, fine, if not, that was fine too. Efforts were made by some of the members of student government to elicit participation from whites and a commuters' association was established in the mid 1960s. Researchers of racial climate on college campuses have identified leadership as the essential ingredient in generating a positive climate (Hurtado et al., 1999, Kezar, 2000, $2007,2008)$. None of the participants could identify any administrative initiatives to understand or promote a positive racial climate at Lincoln during the period bracketed for this study. One participant suggested that a Black University president doing so at the time would have been political suicide, which ties to Kezar's (2008) study of the politics of diversity. 
Experiences of Black and White Students at Lincoln between 1954 and 1969

In most respects, the experiences of Black students and White students at Lincoln reflected those found in the literature for each group. An examination of the experiences of Whites at this HBCU compared to those of African-Americans at $\mathrm{HWls}$ produced some analogous and some disparate findings.

The experiences of Black students as the minority at HWls were similar as those of White students at Lincoln in that White students at Lincoln felt that campus activities were geared toward the Black majority; White students who were more socially engaged felt they had had a richer college experience; Even though White students reported being satisfied with their education at Lincoln, very few recommended it to others or contributed monetarily as alumnae/l (Gartland, Hojat, Christian, Callahan, \& Nasca, 2003). Other researchers, (Cabrera, Nora, Terenzini, Pascarella, \& Hagedorn, 1999; Eimers \& Pike, 1997; Hurtado et al., 1999; Milem, Chang, \& Antonio, 2005; Zea, Reise, Beil, \& Caplan, 1997) have found that campus hostilities toward minorities have an adverse effect on the retention of both minority and majority students. Many of the participants in this study mentioned their appreciation for having attended a desegregated campus free of hostility. This situation was highlighted as a reason for attending and persisting by many of the Black participants. White students at Lincoln engaged in self-segregation and their Black peers noticed. This taking notice of the outgroup's self-segregation is consistent with published research for conditions at PWIs, where the numerical majority tends to be the one noticing 
this practice. Just as Black students report at HWls, White students took cues from campus publications, activity flyers and other forms of communication to decide that Lincoln's was not their campus. When institutional communications have this effect on minority students at HWls, they are considered microaggressions (Solórzano et al., 2000). Because microaggressions are framed in terms of implicit White superiority, they have not been studied at HBCUs.

There were also many aspects of college life experienced by Black students as a minority group at HWls that did not match the experience of White students at Lincoln. White students at Lincoln felt that in the academic setting there was no differential treatment for the two racial groups. Although this sense did not extend to all social settings, it was present in the football team, the newspaper, the theater troupe and the residence halls for those students who chose to engage in those settings. Black students at HWls repeatedly reported perceiving negative attitudes from the White faculty. White student participants spoke glowingly of the way they were treated in and out of class by their Black professors. Black students have also reported feeling disrespected at HWIs. Contrarily, White students in this study reported feeling respected and valued by professors who gave them positive reinforcement and plenty of feedback. Research on the conditions encountered by African-American students at HWls revealed that they are often the targets of racial jokes, slurs, graffiti and representations. White student participants stated that they never encountered any form of racial hostility on campus, and those who heard comments about 
"crackers," for example, noted that the term had been used in reference to off campus whites.

Findings from studies conducted at HWls and the Lincoln study suggest that Blacks in both settings perceive Whites to be uneasy around them (Peterson et al., 1978). At Lincoln this perception came from the lack of White involvement and the way they were absent from campus after dark. In both settings, Black participants also suggested that Whites were unaware of issues that affect Blacks. For the participants in this study, it was not a matter of not being aware, but of feeling impotent to bring about any change. Not being affected by those same issues, White student participants chose to not get involved. In retrospect, many of them wished they had gotten more involved in activities geared toward creating greater equality. Others expressed wishing their Black peers would have educated them on what those issues were.

\section{Implications for Research}

Research in organizational analysis and diversity in higher education can be enriched by the examination of minority institutions, the dynamics of race relations in minority organizations and the role of intergroup dynamics in diverse higher education settings. Conducting future research at other Historically Black organizations can expand our understanding of what aspects of organizational conflict are indeed racial in nature and which may be a function of situational power.

The integration of Blacks and other minorities into predominantly White organizations has received plenty of attention from analysts and scholars. In 
order to truly understand race dynamics in organizations is important to also conduct organizational analyses at historically Black institutions.

The present study obtained information from a group of participants who could provide information about the lasting effects of the intergroup contact they had while attending Lincoln. Many of the benefits of intergroup contact were not experienced by the participants at the time of engagement, but revealed themselves as they functioned in the world beyond graduation. Because it has been suggested that desegregation had few short-term and many long-term positive effects, it would be useful to conduct quantitative and qualitative studies about those effects upon populations that attended diverse HWIs or HBCUs in the last 50 years.

Research on how Blacks and Whites relate to one another needs to be conducted in contexts where Blacks hold situational power and a legacy of control in order to expand our understanding of the role of Blacks in interracial relations in organizations and of race upon intergroup relations in organizations. If Blacks continue to be studied as outsiders, generalizations will continue to be made that perpetuate an image of passive adaptation on the part of Blacks and denies them an active role in intergroup relations (Nkomo, 1992; Shelton, 2000).

The present study could be replicated at other HBCUs that have desegregated and at HWIs. Follow up studies could be conducted at Lincoln by bracketing other time periods. A case study conducted at Lincoln at the present moment would provide a measure of the gains or losses made by the university in intergroup relatedness over the last 40 years. 


\section{Implications for Policy}

Interpersonal relations are at the core of all organizational activities (Shelton, 2000). In the current environment, diversity is becoming more the norm than the oddity. Institutional commitment to diversity needs to be a matter of policy and not be relegated to a numbers game. This commitment should inform

all aspects of institutional life; be publically espoused by top leadership in the form of statements of support, articulation of goals and reporting of results; and generate clear diversity policies with measurable benchmarks and a preestablished plan for evaluation of initiatives (Patton,1990).

The campus diversity climate should be actively monitored and findings should be disseminated to insure that all constituents realize they play a part in the campus wide efforts. Diversity among faculty serves two very important roles. Having minority representation within the faculty insures that members of those minorities have role models with whom they can easily identify. Majority students also benefit by being exposed to minority faculty members who may be instrumental in debunking stereotypes (Milem, et al., 2005). Faculty professional development should highlight the role of the faculty-student relationship and educate professors in ways to address, encourage and provide feedback to students of other groups (Dinka, Mazzella, \& Pilant, 1980). Instructors need also be instructed in pedagogies that foster respectful class exchanges that may project a positive racial climate by exposing and breaking-down prejudice (Kezar, 2000; Milem et al., 2005). 
Resource allocation to diversity agendas is also a matter of policy. It may come in the form of campus-wide diversity training, incentives to faculty who engage in the development of diversity-infused curriculum, the creation of an office for diversity management that communicates directly with top leadership, or is part of top leadership, and the continuous monitoring of racial climate within and among groups of students and campus employees.

\section{Implications for Practice}

The present study can inform practice at institutions of higher education in general and specifically at HBCUs and HWIs. Practice at all institutions of higher education would benefit from recognizing that a positive racial climate on campus is an instrument of retention for members of the majority and the minorities that they serve. It is also important that diversity initiatives have a greater rate of success when publicly supported by the leadership and that such support, or the lack thereof, is a political move that can have short and long term implications. At a time of growing reliance on endowments, leaders must also be mindful of the fact that positive social climates for students engender positive giving trends for alumnae/i. It is also important for HWls as well as HBCUs to measure the racial climate of their campuses and engage in proactive campaigns to foster conditions known to promote positive intergroup relations: a sense of equal status, intergroup cooperation, common goals, explicit support from campus leadership and opportunities for the type of personal interaction that leads to friendships. It is important to note, that these conditions must not only be provided to the students, but must be modeled by the adults around them in a 
genuine manner. Recognizing that leadership plays a crucial role in the success of diversity initiatives, institutions of higher learning should invest in diversity training for their own administrators and include it in the curriculum of future leaders, especially in the areas of business and education.

For HBCUs, the time has come to redefine their mission in terms of the current external and internal factors that affect them. This needs to be done by expanding, not negating, their historic mission. Such expansion would move HBCUs from the narrow mission of educating and socializing African-Americans, to educating all peoples in the scholarship and cultural heritage of African America hence living up to the call of the Talented Tenth assuming their place as "leaders of thought and missionaries of [African-American] culture among [all] peoples" (Dubois, 1903, p. 403). The move toward this updated mission needs to be bold, purposeful and visible. The education of people from any race or ethnicity would be richly enhanced by exposure to the cultural heritage of AfricanAmericans as this aspect of our national legacy is often neglected from curriculum and cultural events in most $\mathrm{K}-16$ educational settings. There are various ways to transmit the African-American legacy: by requiring all students and incoming faculty and staff to complete courses in institutional history, insuring that the curriculum is infused with works by and about African-Americans and providing strong Black academic and social role models. HBCUs are uniquely equipped to redefine the historic portrayal of Blacks as passive victims by communicating the African-American story in terms of a people who could not 
be broken and rose and continues to rise in spite of much adversity: AfricanAmericans as victors.

HBCUs must recognize that in the context of diversity in higher education they need to rise to the same expectations to which HWls are being held. Any $\mathrm{HBCU}$ with a significant non-Black enrollment must pay attention to the messages of inclusion and exclusion that are sent through its pictorial depictions, organizational structures and internal and external communications. Inclusion cannot be only a function of enrollment numbers, but non-Black students must feel they are valued members of the school community.

For HWls the first step is recognizing its role in the historic exclusion of particular groups. It is also important to educate faculty as to the best ways to relate to minority students. The literature on retention of minorities repeatedly highlights the role of interactions with faculty upon the persistence of AfricanAmerican students. For HWls that have large athletic programs, it is imperative to examine current practices and insure that athletic directors and advisors serve the needs of African-American athletes in a manner that makes them feel valued both as athletes and students in the college. It would also be beneficial to survey Black alumnae/i and current students to identify their needs and desires within the campus experience.

\section{Summary}

This chapter discussed the findings of the study as they related to the literature on organizational analysis, intergroup contact and desegregated higher education. It also offered conclusions derived through the merging of findings 
and the literature and proposed implications for future research, policy and practice. The latter was divided among general implications and specific implications for Historically White and Historically Black institutions. 


\section{REFERENCES}

Aber, E. (1959). A reverse pattern of integration. The Journal of Educational Sociology, 32(6), 283-289.

Adams v. Richardson, 480 F, 2d 1159 (D.C. Cir. 1973).

Alderfer, C. P. (1977). Group and intergroup relations. In J.R Hackmanand J.L Suttle (Eds.), Improving life at work (pp. 227-296). Santa Monica, CA: Goodyear.

Alderfer, C. P., \& Smith, K. K. (1982). Studying intergroup relations embedded in organizations. Administrative Science Quarterly, 27(1), 35-65.

Alderfer, C. P., \& Tucker, R. C. (1996). A field experiment for studying race relations embedded in organizations. Journal of Organizational Behavior, 17(1), 43-57.

Allen, W. R., Bobo, L., \& Fleuranges, P. (1984). Preliminary report: 1982 undergraduate students attending predominantly White state-supported universities. Ann Arbor, MI: Michigan University Center for Afro-American and African Studies.

Allen, W. R. (1992). The color of success: African-American outcomes at predominantly White and historically Black colleges and universities. Harvard Educational Review, 62, 26-44.

Allen, W. R., \& Haniff, N. Z. (1991). Race, gender, and academic performance in U.S. higher education (pp. 95 - 110). In W.R. Allen, E.G. Epps, \& N.Z. Haniff (Eds.), College in black and white. New York: SUNY Press.

Allen, W., \& Jewell, J. (2002). A backward glance forward: Past, present, and future perspectives on Historically Black Colleges and Universities. The Review of Higher Education, 25 (3), 241-261.

Allen-Castellitto, A., \& Maillard, K. (2001). Student and faculty perspectives on Black Americans' success in the White academy. The Negro Educational Review, 52(3), 89-99.

Allport, G. (1954) The nature of prejudice. Garden City, NY: Anchor Books.

Amir, Y. (1969). Contact hypothesis in ethnic relations. Psychological Bulletin, $71,319-342$. 
Ancis, J., Sedlacek, W., \& Mohr, J. (2000). Student perceptions of campus cultural climate by race. Journal of Counseling \& Development, 78(2), 180 $-185$.

Anderson, J. (1988a). The education of Blacks in the South, 1860- 1935. Chapel Hill and London: The University of North Carolina Press.

Anderson, J. (1988b) Northern foundations and the shaping of Southern Black rural education, 1902 -1935. In B. E. McClelland and W. J. Reese (Eds.), The social history of American education (pp. 287 - 312). Urbana and Chicago: University of Illinois Press.

Astin, A. (1975a). Preventing students from dropping out. San Francisco: JosseyBass.

Astin, A. (1975b). The myth of equal access in public higher education. Paper presented at the conference on Equality of Access in Higher Education, Atlanta, GA, July, 1975. (ERIC Document Reproduction Service No. ED119551).

Azibo, D. A. Y. (1990). Personality, clinical, and social psychological research on Blacks: Appropriate and inappropriate research frameworks. In. T. Anderson (Ed.), Black studies: Theory, method, and cultural perspectives (pp. 25-41). Pullman: Washington State University Press.

Barley, S. (1991). Semiotics and the study of occupation and organizational cultures. Administrative Science Quarterly, 28, 393- 414.

Bennett, P., \& Xie,

Bennett, P., \& Xie, Y. (2003). Revisiting racial differences in college attendance: The role of Historically Black Colleges and Universities. American Sociological Review, 68(4), 567-580.

Benton, M. A. (2001). Challenges African-American Students Face at Predominantly White Institutions. University of Colorado Journal of Student Affairs Archive. Retrieved March 10, 2009, from http://sahe.colostate.edu/journal-archive.

Bettencourt, A., \& Bartholow, B. (1998). The importance of status legitimacy for intergroup attitudes among numerical minorities. Journal of Social Issues 54(4), 759-775. 
Blair, I. V., Park, B., \& Bachelor, J. (2003). Understanding intergroup anxiety: Are some people more anxious than others? Group Processes and Intergroup Relations, 6(2), 151-169.

Bogdan, R. C., \& Biklen, S. K. (1998). Qualitative research in education: An introduction to theory and methods.Needham Heights,MA: Allyn \& Bacon.

Booker, K. (2007). Perceptions of classroom belongingness among AfricanAmerican college students. College Student Journal, 41(1), 178-186.

Bowen, W., \& Bok, D. (1998). The shape of the river: Long-term consequences of considering race in college and university admissions. Princeton, $\mathrm{NJ}$ : Princeton University Press.

Bowles, F., \& DeCosta, F. (1971). Between two worlds: A profile of Negro higher education. New York: McGraw-Hill.

Brazziel, W. (1983). Baccalaureate college of origin of Black doctorate recipients. Journal of Negro Education, 32, 102-109.

Brazziel, W., \& Brazziel, M. (1987) Recent college and university enrollment patterns of Black students in states affected by Adams litigation. In. A. Pruitt (Ed.), In pursuit of equality in higher education (pp. $25-31$ ). Dix Hills, NY: General Hall.

Brewer, M. B., \& Miller, N. (1984). Beyond the contact hypothesis: Theoretical perspectives on desegregation. In N. Miller \& M. B. Brewer (Eds.), Groups in contact: The psychology of desegregation (pp. 281-302). Orlando, FL: Academic Press.

Brimmer, A. F. (1971). The economic outlook and the future of the Negro college. Daedalus 100, 539-572.

Brown v. Board of Education of Topeka Kansas, 347 U.S. 483 (1954).

Brown v. Board of Education of Topeka Kansas (II), 349 U.S. 294 (1955).

Brown, M. C., \& Davis, J. E. (2001). The Historically Black College as social contract, social capital and social equalizer. Peabody Journal of Education, 76(1), 31-49.

Brown, M. C., Ricard, R. B., \& Donahoo, S. (2004). The changing role of Historically Black Colleges and Universities: Vistas on dual missions, desegregation and diversity. In M.C. Brown, \& K. Freeman (Eds.), Black colleges: New perspectives on policy and practice (pp.3-28). Westport, CT: Praeger Publishers. 
Brunsson, N. (1989). The organization of hypocrisy. Chichester: John Wiley \& Sons.

Cabrera, A., Nora, A., Terenzini, P., Pascarella, E., \& Hagedorn, S. (1999). Campus Racial Climate and adjustment of students to college: a comparison between White students and African-American students. Journal of Higher Education, 70(2),134-160.

Calbert, R., \& Epps, W. P. (1975) Curricular innovations in Historically Black Colleges and Universities. Washington, D.C: Institute for Services to Education.

Carnevale, A., \& Fry, R. (2000). Crossing the great divide: can we achieve equity when Generation Y goes to college? Retrieved March 13, 2009, from http://www.eric.ed.gov/ERICDocs/data/ericdocs2sql/content_storage_01/0 000019b/80/16/5d/a5.pdf

Carney, C. M. (1999). Native American higher education in the United States. New Brunswick, NJ: Transaction.

Chavous, T. (2005). An intergroup contact-theory framework for evaluating racial climate on predominantly White campuses. American Journal of Community Psychology, 36(3/4), 239 - 257.

Clark Hine, D., Harrold, S., \& Hine W. C. (2008). African-Americans. Upper Saddle River, NJ: Prentice Hall.

CNN.com. (October 1, 2002). Mississippi and Meredith remember. Retrieved August 28, 2007, from http://edition.cnn.com/2002/US/South/09/30/meredith/index.html

Conrad, C. F., \& Brier, E. M. (1997). Factors contributing to the matriculation of White students in public HBCUs. Journal for a Just \& Caring Education, 3(1), 37-63.

Constantine, J. M. (1995) The effect of attending HBCUs on future wages of Black students. Industrial and Labor Relations Review 48, 531-46.

Cook, S. W. (1985). Experimenting on social issues: The case of school desegregation. American Psychologist, 40, 452-460.

Cox, T., Jr., \& Nkomo, S. M. (1990). Invisible men and women: A status report on race as a variable in organization behavior research. Journal of Organizational Behavior, 11(6), 419-431. 
Cross, K., \& Astin, A. (1981). Factors influencing Black students' persistence in college. In G. Thomas (Ed.), Beyond Black or White. Westport, CT: Greenwood Press.

D'augelli, A. R., \& Hershberger, S. L. (1993). African-American undergraduates on a predominantly White campus: Academic factors, social networks, and campus climate. Journal of Negro Education, 62, 67-87.

D'Souza, D. (1991). Illiberal education: The politics of race and sex on campus. New York: The Free Press.

Daniel, C. (2007). Outsiders-within: Critical race theory, graduate education and barriers to professionalization. Journal of Sociology \& Social Welfare, $34(1), 25-42$.

Davis, M., Dias-Bowie, Y., Greenberg, K., Klukken, G., Pollio, H. R., Thomas, S. P., Thompson, C. L. (2004). "A fly in the buttermilk": Descriptions of university life by successful Black undergraduate students at a predominantly White Southeastern university. The Journal of Higher Education, 75(4), 420-445.

Davis, S. (1984). Managing corporate culture. Cambridge, MA: Ballinger.

Delany, M. R. (1968). The condition, elevation, emigration, and destiny of the colored people of the United States. New York: Arno Press. (Original work published 1852).

Dennis, M. (2001). The skillful use of higher education to protect White supremacy. The Journal of Blacks in Higher Education, 32(summer), 115123.

Denskins, D. R. (1991). Winners and Losers: A regional assessment of minority enrollment and earned degrees in U.S. colleges and universities, $1974-$ 1984. In W.R. Allen, E. G. Epps, and N.Z. Haniff (Eds.), College in Black and White. (pp. 17 - 39). Albany, NY: State University of New York Press.

Denzin, N. K. (1998). The art and politics of interpretation. In N. K. Denzin \& Y.S. Lincoln (Eds.), Collecting and interpreting qualitative materials (pp. 313344). Thousand Oaks, CA: Sage.

Denzin, N., \& Lincoln, Y. (1994). Strategies of inquiry. In N. Denzin \& Y. Lincoln (Eds.), Handbook of Qualitative Research (pp.199-208). Thousand Oaks: Sage Publications.

Dickerson, N. T., \& Jacobs, J. A. (2006). Race differentials in college selectivity, 1981-2001. Journal of African-American Studies, 10(1), 3-18. 
Dinka, F., Mazzella, F., \& Pilant, D. E. (1980). Reconciliation and confirmation: Blacks and Whites at a predominantly White university. Journal of Black Studies, 11(1), 55-76.

Dovidio, J. F., Gaertner, S. L., \& Kawakami, K. (2003). Intergroup contact: The past, present and future. Group processes and intergroup relations, 6, 521.

Drewry, H., \& Doermann, H. (2001). Stand and prosper: Private Black colleges and their students. Princeton: Princeton University Press.

Drummond, T. (2000). Black schools go White. Time, 155(11). Retrieved August 21, 2007, from Academic Search Premier database.

DuBois, W. E. B. (1969). The Talented Tenth. In The Negro problem: A series of articles by representative Negroes of today (pp. 33-75). New York: James Pott \& Co., 1969. (Original work published 1903).

DuBois, W. E. B. (1941). The future of the Negro state university. In H. Aptheker (Ed.), The education of Black people: Ten critiques by W.E.B DuBois (pp. 129-138). Amherst: The University of Massachusetts Press.

Dwyer, B. (2006). Framing the effect of multiculturalism on diversity outcomes among students at Historically Black Colleges and Universities. Educational Foundations, 20(1/2), 37-59.

Eimers, M., \& Pike, G. (1997). Minority and nonminority adjustment to college: differences or similarities. Research in Higher Education, 38(1), 77-97.

Epps, E. G. (1981). Black students in White schools. Worthington, OH: C.A. Jones.

Espenshade, T., Chang, C., Walling, J. (2004). Admission preferences for minority students, athletes, and legacies at elite universities. Social Science Quarterly, 85(5), 1422-1446.

Feagin, J. (1992). The continuing significance of racism: Discrimination against Black students in White colleges. Journal of Black Studies, 22(4), 546578.

Feagin, J., \& Sikes, M. (1995). How Black students cope with racism on White campuses. Journal of Blacks in Higher Education, 8, 91-97.

Feagin, J., Vera, H., \& Imani, N. (1996) The agony of education: Black students at White colleges and universities. New York: Routledge. 
Fichter, J. H. (1967). Graduates of predominantly Negro colleges - class of 1964. Washington DC: U.S. Government Printing Office.

Fischer, M. (2007). Settling into Campus Life: Differences by race/ethnicity in college involvement and outcomes. The Journal of Higher Education, 78(2), 125-161.

Fleming, J. (1981). Stress and satisfaction in college years of Black students. Journal of Negro Education, 50, 307-318.

Fleming, J. (1984). Blacks in college: A comparative study of students' success in Black and in White institutions. San Francisco: Jossey-Bass.

Foster, G. A. (2001). Is there a conspiracy to keep Black colleges open? Dubuque, IA: Kendall/Hunt Publishing Company.

Fraenkel, J. R., \& Wallen, N. E. (2003). How to design and evaluate research in education $\left(5^{\text {th }}\right.$ ed.), Boston, MA: McGraw-Hill.

Fries-Britts, S., \& Turner, B. (2002). Uneven Stories: Successful Black collegians at a Black and White campus. The Review of Higher Education, 25(3), 315-330.

Gagnier, R. (1990). Feminist-postmodernism: The end of feminism or the end of theory? In D. Rhode (Ed.), Theoretical perspectives on sexual difference (pp. 21-30). New Haven, CT: Yale University Press.

Gartland,J., Hojat, M., Christian, E., Callahan, C., Nasca, T. (2003). AfricanAmerican and White physicians: A comparison of satisfaction with medical education, professional careers, and research activities. Teaching and Learning in Medicine 15(2), 106-112.

Gossett, B., Cuyjet, M., \& Cockriel, I. (1998). African-Americans' perception of marginality in the campus culture. College Student Journal, 32(1), 22-32.

Greene, L. J. (1959). Report to the United States Commission on Civil Rights on desegregation of schools in Missouri. Lincoln University Archives.

Gregory, K. (1983). Native-view paradigms: Multiple cultures and culture conflicts in organizations. Administrative Science Quarterly, 28(3), 359-376.

Gruber, J. E. (1980). Sources of satisfaction among students in postsecondary education. American Journal of Education, 88, 320-344. 
Guiffrida, D. (2004). Friends from home: Asset and liability to African-American students attending a predominantly White institution. NASPA Journal (online) 41(4), 693-708.

Gurin, P. (1975). Black consciousness, identity and achievement: A study of students in Historically Black Colleges. New York: Wiley.

Gurin, P., \& Epps, E. (1975). Black consciousness, identity and achievement-A study of students in historically Black colleges. NY: Wiley-Science.

Hall, B., \& Closson, R. B. (2005). When the majority is the minority: White graduate students' social adjustment at a historically Black university. Journal of College Student Development, 46(1), 28-42.

Hatter, D., \& Ottens, A. (1998). Afrocentric worldview and Black students adjustments to a predominantly White university: Does worldview matter? College Student Journal, 32(3), 472-80.

Hazzard, T. (1988). Attitudes and perceptions of White students attending Historically Black Colleges and Universities. Unpublished doctoral research paper, Florida State University: Tallahassee. (ERIC Document Reproduction Service No. ED298806).

Hazzard, T. (1996). Factors influencing the decision of White students to attend historically Black colleges and universities in the south. (Doctoral dissertation, The Florida State University, 1996). Dissertation Abstracts International, 57, 108.

Hebel, S. (2005). Alcorn State meets nonBlack enrollment goal under desegregation settlement. Chronicle of Higher Education, 52(14), A33A33.

Herbold, H. (1994). Never a level playing field: Blacks and the G.I Bill. Journal of Blacks in Higher Education 6,104-108.

Herbst, J. (1988). The eighteenth-century origins of the split between private and public higher education in the United States. In B. Edward McClelland and William J. Reese (Eds.), The social history of American education (pp. 5360). Urbana and Chicago: University of Illinois Press.

Hewstone, M., \& Brown, R. J. (1986). Contact is not enough: An intergroup perspective on the 'Contact Hypothesis'. Un M. Hewstone \& R. Brown (Eds.), Contact and conflict in intergroup encounters (pp. 1 - 44). Oxford, UK: Basil Blackwell. 
Holland, A. (1991). The soldiers' dream continued: A pictorial history of Lincoln University of Missouri. Jefferson City, MO: Lincoln University Printing Services.

Holliway, M. F. (2004). Jefferson City Junior College: Then and now. Jefferson City Telegraph. December 2, 2004.

Holstein, J. A., \& Gubrium, J. F. (1994). Strategies of inquiry. In N. Denzin \& Y. Lincoln (Eds.), Handbook of Qualitative Research (pp. 262-272). Thousand Oaks: Sage Publications.

Howard University Institute for the Study of Educational Policy (1976). Equal educational opportunity for Blacks in U.S. higher education - An assessment. Washington DC: Howard University Press.

Hurtado, S., Milem, J., Clayton-Pedersen, A., \& Allen, W. (1998). Enhancing campus climates for racial/ethnic diversity: Educational policy and practice. The Review of Higher Education 21(3), 279-302.

Hurtado, S., Milem, J., Clayton-Pedersen, A., \& Allen, W. (1999). Enacting diverse learning environment: Improving the campus climate for racial/ethnic diversity in higher education. ASHE-ERIC Higher Education Reports Series 26(8). San Francisco: Jossey Bass.

Integration: Negro colleges newest challenge. (1966). Ebony Magazine, 21(5), 36-46.

Jackson, K. W., \& Swan, L. A. (1991). Institutional and individual factors affecting Black undergraduate student performance: Campus race and student gender. In W. R. Allen, E. G. Epps, and N. Z. Haniff (Eds.), College in Black and White. (pp. 127 - 141). Albany, NY: State University of New York Press.

Jaffe, A. J., Adams, W., Meyers, S. G. (1968). Negro Higher Education in the 1960s. NY: Praeger.

Jay, G. M., \& D'augelli, A. R. (1991). Social support and adjustment to university life: A comparison of African-American and White freshmen. Journal of Community Psychology, 19, 95-108.

Jencks, C., Riesman, D. (1967). The American Negro College. Harvard Educational Review 37, 3-60.

Johnson, C. S. (1938). The Negro College graduate. College Park, MD: McGrath. 
Kezar, A. (2000). Pluralistic leadership: bringing diverse voices to the table. About Campus (July-August), 6-11.

Kezar, A. (2007). Tools for a time and place: Phased leadership strategies for advancing campus diversity. Review of Higher Education, 30(4), 413-439.

Kezar, A. (2008). Understanding leadership strategies for addressing the politics of diversity. The Journal of Higher Education, 79(4), 406-441.

Kolb, D. M., \& Putnam, L. L. (1992). The multiple faces of conflict in organizations. Journal of Organizational Behavior, 13(3), 311-324.

Krathwohl, D. R. (1991). Methods of educational and social science research. New York: Longman.

Lee, W. (1999). Striving toward effective retention: The effect of race in mentoring African-American students. Peabody Journal of Education, 74(2), 27-43.

Levy, D. W. (2004). Before Brown: The racial integration of American higher education. In C. Cushman \& M.I. Urofsky (Eds.), Black, White and Brown: the landmark school desegregation case in retrospect (pp. 67-88). Washington, D.C.: CQ Press.

Lincoln, Y. S, \& Guba, E. G. (1985). Naturalistic inquiry. Beverly Hills, CA: Sage.

Lincoln University. Lincoln University Facts and Figures 2007. Retrieved November 27, 2007, at http://www.lincolnu.edu/pages/488.asp

List of Land-Grant universities. (2009). Retrieved April, 27, 2009, from http://www.aplu.org/NetCommunity/Page. aspx?pid=254\&srcid=249

Loo, C. M., \& Rolison, G. (1986). Alienation of minority students at a predominantly White university. Journal of Higher Education 57(1), 58-77.

Louis, M. (1985). An investigator's guide to workplace culture. In P. Frost, L. Moore, M. Louis, C. Lundberg, \& J. Martin (Eds.), Organizational culture (pp. 73-94). Beverly Hills, CA: Sage.

Malaney, G. D. (1987) A review of early decisions on Adams v. Richardson. In A.S. Pruitt (Ed.), In pursuit of equality in higher education (pp. $32-39$ ). Dix Hills, NY: General Hall.

Malcom-x.org. (1965). The Pierre Berton interview. Retrieved April, 8, 2009, from http://www.malcolm-x.org/docs/int_pbert.htm 
Marcus-Newhall, A., \& Heindl, T. (1998). Coping with interracial stress in ethnically diverse classrooms: How important are Allport's contact conditions? Journal of Social Issues, 54(4), 813-830.

Martin, J. (1992). Cultures in organizations: Three perspectives. New York: Oxford University Press.

Martin, J. (2002). Organizational culture: Mapping the terrain. Thousand Oaks, CA: Sage.

McBay, S. M. (1978). Black students in the sciences: A look at Spelman College. In C.V. Willie \& R. R. Edmonds (Eds.), Black colleges in AmericaChallenge, Development, Survival (pp. 216-228). NY: Teachers College Press.

McGrath, E. J. (1965). The predominantly Negro colleges and universities in transition. NY: Columbia Teachers College Press.

McLaurin v. Oklahoma State Regents. 339 U.S. 637 (1950).

Menand, L. (1997, April 20). Everybody else's college education [electronic version]. New York Times Magazine. Retrieved March 30, 2008 from http://query.nytimes.com

Mendoza-Denton, R., Downey,G., Davis, A., Purdie, V. J., \& Pietrzak, J. (2002). Sensitivity to status-based rejection: Implications for African-American students' college experience. Journal of Personality and Social Psychology, 83(4), 896-918.

Merriam, S. B. (1998). Qualitative research and case study applications in education. San Francisco: Jossey-Bass.

Milem, J., Chang, M., \& Antonio, A. (2005). Making diversity work on campus: a research-based perspective. Retrieved March, 13, 2009 from http://siher.stanford.edu/AntonioMilemChang_makingdiversitywork.pdf

Miles, M. B., \& Huberman, A. M. (1984). Qualitative data analysis. Beverly Hills, CA: Sage.

Mills, A. (1988). Organization, gender, and culture. Organization Studies, 9(3), 351-370.

Missouri ex rel. Gaines v. Canada. 305 U.S. 337 (1938).

Moore, J. M. (2003). Booker T. Washington, W. E. B. DuBois, and the struggle for racial uplift. Wilmington, DE: Scholarly Resources. 
Mykerezi, E., \& Mills, B. F. (2004). Educational and economic well-being in racially diverse rural communities: The role of Historically Black Colleges and Universities. The Review of Regional Studies, 34(3), 303-319.

National Advisory Committee on Black Higher Education and Black Colleges and Universities. (1979). Black colleges and universities: An essential component of a diverse system of higher education. Washington, DC: US Office of Health, Education and Welfare.

Nealy, M. J (2007, October 21) What scholars make of the noose incidents. Diverse Issues in Higher Education, Article 9814. Retrieved November 08, 2007, from http://www.diverseeducation.com/artman/publish/article_9814.shtml

Nettles, M. T., \& Perna, L. W. (1997). The African-American education data book. Vol. 1: Higher and adult education. Fairfax, VA: United Negro College Fund, Frederick D. Patterson Research Institute.

Nettles, M. T, Thoeny, A. R., \& Gosman, E. (1986). Comparative and predictive analyses of Black and White students' college achievement and experience. Journal of Higher Education, 57, 289-318.

Nettles, M. T, Thoeny, A. R., \& Gosman, E. (1987). Racial differences in college student achievement. In. A. Pruitt (Ed.), In pursuit of equality in higher education (pp. 49-63). Dix Hills, NY: General Hall.

Nkomo, S. M. (1992). The emperor has no clothes: Rewriting "Race in organizations." The Academy of Management Review, 17(3), 487-513.

Olson, K. W. (1982). The G.I Bill, the veterans and the colleges. Lexington: University Press of Kentucky.

Omi, M., \& Winant, H. (1986). Racial formation in the United States from the 1960 s to the 1980's. New York: Routledge \& Kegan Paul.

Outcalt, C., \& Skewes-Cox, T. (2002). Involvement, interaction, and satisfaction: the human environment at HBCUs. The Review of higher Education, 25(3), 331-347.

Pascarella, E., Smart, J., Ethington, C., \& Nettles, M. (1987). The influence of college on self-concept: A consideration of race and gender differences. American Educational research Journal, 24, 49-77. 
Pascarella, E., Smart, J., \& Stoecker, J. (1989). College race and the ealy status attainment of Black students. Journal of Higher Education, 60, 82-107.

Pascarella, E. T., \& Terenzinni, P. T. (1991). How college affects students: Findings and insights from twenty years of research. San Francisco: Jossey Bass.

Pascarella, E. T., \& Terenzinni, P. T. (2005). How college affects student: A third decade of research. San Francisco: Jossey Bass.

Patton, M. Q. (1990). Qualitative research \& evaluation methods (3rd ed.). Thousand Oaks, CA: Sage Publications.

Payne-Brown, R. (2004). The transition of a historically Black college to a predominantly White institution. Unpublished doctoral dissertation. University of Maryland, College Park.

Peterson, R. D., \& Hamrick, F. A. (2009). White, male, and "minority": Racial consciousness among white male undergraduates attending a Historically Black University. The Journal of Higher Education, 80(1), 34- 58.

Peterson, M. W., Blackburn, R. T., Gamson, Z. F., Arce, C. H., Davenport, R.W., \& Mingle, J.R. (1978). Black students on White campuses: The impact of increased Black enrollments. Ann Arbor, MI: Institute for Social Research.

Pettigrew, T. (1998). Intergroup contact theory. Annual Review of Psychology, $49,65-85$.

Pettigrew, T., \& Tropp, L. (2000). Does intergroup contact reduce prejudice? Recent meta-analytic findings. In S. Oskamp (Ed.), Reducing prejudice and discrimination (pp. 93-114). Hillsdale, NJ: Lawrence Erlbaum.

Pettigrew, T., \& Tropp, L. (2006). A meta-analysis test of intergroup contact theory. Journal of Personality and Social Psychology, 90(5), 751 - 783.

Pfeifer, C. M., Jr., \& Sedlacek, W. E. (1974). Predicting Black student grades with nonintellectual measures. Journal of Negro Education 43, 67-76.

Pifer, A. (1973). The higher education of Blacks in the United States. The Alfred and Winifred Hoernle Memorial Lecture for 1973. New York: Carnegie Corporation.

President Carolyn R. Mahoney receives Ralph S. Brown award for shared governance (2007). Retrieved March 30, 2008, from http://www.aaup.org/AAUP/newsroom/prarchives/2007/brown.htm 
Price, G. (2000). The idea of a historically Black university. The Negro Educational Review, 51(3/4), 99 - 113.

Pruitt, A. S. (1987) In pursuit of equality in higher education. Dix Hills, NY: General Hall.

Rankin, S., \& Reason, R. (2005). Differing Perceptions: How students of color and White students perceive campus climate for underrepresented groups. Journal of College Student Development. 46(1), 43-61.

Reddick, R. (2006). The gift that keeps giving: Historically Black College and University-educated scholars and their mentoring at Predominantly White Institutions. Educational Foundations, 20(1/2), 61-84.

Revised criteria specifying the ingredients of acceptable plans to desegregate state systems of public higher education, 43 Fed. Reg. 32, $6658-6664$ (Feb. 15, 1978).

Riley, P. (1983). A structurationist account of political culture. Administrative Science Quarterly, 28 (3), 414-437.

Roebuck, J. B., \& Murty, K. S. (1993). Historically Black Colleges and Universities: Their place in American higher education. Westport, CT: Praeger Publishers.

Roundtree, T. (1978). Teaching in the humanities. In C.V. Willie \& R. R. Edmonds (Eds.), Black colleges in America- challenge, development, survival (pp. 229-234). NY: Teachers College Press.

Savage, W. S. (1939). The history of Lincoln University. Jefferson City, MO: The New Day Press.

Sathe, V. (1985). Culture and related corporate realities: Text, cases, and readings on organizational entry, establishment, and change. Homewood, IL: Irwin.

Sawyer, A. (1989a, March 12). Ebony and Ivory Towers. The Detroit News, pp. $1 \mathrm{D}, 12 \mathrm{D}$.

Sawyer, A. (1989b, March 15). Lincoln University: A study in separation. The Detroit News, pp. 1D, $12 \mathrm{D}$.

Schall, M. (1983). A communication rules approach to organizational culture. Administrative Science Quarterly, 28(4), 557-581. 
Schein, E. (1984). Coming to a new awareness of organizational culture. Sloan Management Review, 25, 3-16.

Schein, E. (1991). What is culture? In P. Frost, L. Moore, M. Louis, C. Lundberg, \& J. Martin (Eds.), Reframing organizational culture (pp. 243-253). Newbury Park, CA: Sage.

Schein, E. (1996). The three cultures of management: Implications for organizational Learning. Sloan Management Review, 38, 9-20.

Schiele, J. H. (1990). Organizational theory from an Afrocentric perspective. Journal of Black Studies 21(2), 145-161.

School that was too good to die (the). (1958). Ebony Magazine 13(5), 17-24.

Sedlacek, W. E. (1999). Black students on White campuses: 20 years of research. Journal of College Student Development.40(5), 538 - 550.

Seidman, I. (1998). Interviewing as qualitative research: A guide for researchers in education and the social sciences $\left(2^{\text {nd }}\right.$ ed.). New York: Teachers College Press.

Sergiovanni, T., \& Corbally, J. (Eds.), (1984). Leadership and organizational culture. Urbana, IL: University of Illinois Press.

Shelton, N. (2000). A reconceptualization of how we study issues of racial prejudice. Personality and Social Psychology Review 4(4), 374-390.

Sherif, M., Harvey, O. J., White, B. J., Hood, W. R., \& Sherif, C.W. (1961). Intergroup conflict and cooperation. The robbers cave experiment. Norman, OK: University of Oklahoma Book Exchange.

Siehl, C., \& Martin, J. (1982) Organizational culture and counterculture: an uneasy symbiosis in H. Leavitt, L. Pondy, \& D. Boje (Eds.), Readings in Managerial Psychology (pp. 498 - 512). Chicago: University of Chicago Press.

Siehl, C., \& Martin, J. (1990) Organizational culture a key to financial performance? In B. Schneider (Ed.), Organizational climate and culture (pp.227-239). Elmsford, NY: Pergamon.

Sigelman, L., \& Welch, S. (1993). The contact hypothesis revisited: Black-White interaction and positive racial attitudes. Social Forces, 71(3), 781-795. 
Sims, G. (2008). Irrelation as a social construct for African-American women on a predominantly White campus. College Student Journal, 42(2), 691-702. Retrieved March 12, 2009, from Academic Search Premier database.

Singer, J. (2005). Understanding racism through the eyes of African-American male student athletes. Race, Ethnicity and Education, 8(4), 365-386.

Sipuel v. Board of Regents of University of Oklahoma. 332 U.S. 631 (1948).

Smith, A. W. (1991). Personal traits, institutional prestige, racial attitudes, and Black student academic performance in college. In W.R. Allen, E. G. Epps, and N.Z. Haniff. (Eds.), College in Black and White. (pp. 111-126). Albany, NY: State University of New York Press.

Smith, A. W., \& Allen, W. R. (1984). Modeling Black students' performance in higher education. Research in Higher Education, 21, 210-225.

Smith, C. U. (1978). Teaching and learning the social sciences in the Predominantly Black Universities. In C.V. Willie \& R. R. Edmonds (Eds.), Black colleges in America- challenge, development, survival (pp. 195215). NY: Teachers College Press.

Smith, J. A., \& Osborn, M. (2003). Interpretative phenomenological analysis. In J.A. Smith (Ed.), Qualitative psychology: A practical guide to research methods (pp. 51-80). London: Sage.

Solórzano, D., Ceja, M., \& Yosso, T. (2000). Critical race theory, racial microaggressions, and campus racial climate: The experiences of AfricanAmerican college students. The Journal of Negro Education 69(1/2), 6073.

Soukhanov, A. H. et al. (Eds.). (1996) The American heritage dictionary of the English language ( $3^{\text {rd }}$. ed.). Boston: Houghton Mifflin Company.

Stake, R. E. (1994). Case Studies. In N. Denzin \& Y. Lincoln (Eds.), Handbook of qualitative research (pp.236 - 247). Thousand Oaks: Sage Publications.

Steele, C. (1999). Thin Ice: "Stereotype threat" and Black college students. The Atlantic Monthly, 284(2), 44-54.

Stephan, W. G., \& Brigham, J. C. (Eds.), (1985). Intergroup contact. Journal of Social Studies, 41(3), 147-175.

Stephan, W. G., \& Stephan, C. W. (1996) Intergroup relations. Chicago: Brown and Benchmark. 
Suárez-Balcazar, Y., Orellana-Damacella, L., Portillo, N., Rowan, J., \& AndrewsGuillen, C. (2003). Experiences of differential treatment among college students of color. The Journal of Higher Education, 74(4), 428-444.

Sweatt v. Painter. 339 U.S. 629 (1950).

Taylor, E., \& Olswang, S. (1997). Crossing the color line: African-Americans and Predominantly White Universities. College Student Journal, 31, 11-18.

Taylor, R. (1976). Black youth and psychosocial development: A framework. Journal of Black studies, 6,353-372.

Taylor, R. (1977). The orientational others and value preferences of Black college youth. Social Science Quarterly, 57, 797-810.

The Supreme Court decision on education: What it means to Missouri. (1954) Midwest Journal, 6(2), 52-73.

Thomas, G., \& Braddock II, J. (1987) Determining the college destination of Black students. In. A. Pruitt (Ed.), In pursuit of equality in higher education (pp. 32 - 39). Dix Hills, NY: General Hall.

Thomas G., \& Gordon, S. (1983). Evaluating the payoffs of college investments for Black, White, and Hispanic students (Report No. 344). Baltimore: Johns Hopkins University, Center for Social Organization of Schools.

Thompson, D. C. (1973). Private Black colleges at the crossroads. Westport, CT: Greenwood.

Thompson, D. C. (1978). The socio-ethical role and responsibility of the Black college graduate. In C.V. Willie \& R. R. Edmonds (Eds.), Black colleges in America- Challenge, Development, Survival (pp. 51-67). NY: Teachers College Press.

Tinto, V. (1975). Dropout from higher education: A theoretical synthesis of recent research. Review of Educational Research, 45, 89-125.

Tinto, V. (1987). Leaving college: Rethinking the causes of student attrition. Chicago: University of Chicago.

Trent, W. J. (1959). Private Negro colleges since the Gaines decision. Journal of Educational Sociology, 32(6), 267-274.

Trent, W. T. (1991). Focus on equity: Race and gender differences in degree attainment, 1975-76; 1980-81. In W. R. Allen, E. G. Epps, and N. Z. Haniff 
(Eds.), College in Black and White. (pp. 41 - 59). Albany, NY: State University of New York Press.

U.S. Census Bureau. School enrollment - social and economic characteristics of students: October 2007. Retrieved March 11, 2009 from http://www.census. gov/population/www/socdemo/school/cps2007.html

U.S. Department of Education, National Center for Education Statistics (NCES), Integrated Postsecondary Education Data System (IPEDS), "Fall Enrollment" surveys 1994 - 2005. Retrieved March 16, 2008 from http://nces.ed.gov/ipeds/find_data/peer_analysis_summary.asp.

U. S. Department of Education. The Condition of Education 2005. Retrieved November 20, 2007 from http://nces.ed.gov/programs/coe).

U.S. Department of Education, The Condition of Education 2008. Retrieved March 19, 2009, from http://nces.ed.gov/programs/coe/2008/ section3/table. asp?table ID=907

U.S. Department of Labor, Bureau of Labor Statistics. retrieved March 19, 2009, from http://www.bls.gov/opub/mlr/2004/02/art3full.pdf

United States Equal Rights Commission. (1961). Equal protection of the laws in public higher education 1960.Washington DC: U.S. Printing Office.

University v. Murray, 169 Md. 478 (1936).

Urofsky, M. I. (2004). Among the most humane moments in our history: Brown v. Board of Education in historical perspective. In C. Cushman \& M. I. Urofsky (Eds.), Black, White and Brown: The landmark school desegregation case in retrospect (pp. 1 - 45). Washington, D.C.: CQ Press.

Van Maanen, J. (1983). Reclaiming qualitative methods for organizational research. In J. Van Maanen (Ed.), Qualitative methodology (pp. 9-18). Beverly Hills, CA: Sage.

Van Maanen, J., \& Barley, S. (1985). Cultural organization: Fragments of a theory. In P. Frost, L. Moore, M. Louis, C. Lundberg, \& J. Martin (Eds.), Organizational culture (pp. 31-54). Beverly Hills, CA: Sage.

Walter, R. A \& Jewell, J.(2002) A backward glance forward: Past, present and future perspectives on historically Black colleges and universities. The Review of Higher Education, 25 (3), 241-261.

Washington, B. T. (1901). Up from slavery. New York: A.L. Burton Company. 
Washington, B. T. (1969). Industrial education for the Negro. In The Negro problem: A series of articles by representative Negroes of today (pp. 929). New York: James Pott \& Co., 1903. (Original work published 1903)

Watkins, W. H. (2001). The White architects of Black education: Ideology and power in America 1865-1954. New York: Teachers College Press.

Whitaker, C. (1986). Is there a conspiracy to take over Black colleges? Ebony Magazine, 41(12), 83-88.

Williams, E. (1994). The "raisin-in-milk" syndrome: Ten survival tips for Black students at predominantly White colleges and universities. Washington DC, Comptex Associates.

Williams, M., \& Shammas, D. (2007). Research on race and ethnic relations among community college students. Community College review 34 (4).

Willie, C., \& Cunnigen, D. (1981). Black students in higher education: A review of studies, 1965 - 1980. In R. Turner \& J. Short (Eds.), Annual Review of Sociology 7, 177-198.

Willie, C., \& McCord, A. (1972). Black students at White colleges. New York: Praeger.

Wise, L. R., \& Tschirhart, M. (2000). Examining empirical evidence on diversity effects: How useful is diversity research for public-sector managers? Public Administration Review, 60(5), 386-394.

Wittig, M., \& Grant-Thompson, S. (1998). The utility of Allport's conditions of intergroup contact for predicting perceptions of improved racial attitudes and beliefs. Journal of Social Studies, 54(4), 795-812.

Yankelovich, D. (1972). Changing values on campus: Political and personal attitudes of today's college student. New York: Washington Square Press.

Yin, R. K. (1984). Case study research. Beverly Hills, CA: Sage.

Young, C. (1966). Will the real Lincoln University please stand up? Focus/Midwest 5(33), 8-10. Student unrest vertical file, Lincoln University collection, Inman E. Page Library, 2007.

Zea, M. C., Reisen, C., Beil, C. Caplan, R. (1997). Predicting intention to remain in college among ethnic minority and nonminority students. The Journal of Social Psychology, 137(2), 149-160. 


\section{Appendix A}

\section{Letter to Possible Participants}

Date

Dear

Your days at Lincoln University constitute a chapter of your personal history and correspond to a unique episode in the history of higher education. I want to appeal to you to share some of that history with me.

I first came to Lincoln as an international student from Colombia, South America. At the time of my arrival and through my first semesters at the university, I had very little notion of Lincoln being a historically Black university and what that meant. I have learned much since then. For the last ten years, I have been teaching at Lincoln and I am also a doctoral candidate in the Department of Educational Leadership and Policy Analysis at the University of Missouri. For my dissertation, I am conducting a qualitative inquiry on the desegregation of Lincoln University. There has been extensive research on the effects of desegregation at traditionally White institutions, but very few studies have explored the desegregation of historically Black institutions. I want to contribute to filling that gap.

The purpose of my study is to examine how the initial Black/White intergroup contact generated by the mandated racial desegregation of Lincoln University of Missouri influenced the institution's organizational culture. The period on which I am focusing encompasses the time between September of 1954 and May of 1969. In addition to the written dissertation, I also seek to produce an audio/visual archival document.

If you are interested in contributing to this study, please respond by answering the attached questionnaire and returning it in the enclosed envelope at your earliest convenience. In participating in this study, you will be expected to engage in a one to two hour interview scheduled at your convenience and/or participate in a focus group. All interviews and focus groups will be audio and visually recorded.

I thank you in advance for your collaboration in this endeavor.

Appreciatively,

Gabrielle Malfatti-Rachell

418 Martin Luther King Hall

814 E. Dunklin Street

Jefferson City, MO 65101

(573)681-5232

rachellg@lincolnu.edu 


\section{Appendix B}

\section{Preliminary Questionnaire \\ Lincoln Alumnae/i}

Name

Age

Race

Gender

Attended Lincoln from to

Involvement with Lincoln (please check all that apply)

Remained involved through employment at the university.

Dates of employment through

Remained involved through social interactions with the LU

community

Remained involved through LU alumni groups

Remained involved through committee /task force assignments

Remained involved by participating in campus events such as

homecoming, fundraising activities, sporting or cultural events

Remained informed of campus happenings through LU communications

Have had little involvement with the university since my departure Have had almost no involvement with the university since my

departure

I would like I would not like to participate in the study described in the attached letter.

Contact Information

Address

Preferred phone number

Preferred time to receive calls

Email address

Preferred mode of contact

Mail

Phone

Email 


\section{Appendix C \\ Preliminary Questionnaire \\ Lincoln Employee}

Name

Age

Race

Gender

Employed at Lincoln from to

I would like described in the attached letter.

I would not like to participate in the study

Worked at Lincoln prior to its desegregation in 1954

Worked at Lincoln for years after its desegregation in 1954

Attended Lincoln as a student prior to being employed at Lincoln If so, when

Contact Information

Address

Preferred phone number

Preferred time to receive calls

Email address

Preferred mode of contact

Mail

Phone

Email 


\section{Appendix D}

\section{INFORMED CONSENT}

I, (Name

), (Date

) consent to

participate in this research project and understand the following:

PROJECT BACKGROUND: This is a dissertation project to be presented to the faculty of the Department of Educational Leadership and Policy Analysis at the University of Missouri, in partial fulfillment of the requirements for the Doctor of Education degree (Ed.D). This project involves gathering data through documents, interviews and/or focus groups based on the attached interview protocol and any other questions that may arise from conversation with participant. The data collected will be analyzed and may be published.

PURPOSE: The purpose of this study is to examine how the initial Black/White intergroup contact generated by the 1954 mandated racial desegregation of Lincoln University of Missouri influenced the institution's organizational culture.

VOLUNTARY: Participation in this project is entirely voluntary. You may refuse to answer any question or choose to withdraw from participation at any time without any penalty or loss of benefits to which you are otherwise entitled. You must be at least 18 years of age to participate.

WHAT DO YOU DO? You will engage in a conversation with the researcher using the attached interview questions as a point of departure AND/OR you will engage in a focus group discussion led by the researcher. The conversation and/or focus group will be audio and visually recorded and later transcribed for coding. You will have the opportunity to review transcripts of conversations before the final project is submitted to the Educational Leadership and Policy Analysis faculty at the University of Missouri.

BENEFITS: Your participation in this research project will enrich the knowledge base on the subject of desegregation in higher education. Many scholars have documented the presence of Black students at Historically White Institutions, but few have explored reverse integration. Your story is an essential part of the historic legacy of Lincoln University and academia in Missouri and the Nation.

RISKS: This project does not involve any risks greater than those encountered in everyday life.

CONFIDENTIALITY: I agree / do not agree to have my name connected to the findings of this project.

I agree__ / do not agree to have my interview/focus group audio and video recorded.

Thank you for your assistance in compiling a unique piece of higher education history that will surely enrich the annals of the university and the history of education in Missouri and the United States. Recording and preserving this unique perspective is a true honor. For additional information, please contact Gabrielle Malfatti-Rachell at gm2b2@mizzou.edu or rachellg@lincolnu.edu. If you have questions regarding your rights as a participant in research, please feel free to contact the University of Missouri Campus Institutional Review Board at (573) 882-9585.

Gabrielle Malfatti-Rachell

Student Investigator
Participant 


\section{Appendix E}

\section{Public Service Announcement for Recruitment of Participants}

Claim your rightful place in history.

If you attended or were employed at Lincoln University between the fall of 1954 and May of 1969, your contribution is needed for a study of the unique desegregation of Lincoln and its impact on the institutional culture of the university at that time.

For additional information, please contact Professor Gabrielle Malfatti-Rachell at 681-5232. 


\section{Appendix F}

\section{Student Interview Guide}

1. What did you know about Lincoln before you came to campus?

2. Describe the reasons why you chose to attend Lincoln

3. Describe your first impressions of LU

4. How would you characterize the racial climate at Lincoln at the time you were a student?

5. What can you tell me about the status of White and Black students on campus at the time you were a student?

6. What instances did you observe when cooperation between Black and White students was evident to you?

7. What are some examples of institutional and/or community goals that were common to both Black and White students?

8. How would you describe the attitude of faculty and administrative staff toward the desegregation of Lincoln?

9. How would you describe the attitude of people in your family and community toward you attending a desegregated Lincoln?

10. What can you tell me about your interactions with (other race) students while you were at Lincoln?

11. What can you tell me about your interactions with (other race) faculty and staff while you were a student at Lincoln?

12. Can you tell me about possibilities for interracial friendship building while you were a student at Lincoln?

13. In retrospect, how did you think Lincoln's desegregation would affect the culture of the institution?

14. How do you feel desegregation affected the culture of Lincoln? 


\section{Appendix G}

\section{Faculty/Staff Interview Guide}

1. What did you know about Lincoln before you came to campus?

2. Describe the reasons why you chose to seek employment at Lincoln

3. Describe your first impressions of LU

4. How would you characterize the racial climate at Lincoln at the time you worked at the University?

5. What can you tell me about the status of White and Black faculty/staff on campus at the time you worked at the University? What about the students?

6. What instances did you observe when cooperation between Blacks and Whites was evident to you?

7. What are some examples of institutional and/or community goals that were common to both Blacks and Whites?

8. How would you describe the attitude of faculty and administrative staff toward the desegregation of Lincoln?

9. How would you describe the attitude of people in the community toward the desegregation of Lincoln?

10. What can you tell me about your interactions with (other race) faculty/staff while you worked at Lincoln?

11. What can you tell me about your interactions with (other race) students while you worked at Lincoln?

12. What can you tell me about possibilities for interracial friendship building while you were at Lincoln?

13. In retrospect, how did you think Lincoln's desegregation would affect the culture of the institution?

14. Looking at Lincoln today, how do you feel desegregation has affected the culture of the institution? 


\section{Appendix $\mathbf{H}$}

\section{4 - 1969 NATIONAL AND INSTITUTIONAL TIMELINE}

\begin{tabular}{|c|c|c|c|}
\hline Date & National Event & Date & Lincoln Happenings \\
\hline \multirow[t]{2}{*}{ May 17,1954} & $\begin{array}{l}\text { The U.S. Supreme court } \\
\text { rules on the case of } \\
\text { Brown } v \text {. Board of } \\
\text { Education of Topeka, } \\
\text { Kansas declaring } \\
\text { segregation in public } \\
\text { schools unconstitutional }\end{array}$ & July 31, 1954 & $\begin{array}{c}\text { The Lincoln University } \\
\text { Board of Curators decides } \\
\text { that Fall } 1954 \text { enrollment } \\
\text { will be open to white } \\
\text { students. } \\
\text { During that first semester } \\
18 \text { white students enrolled } \\
\text { at Lincoln University. }\end{array}$ \\
\hline & & Fall of 1954 & $\begin{array}{l}\text { President Scruggs is } \\
\text { unable to resume duties as } \\
\text { president and is replaced } \\
\text { by Dr. Earl Dawson as } \\
\text { interim chief administrative } \\
\text { officer. }\end{array}$ \\
\hline \multirow[t]{3}{*}{ Dec. 1, 1955} & $\begin{array}{l}\text { Rosa Parks refuses to } \\
\text { give up her seat to a white } \\
\text { patron in an Alabama bus }\end{array}$ & 1955 & $\begin{array}{l}\text { Representative Icie May } \\
\text { Pope sponsored a } \\
\text { resolution to investigate } \\
\text { whether or not Lincoln } \\
\text { should be closed in light of } \\
\text { desegregation of the } \\
\text { University of Missouri. }\end{array}$ \\
\hline & & Feb. 1955 & $\begin{array}{l}\text { Lincoln closes its Law } \\
\text { School and demotes the } \\
\text { Journalism School to a } \\
\text { department as a result of } \\
\text { dwindling enrollments } \\
\text { caused by the acceptance } \\
\text { of black students into } \\
\text { graduate programs at the } \\
\text { University of Missouri. }\end{array}$ \\
\hline & & Spring 1956 & $\begin{array}{c}\text { LU's white student } \\
\text { enrollment reaches } 200 \\
(22 \%)\end{array}$ \\
\hline Sept. 1957 & $\begin{array}{l}\text { In Little Rock Arkansas, } \\
\text { nine black students are } \\
\text { blocked from entering } \\
\text { Central High School on } \\
\text { orders of Gov. Orval } \\
\text { Faubus. President } \\
\text { Eisenhower sends federal } \\
\text { troops and National } \\
\text { Guard to intervene. }\end{array}$ & Jan. 4, 1957 & $\begin{array}{l}\text { The Pope committee } \\
\text { reports to the Senate and } \\
\text { House Committee on } \\
\text { Higher Education that } \\
\text { Lincoln University should } \\
\text { remain open. The } \\
\text { committee gives Lincoln } \\
\text { much praise and cites } \\
\text { statistics that forecast a } \\
\text { significant increase in the } \\
\text { future number of college } \\
\text { students nation-wide. }\end{array}$ \\
\hline
\end{tabular}




\begin{tabular}{|c|c|c|c|}
\hline Date & National Event & Date & Lincoln Event \\
\hline & & Spring 1958 & $\begin{array}{l}\text { Out of a total enrollment of } \\
1,184 \text { students, Lincoln's } \\
\text { white student enrollment } \\
\text { reaches } 385(32.5 \%)\end{array}$ \\
\hline & & March 1958 & $\begin{array}{l}\text { Ebony magazine publishes } \\
\text { article highlighting the } \\
\text { harmonious unfolding of } \\
\text { integration at Lincoln. }\end{array}$ \\
\hline & & Fall 1958 & $\begin{array}{c}\text { Visanio Johnson petitions } \\
\text { the NAACP for a student } \\
\text { chapter at LU }\end{array}$ \\
\hline Feb. 1, 1960 & Sit-ins in Greensboro, NC & & \\
\hline April 1960 & $\begin{array}{l}\text { Student Nonviolent } \\
\text { Coordinating Committee } \\
\text { (SNCC) is founded at } \\
\text { Shaw University. }\end{array}$ & & \\
\hline \multirow[t]{5}{*}{ Oct. 1, 1961} & $\begin{array}{c}\text { James Meredith } \\
\text { integrates University of } \\
\text { Mississippi - President } \\
\text { Kennedy has to send } \\
\text { troops to dissolve } \\
\text { violence. }\end{array}$ & & \\
\hline & & $\begin{array}{c}\text { Fall } 1961 \text {-Spring } \\
1962\end{array}$ & $\begin{array}{l}\text { Black and white students } \\
\text { participate in sit-ins in } \\
\text { downtown JC- Students } \\
\text { hold demonstrations on } \\
\text { campus and outside a } \\
\text { segregated bowling alley. }\end{array}$ \\
\hline & & Feb/March 1962 & $\begin{array}{l}\text { Desegregation efforts } \\
\text { against the bowling alley } \\
\text { intensify. Students "hang" } \\
\text { an effigy of President } \\
\text { Dawson }\end{array}$ \\
\hline & & March 17,1962 & $\begin{array}{l}\text { President Dawson orders } \\
\text { the dismissal of } 9 \text { students } \\
\text { who had participated in a } \\
\text { NAACP rally on campus. }\end{array}$ \\
\hline & & $1963-1969$ & $\begin{array}{c}\text { Academic brain drain } \\
\text { begins in } 1963 \text { with the } \\
\text { departure of Dr. Talbot. It } \\
\text { continues through the rest } \\
\text { of the } 60 \text { 's as many other } \\
\text { faculty members leave or } \\
\text { retire. }\end{array}$ \\
\hline $1962-1965$ & $\begin{array}{l}\text { Civil Rights Protests } \\
\text { grounded on the non- } \\
\text { violent principles of Dr. } \\
\text { Martin Luther King }\end{array}$ & 1963-1964 & $\begin{array}{c}\text { Relative calm on campus } \\
\text { but an undercurrent of } \\
\text { student unrest was } \\
\text { present. }\end{array}$ \\
\hline July 2, 1964 & $\begin{array}{c}\text { President Johnson signs } \\
\text { the Civil Rights Act of } \\
1964 \\
\end{array}$ & & \\
\hline
\end{tabular}




\begin{tabular}{|c|c|c|c|}
\hline Date & National Event & Date & Lincoln Event \\
\hline \multirow[t]{2}{*}{ Mar. 7, 1965} & $\begin{array}{c}\text { Martin Luther King leads } \\
\text { marches in Selma, } \\
\text { Alabama }\end{array}$ & March 1965 & $\begin{array}{l}\text { A bus-load of LU students } \\
\text { and some faculty travels to } \\
\text { Selma to participate in the } \\
\text { marches. }\end{array}$ \\
\hline & & March of 1966 & $\begin{array}{l}\text { Ebony magazine article } \\
\text { declaring Integration the } \\
\text { newest challenge for } \\
\text { Negro Colleges and } \\
\text { reporting on how Lincoln's } \\
\text { black and white students } \\
\text { move in separate circles. }\end{array}$ \\
\hline \multirow[t]{2}{*}{ Summer 1966} & $\begin{array}{c}\text { James Meredith March } \\
\text { Against Fear }\end{array}$ & Summer of 1966 & $\begin{array}{l}\text { Students and some faculty } \\
\text { from Lincoln join in the } \\
\text { march }\end{array}$ \\
\hline & & Fall 1966 & $\begin{array}{l}\text { Students returning to } \\
\text { campus from summer } \\
\text { break report having } \\
\text { participated in Civil Rights } \\
\text { activities in their home } \\
\text { communities }\end{array}$ \\
\hline \multirow[t]{2}{*}{ April 1967} & $\begin{array}{c}\text { Stockley Carmichael } \\
\text { assumes leadership of } \\
\text { SNCC - his approach of } \\
\text { liberation "by any means } \\
\text { necessary" is a radical } \\
\text { change from the } \\
\text { nonviolent efforts of MLK. }\end{array}$ & April 1967 & $\begin{array}{l}\text { LU students present a long } \\
\text { list of grievances to the } \\
\text { administration } \\
\text { Demonstration caused by } \\
\text { poor quality of food at the } \\
\text { cafeteria among other } \\
\text { issues } \\
\text { (4/11/1967) Reports in the } \\
\text { Kansas City Star about LU } \\
\text { students feeling that the } \\
\text { administration "kowtows to } \\
\text { the white community and } \\
\text { actively forces students } \\
\text { into the pattern of the white } \\
\text { man" } \\
\text { (4/21/1967) The Kansas } \\
\text { City Call noted that Blacks } \\
\text { complained about the low } \\
\text { involvement of white } \\
\text { students in campus life. }\end{array}$ \\
\hline & & October 1967 & $\begin{array}{l}\text { Another food riot that } \\
\text { culminated with the } \\
\text { expulsion of student } \\
\text { leaders. Among them Joe } \\
\text { Scoggin who later sued the } \\
\text { university, won and was } \\
\text { reinstated in } 1968 .\end{array}$ \\
\hline
\end{tabular}




\begin{tabular}{|c|c|c|c|}
\hline Date & National Event & Date & Lincoln Event \\
\hline February 8,1968 & $\begin{array}{c}\text { Orangeburg Massacre at } \\
\text { South Carolina State } \\
\text { University - an HBCU } \\
\text { where students had } \\
\text { protested the segregation of } \\
\text { the local bowling alley. } \\
\text { Police shootings resulted in } \\
\text { the death of three students } \\
\text { and injuries sustained by } 28 . \\
\text { One police officer received } \\
\text { medical attention at the local } \\
\text { hospital. }\end{array}$ & & \\
\hline April 4, 1968 & $\begin{array}{l}\text { Martin Luther King is } \\
\text { assassinated in } \\
\text { Memphis, TN. }\end{array}$ & April 5, 1968 & $\begin{array}{l}\text { AM - Peaceful memorial } \\
\text { service for MLK held at the } \\
\text { LU auditorium. JC mayor in } \\
\text { attendance } \\
\text { PM - "Campus Radicals" } \\
\text { are credited with inciting } \\
\text { student protesters using two } \\
\text { editorials previously } \\
\text { published in the Jefferson } \\
\text { City News Tribune. These } \\
\text { editorials called MLK a } \\
\text { dangerous man and an } \\
\text { apostle of Marx. } \\
\text { A peaceful march led by } \\
\text { campus students and joined } \\
\text { by many - including a group } \\
\text { of Catholic nuns- went to the } \\
\text { newspaper offices to } \\
\text { demand retraction of the } \\
\text { articles. The demonstration } \\
\text { turned violent. There was } \\
\text { looting and property } \\
\text { damage. Police got } \\
\text { involved. }\end{array}$ \\
\hline & & May $9-19,1969$ & $\begin{array}{l}\text { Students ask for Dr. } \\
\text { Dawson to meet with } \\
\text { them and agree to meet } \\
\text { their demands. The } \\
\text { president refuses. } \\
\text { Students remain in the } \\
\text { student union against } \\
\text { orders to vacate - faculty } \\
\text { members remain there } \\
\text { with them through the } \\
\text { night to avoid students' } \\
\text { arrests. On May } 18^{\text {th }} \\
\text { several fires are set } \\
\text { throughout the campus } \\
\text { and the student union is } \\
\text { burned to the ground. JC } \\
\text { police and Missouri } \\
\text { Patrolmen sent to } \\
\text { campus. Dr. Dawson } \\
\text { resigns and a new } \\
\text { president, Walter Daniel } \\
\text { assumes the } \\
\text { administration of LU on } \\
\text { July } 1,1969 \text {. }\end{array}$ \\
\hline
\end{tabular}


VITA

Gabrielle Malfatti-Rachell was born and raised in Colombia, South America. In 1983 she travelled to the United States on vacation and as a result of a myriad of opportunities remained in the country and became a U.S. Citizen in 1992.

In 1984 Malfatti-Rachell enrolled at Lincoln University as an International Student. She went on to attend the University of Missouri at Columbia where she received a Bachelor of Science in Education degree and a Master of Arts degree in Spanish literature. In May 2009, she received her Doctor of Education degree in Educational Leadership.

Malfatti-Rachell is an Assistant Professor of Spanish and Latin American studies at Lincoln University since 1998. Her areas of research include organizational analysis, diversity and leadership in organizations, the effects of policies on underrepresented and silent constituencies, dynamics of intergroup contact, and Latino immigrant issues.

In 2008, the Forum on Public Policy published her article entitled: Expedited citizenship for immigrant soldiers: tribute or bounty? This article was based on a presentation made at the Oxford Round Table in Oxford, England. Also in 2008, Malfatti-Rachell completed a three-year grant-funded project that created an interactive training module for suicide prevention. Beyond the Front was completed by a team of Lincoln University faculty, U.S. Army personnel, Will Interactive, and researchers from the Army Research Lab. The new training 
module is now widely used throughout the Army and related projects are underway.

Malfatti-Rachell has made presentations on cross-cultural communication at the U.S. Department of Defense Suicide Prevention Conference, Missouri League of Nurses Conference and has conducted multiple workshops on Latino issues ranging from healthcare to banking. She is a free-lance interpreter for the Federal Court and has consulted on multi-cultural issues with various state agencies and private enterprises.

Beyond her teaching and research responsibilities, Malfatti-Rachell is also the Director for Study Abroad at Lincoln University, faculty advisor for Sigma Delta $\mathrm{Pi}$, the Hispanic Collegiate Honor Society, faculty advisor for the International Student Association, chair of the International Studies and Study Abroad Committee, and also serves in various departmental, college and university committees. Since 2006 she has served on the Board of Directors of St. Mary's Health Center and is a member of the hospital's Diversity Council.

Malfatti-Rachell credits her achievement to the guidance and support she received from teachers throughout her life, at el Liceo Benalcázar, South Philadelphia High School, Lincoln University and the University of Missouri. At the center of her life are her husband, David Rachell and their children, Carolyn, Nikolas and Alexandria. Malfatti-Rachell sees them as a constant source of inspiration fueling her personal and professional growth. 